

\title{
LA CULTURA DEL EMPRENDIMIENTO EN POPAYÁN Experiencias y aprendizajes
}

\author{
Autora: Diana Ximena Sánchez Tróchez \\ Coautores: Felipe Acosta Ortega \\ Laura Beatriz Potes Ordoñez \\ Gabriel De la Torre Solarte
}

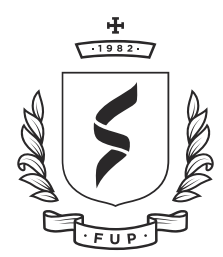

Colección Trabajos de Investigación Fundación Universitaria de Popayán

Cauca - Colombia 2020 


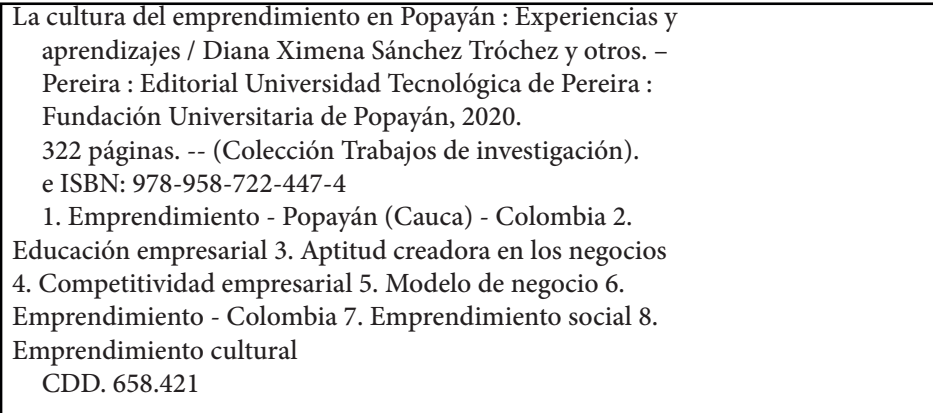

Colección Trabajos de Investigación

Cultura del Emprendimiento en Popayán Experiencias y aprendizajes

Autora:

Diana Ximena Sánchez Tróchez

Coautores:

Felipe Acosta Ortega

Laura Beatriz Potes Ordoñez

Gabriel De la Torre Solarte

Fundación Universitaria de Popayán

Cauca - Colombia

Septiembre 2020

\section{Universidad Tecnológica de Pereira}

Vicerrectoría de Investigaciones, Innovación y Extensión

Editorial Universidad Tecnológica de Pereira

Pereira, Colombia

\section{Coordinador editorial:}

Luis Miguel Vargas Valencia

luismvargas@utp.edu.co

Teléfono 3137381

Edificio 9, Biblioteca Central "Jorge Roa Martínez"

Cra. 27 No. 10-02 Los Álamos, Pereira, Colombia

www.utp.edu.co

Montaje y producción:

David Restrepo Suarez.

Universidad Tecnológica de Pereira 
Diana Ximena Sánchez Tróchez, (Popayán, Cauca, Colombia ,1987). Magister en Dirección y Administración de Empresas de la Universidad Internacional de la Rioja, España. Profesional en Mercadeo y Negocios Internacionales de la Universidad Autónoma de Occidente, Cali, Valle. Docente de Tiempo Completo de la Facultad de Ciencias Económicas, Contables y Administrativas de la Fundación Universitaria de Popayán. Ha publicado artículos sobre emprendimiento en revistas especializadas nacionales e internacionales como docente investigadora perteneciente al grupo IDEESE-Desarrollo Empresarial, Innovación y TIC.

diana.sanchez@docente.fup.edu.co

Felipe Acosta Ortega - (Popayán,, Cauca, Colombia, 1984). MBA énfasis en Finanzas Corporativas de la Universidad ICESI y Administrador de empresas de la Universidad del Cauca. Docente de tiempo completo adscrito al programa de Administración de Empresas de la Facultad de Ciencias Económicas, Contables y Administrativas de la Fundación Universitaria de Popayán. Ha publicado artículos en revistas especializadas nacionales e internacionales en temas de Negocios, Administración y Economía. Es miembro del grupo de investigación Desarrollo, Empresarial, Innovación y TIC- IDEESE.

Felipe.acosta@fup.edu.co

Laura Beatriz Potes Ordoñez, (Popayán, Cauca, Colombia, 1990). Magister en Gestión de Organizaciones, Administradora de Empresas, ambos títulos de la Universidad Cooperativa de Colombia. Docente de Tiempo Completo de la Facultad de Ciencias Económicas, Contables y Administrativas de la Fundación Universitaria de Popayán. Autora del capítulo de libro "Ideas Preponderantes sobre la Responsabilidad Social Empresarial RSE” (2019). Docente investigadora perteneciente al grupo IDEESE-Desarrollo Empresarial, Innovación y TIC.

laura.potes@docente.fup.edu.co.

Gabriel De la Torre Solarte, (Popayán, Cauca, Colombia, 1966). Magister en Administración de la Universidad del Valle e Ingeniero de Minas de la Fundación Universitaria de Popayán. Docente Investigador del programa de Administración de Empresas de la Facultad de Ciencias Económicas, Contables y Administrativas de la Fundación Universitaria de Popayán. Ha sido autor de libros y capítulos de libros, entre ellos: "Agencia Pública para el Patrimonio, visiones Alternativas del Patrimonio Local. Popayán una Ciudad en Construcción" (2004), "Pensamiento Universitaria. Propuesta Educativa",( 2006). "Empaques del Cauca S.A: Historia de Políticas y Estrategias", (2012). También ha publicado artículos en revistas especializadas nacionales e internacionales en temas de la administración de empresas relacionados con historia empresarial, el emprendimiento desarrollo organizacional y la educación. Es miembro del grupo de investigación Desarrollo Empresarial, Innovación y TIC - IDEESE.

gades10@hotmail.com y gabriel.

solarte@docente.fup.edu.co 


\section{Dedicatoria}

Dedico este libro a cada una de las personas que, desde su rol como colaboradores y emprendedores, compartieron conmigo sus alegrías, tristezas y sueños, me llenaron de motivos para seguir creyendo que la sociedad se construye y que las personas son lo más importante de los territorios. De nada nos sirven las cosas materiales, si no tenemos claro quiénes somos, de dónde venimos y cuál es nuestro papel en el mundo.

A la Fundación Universitaria de Popayán por enseñarme su gran legado social y a los docentes investigadores que hicieron parte de este proyecto, gracias por confiar en mí.

Dedico también este libro a mi familia, especialmente a mi esposo y a mis hijos que siempre están ahí, porque son mi razón

de ser.

A Fabián y a Carmen por ser ángeles en el camino. Sin su ayuda jamás lo habría logrado.

Gracias

Diana Ximena Sánchez Tróchez 


\section{Agradecimientos}

Llegar a los resultados de este libro fue posible gracias a la participación de las entidades que pertenecen a la Red Regional de Emprendimiento del Cauca, quienes, desde sus capacidades y compromiso con la región, aportan y promueven nuevas formas de estimular el emprendimiento, entre ellas, agradecemos a la Cámara de Comercio del Cauca, a la Oficina de Gestión de Empleo y Emprendimiento del Municipio de Popayán, al Centro de Desarrollo Tecnológico Clúster CreaTIC, al Servicio Nacional de Aprendizaje SENA Cauca, al Colegio Comercial del Norte (Popayán), a la Universidad del Cauca, a la Institución Universitaria Colegio Mayor del Cauca, a la Corporación Autónoma del Cauca, a la Corporación Universitaria Comfacauca Unicomfacauca y a la Escuela Superior de Administración Pública - ESAP.

De igual forma, a cada uno de los emprendedores que, a través de sus historias de vida, demuestran tenacidad y perseverancia, siendo un punto de referencia para aquellos que deciden este camino como su razón de ser y, al tiempo, dinamizan su relación con las entidades dedicadas a esta labor. Habríamos querido llegar a más emprendedores, sin embargo, estamos convencidos que el aprovechamiento de sus aportes permitirá fortalecer la capacidad de acompañamiento para más emprendimientos. Finalmente, y sin ser menos importante, agradecer el apoyo de la Fundación Universitaria de Popayán que, desde su invaluable compromiso social con el entorno, permanentemente se encuentra explorando estrategias de trabajo colaborativo para el beneficio de la sociedad, así como a los docentes investigadores Felipe Acosta Ortega, Laura Beatriz Potes Ordoñez y Gabriel De la Torre Solarte por ser parte de este proyecto académico e investigativo. 


\section{CONTENIDO}

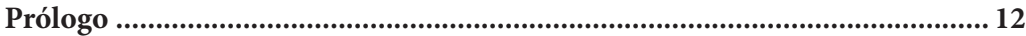

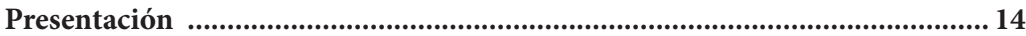

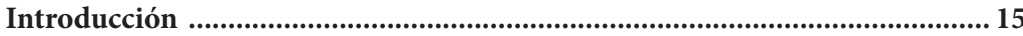

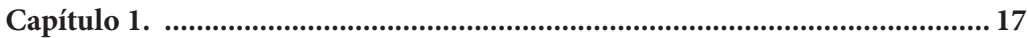

Evolución del emprendimiento .................................................................... 18

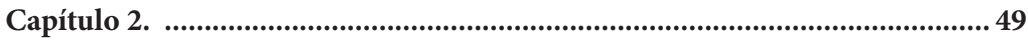

Una aproximación conceptual para comprender los distintos tipos de emprendimiento ...............................................................................................5 50

Capítulo 3 ................................................................................................................ 74

El emprendimiento universitario desde la revisión literaria............................. 75

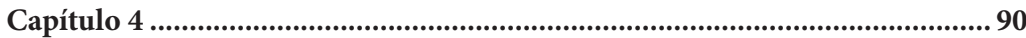

Actores públicos y privados que acompañan el emprendimiento....................91

La Red Regional de Emprendimiento del Cauca.................................................. 91

Institución Educativa Colegio Comercial del Norte ............................................. 92

Oficina de Gestión de Empleo y Emprendimiento del Municipio de

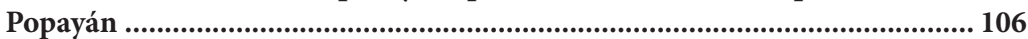

Servicio Nacional de Aprendizaje Sena ............................................................ 112

Centro de Desarrollo Tecnológico Clúster Creatic ........................................... 116

Fundación Universitaria de Popayán......................................................... 124

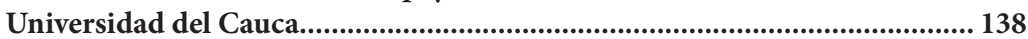

Corporación Universitaria Autónoma del Cauca............................................ 155

Institución Universitaria Colegio Mayor del Cauca .......................................... 160

Escuela Superior de Administración Pública - ESAP ...................................... 165

Corporación Universitaria Comfacauca............................................................ 170

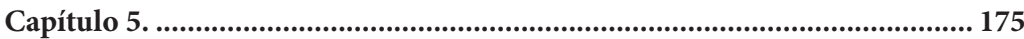

El emprendimiento desde historias de vida ...................................................... 176

El Emprendimiento como apuesta desde la formación básica y media ........ 176

Estudiantes del Colegio Comercial del Norte Popayán..................................... 176

Emprender desde una mirada de la administración pública y privada ......... 187

Emprendimiento Tecnológico............................................................................. 193

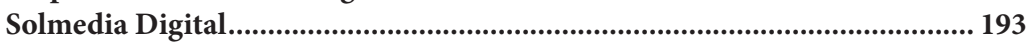

Inmodigital............................................................................................................ 204

Suricata Teach....................................................................................... 210

Popayán puede hacer Industria.................................................................. 214

Bioseguridad Colombia Company S.A.S (BSC COMPANY)...........................214

INTERA, productos sostenibles en plástico ………………………………….....221

Nube de Tacones, dejando huella desde lo alto .................................................227

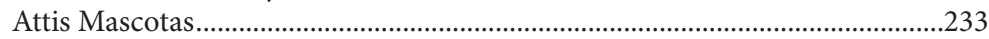

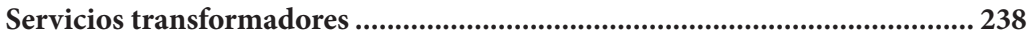


Fundación Red Emprendedoras Popayán...........................................................238

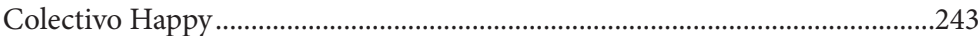

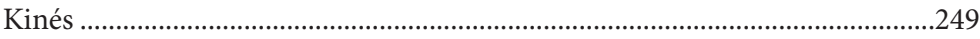

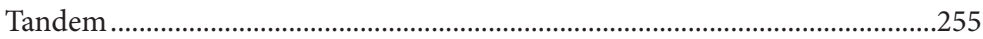

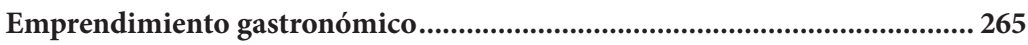

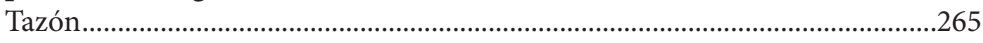

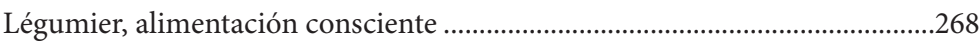

Munchys By Manu ..................................................................................2

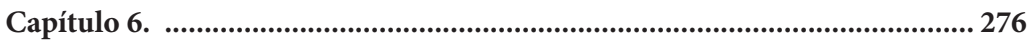

Modelo Ecosistema Popayán Emprende............................................................. 277

Conclusiones y recomendaciones ...................................................................... 301

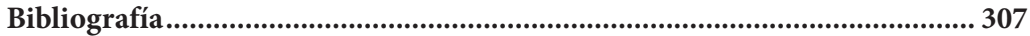




\section{TABLAS}

Tabla 1. Definiciones del emprendimiento sostenible.

.64

Tabla 2. Definiciones cronológicas del término emprendimiento tecnológico. ....65

Tabla 3. Diferentes denominaciones de NEBT. Marco general del emprendimiento tecnológico .66

Tabla 4. Revistas identificadas con la cantidad de artículos publicados, de acuerdo a los criterios de selección escogidos....

Tabla 5. Revistas identificadas en el recurso JCR...................................................80

Tabla 6. Criterio de selección de artículos ............................................................81

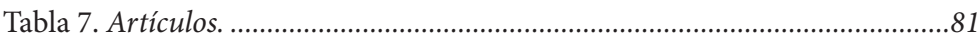

Tabla 8. Indicadores del Plan de Desarrollo Municipal 2016 2019................... 107

Tabla 9. Indicadores emprendimientos incubados y empresas aceleradas 2014-

2019

Tabla 10. Facultades de la Fundación Universitaria de Popayán ...................... 124

Tabla 11. Definiciones de emprendedores por oportunidad y necesidad.......... 279

Tabla 12. Distintas clasificaciones de la cadena de emprendimiento................ 285

Tabla 13. Actores del ecosistema....................................................................... 296 


\section{ILUSTRACIONES}

Ilustración 1. El principal marco jurídico colombiano en materia de emprendimiento

Ilustración 2. Tipos de emprendimiento

Ilustración 3. Publicaciones por año con las palabras "University

Entrepreneurial" y "Education", en el tema (Web of Science, 2019). .79

Ilustración 4. Clasificación del proceso emprendedor según la etapa en la cadena

de emprendimiento.

280

Ilustración 5. Clasificación del tipo de emprendimiento, según la etapa en la cadena de emprendimiento

Ilustración 6. Clasificación de los distintos papeles de las entidades de un EE, según la etapa en la cadena de emprendimiento. ............................................. 288

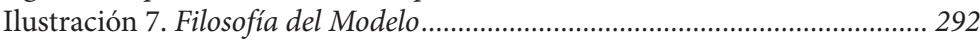

Ilustración 8. Modelo Ecosistema Popayán Emprendedora.............................. 295 


\section{IMAGENES}

Imagen 1. Representantes de entidades de la Red Regional de Emprendimiento del Cauca

Imagen 2. Estudiantes del Colegio Técnico Comercial del Norte y docente de emprendimiento ......................................................................................... 177

Imagen 3. Estudiante Corporación Universitaria Autónoma del Cauca ......... 181

Imagen 4. Emprendedor del sector público ..................................................... 187

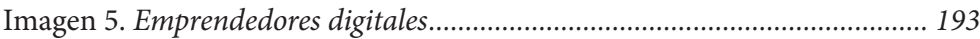

Imagen 6. Emprendedor digital en derecho ...................................................... 204

Imagen 7. Emprendedor en tecnología .........................................................210

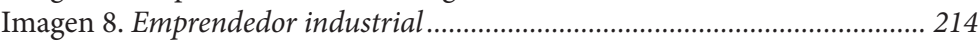

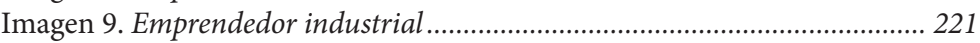

Imagen 10. Emprendedora de manufactura .................................................... 227

Imagen 11. Emprendedora textil.................................................................... 233

Imagen 12. Emprendedora Social ................................................................. 238

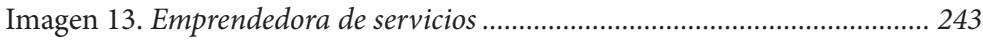

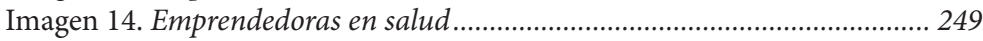

Imagen 15. Emprendedor cultural ............................................................... 255

Imagen 16. Emprendedora gastronómica ....................................................... 265

Imagen 17. Emprendedoras en gastronomía saludable................................... 268

Imagen 18. Emprendedor de comidas rápidas .............................................. 272 



\section{Prólogo}

Las oportunidades del comercio de bienes y servicios en la ciudad de Popayán, han sufrido cambios importantes que están generando nuevas formas de crear negocios a través del emprendimiento. De este modo, una región que se caracterizaba por tener actividades económicas empíricas y artesanales, ha recibido, de las entidades públicas y privadas, un interés permanente por promover y apoyar estrategias encaminadas a fortalecer el ecosistema de emprendimiento, logrando que estas iniciativas alienten a los habitantes de la ciudad y, en especial, a los jóvenes con pretensiones de sacar adelante sus ideas y propuestas.

En este sentido, el joven que antes quería graduarse y salir de la región, hoy ve en esta ciudad grandes oportunidades para lograr el éxito en su propósito de crear empresa o de ser un profesional que, mediante el intra emprendimiento, puede generar cambios importantes dentro de una organización.

Hoy en día, las redes institucionales han ido fortaleciendo su gestión y la ciudadanía en general, reconoce este esfuerzo, que se ha visto reflejado en el empoderamiento de los emprendedores frente al futuro económico de la ciudad. En este sentido, la Red Regional de Emprendimiento del Cauca, ha propiciado espacios oportunos y pertinentes para el diseño de estrategias que van posicionando a la ciudad como una apuesta emprendedora de vanguardia y es un referente para todas las entidades vinculadas a estos procesos.

La academia, en su interés de reconocer y valorar el desarrollo del emprendimiento payanés y de destacar al emprendedor y a las instituciones como un gestor de cambio, así como a los líderes que creen en el emprendimiento, protagonistas clave para que las ideas y proyectos se materialicen, adelantó, a través de la Fundación Universitaria de Popayán y su equipo 
de trabajo, el presente documento denominado "Cultura del Emprendimiento en Popayán. Experiencias y aprendizajes", investigación que merece nuestro reconocimiento y apoyo.

Mg. Yenny Patricia Imbachí Cerón Docente Programa Administración de Empresas Facultad Ciencias Económicas, Contables y Administrativas Fundación Universitaria de Popayán 


\section{Presentación}

El emprendimiento se convierte en un articulador de los conocimientos y saberes, con la realidad de cada persona. En ese orden de ideas, explorar este término a la luz de revisiones bibliográficas, del ejercicio de la institucionalidad y desde las historias de vida de los emprendedores, se convierte en un facilitador de estrategias necesarias para lograr un mayor impacto social.

Para ello, mediante una investigación cualitativa, se pretendió describir las características, cualidades, problemas, causas y efectos relacionados con el emprendimiento, que permitieron con ello evidenciar aprendizajes y experiencias. Es decir, no pretende probar o medir en qué grado de madurez se encuentra el emprendimiento en la ciudad de Popayán, sino de descubrir cualidades y características del mismo en contextos específicos.

Su población objetivo fueron 11 entidades pertenecientes a la Red Regional de Emprendimiento del Cauca, interesadas en hacer parte de la investigación y 17 emprendedores de la ciudad de Popayán seleccionados desde las instituciones, como casos a resaltar por su interés en el ecosistema de emprendimiento.

De esta forma, el siguiente documento, producto generado por el Grupo de Investigación IDEESE, del programa de Administración de Empresas de la Facultad de Ciencias Económicas, Contables y Administrativas de la Fundación Universitaria de Popayán, se encuentra estructurado en seis capítulos. 


\section{Introducción}

La ciudad de Popayán requiere ejercicios de recopilación de experiencias y de aprendizajes colectivos, adquiridos para la promoción, gestión y formación de emprendimientos, gestados tanto desde diferentes instituciones públicas y privadas, como desde los emprendedores, actores principales del ecosistema. Se partió de la hipótesis que cada organización adelanta y atiende el emprendimiento desde un enfoque general, dificultando focalizar esfuerzos y delegar en otras entidades, la continuación del proceso de acompañamiento; situación que soportó la necesidad de conocer y sistematizar, mediante un estudio cualitativo, los logros y desafíos que han sido resultado de las apuestas de las instituciones del municipio de Popayán y de la realidad que ha vivido el emprendedor.

De igual forma, siendo el emprendimiento, un factor destacado en la formación de profesionales y en el perfil de futuros egresados, la Fundación Universitaria de Popayán, encontró necesario disponer de su capacidad instalada para entregar estos resultados al servicio del ecosistema de emprendimiento de la ciudad de Popayán, con el fin de contribuir en el diseño y fortalecimiento de estrategias atemperadas a las necesidades y expectativas de la región.

En este sentido, esta sistematización de resultados pone sobre la mesa una realidad contada por líderes de las unidades de emprendimiento y emprendedores, con miras a contribuir en el diseño de políticas públicas desde la administración central y demás entidades gestoras de emprendimiento, en pro de continuar fortaleciendo y enriqueciendo la promoción de la cultura del emprendimiento en el municipio de Popayán.

El presente documento se encuentra estructurado en seis capítulos, abordando, de manera general, el emprendimiento desde dos vertientes. La primera, relacionada con un acercamiento 
conceptual a esta disciplina, y la segunda, desde la práctica de 11 organizaciones ubicadas en la ciudad de Popayán, Cauca, algunas de alcance departamental que pertenecen al Comité Regional de Emprendimiento del Cauca. Los resultados presentados en seis capítulos abordaron las siguientes temáticas, así:

Primer capítulo: acercamiento al concepto de emprendimiento, recorrido cronológico y etapas, desde la revisión de fuentes de información secundaria.

Segundo capítulo: exploración de los tipos de emprendimiento, reflexionando sus diferencias e interés, partiendo de fuentes de información secundaria.

Tercer capítulo: el emprendimiento universitario, dada la gran cercanía con el sector de educación superior y su papel preponderante en el ecosistema del emprendimiento.

Cuarto capítulo: el aprendizaje de las instituciones desde sus directrices en emprendimiento, estrategias empleadas y percepción del estado actual del emprendimiento local.

Quito capítulo: las historias de vida de los emprendedores, resaltando sus características personales como factor determinante para lograr emprender y sus aportes desde la realidad diaria como una contribución al ecosistema y a las entidades. Estas referencias tienen como fin contrarrestar desde el estudio de casos, 18 historias de vida relatadas por sus emprendedores alrededor del ejercicio de emprender que, encontrándose en contextos distintos, conservan algunas similitudes. Por el contrario, no pretende ser un estudio socioeconómico o un boletín estadístico.

Sexto capítulo: una propuesta de modelo. Es decir, un punto de partida como ejercicio articulador de los actores que intervienen en el ecosistema de emprendimiento.

Muestra entonces la cara amable de aquellos que le apuestan a la ciudad, sin pretender con ello ser una representación o muestra de los sectores socioeconómicos. 


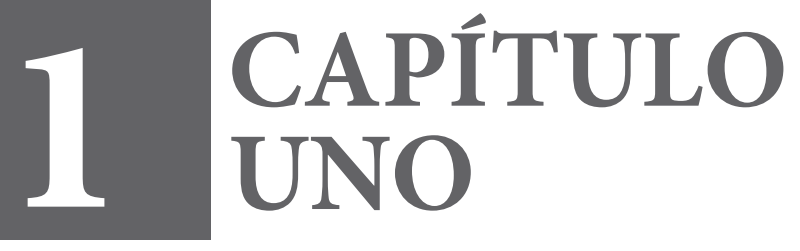




\section{Evolución del emprendimiento}

El rol de los actores del emprendimiento a lo largo de la historia: hablar de emprendimiento es una forma de establecer conexión con el concepto de progreso a nivel social y educativo que se ha instaurado en el mundo en los últimos años. Según el Diccionario de la Real Academia de la Lengua Española, se define como toda acción y efecto de acometer y comenzar una obra, un negocio, un empeño, especialmente si encierran dificultad o peligro (RAE, 2019). Además, se define a la persona que lo realiza como un Emprendedor, vocablo derivado del término francés entrepreneur, que significa "pionero", o estar listo para tomar decisiones, o para iniciar algo.

En esta medida, diversos teóricos y emprendedores alrededor del mundo han establecido diferentes parámetros para definirlo como una cultura de trabajo necesaria en una sociedad inmersa en dinámicas capitalistas. Por ejemplo, Vérin (1982), quien en sus escritos detalla cómo a partir de los siglos XVII y XVIII se calificaba de "emprendedor" al arquitecto y al maestro de obra, identificando en ellos características de personas que emprendían la construcción de grandes obras, como edificios y casas, por encargo. Así, se empieza a tener una analogía con el concepto de empresa de la modernidad, con una economía particular, modos de producción específicos y retribuciones materializadas en dinámicas mercantiles con el capital. En este sentido, académicos como Richard Cantillón, el más representativo de esta teoría moderna del emprendimiento, introduce el concepto de entrepreneur, definido por él como el individuo que asume riesgos en condiciones de incertidumbre, un hombre racional por excelencia, que actuaba en una sociedad mercantil en que la competencia y la incertidumbre hacen evaluar las probabilidades para tomar decisiones (Cantillon, 1755). Luego, Jacques Turgot, político y economista francés, cofundador de la escuela de pensamiento económico conocida como fisiocracia, en 
su obra Reflexiones sobre la formación y distribución de la riqueza (1766), consideró que los riesgos que asume el entrepreneur son respaldados por su propia porción de capital, clasificando sus formas de uso en la compra de tierras, la inversión en agricultura, la industria, el comercio y los préstamos a interés que, según su postura, proporcionan ganancias distintas de acuerdo a la dinámica capitalista que se emplee.

Asimismo, desde la escuela inglesa, con Adam Smith, se planteó que la naturaleza humana estaría diseñada para avanzar a fines que no necesariamente son conocidos por los empresarios, que se guían por las causas eficientes e indirectas sobre el papel del empresario en la economía, destacando la innovación como un sello de actividad profesional en el trabajador superior (Hebert \& Link, 1982). Por su parte, J. H. Von Thunen (1826), reconocido economista alemán, consideró al hombre-empresario como un sujeto económico que tiene como único objetivo maximizar los beneficios, estableciendo la teoría de la productividad marginal. Aquí, es clara la relación entre el emprendedor y la descripción del beneficio, que se concibe sobre la base de lo complicado del riesgo y el ingenio usado.

En este sentido, Schumpeter (1950), Ministro de Finanzas en Austria y docente en la Universidad de Harvard, reconocido por sus aportes a las teorías de la economía moderna, definiría nuevos parámetros para el entrepreneur:

La función de los emprendedores es reformar o revolucionar el patrón de producción al explotar una invención, o más comúnmente, una posibilidad técnica no probada, para producir un nuevo producto o uno viejo de una nueva manera; o proveer de una nueva fuente de insumos o un material nuevo; o reorganizar una industria, etc. Este tipo de actividades son las responsabilidades primarias de la prosperidad recurrente que revoluciona el organismo económico y las recesiones recurrentes que se deben al impacto desequilibrado de los nuevos producto o métodos. Esta función no consiste esencialmente en inventar 
algo o en crear las condiciones en las que la empresa puede explotar lo innovador; consiste básicamente en conseguir que las cosas se hagan. $(1999$, p. 5$)$

De este modo, el emprendimiento ha sido fuente de estudio en diversos ámbitos y momentos del mundo. González (2010) afirma que varios saberes han intentado extender la definición del espíritu emprendedor como la distinción entre los empresarios innovadores fuera y dentro de las organizaciones existentes (Gartner, 1989, 1990; Carland, 1984). Además, investigaciones como las de Sharma y Chrisman (1999) proponen una definición para el emprendimiento que es altamente consistente con los autores principales (Schumpeter, 1934 y Gartner, 1990) y del proceso intraempresarial, conocido también como emprendimiento corporativo (Zahra, 1995). De este modo, se identifica a los empresarios como individuos, o grupos de individuos, que actúan ya sea independientemente o como parte de un sistema corporativo, que crean nuevas organizaciones, o instigan la renovación o innovación dentro de una organización existente (Sharma \& Crhrisman, 1999).

El empresario, entonces, fue definido como un individuo que tiene una orientación gerencial de crear una empresa, de innovar, tiene una ventaja comparativa en la toma de decisiones porque tendrá un mayor conocimiento sobre los acontecimientos y las oportunidades, es quien asume riesgos y obtiene beneficios (Pickle \& Abrahamson, 1990).

Por otra parte, para Formichella (2004), ser emprendedor significa ser capaz de crear algo nuevo o de dar uso diferente a algo ya existente y de esa manera generar un impacto en su propia vida y en la comunidad en la que habita, es suficientemente flexible como para adaptar ideas, posee la creatividad necesaria para transformar cada acontecimiento en una oportunidad. Tal como expone Moncayo (2009), el emprendimiento es una manera de pensar y actuar orientada hacia la creación de riqueza. Es una forma de pensar, razonar y actuar centrada en las oportunidades, 
planteada con visión global y llevada a cabo mediante un liderazgo equilibrado y la gestión de un riesgo calculado, su resultado es la creación de valor que beneficia a la empresa, la economía y la sociedad.

Sería menester decir, por lo tanto, que un empresario puede y debe ser emprendedor, pero no necesariamente un emprendedor es empresario (Gartner, 1989).

En conclusión, parafraseando a Moreno \& Olmos (2010), según lo estudiado por Hisrich, Peters y Dean (2005), la definición de lo que es un emprendimiento se da desde diferentes puntos de vista:

1.El comportamiento: es el que emprende la iniciativa, organiza y reorganiza los mecanismos sociales y económicos para convertir en recursos y situaciones en algo práctico, y la aceptación del riesgo por fracasar.

2.Visión economista: quien convierte recursos, trabajo, materiales y otros insumos, en establecer mejoras para modificar y aumentar su valor económico, y en complemento a esto, introduce cambios, innovaciones y nuevas estructuras socioeconómicas.

3.Visión psicológica: quien está impulsado por la fuerza de alcanzar o lograr un ideal, de experimentar, de conseguir (o en su caso), la capacidad de escapar o no depender de otros.

4.Visión generalista: es el proceso de crear algo nuevo con valor, dedicando el esfuerzo y tiempo necesarios, asumiendo los riesgos financieros, psicológicos y sociales, con el fin de obtener las recompensas de satisfacción e independencia económica y personal.

Todo ello presenta estas características básicas del emprendedor:

1.El estímulo por crear o modificar procesos o productos.

2.Se exige a sí mismo un esfuerzo para conceder tiempo y dedicación para terminar sus ideales.

3.No importarle asumir riesgos.

4.Asume una independencia y tiene su satisfacción personal. 
Así entonces, ninguna definición de emprendimiento es lo suficientemente precisa o descriptiva para los ejecutivos que desean tener más emprendimiento, ya que todo el mundo desea ser innovador, flexible y creativo. En contraposición, por cada empresa establecida hay miles de nuevos negocios, tiendas de ropa y empresas consultoras, que presumiblemente han tratado de ser innovadoras, de crecer y mostrar otras características que exponen la existencia de emprendimiento en un sentido dinámico, pero que han fracasado (Rodríguez Ramírez, 2009). Por lo tanto, la definición de emprendimiento, emprendedor y emprender está más enfocada a preguntar: ¿cómo puedo hacer que la innovación, la flexibilidad y la creatividad sean más operacionales? (Timmons, 1998), asuntos determinantes para concluir el proceso o ruta que se debe llevar a cabo para ayudar a descubrir algunas respuestas, como analizar el comportamiento que se deriva del espíritu emprendedor. De hecho, para Timmons (1998) es más realista considerar el espíritu emprendedor en el contexto de un rango de comportamiento.

La transformación del emprendimiento: en Latinoamérica, algunos autores sugieren que el aprendizaje y la acumulación de capital físico propician las mayores dinámicas en la productividad total factorial. Otros apuntan a la valoración social y las posiciones ideológicas de los Estados y de la sociedad sobre las dinámicas empresariales y de emprendimiento, como los factores de mayor influencia. El elemento que une estos dos puntos de vista es la innovación, tanto incremental, relacionada con mejoras de procesos, como disruptiva, que lleva a nuevos bienes, servicios y soluciones. La innovación, en este sentido, es crítica, tanto para el aprendizaje y la acumulación de capital, como para nutrir una cultura empresarial y de emprendimiento entre los agentes tomadores de decisiones y la ciudadanía en general (Gómez \& Mitchell, Innovación y emprendimiento en Colombia: balance, perspectivas y recomendaciones de política, 2014-2018, 2014). 
En Colombia, por su parte, desde los últimos años se han establecido políticas que han influenciado el imaginario colectivo respecto del emprendimiento, llevando a cabo dinámicas empresariales inmersas en la cotidianidad del país. Así, el Congreso de la República, con el ánimo de reglamentar esta cultura en Colombia, estableció que:

El Emprendimiento se define como una manera de pensar y actuar orientada hacia la creación de riqueza. Es una forma de pensar, razonar y actuar centrada en las oportunidades, planteada con visión global y llevada a cabo mediante un liderazgo equilibrado y la gestión de un riesgo calculado, su resultado es la creación de valor que beneficia a la empresa, la economía y la sociedad. (Ley 1014, 2006)

De este modo, la definición y ejecución de la palabra emprendimiento estará en constante cambio, gracias al vertiginoso aceleramiento del progreso y desarrollo empresarial en la sociedad. Ante esto, y según diferentes posturas, se considera que el emprendedor en muchas ocasiones establece el deseo de convertirse en empresario y se presta a la decisión de instaurar el cambio de estilo de vida actual.

Por esto, un gran valor para la transformación entre los emprendedores es el descontento actual con su forma de vida, que puede darse desde el joven que sale de la universidad y desea crear y vivir sus propias experiencias en la formación de un negocio, hasta el profesional o empleado que cuenta con gran experiencia en su campo de trabajo o está jubilado, y no desea obedecer más órdenes de sus jefes y emprende una empresa. En ambos se percibe la sensación de que el establecer una empresa es tan deseable como posible (Moreno \& Olmos, 2010).

Fases del emprendimiento: hablar de emprendimiento, es también pensar en diferentes actitudes de positivismo asociados a la psicología y sociología que la persona que emprenda debe poseer. En este sentido, diferentes teorías, portales web, organizaciones 
y académicos asocian el emprendimiento como una ruta que la persona debe seguir con el objetivo de llevar a buen término su idea de negocio.

Evidentemente, los emprendedores no realizan sus actividades de manera aislada, se encuentran embebidos en redes que les proveen acceso a poder, información, conocimiento y capital financiero; así, las redes sociales se convierten en el activo más valioso que posee el emprendedor para apalancar el éxito de su labor. Un emprendedor que participa de una red más desarrollada (en términos del número y la calidad de los lazos creados), tendrá mayor posibilidad de acceder a recursos escasos, incrementando la probabilidad de éxito del emprendimiento. La noción del embeddedness de la actividad económica sugiere que los emprendedores construyen lazos sociales basados en la racionalidad económica, pero también fundamentados en la búsqueda de legitimidad y aceptación social. El concepto de embeddedness se aborda desde dos corrientes de pensamiento, una desde el ámbito económico y otra desde el social. Para efectos de este análisis, se considera que las esferas sociales no son separables de la esfera económica, y que las primeras proveen motivación suplementaria y ponen al emprendedor dentro de realidades alternativas (Echeverri, 2009). Así, las nuevas firmas no solo operan en redes de negocios, sino que interactúan con otras organizaciones e instituciones de carácter social y económico, que hacen que la actividad de emprendimiento se refleje como un fenómeno socioeconómico de carácter complejo. Muchos emprendimientos emergen de las redes personales de los emprendedores, las cuales, sin dejar de existir, dan origen a redes de negocios, embebidas en marcos institucionales.

Por tanto, es evidente que los emprendimientos son el resultado de un proceso de tipo social (Herrera Echeverri, 2019).

Por lo tanto, normalmente, y sin ánimo de especular sobre alguna fórmula secreta, estos parámetros tienen que ver con sensibilización y motivación al emprendimiento, 
mentalidad y cultura, ideación, modelo de negocio, prototipado, validación, mejoramiento de producto, primeros clientes, ventas, fortalecimiento empresarial y formalización (Torregroza, 2019). Sin embargo, se presentan algunas fases propuestas por diferentes grupos económicos, organizaciones sin ánimo de lucro, empresas fomentadoras del emprendimiento, entre otras, para tener un panorama más claro.

Ahora bien, desde la política nacional de emprendimiento (Ley 01014, 26 enero 2006 de Fomento a la Cultura del Emprendimiento) se plasman etapas que, para acompañar a los emprendedores, a saber:

1.Sensibilización: procesos que permitan motivar a la comunidad del programa para que se involucre en el emprendimiento, logrando masificación del mensaje mediante el uso eficiente de los recursos.

2.Formación: adquirir conocimientos en emprendimiento.

3.Preincubación: (Planes de Negocio) identificación de oportunidades de negocio mediante una metodología de Plan de Negocios orientado a simplificar procesos y adecuarlos a la toma de decisiones de inversionistas y del sector financiero.

4.Financiación: impulsar la presentación del o los proyectos a fuentes de recursos financieros que se desarrollan en el programa. Estudios de factibilidad adelantados para dar paso a este proceso. Mecanismos viables de estructuración financiera (identificación de capital semilla, capital de riesgo, préstamos, financiación e inversionistas) a nivel nacional e internacional.

5.Creación de Empresas: la iniciación de operaciones de las empresas para que alcancen su maduración en el corto plazo y se garantice su autosostenibilidad. Buscar mecanismos para resolver problemas de comercialización e incentivar la investigación de nuevos mercados y nuevos productos.

6.Capacitación Empresarial y Sostenibilidad: diseño y gestión en la orientación a empresas (mercados, finanzas, técnicos, etc.) que faciliten planes de acción que permitan el mejoramiento continuo de las mismas y su sostenibilidad en el largo plazo.

7.Sistemas de Información: contar con información suficiente 
que permita articular y estructurar las mesas de trabajo desde un Sistema de Información, logrando con ello contribuir a la labor de las instituciones que participan en red y que promueven estrategias para el beneficio de emprendedores, principalmente en aspectos relacionados a la formación.

En este sentido, estas fases pueden adaptarse según la dinámica de trabajo de cada red y de su contexto.

Emprender Fácil es una empresa online española que tiene como misión ayudar a cualquier emprendedor del mundo a conseguir más rentabilidad en su pequeña o mediana empresa con la ayuda de la tecnología fácil de usar, distingue las etapas de un emprendimiento así:

Etapa 1. La idea

Etapa 2. Puesta en marcha

Etapa 3. Funcionamiento regular

Etapa 4. Funcionamiento estable

Etapa 5. Funcionamiento óptimo

Etapa 6. Expansión o traspaso

En este sentido, para Molina (2019) se destacaría la organización que se tiene a la hora de emprender y las formas posibles de crear empresa, con el ánimo de hacerla sustentable y rentable en el tiempo. También, Más y Mejor (Isa \& Juanmi, 2019), una comunidad de emprendedores latinoamericanos en Estados Unidos, define las 5 fases de crecimiento de un negocio que se deben conocer para tener éxito como emprendedor. Se trata de:

Fase 1: Idea

Fase 2: Arranque

Fase 3: Consolidación

Fase 4: Escalada

Fase 5: Liderazgo

Por otra parte, Grandes Pymes, una empresa argentina que fomenta el emprendimiento en sus lectores, determina como fases 
del emprendimiento la ruta establecida por el pre-emprendimiento, la germinación, la primera venta, el punto de equilibrio y la expansión, transformación o cierre. Aquí, siguiendo a Pinzón (2019), esta ruta establece el ser socio estratégico que necesita todo emprendedor o empresario decidido a cambiar la manera de ver, vivir y gestionar su negocio a partir del convencimiento de que hacer más de lo mismo no lo llevará mucho más allá de donde ya se encuentra. Así, sería posible entonces una congruencia entre la visión que se tiene de la empresa y el espíritu emprendedor de aquel que tiene el propósito de hacerlo.

Para Arias \& Pérez (2014), el emprendimiento es, entonces, una metodología crucial para el crecimiento económico y el desarrollo de la innovación de una región. La creación de nuevas empresas va asociada a la mejor calidad de vida y generación de empleo, la creación de riqueza, el incremento de la competitividad y el desarrollo tecnológico, los cuales resultan puntuales en el desarrollo efectivo de una sociedad. Para poder hacerlo efectivamente proponen los siguientes pasos para su extensión y ejecución:

\section{Gestación \\ 2.Puesta en marcha \\ 3.Escalamiento y consolidación \\ 4.Internacionalización}

Así, para estas autoras, con dichas etapas empresariales finiquitadas es cuando el emprendedor empieza a escalar su modelo de negocio, iniciando realmente su empresa, con todo lo que esto implica, siendo el financiamiento vital para arrancar.

En el caso de Colombia, la Cámara de Comercio de Bogotá $(\mathrm{CCB}, 2019)$ tiene una gran apuesta por el emprendimiento, dado que aporta al desarrollo económico de la capital del país y la región. Como parte de esta apuesta, ofrece servicios integrales y especializados a los emprendedores y empresarios interesados en sacar adelante sus ideas de negocio. Las estaciones que proponen son: 
1.Identifique una idea de negocio: este es un elemento clave en el proceso de creación de una empresa. Una idea de actividad o producto debe ser validada para que se convierta en una oportunidad de negocio.

2.Desarrolle un modelo de negocio: este modelo define la estrategia que le permite a una empresa crear, proporcionar y captar valor.

3.Conozca los trámites de funcionamiento de su empresa: la calidad de vida empresarial no solo se define por el nivel de ventas o los indicadores financieros, sino por el cumplimiento de sus obligaciones. Una empresa formal cuenta con la identidad y seriedad que se requiere para hacer negocios y para generar confianza en los clientes.

4.Mercadeo y financiación: para hacer negocios es fundamental generar contactos que abren puertas. En esta estación, los asistentes aprenderán a ser acertados en su relacionamiento con otros actores del ecosistema emprendedor.

5.Entidades de apoyo: teniendo en cuenta la necesidad de brindar apoyo al emprendimiento con alto potencial de crecimiento en Bogotá y de articular la oferta institucional, existen entidades que apoyan a los emprendedores y empresarios en todo su proceso.

Por otra parte, Alfonso Rodríguez Ramírez (2009), académico colombiano que ha trabajado diversas experiencias del emprendimiento empresarial, aborda el emprendimiento como una comprensión de un fenómeno práctico, sencillo y complejo, que los empresarios/emprendedores experimentan directamente en sus actividades y funciones, como un acto de superación y mejoramiento de las condiciones de vida de la sociedad. Para su teoría, el emprendimiento tiene diversas fases y áreas de praxis:

1.Perspectivas: esta mirada interdisciplinaria permite observar lo complejo y variado que es el fenómeno del emprendimiento. Un punto de partida para estudiarlo es reconocer su complejidad y variedad en su análisis. Desde el punto de vista de estudio del emprendimiento, se identifican cuatro perspectivas de pensamiento: la comportamental, la psicológica o cognitiva, la 
económica y la de procesos (Fonrouge, 2002). Esta clasificación se caracteriza por el énfasis en los aspectos estratégicos, beneficiándose de los avances recientes en el campo de la estrategia.

2.Interdisciplinariedad: el emprendimiento hay que entenderlo e interpretarlo desde diversas perspectivas para estudiar su complejidad, construyendo un discurso inter y transdisciplinario que establezca nuevas formas para su consulta, estudio y entendimiento.

3.Contexto cultural: dependiendo del grado de incertidumbre y riesgo, el emprendedor busca tomar decisiones para aprovechar oportunidades que existen en el entorno, con base en su pensamiento creativo e innovador para elaborar, mejorar $\mathrm{y}$ transformar productos y servicios, para sacarlos al mercado, decidiendo sobre sus especificaciones y características.

4.Ejecución: la creación y consolidación de una empresa es similar a una proyección sobre la amplia pantalla o espejo del mercado. Prueba la capacidad de relación y de escucha, obligando al emprendedor a poner en práctica su capacidad de convencimiento para implementar su proyecto, a vender su idea, a utilizar una denominación con significantes. El proyecto de empresa entraña significantes. El conjunto de significantes constituye una cultura, es decir, un registro simbólico ofrecido al individuo por la sociedad que lo acoge, fundamental para el desarrollo de la persona en el curso de su evolución para "salir" de su relación consigo mismo, y por ende adoptar comportamientos emprendedores. Por medio del lenguaje las personas toman forma y gusto por crear, inventar, crecer y progresar. Se puede hacer una analogía con la organización donde los símbolos reúnen las individualidades, obedeciendo ellos mismos a una dinámica que instituye su valor. De esta manera, el emprendimiento aparece como resultante de la capacidad de hacerse su lugar, de afrontar la mirada de los otros, de tomar el poder, en suma, de persistir en el juego de ser emprendedor. (2009, p. 12)

Colombia se enmarca en un contexto de bajo crecimiento empresarial, desempleo, e inestabilidad económica. Como respuesta a esta crisis, se ha transformado la visión de las políticas 
de desarrollo económico que anteriormente se encontraban orientadas a nivel nacional a la atracción de empresas extranjeras de gran dimensión. Ahora, dichas políticas comienzan a potenciar el desarrollo endógeno que se materializa por lo general en la creación de Pymes, a partir de oportunidades de negocio en el escenario local. También se han creado propuestas de políticas locales asociadas al crecimiento de las Pymes, las cuales desempeñan un papel creciente en la economía y contribuyen a la generación de empleo, al desarrollo socio-económico local y a la dinamización de las cadenas productivas de las regiones. Estas propuestas hacen referencia a los programas de emprendimiento empresarial, basados en:

\section{Formación}

2.Sensibilización

3.Formulación del proyecto

4.Construcción de nodos y redes de emprendimiento 5.Legalización

Finalmente, la Cámara de Comercio del Cauca, en su Programa Ingenia, apoya y fortalece el emprendimiento de los caucanos que deciden iniciar su idea de negocio. Ahí se plantean los siguientes aspectos a trabajar:

1.Pensar: durante esta etapa el emprendedor trabaja para obtener su primer modelo de negocio, a través de la herramienta Ingecanvas. El Modelo Canvas es una metodología que considera de forma lógica la relación entre los componentes de una organización, así como todos los factores que inciden para que se tenga o no éxito. En un lienzo se detallan todos los aspectos que inciden y, de manera gráfica, el emprendedor podrá visualizar mejor su negocio (Ferreira-Herrera, 2016). Sus objetivos son conceptualizar el modelo de negocio, guiar al emprendedor a que investigue más sobre el sector, entorno en el que desea trabajar y revisar las tendencias. 
2.Probar: poner a prueba el modelo de negocio con el mercado objetivo es primordial en esta etapa, por eso al inicio se orienta el tema de validación (ver hoja de vida del taller de validación), y en adelante se trabaja con el emprendedor en la forma en la que irá al mercado a aprender más de él. Su objetivo es validar el modelo de negocio.

3.Empezar: en esta etapa se busca ayudar al emprendedor en su paso al rol de empresario, intentando que vivan las primeras actividades de la operación y constitución de la empresa. Como objetivo primordial se tiene iniciar la operación de la empresa.

4.Crecer: el objetivo de esta etapa final es acelerar el crecimiento de la empresa (CCC, 2019).

Progreso del emprendimiento: hablar del emprendimiento en un contexto regional, es hablar de la oportunidad que ha tenido la sociedad colombiana de poner en marcha diferentes perspectivas emprendedoras en ámbitos culturales, sociales y económicos. El emprendimiento se materializa con la creación de empresas que contribuyen al crecimiento y desarrollo económico de cualquier país. El análisis de las políticas públicas y las leyes implementadas para favorecer el espíritu emprendedor, han establecido un impacto en la práctica dentro de un contexto real e igualmente la manera como se están tomando y llevando a cabo cada una de las estrategias implementadas por el Estado (Buitrago, 2014).

En el caso de Colombia, el emprendimiento, desde el Estado, está a cargo del Ministerio de Comercio, Industria y Turismo, entidad encargada de direccionar y plantear los parámetros al respecto a nivel nacional. Sin embargo, está contemplado también desde la Constitución Política de 1991, en la cual se basan las demás reglamentaciones jurídicas, empezando por las leyes y decretos que sustentan legalmente las normas del 
emprendimiento en la nación. Según el Artículo 333 se considera que "la libre competencia económica es un derecho de todos que supone responsabilidades".

"La empresa, como base del desarrollo, tiene una función social que implica obligaciones. El Estado fortalecerá las organizaciones solidarias y estimulará el desarrollo empresarial” (Constitución Política de Colombia, artículo 333, 1991).

Luego, desde las dinámicas gubernamentales del país, se han regido diferentes leyes que han pretendido un avance en cultura de emprendimiento en la sociedad colombiana (Ver ilustración 1)

Ilustración 1. El principal marco jurídico colombiano en materia de emprendimiento.

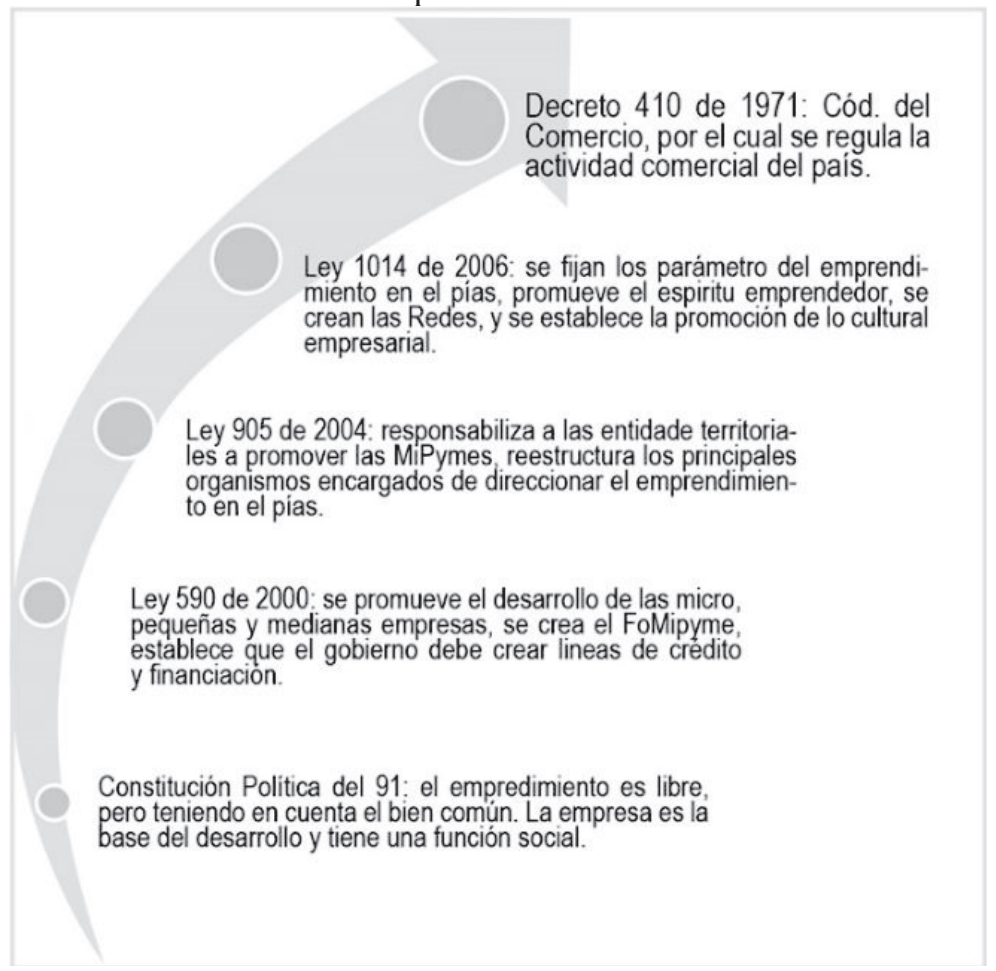

Fuente: (Buitrago, 2014) 
Según Buitrago (2014), estas normas jurídicas, básicamente, son el sustento legal sobre el cuales se fundamenta las políticas públicas, las cuales han tenido un avance o evolución a través del tiempo, así:

Para evidenciar la reglamentación en materia de emprendimiento en el país, es la Constitución Política de 1991 la norma principal, que cumple con el fin del Estado de promover la prosperidad y fija las primeras bases del emprendimiento, lo que permite evidenciar que el interés en promover y proteger, de algún modo, la actividad económica se orienta a motivar el bienestar de la sociedad en general, así como ser el garante del emprendimiento y planear políticas públicas que faciliten la creación de empresas, su estabilidad en el mercado y, a la vez, su crecimiento para propiciar el desarrollo empresarial.

Las Leyes 590 de 2000, 905 de 2004 y 1014 de 2006 plantean la necesidad de promover, incentivar e inducir la capacidad emprendedora del país, establecen los parámetros y fijan las características básicas, así mismo se crean organismos como el FoMipyme y las Redes de Emprendimiento, organismos encargados de facilitar y cultivar el emprendimiento. En estas, se define emprendedor colombiano como una persona con capacidad de innovar; entendida esta como la capacidad de generar bienes y servicios de una forma creativa, metódica, ética, responsable y efectiva. (p. 12)

Cuando se habla de emprendimiento, se habla de nuevas oportunidades de negocio y de impulsar a la creación de empresas grandes, medianas o pequeñas, que generan un crecimiento económico. En Colombia esta tendencia va en incremento ayudando a la sostenibilidad del país, generando, a su vez, reducción en los índices de desempleo, teniendo en cuenta que un emprendedor requiere de innovación y constancia para que su nueva oportunidad de negocio llegue al éxito (El Tiempo, 2017).

Por otra parte, la investigación sobre emprendimiento emergió como un importante aporte, fundamentándose como la necesidad de aquellos que buscaban transformar su entorno social 
y económico. Para ello, se aborda a continuación el concepto de forma cronológica con el fin de identificar similitudes y diferencias entre periodos, rescatando aspectos relevantes que permitan ampliar el análisis y asentar las bases conceptuales de los tipos de emprendimiento, del acompañamiento de entes públicos y privados, así como documentar las experiencias de emprendedores.

\section{8-2009:}

El año recordado en el mundo como el año de la crisis financiera de los Estados Unidos, repercutió sobre los países que dependen en gran parte de la economía de este país. Colombia y Latinoamérica no fueron la excepción. Esta,

Afectó la economía colombiana a través de varias rutas: la desaceleración del crecimiento mundial, producto de la crisis, afectó el dinamismo de las exportaciones colombianas y disminuyó los precios del carbón, el petróleo, el ferroníquel, etc. La liquidez mundial también disminuyó como resultado de la crisis, lo que afectó adversamente los flujos de inversión. La menor inversión, a su vez, llevó a una depreciación de la moneda colombiana, a una caída de la bolsa y a un aumento del costo de la deuda" (El Espectador, 2008).

Sin embargo, y ante esta situación, el emprendimiento colombiano ha logrado mantenerse estable desde entonces y creció, no solo en este periodo, sino también en años posteriores. Esto se debe, en gran medida, a que en el país se ha estado invirtiendo y generando mayor valor agregado, y dinamizando la economía de manera más estable (Buitrago, 2014).

Así entonces, el emprendimiento colombiano también marchó acorde a las dinámicas financieras del planeta, pues la crisis financiera mundial afectó sin duda todas las micro y macroeconomías nacionales, procurando buscar soluciones políticas prontas para abastecer las necesidades sociales marcadas 
por el comercio. Según Zona Económica (2010) los emprendedores, así como los empresarios colombianos, supieron solventar la situación de tal manera que hubo medidas de aseguramiento de las economías locales, de acuerdo a las diferentes zonas comerciales del país, a pesar de las adversas condiciones a las que debieron enfrentarse al respecto.

Así, el emprendimiento colombiano también debió solventar dicha crisis, buscando satisfacer la creación de pequeñas y medianas empresas. Sin embargo, la situación política del país no fue favorable para entonces, ya que la sociedad colombiana tuvo que enfrentar cruciales hechos como la crisis de las pirámides a finales del año. Tras la quiebra de varias de ellas, el gobierno declaró el "estado de emergencia social", interviniendo a D.M.G. Grupo Holding S.A. desatándose así una crisis interna por los miles de personas afectadas económicamente (Semana, 2009).

Respecto al dinamismo del tipo de cambio, después de presentar un proceso de apreciación de la moneda colombiana durante los últimos 5 años, en 2009 se estimó una devaluación promedio del peso de $18 \%$. Esta devaluación fue esperada por las empresas colombianas, gracias a la menor entrada de divisas en la economía, producto de diversas razones como la reducción en las remesas, caída en las exportaciones y una menor entrada de capitales como consecuencia de la incertidumbre experimentada en el ámbito económico. Los emprendedores entonces debieron afrontar situaciones como la cotización del oro a 1.000 dólares la onza a nivel mundial y el hecho que el petróleo alcanzara precios de hasta 147 dólares el barril, asuntos que, incluyendo los aranceles a materias primas y otra tramitología y burocracia estatal, poco favorecían la fomentación del emprendimiento nacional.

Finalmente, y a puertas de terminar el segundo periodo presidencial de Álvaro Uribe Vélez, el SENA se había convertido en un centro importante de fomento al emprendimiento apoyado por políticas públicas y gubernamentales, y que se requería en el 
país para el soporte de una institución con cobertura nacional y que sirviera de plataforma para expandir las acciones que se llevarían a cabo en emprendimiento. "Esa entidad era el SENA, ya que ninguna otra institución del Estado tenía la experiencia, talento humano formado en emprendimiento, cobertura, flexibilidad, infraestructura, credibilidad y presupuesto para afrontar un reto tan importante en la ejecución de los programas estratégicos de formación de emprendedores y creación de empresas, brindando el soporte y el liderazgo de una institución que les permitiera actuar de manera adecuada" (Chamorro, Osorio, \& Botero, 2013).

\section{0-2011:}

Para finales del 2009 y principios de 2010, el gobierno nacional estableció la Política de Emprendimiento en Colombia, la cual se concebía como

Un conjunto de personas, variables y factores que intervienen en el proceso de crear una empresa. Una manera de pensar y actuar orientada hacia la creación de riqueza [...] centrada en las oportunidades, planteada con visión global y llevada a cabo mediante un liderazgo equilibrado y la gestión de un riesgo calculado; su resultado es la creación de valor que beneficia a la empresa, la economía y la sociedad. (Ministerio de Cultura, 2010, p. 26)

Según Chamorro (2013), de manera oficial, la PNE se adoptó mediante un documento expedido específicamente por el Ministerio de Comercio, Industria y Turismo para tal fin, en el que se establece que el Estado tiene un papel múltiple, y a la vez protagonista, en el fomento del emprendimiento. La PNE nació con diversos objetivos estratégicos que conformaron un esquema integral en el que se incluyen los diferentes aspectos que tienen que ver con el desarrollo y fortalecimiento de las nuevas empresas y de las ya creadas. Entre otros, se trabajaría desde entonces los componentes de innovación, capacitación, comercialización, financiación, medio ambiente, reglamentación y trámites legales. 
Así entonces, durante este periodo gubernamental se decretó el incremento del salario mínimo en un 3,6\% calculado por encima de la inflación de ese año, estimada en casi el 3\%. El sueldo mínimo para los colombianos se determinaría en $\$ 515.000$ y el subsidio de transporte, de $\$ 61.500$. En esa medida y bajo esta situación financiera del país, el SENA continuaba forjando esfuerzos para la formación de empresarios, Institución que, en compañía de las Universidades en todo el territorio nacional, se consolidaba como el apoyo principal a los emprendedores, creadores de pequeñas y medianas empresas. En el estudio realizado por Chamorro (2013) el $79,4 \%$ de las opiniones de los emprendedores encuestados estarían a favor de que fueron los sectores educativo y productivo (universidades, SENA, empresarios, gremios e incubadoras), los que mayor influencia tuvieron en la inclusión del emprendimiento en la agenda de gobierno, en tanto que el 20,6\% de las mismas se orienta a que fueron algunos representantes del Estado (congresistas y tecnocracia gubernamental).

Desde su inicio, se planteó que el SENA debía realizar el trabajo articulado y en alianzas estratégicas con todas las fuerzas vivas del país para liderar, asegurar, medir y consolidar su misión, en una interacción continua con diversas entidades que desarrollaban programas a lo largo de la cadena de valor de la creación de empresas. Esta estrategia se pudo dar por la cobertura de la entidad en el ámbito nacional, ya que posiblemente ninguna otra tenía la infraestructura para hacerlo.

De igual manera, se definieron 8 vectores estratégicos que orientarían la gestión del SENA hacia la proyección y modernización del quehacer de la entidad. El tercero correspondió a emprendimiento y empresarismo, definiéndolo como:

Desarrollo de competencias emprendedoras de las personas, [que] debe orientarse a la creación de empresas innovadoras, que permitan incrementar en número y calidad los puestos de trabajo del país y fortalecer las empresas existentes. (González, 2010, p. 8) 
Por otra parte, finalizando el 2010, se aprobó la Ley 1014 de 2006 (Congreso de la República de Colombia, 2006) más conocida como Ley de Emprendimiento, la cual generó instrumentos adicionales para promover el emprendimiento y creó un ambiente propicio para incluir la creación de nuevas empresas como un tema específico que debe ser coordinado por el Estado en unión con una variedad de instituciones públicas y privadas que de una $u$ otra manera tienen que ver con la cadena de valor. A esta fecha, el país contaba con las leyes 590 de 2000, 905 de 2004 (que modifica parcialmente la anterior) y 1014 de 2006 sin embargo, aún no había una política pública de emprendimiento explícitamente establecida, a pesar de que muchos de los esfuerzos conjuntos y articulados ya se venían dando desde principio del gobierno de la fecha.

Para entonces, uno de los cuellos de botella que más limitaba la capacidad del país de dar el salto en ciencia, tecnología e innovación, es la falta de capital humano. En esos años, se dieron pasos sustanciales en la materia. Por ejemplo, entre 2002 y 2011, el número de graduados en instituciones de educación superior colombianas se duplicó, al pasar de 133.442 a 267.708 . De estos, sobresale el aumento en graduados en carreras técnicas y tecnológicas que pasó de 23.249 a 90.621 , o de doctorados que incrementaron de 32 a 258 finalizando el 2010.

Pero, la baja inversión histórica de Colombia en actividades de ciencia, tecnología e innovación, y en particular de investigación y desarrollo, se ha traducido en una falta de cultura de innovación y emprendimiento. Esta falta de un ecosistema de innovación que permee a la sociedad, y a su actividad empresarial, ha generado, como se describe anteriormente, un déficit de capital humano especializado y preparado para enfrentar los retos de una economía moderna. La falta de investigadores y personal capacitado dedicado a la ciencia, tecnología e innovación, explica, en buena medida, la reducida producción científica, ya sea mediante publicaciones o registros de propiedad intelectual (Gómez \& Mitchell, 2014, p. 20). 
Ya en el 2011, la firma colombiana The Breakthrough, con metodología de Monitor Group de Boston, ubicó al país en el puesto 23 entre la medición de 24 naciones (Revista Dinero, 2011), dejando serias preocupaciones entre los emprendedores y las políticas públicas del emprendimiento del país en ese entones. Para ello, desde el gobierno nacional se estableció generar diversas estrategias desde las Redes Regionales de Emprendimiento nacidas a partir de la Ley 1014 donde se fortalecieron alrededor de 400 unidades de emprendimiento en Universidades y sedes del SENA en todo el país, 11 laboratorios para la innovación empresarial, 27 incubadoras de empresas de base tecnológica, 20 Cámaras de Comercio orientadas al emprendimiento, entre otras (CCC, 2012).

Este reto, asumido por el nuevo gobierno de turno, se vio materializado años más tarde, gracias a las implementaciones hechas por las autoridades competentes y por el fomento al emprendimiento a las nuevas generaciones, hechas desde las aulas de clase de instituciones de educación superior y secundaria, generando nuevas oportunidades de negocio e impulsando la creación de nuevas empresas grandes, medianas o pequeñas, que generaran un potencial crecimiento económico.

Al cabo de este esfuerzo, el país había alcanzado algunos avances importantes, pero todavía la inversión en ciencia, tecnología e innovación era comparativamente baja, la participación del sector privado insuficiente, y el enfoque de la estrategia en la innovación aplicada prácticamente mínimo. Como respuesta a esto, en 2011, se asignó el 10\% de los recursos de regalías a ciencia, tecnología e innovación, y se creó la Unidad de Desarrollo de Bancóldex, denominada iNNpulsa, que sería la entidad encargada de financiar y apoyar proyectos de innovación empresarial y emprendimiento dinámico en el país (Gómez \& Mitchell, 2014). 


\section{2-2013:}

Para los años futuros, el panorama sería mucho más alentador para el emprendimiento colombiano, hasta el punto de consolidar al país como uno de los mejores en Latinoamérica (Latin Business Chronicle, 2013). Según el Informe de Coyuntura Empresarial 2012, de Confecámaras, durante ese año se crearon 278.063 empresas con un incremento del 17,3\% frente al 2011, delas cuales solo el 0,13\% fueron grandes empresas. Para Confecámaras, estas cifras fueron muestra de un comportamiento positivo en el sector empresarial colombiano, donde el emprendimiento era cada vez mayor, así como también la formalización y la inversión de extranjeros y nacionales se incrementó, gracias a una mayor confianza en el país. Esto significó que los emprendedores empezaron a ser reconocidos a nivel nacional como una de las fuerzas más importantes en generación de empleo (Portafolio, 2013).

Además, el 2012 fue el primer año de iNNpulsa Colombia, la Unidad de Gestión de Crecimiento Empresarial del Gobierno Nacional, creada en febrero de 2012 para promover el emprendimiento, la innovación y la productividad como ejes para el desarrollo empresarial y la competitividad de Colombia. Este programa, con cerca de $\$ 100.000$ millones apoyó a más de 515 empresas en quince departamentos del país, ubicándolo como uno de los países que más invierte y avanza en programas de emprendimiento e innovación en el continente. Tal como lo aseguró Pedro Vera Castillo, fundador y presidente de la Red de Emprendimiento e innovación de América Latina, Emprendesur. "Estudios internacionales emblemáticos como el Global Entrepreneurship Monitor's, GEM, siempre ubican a Colombia como un referente para América Latina y para mí, es el primer o segundo mejor país del continente" (Amorós, 2012).

Cabe anotar también que en noviembre de 2012 explotó el caso de Interbolsa, la más grande firma de valores de Colombia, que por poco se lleva por delante a todo el sistema de inversión en 
el mercado de capitales. Las apuestas arriesgadas en mecanismos de reposición con acciones por poco tumban toda la estantería (Dinero.com, 2016). Esto generó también una rápida respuesta por parte de los empresarios, empleadores y emprendedores, quienes fueron testigos de cómo la liquidación de la principal comisionista de bolsa del país fue dejando incertidumbre en el mercado y lecciones de cómo las prácticas riesgosas pueden llevar a la caída de un grande de la bolsa (Mayorga, 2012).

Por otra parte, la inversión en investigación y desarrollo en Colombia fue, en 2012, de tan solo 0,17\% del PIB, frente a cifras cercanas o superiores a 0,5\% de Chile, y de más de $1 \%$ en Brasil y España. De estas inversiones, el sector privado en Colombia aportó alrededor del 40\%, mientras en Corea del Sur e Israel, dicha participación superó el 75\%. Al analizar la evolución de las inversiones en ciencia, tecnología e innovación de Colombia, se evidencia en contravía de las tendencias internacionales y contra las necesidades apremiantes del país- un lento dinamismo. La inversión en investigación y desarrollo aumentó, entre 2002 y 2012 , de $0,12 \%$ a tan solo $0,17 \%$, con una participación del sector privado que osciló, durante el período, en un rango, sin tendencia clara, entre 30\% y 50\% del total (Gómez \& Mitchell, 2014).

Por su parte, COLCIENCIAS, y contando con la posterior Ley de Ciencia y Tecnología de la Constitución de 91, adelantó entre otras importantes actividades, la de promover la constitución de incubadoras de empresas de base tecnológica. La primera fue INNOVAR en Bogotá y alrededor de esa época se adelantó una experiencia en Pereira que no perduró, luego aparecen la Incubadora de Empresas de Base Tecnológica de Antioquia, la de Santander y Cali. A finales del 2012 y principios de 2013, gracias al impulso del tema por parte del SENA sumaron 34 de ellas que hacen parte del Sistema Nacional de Creación e Incubación de Empresas, algunas en su fase de arranque, a través del cual se promovió la conformación de 801 empresas que aportaron al país 6.901 empleos. 
En Colombia, para 2013, hubo alrededor de 790 organizaciones de apoyo al emprendimiento. Son de carácter público, privados, lideradas por las cámaras de comercio, las gobernaciones y las alcaldías. En el país funcionan 31 redes, una por departamento, con excepción de Guainía. Además de iNNpulsa y de las 116 unidades de Emprendimiento del Fondo Emprender, a nivel gubernamental y mixto, hay organizaciones de apoyo como la Unidad Especial Administrativa para Organizaciones Solidarias; los Laboratorios Sociales de Cultura y Emprendimiento (Laso), del Ministerio de Cultura; Valle Impacta, programa liderado por la Cámara de Comercio de Cali en compañía de Endeavor Colombia; + Ideas + Empresas, de Bucaramanga; Avanza Atlántico, de Barranquilla. Y por el otro lado están las iniciativas privadas como Destapa Futuro, Corporación Ventures, Endeavor Colombia, Andi del Futuro; y varias incubadoras, como la Fundación Incubar Colombia, Incubadora Gestando; pero también empresas de financiación de proyectos como el Banco de la Mujer, el Banco Caja Social y Bancolombia. (Portafolio, 2013, p. 1)

\section{4-2015:}

En 2014, Colombia fue seleccionado por el Banco de Desarrollo de América Latina (CAF) como caso destacado por la pertinencia y flexibilidad en la tarea de acompañar y apoyar a empresas y organizaciones emprendedoras e innovadoras y en 2015, iNNpulsa fue reconocida como la segunda mejor experiencia aleccionadora para el desarrollo del ecosistema de innovación y emprendimiento en América Latina en el marco del Quinto Seminario Taller para el Ecosistema Emprendedor de América Latina, organizado por PRODEM, BID-FOMIN, Gulliver e Incubatec de la Universidad de la Frontera de Chile (iNNpulsa Colombia, 2019).

Ante este nuevo escenario, para Gómez \& Mitchael:

Las empresas perdieron rentabilidad y capacidad de competir en costos en los mercados internacionales de productos básicos, y, a su vez, no alcanzaron los estándares de calidad y 
de valor agregado para llevar al mundo bienes y servicios más sofisticados. A través de la ciencia, la tecnología, la innovación y la generación de emprendimientos dinámicos (CT\&IE), el país sobrepuso la inercia y transitó con éxito hacia una economía diversificada y competitiva. Para seguir por este camino, resultó prioritario convertir la CT\&IE en las grandes apuestas de la próxima administración presidencial en sus políticas económicas, sociales y ambientales; debe ser esta la brújula que guíe un plan de gobierno. (2014, p. 13)

Por tanto, se requirió, además, fortalecer las alianzas entre iNNpulsa y Colciencias con el sector financiero, y promover una mayor destinación de recursos de las empresas en actividades de CT\&I. Lo anterior, con el fin de generar una cultura de apoyo a la formación de capital humano en el sector bancario y fomentar el surgimiento de emprendimientos dinámicos e iniciativas de innovación que sean independientes, o tan solo se apalanquen parcialmente, de la intervención estatal.

Por otra parte, en octubre de 2014, la Selección Colombiana de Fútbol logró clasificar al Mundial de Brasil, luego de diversas versiones de no dar esa alegría al pueblo colombiano. Sin embargo, por otra parte, hubo viarias cifras que contrarrestaban dicha alegría: la tasa de desocupación fue de 7,9 por ciento, la segunda más baja desde el 2001, cuando se iniciaron los registros mensuales (el récord es 7,8 por ciento). Un mes antes, el DANE publicó la última cifra de pobreza: 29,3 por ciento, casi tres puntos menos que un año antes. Fue la primera vez, desde que se llevan estadísticas sobre pobreza, que esta se sitúa por debajo del 30 por ciento y que la extrema marca menos del 9 por ciento (El Tiempo, 2014).

Así entonces, el gobierno nacional tuvo en cuenta las rápidas decisiones a tomar al respecto y considerando el monto de 949 mil millones de pesos aprobado en 2013 en proyectos de regalías de ciencia, tecnología e innovación, se estimó una inversión de cerca de $0,6 \%$ del PIB. El presupuesto estimado 
para 2014 de los seis principales rubros públicos destinados a CT\&I, fueron el presupuesto de iNNpulsa, el presupuesto de Colciencias, los recursos del SENA para desarrollo tecnológico y competitividad, según la Ley 344 de 1996, los beneficios tributarios para inversiones en ciencia, tecnología e innovación, el Fondo de Ciencia, Tecnología e Innovación del Sistema General de Regalías (10\% del total), y el presupuesto de Corpoica y otras inversiones en CT\&I para el sector agropecuario (Buitrago, 2014).

En el 2015 Confecámaras realizó un balance en el cual se evidencia la buena actitud a la hora de crear empresa, ya que sus resultados indican que 301.334 empresas fueros creadas en Colombia para dicho año, lo que significó un aumento del 9,6\% con relación al año inmediatamente anterior. Por lo tanto, los principales beneficios del emprendimiento en Colombia estuvieron dados por las condiciones de demanda que se generaron a nivel nacional, el ambiente que se ha desarrollado para la creación de negocios con valores agregados y el interés del capital humano para generar ingresos propios y solidez en los mercados locales. En dicho estudio, se resaltó también que el sector con mayor participación de mano de obra en la economía nacional, fue el HORECA (Hoteles, Restaurante y Catering), con una participación del $26,8 \%$, evidenciando el crecimiento sustancial y el aporte que este gremio generó en dicha época en aspectos como desarrollo, empleo, competitividad e innovación en Colombia. Este sector ha tenido un crecimiento importante en los últimos cinco años. De acuerdo con los reportes del DANE, que muestran que, desde el año 2010, el PIB del sector en Colombia creció en un promedio de $4,3 \%$. Para ese entonces, el país registró la llegada de 175 hoteles de cadenas internacionales en los últimos cinco años, entre los cuales se destacan Hilton, Marriott, Pestana, Accor, Atton, NH Hoteles, provenientes de mercados como Estados Unidos, Chile, Francia, España, Portugal y México, principalmente. (El Tiempo, 2015, p. 1) 


\section{6-2017}

En 2016, hubo diversas noticias de interés para los emprendedores nacionales. Entre ellas, el hecho que la Contraloría General de la República presentó un informe en el cual denunció que los sobrecostos por la modernización de la refinería de petróleo de Cartagena Reficar, ascendieron a 4.023 millones de dólares por irregularidades en la contratación de la obra. Por otra parte, en Medellín, la Feria Colombiatex de las Américas 2016, conocida como una de las ferias más importantes de la región, en su edición $28^{\circ}$ recibió 21.300 visitantes, tuvo 510 expositores de 24 países, logró 13.950 compradores (12.180 nacionales y 1.770 internacionales), 26 conferencias y negocios por unos 300 millones de dólares. Finalmente, el Banco Mundial destacó a iNNpulsa como institución clave y protagónica en el desarrollo productivo del país, gracias a la implementación de programas de emprendimiento, innovación y productividad empresarial.

Por otra parte, en 2016, el precio del dólar alcanzó el valor más alto en la historia de la economía colombiana, registrando una tasa de cambio de 3.439 pesos colombianos, lo que llevó rápidamente a generar estrategias de comercio pronto para no generar pérdidas económicas en el país. A la par, el informe Global Entrepreneurship Monitor AGER 2016 explicó que el potencial emprendedor de la población colombiana es del $80 \%$, mientras que el promedio latinoamericano es del $71 \%$ y el mundial del $43 \%$ (Global Entrepreneurship Monitor AGER , 2016) insinuando que Colombia tenía en ese entonces más potencial en emprendimiento que la Unión Europea, Norteamérica y Asia.

Por tanto, el gobierno de turno se dio a la tarea de gestar dinámicas para continuar fomentando dicha actividad.

Entender la manera como los Gobiernos pueden aprovechar el poder transformador que tiene el emprendimiento a través de sus políticas públicas es un tema de suma importancia que merece ser investigado más a fondo. Para el caso colombiano, el emprendimiento ha sido considerado, tanto por expertos 
como por el Gobierno Nacional, como un instrumento clave en la construcción de la paz en el territorio durante la presente etapa de post-conflicto. Por tanto, se hace necesario entender y comprender en qué consiste la política pública de emprendimiento en Colombia, pues en los pocos análisis que se han realizado de la misma, ninguno establece con claridad qué es, qué medidas la componen y cómo ha sido su desarrollo a través del tiempo, lo que dificulta la elaboración de propuestas concretas que lleven a aprovechar todo el potencial que la actividad emprendedora puede brindarle al país. (Martínez, 2018, p. 34)

Colombia es la séptima nación de Latinoamérica que cuenta con los requisitos idóneos de demanda para el emprendimiento, por la facilidad de los trámites que deben hacerse para iniciar un negocio y el acceso a préstamos bancarios con un buen plan de negocios. En 2016, diversos estudios demostraron que cada año se creaban más de 100 mil nuevas empresas en el país, lideradas por personas impulsadas por sus ganas de progresar asumiendo sus propios retos laborales y promoviendo el mejoramiento del territorio nacional (El Tiempo, 2015).

Así, según la revista Portafolio, durante estos años (2016 y 2017) el emprendimiento en Colombia presentó un aumento significativo. El país llegó a ser uno de los principales HUBS de emprendimiento, es decir un espacio donde los emprendedores realizan ejercicios de colaboración y forman comunidades, impactando de forma importante a las ciudades donde se ubican. Colombia ha logrado que las diferentes marcas y negocios rompan barreras geográficas y posicionen los negocios y productos en otros países de la región sin necesidad de estar radicados allí, hasta el punto que Rockstart -una de las principales aceleradoras de emprendedores del mundo de origen holandés- escogió a Colombia como su sede única para Latinoamérica y decidió montar sus operaciones en el país ayudando al posicionamiento regional. Esto hizo que 7 inversionistas internacionales provenientes de Europa y más de 200 emprendedores internacionales hayan ingresado y aplicado para ser parte del primer programa en Latinoamérica (Portafolio, 2017). 
En este sentido, en 2017, según el informe Global Entrepreneurship Monitor, "los colombianos son los más emprendedores de Latinoamérica y los terceros a nivel mundial" (GEM, 2017). En este informe se muestra que el 53\% de los ciudadanos colombianos mostró su intención de crear una empresa, cifra que se reduce hasta el 35,5\% al hablar de la región latina. "Es necesario trabajar en el $26 \%$ de los colombianos que afirman que el temor al fracaso los detendría al momento de tomar la decisión de crear una empresa", explica el informe.

En este sentido, cabe destacar que las variables que explican este panorama positivo son, un $74 \%$ que asegura no tener temor al fracaso, 68\% que considera tener las cualidades necesarias y el $51 \%$ que cree que encontrará buenas oportunidades para emprender. En cuanto a las motivaciones que impulsan el emprendimiento en Colombia, señala que el 51\% decide crear una empresa para lograr una mayor independencia, mientras que el $40 \%$ busca incrementar sus ingresos y el $8 \%$ quiere mantener su nivel económico actual. De igual forma, entre los nuevos empresarios, el 58\% afirmó que decidió dar el paso por una oportunidad en el mercado; mientras que el 29\% encontró oportunidad y necesidad. Por otro lado, el GEM presentó datos positivos en cuanto a la tasa de actividad empresarial temprana, valor que llegó al 27\%. En esta línea, no todas las cifras son positivas. De acuerdo con el informe, el $70 \%$ de las empresas se ubican en el sector terciario, al tiempo que el $80 \%$ de estas compañías usa tecnologías que están disponibles desde hace más de cinco años y también el $80 \%$ dice que provee productos similares a la competencia. Solo el 12\% de los empresarios afirmó tener artículos novedosos. Por último, el GEM refleja que, de las nuevas empresas, tan solo el $56 \%$ de las empresas establecidas están registradas ante la cámara de comercio, mientras que, en las nuevas empresas, la cifra se reduce hasta el $41 \%$. (Portafolio, 2017, p. 1)

De este modo, Colombia se prepara para fortalecer dinámicas de emprendimiento social y cultural dada la coyuntura del posconflicto, buscando también apoyar a las minorías sociales 
para emprender ideas de negocio viables y amigables con la situación social del país. Por otra parte, instituciones como el SENA, iNNpulsa Colombia, Cámaras de Comercio de cada región, así como las Unidades de Emprendimiento instituidas en las Universidades nacionales, continúan trabajando en temas de la generación de empleo, tecnología, innovación, etc., con los jóvenes profesionales y futuras generaciones de la nación, esperando así continuar mejorando el panorama del emprendimiento colombiano. 


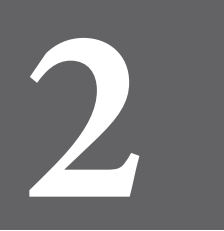

CAPÍTULO DOS 


\section{Una aproximación conceptual para comprender los distintos tipos de emprendimiento ${ }^{1}$}

El emprendimiento está llamado a generar soluciones concretas desde dimensiones económicas y sociales por lo que se reconoce que no todos persiguen el logro de los mismos objetivos. Cada uno de ellos depende de las necesidades que demanda el contexto el cual permite visibilizar tipos de emprendimiento. Desde la época primitiva, ha existido un hombre emprendedor que surge a partir de la necesidad de supervivencia. Su emprendimiento se basó en la búsqueda de las mejores estrategias como la creación de instrumentos de caza, vestimenta, construcción de viviendas y descubrimiento del fuego entre otros para salvaguardar necesidades de alimentación y abrigo. Se devela entonces, su interés por generar soluciones eficientes a problemas humanos.

De hecho, el que hoy se pueda disfrutar de una serie de comodidades producto de los desarrollos tecnológicos o invenciones es debido a que en un momento determinado la invención se transformó en un producto comercializable a través de la actividad emprendedora de una persona, de un grupo o de una organización. Este fenómeno comienza a llamar la atención en el mundo académico debido a que empieza a descubrirse su vinculación con el desarrollo económico, el mejoramiento de las condiciones de vida de una comunidad. Lo que despierta el interés de la academia luego lo hace con la política debido a su posibilidad de influir en el desarrollo de sus comunidades. (Marvez, 2011)

1 Laura Beatriz Potes Ordoñez. 
Ilustración 2. Tipos de emprendimiento

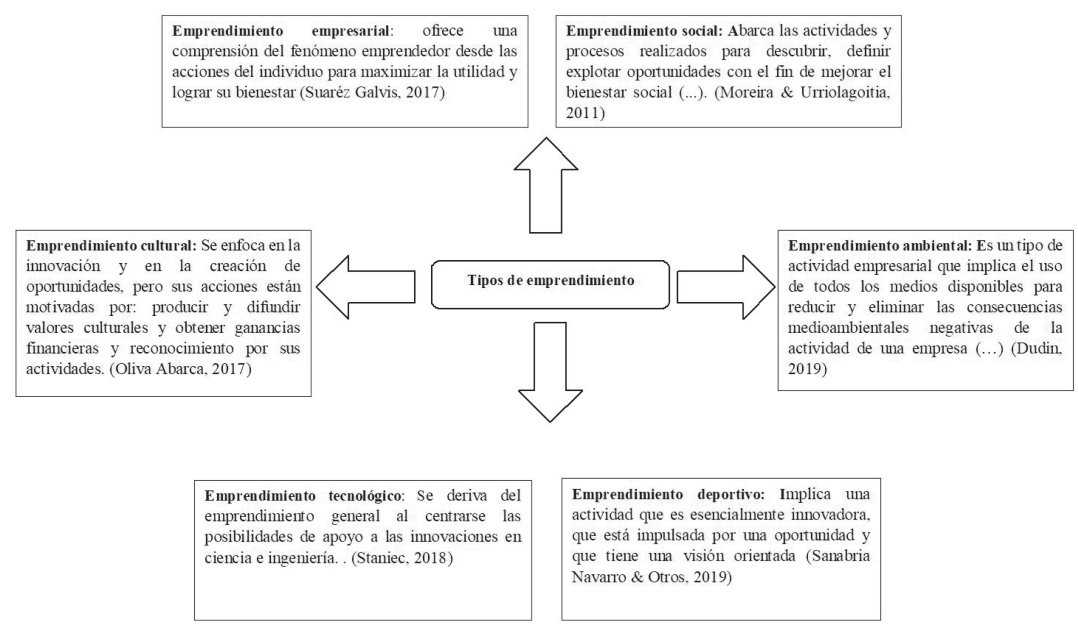

Fuente: Elaboración propia

El emprendimiento se describe dentro de múltiples acepciones el cual persigue un determinado fin económico, político o social, entre otros, y que posee ciertas características como la incertidumbre y de innovación (Formichella, El concepto de emprendimiento y su relación con la educación, el empleo y el desarrollo local, 2004). La figura del emprendedor ha sido estudiada desde diferentes áreas de conocimiento: en el ámbito de la economía, la psicología, la sociología, la organización de empresas, la historia y la antropología.

Adicionalmente, Veciana (1999) resalta su papel en la economía y la sociedad analizado a nivel individual, empresarial $\mathrm{u}$ organizativo y a nivel regional y/o global. Por otra parte, con el transcurso de los años han ido apareciendo nuevas teorías que intentan explicar su comportamiento (Morales Gualdrón, 2008). Estas teorías y/o enfoques permiten vislumbrar diferentes tipos de emprendimiento e igualmente son varios los autores que desde la pluralidad de perspectivas aportan a la categoría: 


\section{Emprendimiento empresarial}

Desde el enfoque microeconómico, autores de la literatura económica, han estudiado al emprendedor y su papel en la economía. Hébert \& Link (1988), señalan que fue Cantillon (1975) quien por primera vez se centra en este análisis. Posteriormente muchos economistas han intentado explicar el papel del empresario en el sistema económico en donde es posible señalar casos ampliamente conocidos como los planteamientos de Say, Menger, Schumpeter, Kirzner, Baumol y Casson, entre otros (Binks \& Vale, 1990). Desde este enfoque, la decisión de crear empresa se ha abordado específicamente a través de los modelos sobre la elección ocupacional bajo incertidumbre (Veciana, 2007), que pretenden explicar el hecho de que un individuo decida crear empresa o decida convertirse en empleado. (Morales Gualdrón, 2008).

Lucas (1978) argumenta que las personas se diferencian en cuanto a su capacidad empresarial innata y que aquellos que se consideran más aptos eligen convertirse en empresarios. Este tipo de modelos parecen poco realistas, al suponer que todas las personas "tienen la misma aptitud" para hacer indistintamente de empresario y de trabajador (Veciana, 1999, p. 18). No obstante, los nuevos modelos microeconómicos de comportamiento emprendedor están incorporando otras variables, tanto objetivas como subjetivas, provenientes de áreas como la sociología y la psicología aplicadas al estudio del entrepreneurship, así como algunas variables económicas y sociodemográficas más comunes en el estudio de la economía, tales como el género, edad, nivel socioeconómico, zona de residencia, la percepción del riesgo, actitudes sociales hacia el empresario, entre otras (Ashcroft et al., 2004). (Morales Gualdrón, 2008).

Lo expuesto deja entrever la preocupación de los autores por comprender las variables que inciden en el individuo para ser emprendedor y sus componentes para la creación de empresa. Lo 
cierto, es el interés por reconocer el emprendimiento empresarial como un tipo de emprendimiento.

Nueno (2005) señala que éste se relaciona con la creación de nuevos negocios y en intra emprendimiento que se relaciona con la creación de nuevas unidades de negocio en una empresa constituida. (Bernal, 2013). Es una de las vías más atractivas para generar empleo. Los beneficios para la sociedad son múltiples: impulsa la innovación, crea puestos de trabajo, acrecienta el potencial humano y satisface las nuevas demandas de los clientes (Caro González \& Otros, 2016).

Por su parte, (Suaréz Galvis, 2017) afirma que, desde la escuela económica, el emprendimiento empresarial ofrece una comprensión del fenómeno emprendedor desde las acciones del individuo para maximizar la utilidad y lograr su bienestar; por otra parte, la visión sociológica considera al individuo y su relación con la búsqueda del desarrollo, a partir de la creación de valor económico. Desde un enfoque individual, al autor apoyado en Urbano \& Toledano (2008), afirma que es una forma de pensar, razonar y actuar vinculada y suscitada por la búsqueda de una oportunidad de negocio.

De manera más amplia, el autor desde la visión de Hisrich et al. (2005), define al emprendimiento empresarial como el proceso de crear algo nuevo con valor, asumiendo los correspondientes riesgos financieros, psicológicos y sociales, para obtener así las recompensas resultantes de la independencia económica y personal. Por su parte, desde la perspectiva de Robbins (2005), lo denomina "espíritu emprendedor", definiéndolo como el proceso mediante el cual un individuo o un grupo empeña sus esfuerzos organizados en la búsqueda de oportunidades para crear valor, satisfaciendo deseos y necesidades mediante la innovación y la diferenciación, independientemente de los recursos disponibles. 
Morales Gualdrón, (2008) referencia el enfoque social o demográfico, que asume éste concepto desdela postura de Robinson et al. (1991) al partir del supuesto de que los emprendedores poseen el mismo perfil demográfico e historial; por ende, la comparación entre el sociodemográfico de cada individuo con el perfil del emprendedor, permitiría la identificación de los emprendedores potenciales.

La autora señala investigaciones en esta línea, y resalta el trabajo realizado por Collins y Moore (1964) quienes evidenciaron que muchos emprendedores provienen de entornos sociales "hostiles", con una infancia marcada por la pobreza y el rechazo paternal. Focalizada desde la creación de empresa, (Morales Gualdrón, 2008) enuncia que se ha logrado establecer la relación entre la decisión de su creación y algunas de las características sociodemográficas de los individuos, el cual imposibilita la identificación de un perfil propio del emprendedor. No obstante, resulta posible resaltar algunas aportaciones importantes. En primer lugar, existe abundante evidencia empírica que sugiere que los emprendedores provienen de familias en donde los padres eran empresarios o autónomos y otros estudios han encontrado que los emprendedores, frecuentemente, provienen de ciertos grupos étnicos y religiosos u otro tipo de grupo minoritario en la sociedad.

Este enfoque referencia la influencia de los aspectos sociales que enmarcan el perfil emprendedor y que lo condiciona en su forma de pensar y actuar ante una determinada situación. Desde una postura centrada en la empresa, funciona como un componente catalizador en su decisión de potencialización de este fenómeno que es dinámico y multifacético. No obstante, se evidencia autores que dejan entrever la importancia de asumir el emprendimiento desde una postura con una respuesta máshumana. Se reconoce no sólo la necesidad de la creación de empresa desde el punto de vista económico sino desde la capacidad para centrar al individuo hacia la creación de valor social a la sociedad. De 
esta manera, se resalta el aporte de (Orrego, 2008) quien reclama que el emprendimiento está orientado desde una perspectiva de creación de riqueza y gestión administrativa, desconociéndose la condición humana que fortalezca la convivencia social y la calidad de vida a nivel individual y grupal.

Desde esta postura, se visualiza el emprendimiento social. Los diversos autores orientan este tipo de emprendimiento pensado en la generación de valor social donde el fin va más allá de los retornos económicos. No todas las empresas dan lugar a la existencia de generar lucro, siendo éstas competitivas. Al mismo tiempo generan un beneficio con impacto que oriente la transformación social.

\section{Emprendimiento social}

Harding, (2004) relaciona el emprendimiento social con iniciativas orientadas a cambios en el sector social, innovando y actuando de acuerdo con el deseo de crear valor social sostenible. Citando a Roberts \& Woods (2005) lo relaciona a la construcción, evaluación y persecución de oportunidades para el cambio social transformativo llevado a cabo por una persona y/o grupos de personas visionarias; o también señalando a Austin, Stevenson \& Wei-Skillern (2006) quienes refieren las actividades innovadoras, de creación de valor social, que ocurren en y a través de los sectores sin ánimo de lucro y gubernamentales (Guzmán \& Trujillo, 2008).

Moreira \& Urriolagoitia, (2011) reconocen su importancia y la necesidad de desarrollar de manera innovadora nuevas formas de capital social orientada hacia la erradicación de la pobreza y solución a los problemas sociales. Apoyados en (Dess et al.) aseveran que, a pesar del creciente interés académico en esta temática, muchos autores destacan la falta de una definición clara de este campo. Aseguran que esta tarea se ha complicado por la diversidad de tipos de emprendimientos sociales que se manifiestan y la variedad de comunidades académicas estudiando el tema. 
No obstante, las autoras desde la postura de Martin \& Osberg (2007) apuntan que para avanzar en el entendimiento del emprendimiento social es importante enfatizar que se debe distinguir el emprendimiento social y activismo social. El activismo social se diferencia del emprendimiento social por el tipo de acción. En lugar de emprender una acción directa, el activista intenta influir en organismos como el gobierno y la ONG con el propósito de que éstos realicen acciones directas para resolver un problema social. Aunque pueden generar un cambio social, no se les debe considerar emprendedores sociales dada la naturaleza estratégica de su acción

Desde la visión de Neck, Brush y Allen (2009), (Moreira \& Urriolagoitia, 2011) parten de la premisa que el emprendimiento está enraizado en su propósito o misión, que constituye la base de su existencia. Por tanto, reconocen tres tipos de emprendimiento: Los emprendimientos tradicionales, el cual focalizan sus operaciones en una misión económica y buscan el impacto económico; los emprendimientos con consecuencia social, similares a los emprendimientos tradicionales excepto que algunas de sus prácticas pueden generar beneficios sociales; $y$ las organizaciones no lucrativas donde su razón de ser es social y buscan por tanto un impacto social. Aunque a diferencia de un emprendimiento social, este tipo de organizaciones no lucrativas no generarán un cambio sistémico producido por distintos medios innovadores capaces de generar un valor social en forma sostenible y de gran impacto.

Dees y Anderson (2006) distinguen al emprendimiento social como un espectro de la empresa social. En un extremo están los emprendimientos puramente filantrópicos cuya misión fundamental es la creación de valor social y en el otro extremo están los emprendimientos puramente comerciales cuya misión es la creación de valor económico. Es de resaltar, el aporte de las autoras al mencionar que los emprendimientos sociales están cada vez más a la vanguardia de la transformación social, mejorando 
la calidad de vida de los más necesitado a nivel global. Otra característica distintiva del emprendimiento social es su limitado potencial de captar el valor creado. (Moreira \& Urriolagoitia, 2011)

Las autoras apoyadas en Zabra et al (2009) enuncian que el emprendimiento social abarca las actividades y procesos realizados para descubrir, definir explotar oportunidades con el fin de mejorar el bienestar social creando nuevas empresas o gestionando organizaciones de una manera innovadora.

Toledano (2012) lo enfoca hacia el desarrollo de proyectos cuyos objetivos sociales priman sobre los económicos, creando en consecuencia entidades no lucrativas. Desde esta perspectiva, y la importancia de crear empresas que agreguen valor social, (Guil Marchante \& Montoya Sánchez, 2015) ponen en manifiesto dos tipos de iniciativas en tiempos de crisis: el emprendedor social que constituye nuevas empresas sociales; y las empresas de capitales en crisis que se transforman en cooperativas de trabajo asociado para poder mantenerse en el mercado. Según estos autores los emprendedores sociales y las empresas de economía social representan un instrumento apropiado para hacer frente a la actual crisis económica, enfocando el crecimiento empresarial hacia la inserción laboral y el desarrollo local.

La importancia del emprendimiento social radica en su impacto sobre el desarrollo económico y social, como manifestación de la actividad del emprendedor en la economía. Surge con la esperanza de encontrar respuestas a los problemas actuales, sobre todo en tiempos de crisis. La diferencia entre el emprendimiento económico y el emprendimiento social radica en que éste último procura valor social sostenible a través del desarrollo de oportunidades para el cambio social, en aquellos sectores en donde se identifica un equilibrio estable pero injusto que causa exclusión, marginalización o sufrimiento a determinados segmentos de la población. Todo emprendimiento 
conlleva un balance de comportamiento social y económico que va a permitir la generación de valor social y valor económico. La persona que emprende socialmente no actúa necesariamente motivada para generar remuneraciones materiales o monetarias para sí mismo, sino que tomando las mismas herramientas que existen en el sector privado, las aplica para resolver problemas sociales, siendo su propósito fundamental la creación de valor social para el bien público (Guil Marchante \& Montoya Sánchez, 2015).

Es reconocido como una herramienta clave para superar los problemas sociales en la sociedad apoyado en el desarrollo sostenible. Si bien el emprendimiento social no es un fenómeno nuevo, ha experimentado un crecimiento significativo en los últimos 15 años. La mayoría de las definiciones de emprendimiento social se refieren a habilidades que aprovechan recursos para abordar los problemas sociales. Por otra parte, su definición radica en crear valor para la sociedad en lugar de capturar valor. Apunta a resolver problemas sociales y ambientales. Los emprendedores sociales han sido llamados "los motores" del desarrollo; pueden crear efectos ambientales y sociales positivos en todas las organizaciones empresariales sociales (es decir, empresas sociales) (Defourny \& Nyssens, 2008). También puede verse como un fenómeno que ocurre a través de la operación de empresas sociales.

Las empresas sociales mezclan diferentes lógicas: comercian en el mercado, pero no con el objetivo de maximizar el retorno financiero de la inversión para sus accionistas; reciben apoyo público a través de políticas públicas que contribuyan a su conformación; están incrustados en la sociedad civil mediante el desarrollo de una acción colectiva voluntaria en torno a objetivos comunes caracterizados por una dimensión de beneficio público". (Bozhikina, Macke, \& da Costa, 2019, p. 731)

Es entonces el emprendimiento social, el acercamiento de las empresas hacia la misión social que involucra un grado de un problema orientada hacia una estrategia sostenible de impacto. 
Es un fenómeno que ha venido emergiendo por la coyuntura y crisis económica siendo necesario proporcionar soluciones innovadoras. Lo anterior implica, derribar barreras de acceso a los mercados, fortalecer a poblaciones débiles y con derechos vulnerados y reducir las externalidades negativas de la actividad económica entre otros.

\section{Emprendimiento cultural}

Elemprendimientoculturalesunaapuesta delemprendedor para potencializar el sector de las industrias culturales. No sólo busca fortalecer el componente comercial, sino que involucra el ámbito creativo donde se valoriza los eslabones en las diferentes cadenas de valor como organizaciones culturales, artistas y productores entre otros. Este concepto ha venido evolucionando y son diferentes los aportes al respecto. En tal sentido, los siguientes autores señalan lo siguiente:

El emprendimiento cultural constituye como un conjunto de acciones que motivan y se fundamentan en nuevos modelos gerenciales, económicos, organizacionales que valorizan, en el sentido amplio de la palabra, productos y prácticas que hacen parte del quehacer cultural de la sociedad. En específico, lo definen como una actividad que incorpora los valores intangibles que, en su conjunto, permiten la generación de una idea que se consolide en negocio, empresa u organización cultural (Red Colombiana de Universidades en Gestión Cultural, 2012).

Oliva Abarca (2017) añade que, al día de hoy, el emprendimiento se promueve cada vez con mayor frecuencia y en diferentes ámbitos, ya sea en la política, en las instituciones educativas, e incluso, en la cultura. En este ámbito, el emprendedor se erige como una figura capaz de conciliar a la cultura con la economía, a través de la planeación y creación de productos innovadores que representan valores culturales. Aún más, siendo un sujeto al que se le atribuye una notable capacidad creativa y un 
deseo constante por innovar, el emprendedor logra posicionarse como uno de los personajes más importantes de la economía creativa, sistema económico que funciona a partir de la generación de ideas y de novedades.

Desde la visión de (Piedras, 2004), subraya la apertura de los mercados locales a una economía de interacciones globales, propicia el despunte de las industrias culturales y creativas o, si se prefiere, de las industrias sustentadas en el derecho de autor, sector del que han surgido diversas propuestas emprendedoras. Y si de industrias culturales se trata, éstas impulsan la innovación y el desarrollo económico de las regiones países (Porfírio, Carrilho, \& Mónico, 2016).

Desde este panorama, las industrias culturales constituyen un componente cada vez más importante en las economías basadas en el conocimiento. No solo contribuyen al crecimiento económico, sino que también actúan como elementos vehiculares en la transmisión de la identidad cultural. Durante los diez últimos años, se ha empezado a reconocer este hecho y se han desarrollado políticas específicas para la promoción de las industrias culturales. Este creciente interés por este tipo de industrias ha supuesto la proliferación de análisis entre las industrias culturales y el desarrollo económico de las naciones (Ríos Cortés, 2015).

Si bien es cierto, se resalta la importancia de las artes y la cultura el cual radica en dimensiones de valor como el histórico, estético y educativo, durante la última década se ha evidenciado una gran inclinación a medir su impacto económico en indicadores como el PIB, el empleo y el comercio internacional. Las industrias culturales son un sector muy diverso que cuenta con un alto nivel de autoempleo. Es común encontrar artistas que ejercen los roles de productor, gestor y administrador de sus propuestas creativas, en muchas ocasiones sin un conocimiento formal en administración de empresas. De igual forma, el sector cuenta con una alta concentración de emprendedores individuales 
o pequeñas empresas, y otro grupo de grandes empresas, en muchos casos multinacionales, que acaparan la mayor parte de la actividad económica de los distintos sectores, sobre todo en la industria musical y editorial (Hernández Acosta, 2013).

Para referir el emprendimiento cultural, es de mencionar al emprendedor cultural quien posee un talento para desarrollar un proyecto encaminado a potencializar el componente artístico. (Oliva Abarca, 2017) afirma que este se enfoca en la innovación y en la creación de oportunidades, pero sus acciones no están motivadas únicamente por fines comerciales, su propósito es doble: por una parte, producir y difundir valores culturales y, por otra parte, obtener ganancias financieras y reconocimiento por sus actividades. Una definición más acertada del emprendedor cultural y creativo, figura a la que se describe como quien crea o innova un producto o servicio cultural o creativo y que emplea principios empresariales para organizar y administrar su actividad creativa de forma comercial.

El autor realiza un aporte al destacar las micro y pequeñas empresas. Desde este ámbito afirma que las mismas no funcionan de acuerdo con una estructura jerárquica típica, es decir, no existe una diferencia especifica entre jefe y empleados; antes bien, se organizan en torno a redes de colaboradores y colegas que comparten metas en conjunto el cual enfocan sus capacidades creativas a un mismo objetivo que conlleva a la reorganización de la praxis cultural. Se hace necesario adherirse a las exigencias de la competitividad cultural y de la creatividad como norma y aceptar el tránsito de un paradigma tradicional a uno contemporáneo en lo que respecta al trabajador cultural.

El emprendimiento cultural genera aportes en la clasificación de valores culturales. El emprendedor actúa desde un papel en promoción de las condiciones y oportunidades de desarrollo a partir de interacción entre los ámbitos de la cultura y de la economía. Los bienes y servicios culturales propician el 
surgimiento de sentimientos de vínculo de los individuos hacia un territorio, que aportan en la formación de ciudadanos en cuanto a la construcción de saberes, valores y significaciones tradicionales y culturales de una región o comunidad.

\section{Emprendimiento ambiental}

Hoy en día, es indiscutible los problemas ambientales presentes en el mundo, derivados del modelo económico y el modo de vida adoptado por el hombre producto de sucesos que marcaron la historia de la humanidad como la revolución industrial y la globalización. El consumo de bienes y servicios en exceso y el uso indiscriminado de los recursos naturales han propiciado un impacto desfavorable para el medio ambiente. Es así como hoy en día se viene presentado con mayor frecuencia el término de emprendimiento ambiental, verde, o sostenible las cuales se presentan a continuación:

El emprendimiento verde es un concepto reciente, cuya atención ha aumentado particularmente desde la década de los noventa y es entendido como el proceso de descubrir, evaluar, y explotar oportunidades económicas presentes en fallas de mercado hacia actividades sostenibles potencialmente rentables, relacionadas con el área ambiental. (Dean \& McMullen; 2007). (Sanabria \& Hurtado, 2013, p. 44)

Sanabria \& Hurtado (2016) afirman que, si bien la empresa y el emprendimiento han sido asociados históricamente a objetivos de generación de riqueza, incremento de la competitividad de los mercados globales y creación de empleo, la nueva ola de literatura sobre emprendimiento, ha añadido como otra de sus promesas, la responsabilidad social y la reducción del impacto ambiental de las actividades empresariales. Y es así, debido a que, si bien las empresas como creación humana para la organización de la actividad económica han sido señaladas como corresponsables directas de la actual crisis ambiental, paradójicamente, son reconocidas como agentes clave en la transformación de la economía hacia un modelo más sostenible. 
Los autores afirman que la crisis ecológica actual es vista como una oportunidad para el emprendimiento en diversos sectores, tanto ambientales como tradicionales. Hay quienes afirman que ya ha surgido una nueva clase de emprendedores, denominados alternativamente como emprendedores sostenibles, emprendedores verdes o eco-emprendedores, quienes transforman los métodos de producción convencionales, productos, estructuras de mercado y modelos de consumo, y los reemplazan con productos y servicios superiores ambientalmente a través de innovaciones ambientales.

Diferentes acepciones han sido introducidas en la literatura para referirse a esta nueva perspectiva del emprendimiento: emprendimientos de base ecológica, sostenible y ambiental. (Sanabria \& Hurtado, 2016) apoyados en Kuckertz \& Wagner (2010) refieren al "emprendimiento sostenible" como aquel que además de satisfacer la definición de Schumpeter, gestiona el "triple bottom line" balanceando el bienestar económico, la equidad social y la resiliencia ambiental, esto es, es un emprendimiento que añade el beneficio de obtener más que un resultado meramente económico.

El emprendimiento verde se entiende como el desarrollo de actividades orientadas a la mitigación, reducción o eliminación de problemáticas ambientales, las cuales son consideradas de entrada como innovadoras, en la medida en que proponen cambios en los patrones de producción y consumo que deterioran las condiciones naturales del planeta y en el relacionamiento del ser humano con el entorno. (Sanabria \& Hurtado, 2016)

Rodríguez Moreno (2016) asume el concepto de emprendimiento sostenible reconociendo la identificación de una baja información teórica y empírica. Este campo poco explorado involucra no sólo el componente económico o de beneficios monetarios sino la protección ambiental y el desarrollo social. En este sentido, se apoya de diferentes autores para aportar a este campo: 
Tabla 1. Definiciones del emprendimiento sostenible

\begin{tabular}{|l|l|}
\hline \multicolumn{1}{|c|}{ Autor } & \multicolumn{1}{|c|}{ Descripción del emprendimiento sostenible } \\
\hline $\begin{array}{l}\text { Dean \& McMullen } \\
\text { (2007) }\end{array}$ & $\begin{array}{l}\text { Es el proceso de descubrir, evaluar y aprovechar las oportunidades } \\
\text { económicas presentes en las fallas de mercado (cuando hay una } \\
\text { inapropiada asignación de recursos) que obstaculizan la sostenibilidad, } \\
\text { incluyendo las que son relevantes para el medio ambiente, como bienes } \\
\text { públicos, externalidades, poder de monopolio, inapropiada la } \\
\text { intervención del gobierno e información imperfecta; para el desarrollo } \\
\text { del emprendimiento sostenible es necesario superar las barreras del } \\
\text { funcionamiento eficiente de los mercados }\end{array}$ \\
\hline $\begin{array}{l}\text { Cohen, Smith, \& } \\
\text { Mitchell (2008) }\end{array}$ & $\begin{array}{l}\text { En emprendimiento sostenible la ganancia es interpretada ampliamente } \\
\text { para incluir los beneficios económicos y no económicos para los } \\
\text { individuos, la economía y la sociedad (Shepherd \& Patzelt, 2011). Y en } \\
\text { este sentido el campo del emprendimiento puede beneficiarse de una } \\
\text { visión más holística de la creación de valor }\end{array}$ \\
\hline $\begin{array}{l}\text { Guzmán \& Trujillo } \\
\text { (2008) }\end{array}$ & $\begin{array}{l}\text { El emprendimiento sostenible es en esencia la realización de una } \\
\text { innovación sostenible dirigida a un mercado masivo que proporciona } \\
\text { beneficio a gran parte de la sociedad. Desde lo ambiental los empresarios } \\
\text { y compañías que hacen del progreso ambiental su actividad principal se } \\
\text { pueden llamar empresarios sostenibles, generando nuevos productos, } \\
\text { servicios, técnicas y modos de organización que reduzcan } \\
\text { sustancialmente el impacto al ecosistema y aumenten la calidad de vida. }\end{array}$ \\
\hline $\begin{array}{l}\text { Schaltegger } \\
\text { Wagner (2011) }\end{array}$ & $\begin{array}{l}\text { En el esquema de emprendimiento sostenible la responsabilidad de la } \\
\text { empresa va más allá de la visión clásica de maximización del beneficio } \\
\text { para los llamados stakeholders. Aunque los objetivos económicos son los } \\
\text { fines principales de la empresa, el reto de la organización es la } \\
\text { integración de un mejor desempeño ambiental y social en la lógica de un } \\
\text { negocio económico }\end{array}$ \\
\hline
\end{tabular}

Fuente: Elaboración propia a partir de Rodríguez Moreno (2016)

El emprendimiento ambiental es un tipo de actividad empresarial que implica el uso de todos los medios disponibles para reducir y eliminar las consecuencias medioambientales negativas de la actividad de una empresa y los resultados en la búsqueda de prácticas de producción que sean respetuosas con el medio ambiente (Dudin, 2019).

\section{Emprendimiento tecnológico}

El avance de la tecnología ha generado una transformación en los mercados y, con ello, la forma de responder y acceder a ellos. El panorama abre oportunidades para impulsar el desarrollo económico y promover la economía del conocimiento. Venkataraman (2004) enuncia que el emprendimiento tecnológico juega un papel central en la transformación regional. Schumpeter fue el primero en plantear claramente la centralidad del empresario para la economía. Es esencial para la progresión del capitalismo porque crea el cambio. 
En ese sentido, Nacu \& Avasilcă (2013) presenta las siguientes definiciones de emprendimiento tecnológico:

Tabla 2. Definiciones cronológicas del término emprendimiento tecnológico.

\begin{tabular}{|l|l|l|}
\hline Año & \multicolumn{1}{|c|}{ Autor } & \multicolumn{1}{|c|}{ Definición de emprendimiento tecnológico } \\
\hline 1992 & Abetti & Un sistema (Abetti, 1992) \\
\hline 2003 & Gnas y Stern & Una estrategia (Gnas \& Stern, 2003) \\
\hline 2004 & Burgelman & $\begin{array}{l}\text { Vincula los conceptos de tecnología e innovación de } \\
\text { marketing. }\end{array}$ \\
\hline 2005 & Dorf and Byers & Un enfoque individual (Dorf \& Byers, 2005) \\
\hline 2008 & Antoncic and Prodan & Un proceso (Antoncic \& Prodan, 2008) \\
\hline 2008 & Zhang & Una política (Zhang, Xuebing \& Li, 2008) \\
\hline 2009 & Claudio Petti & $\begin{array}{l}\text { Incorpora cuatro actividades relacionadas con: crear nuevas } \\
\text { tecnologías o identificar tecnologías; reconocimiento y } \\
\text { emparejamiento de oportunidades que surgen de la aplicación } \\
\text { de estas tecnologías a las necesidades de mercados } \\
\text { emergentes, desarrollo / aplicación de tecnología y creación } \\
\text { de negocios. (Petti, 2009) }\end{array}$ \\
\hline 2011 & Petti y Zhang & $\begin{array}{l}\text { Un fenómeno complejo que abarca múltiples disciplinas y } \\
\text { niveles de análisis (Petti \& Zhang, 2011) }\end{array}$ \\
\hline
\end{tabular}

Fuente: (Nacu \& Avasilcă, 2013)

Mihai Nacu \& Avasilcăi (2014) afirman que el desarrollo de una nueva idea de negocio en el dominio de la tecnología, junto con la toma de riesgos, define el emprendimiento tecnológico. Momete (2016) lo relaciona con la innovación basada en la tecnología donde la calidad del capital humano es fuente importante de desarrollo.

El emprendimiento tecnológico podría ser catalogado como una tipología del concepto en general. Beckman et al. (2012) lo diferencian de las demás corrientes del emprendimiento debido a su interés en nuevas oportunidades de negocio impulsadas a través de la innovación en ciencia e ingeniería. En la misma línea, Bailetti (2012) lo define como una inversión en un proyecto que reúne y distribuye individuos especializados y activos heterogéneos, los cuales están estrechamente relacionados con los avances del conocimiento científico y tecnológico con el propósito de generar y capturar valor para una empresa. Puede ser identificado en un marco general como la creación de Nuevas Empresas de Base Tecnológica- NEBT. (Zapata, 2017). 
De acuerdo a ello, se presentan diferentes concepciones de esta categoría según el autor en mención:

Tabla 3. Diferentes denominaciones de NEBT. Marco general del emprendimiento tecnológico

\begin{tabular}{|c|c|}
\hline Autores & Denominación \\
\hline $\begin{array}{l}\text { Autio (1997); Laranja y Fontes } \\
\text { (1998); Fontes y Coombs } \\
(2001)\end{array}$ & Nuevas empresas de base tecnológica \\
\hline $\begin{array}{l}\text { Mason y Harrison (1994); } \\
\text { Dahlstrand (1999) }\end{array}$ & $\begin{array}{l}\text { Pequeñas y medianas empresas de } \\
\text { tecnológica }\end{array}$ \\
\hline $\begin{array}{l}\text { Meyer y Roberts (1986); } \\
\text { Forrest (1990); Klofsten y } \\
\text { Jones-Evans (1996) }\end{array}$ & Pequeñas empresas de base tecnológica \\
\hline Keeble et al. (1998) & Pequeñas empresas de intensidad tecnológica \\
\hline Oakey (1991) & Pequeñas y medianas empresas de alta tecnología \\
\hline
\end{tabular}

Fuente: (Zapata, 2017) apoyado en Cunha et al. (2013)

Para (Staniec, 2018) El emprendimiento tecnológico se deriva del emprendimiento general al centrarse las posibilidades de apoyo a las innovaciones en ciencia e ingeniería. Se refiere principalmente a la introducción de innovaciones técnicas a mercados emergentes, y nuevos productos que permiten esta introducción. Este fenómeno se produce cuando el desarrollo de la ciencia y la tecnología crea un elemento clave de una oportunidad empresarial, que permite la generación de una empresa determinada. Así, las características típicas del emprendimiento tecnológico son las siguientes:

- Anticipación de los cambios tecnológicos

- Gestión de las relaciones externas e internas

- Método de organización de los recursos y su externalización que facilitaría el desarrollo a través de la explotación de la oportunidad tecnológica emergente

Consiste en crear nuevas opciones reorganizando y transformando los recursos existentes. También muestra que, en el emprendimiento tecnológico, además de las características del empresario, es necesario tener en cuenta las características del 
entorno y los requisitos del propio mercado, que pueden favorecer (o inhibir) el desarrollo de este tipo de emprendimiento (Staniec, 2018).

El emprendimiento tecnológico es una forma vital de comercializar innovaciones tecnológicas, ya sea creando una nueva entidad empresarial o establecer una nueva empresa dentro de una empresa existente. Transforma tecnologías prometedoras en valor. De acuerdo Bayers et al. (2014), es un estilo de liderazgo empresarial que reúne recursos como el talento y el capital. Por su parte, Bailetti (2012) lo asume como un proyecto de inversión para el montaje y despliegue de personas especializadas y activos heterogéneos que están estrechamente relacionados con la ciencia y el conocimiento tecnológico. (Shan \& Otros, 2018)

Hablar de este tipo de emprendimiento, es referenciar los emprendedores tecnológicos. González (2017) menciona que son creativos, generan empleo, dan impulso a la economía, son motores de cambio y de crecimiento. De acuerdo a ello, presentan las siguientes características:

- Revolucionario: pretende cambiar el mundo con nuevas ideas y nuevas tecnologías.

- Quiere ser actor global desde el principio.

- Experto en desarrollar amplias redes locales.

- Altamente competitivo y dispuesto a asumir riesgos.

- Cree en la velocidad (entendida como time-to-market).

- Es un jugador de equipo tanto en la organización como en la red.

- Le gusta reconocer y celebrar los logros y éxitos de los demás.

- Muchos se convierten en inversores para repetir el éxito y compartir conocimientos e ideas

\section{Emprendimiento deportivo}

El sector deportivo ha reflejado un crecimiento en los últimos años. Las prácticas deportivas construyen significativamente al mantenimiento de la calidad de vida del ser 
humano debido a la prevención de enfermedades. Es importante señalar que las sociedades modernas promueven estructuras basadas en el sedentarismo por lo que cada vez más se dedica menos esfuerzo a la actividad física. Si bien es cierto, son pocos los autores que referencian el emprendimiento desde este campo, se resalta esta categoría como un campo que merece ser estudiado y abordado por los autores científicos.

Desde esta perspectiva, (González, Valantine, \& Crespo, 2014) atañen que el emprendimiento en el deporte es un nuevo campo emergente. Aunque ha sido estudiado desde diferentes disciplinas académicas incluyendo la psicología, la economía y el marketing, solamente recientemente ha sido discutido desde un paradigma emprendedor. Desde la visión de Ratten (2012), los autores señalan que el emprendimiento en este ámbito, se describe de forma general por los comportamientos de innovación, toma de riesgos y pro actividad dentro del contexto deportivo. Ser emprendedor en este sector no significa solamente ser propietario de franquicias o empresas de deportes profesionales. La industria del deporte implica una amplia variedad de sub- empresas, tanto de grandes como de pequeños tamaños. Por ejemplo, hay propietarios de instalaciones de clubes de salud, campos de deportes y operadores de instalaciones, propietarios de ligas y tiendas de artículos deportivos.

En diversas investigaciones científicas se ha podido avalar que la actividad física no sólo es un abordaje teórico de la cultura física que analiza las condiciones fisiológicas y psicológicas del individuo, sino que se ha convertido también en un fenómeno social, político y económico que deviene en emprendimientos como parte integral de la gestión deportiva. (Sanabria Navarro \& Otros, 2019, p. 140)

El deporte basado en el emprendimiento implica una actividad que es esencialmente innovadora, que está impulsada por una oportunidad y que tiene una visión orientada (Ratten, et al., 2011; Méndez, 2015). Involucra aspectos de innovación, toma 
de riesgos y proactividad dentro de este escenario. Por su parte, dentro del punto de vista social permite la inclusión de personas con todo tipo de condiciones, estatus y niveles sociales preestablecidos por las distintas sociedades, reflejando su compromiso social que posee en relación a la inclusión. Como fenómeno económico, la actividad física y los deportes se han convertido en una idea de negocio con el surgimiento de diferentes tipos de emprendimientos que transitan desde gimnasios de pequeña mediana y sofisticada estructura, empresas de fitness, clubes deportivos con altos índices de ingresos, patrocinios de marcas, entre otros. (Sanabria Navarro \& Otros, 2019)

\section{Consideraciones sobre las distintas tipologías de emprendimiento}

Las tendencias generadas por el entorno y sus diversas variables que afectan el comportamiento humano y el desarrollo social, denotan la generación de diferentes tipos de emprendimiento. La historia demuestra que inicialmente fueron atribuidos netamente al campo económico pero que las propensiones de hoy en día demuestran la necesidad de generar un dinamismo desde el punto de vista social, cultural, ambiental, tecnológico y deportivo. Cada uno de ellos, rescata la figura del emprendedor como principal agente generador de las iniciativas emprendedoras.

La complejidad del contexto, obliga a que cada uno de estos emprendimientos refleje la necesidad de ser innovadores y creativos; el individuo debe hacer uso de todas sus capacidades emprendedoras para lograr el éxito de las mismas. En las sociedades modernas, las estrategias deben enmarcarse desde su medio interno y autónomo, hacia una posición abierta a las influencias externas, desde una relación recíproca, de constante retroalimentación con el medio circundante de tal modo que se puedan propiciar emprendimientos de alto impacto. En ese contexto, la sociedad es la primera beneficiada siendo el emprendimiento una promesa de cambio y transformación. 
El desarrollo hace visibles las dinámicas variables y transformadoras que tienen lugar en la interacción entre los sujetos individuales como parte de un todo social, pero es menester la cualidad humana, resultado de la transformación histórica, política, socio-cultural, en el sentido de desarrollar todas las dimensiones como ser humano evidenciado en un desarrollo simbólico como base del pensamiento y de la construcción de conocimiento, pero principalmente su construcción como ser íntegro (Duarte \& Ruiz , 2009).

Para el caso concreto de Popayán, el surgimiento de los emprendimientos responde a necesidades propias de la región. Sus experiencias de vida han permitido impulsar iniciativas innovadoras que permean un testimonio empresarial para el departamento del Cauca. Conocer las historias de vida en el capítulo 5 , demuestran que los obstáculos no son un impedimento para la puesta en marcha de sus ideas; algunos de ellos gestados de manera empírica pero que fueron orientándose hacia emprendimientos formales. El surgimiento de los mismos, empezó a materializarse desde la asociatividad, la formación académica y la búsqueda de financiación entre otros.

Resulta interesante reconocer que cada una de las 18 historias de vida que se conocerán más adelante, evidencian el desarrollo de diferentes tipologías de emprendimiento. Es preciso entonces afianzar sus bondades desde cada ámbito:

Desde el contexto económico, el emprendimiento es una respuesta a los fenómenos de desempleo y exclusión. Bajo las condiciones de la globalización de la economía y del nuevo paradigma tecnológico y científico, donde surgen los emprendimientos en este campo, se constituye como factor diferenciador e importante en la supervivencia y el éxito empresarial, el cual es, en buena forma, el responsable del desarrollo económico y social del presente siglo. Las bases de 
este modelo de competitividad están dadas por la innovación, la tecnología y el capital humano, los cuales éstas últimas surgen de las habilidades emprendedoras.

El emprendimiento social acapara la atención como fenómeno diferencial del tradicional emprendimiento empresarial. Sus definiciones han permitido puntualizar aspectos importantes rescatando que una de sus características se encuentra relacionada con la resolución de problemas sociales. Es interesante cómo esta apuesta permite la integración y promoción de nuevas formas y expresiones de innovación social que dan lugar a nuevos modelos de negocio; implica recurrir con nuevas prácticas, estrategias y filosofías corporativas que generen valor social donde las fuerzas transformadoras de la sociedad, involucra la redefinición del que hacer tradicional.

Por su parte, los emprendimientos culturales apuntan hacia el desarrollo del potencial productivo de los diferentes agentes de la cadena de valor de las industrias culturales. Son múltiples los desafíos en la preparación, el fortalecimiento de las diferentes áreas culturales, aunque permitirán desde estrategias de sostenibilidad, la organización y el fortalecimiento del sector el cual conjuga una serie de aspectos como la creación, producción y comercialización de bienes y servicios de carácter cultural.

Este emprendimiento cultural refleja una motivación más allá del componente económico. Su interés responde hacia la necesidad de conocer la cultura, conservar el patrimonio cultural, reconocer el talento de los artistas, cuestionar la sociedad a partir del arte o generar productos innovadores y útiles para la sociedad.

Hoy la sociedad exige que la actividad empresarial debe ser responsable, sostenible y por eso se referencia los emprendimientos ambientales y/o sostenibles. Es innegable que la acción empresarial es una actividad humana necesaria, sin embargo, también se conoce que su existencia genera externalidades negativas, por medio de la explotación de los recursos naturales con el objetivo 
de maximizar los beneficios económicos para los accionistas. (Rodríguez Moreno, 2016). El cuidado del medio ambiente atiende a una necesidad hacia la generación de acciones para combatir el deterioro del planeta, siendo además una oportunidad de negocio para el emprendedor. Su impacto demuestra la preocupación del ser humano por superar la crisis actual ecológica, adherido a demás a las fracturas económicas con grandes desigualdades mundiales.

En la llamada sociedad del conocimiento, se refleja los emprendimientos tecnológicos. Debido a ello, hay un interés de los agentes públicos y privados para el desarrollo de este tipo de empresas el cual constituye la fuerza motora para la innovación continua. Se asume una posición privilegiada al poner valor el conocimiento de sus emprendedores bajo un dinamismo de transformación, generación de red de alianzas estratégicas y renovación de productos y servicios.

Un tema poco explorado, se enuncia el emprendimiento deportivo que de acuerdo con (González, Valantine, \& Crespo, 2014) en el entorno dinámico global, el asunto sobre qué constituye el emprendimiento en el deporte todavía no está resuelto; todavía se tiene que desarrollar una idea clara y aceptada sobre su concepto. Sin embargo, se resalta que los aportes teóricos en este campo, permiten resaltar su importancia en cuanto a la generación del autoempleo y la creación de nuevas unidades económicas. Esta tipología también representa una oportunidad de desarrollo siendo relevante para cualquier sistema económico.

Si bien es cierto, los relatos en las historias de vida mostrarán mayor preponderancia por ciertas tipologías de emprendimiento como el empresarial, tecnológico y ambiental, es innegable reconocer que las bondades de cada uno de ellos, obedece a la necesidad de la búsqueda constante de un impacto positivo en la región; algunos emprendimientos desarrollados a mayor escala que otros, pero con la funcionalidad de enriquecer una economía quebrantada por el desempleo y las pocas 
oportunidades. El panorama y el contexto de Popayán, muestra que en el Cauca "la pobreza monetaria viene presentando una reducción leve pero sostenida. No obstante, el departamento aún está lejos de la media nacional y de las metas planteadas por el Conpes ODS al año 2030(...)” (PNUD, 2019, pág. 4). Siendo así, los diferentes tipos de emprendimiento de la ciudad, se convierten en un elemento determinante para ubicarse en un modelo de cambio y transformación para la región.

Ante la opción de su desarrollo para conseguir beneficios según la tipología emprendedora, se visibilizan iniciativas válidas para el dinamismo económico. En esta línea, "Lecuna et al. (2017) proponen al emprendimiento por oportunidad como un medio para conseguir el crecimiento económico en las economías en desarrollo" (Almodóvar, 2018, p. 240).

Finalmente, es de resaltar que el reconocimiento de cada uno de ellos, abre la brecha para encauzar nuevos escenarios que posibiliten para los futuros emprendedores de la ciudad, la búsqueda de nuevas oportunidades orientadas a explorar distintas tipologías relevantes para el entorno. 


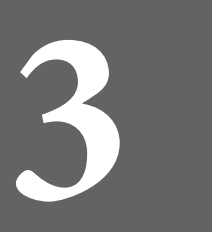

CAPÍTULO

TRES 


\section{El emprendimiento universitario desde la revisión literaria. ${ }^{2}$}

El emprendimiento se ha constituido en un proceso determinante para el progreso, entre otros, económico, social y económico de una sociedad. A través de numerosos estudios se ha demostrado la importancia que tiene, más allá del empírico, el desarrollo académico de la temática, siendo las instituciones de educación superior un espacio propicio para materializar el sentimiento generalizado en el que se ha convertido la voluntad de creación de nuevas empresas.

En este sentido, se busca conocer el estado actual sobre el emprendimiento universitario, a través de una revisión de literatura, logrando, por medio del análisis de resultados de las investigaciones identificadas, determinando oportunidades de investigación futura.

En ese orden, en los contextos universitarios concurren estrategias que sirven para potencializar las ideas innovadoras en cada uno de los diferentes niveles de educación, es por eso que existe el emprendimiento estudiantil, y se define como cualquier intento de lanzar una nueva empresa emprendida por uno o varios estudiantes (Reynolds, 2005), en un ambiente educativo.

Las universidades y la participación estudiantil en la actividad emprendedora dependen de múltiples influencias tales como rasgos personales y factores de situación (Ajzen, 1991); aunque un ambiente de educación emprendedora no siempre garantiza el éxito ni el aporte al desarrollo económico de la región (Krueger, Reilly, \& Carsrud, 2000), pero sí ofrece a los estudiantes más probabilidades de convertir sus ideas en empresas, de hecho,

2 Ana Virginia Moreno Charris - Felipe Acosta Ortega 
Peterman y Kennedy (2003) presentan evidencia que el contacto de los estudiantes con el emprendimiento despierta o refuerza su deseo de crear nuevas empresas.

Al mismo tiempo, la educación superior centrada en los ecosistemas empresariales ayuda a desarrollar actitudes positivas sobre el emprendimiento como una opción de carrera (Kourilsky \& Walstad, 1998; Peterman \& Kennedy, 2003). Es por eso que las universidades necesitan estrategias para desarrollar ecosistemas empresariales, más allá de una estrategia para la educación empresarial (Katz, 2003), analógicamente desarrollar estrategias para la educación empresarial sin considerar el ecosistema circundante es como sembrar semillas sin tener en cuenta la naturaleza del semillero.

Estas estrategias motivan las iniciativas, tanto que han sido adoptadas por instituciones educativas y son estimuladas por políticas responsables en respuesta a la creencia generalizada que el emprendimiento actúa como un motor para prosperidad y desarrollo económico (Laukkanen, 2000; Shah \& Pahnke, 2014). Las universidades tienen el reto de preparar a los estudiantes para ser competentes en un mercado laboral donde la capacidad de comportarse y pensar de manera emprendedora y proactiva es un factor clave para el éxito (Audretsch, 2014; Urbano \& Guerrero, 2013).

Con el pasar del tiempo se ha enfocado la enseñanza del emprendimiento en cada uno de los diferentes niveles de educación en cualquier país del mundo, y se toma la universidad como eje y herramienta estratégica de desarrollo económico regional. Es por eso, que el objetivo de la Universidad con las capacitaciones no sólo es aumentar el número de nuevas empresas, sino garantizar que las personas prosperen en su actividad emprendedora (Audretsch, 2014). Al ofrecer estas capacitaciones y cursos de emprendimiento, las universidades buscan mejorar la motivación y la capacidad de los estudiantes para iniciar un negocio (Mwasalwiba 2010; Solomon 2007; Walter et al. 2013). 
Los cursos de emprendimiento pueden ayudar de manera conjunta en la acumulación de conocimientos importantes para los empresarios nacientes. Por consiguiente, se encuentra que la educación para el emprendimiento tiene un impacto positivo en el capital humano (Martin et al., 2013) y, específicamente, afecta las creencias, la capacidad de explotar oportunidades y el conocimiento empresarial (Volery et al., 2013). También se debe tener en cuenta que las universidades obtienen ingresos de sus invenciones realizadas o guiadas en las aulas de clase, a través de regalías sobre las ventas de licencias de tecnología.

La educación empresarial motiva y pule ideas y sueños innovadores desarrollados a través de capacidades, habilidades y experiencias adquiridas en las aulas de clase, que son factor clave para desarrollar ecosistemas de emprendedores exitosos. En el caso que esas habilidades y la experticia sea muy amplias, existen eventos como los Startup que se emplean como plataforma para adquirir y desarrollar competencias demostrables en experiencias emprendedoras. Un Startup, es una empresa de nueva creación que comercializa productos y/o servicios a través del uso intensivo de las tecnologías de la información y la comunicación, con un modelo de negocio escalable el cual le permite un crecimiento rápido y sostenido en el tiempo (Fernández, 2018).

\section{El emprendimiento universitario}

La educación para el emprendimiento universitario, entendiéndose según Laguía, Jaén, Topa \& Moriano (2019) como aquellos cursos o programas que brindan las universidades sobre la creación de empresas o cómo volverse un emprendedor, ha proporcionado evidencia sobre el impacto positivo que tiene en, citando a Athayde (2012), Souitaris, Zerbinati, \& Al-Laham (2007), y Zhang, Duysters \& Cloodt (2014), las actitudes, normas subjetivas y la intención empresarial de los estudiantes universitarios, quienes independientemente de sus posibilidades, de acuerdo a lo expresado por Lima, Lopes, Nassif y da Silva (2015) 
desean tener sus propios negocios. Entonces, las universidades juegan un importante papel en cuanto albergan a estudiantes que buscan oportunidades que les permitan lograr sus objetivos.

Así, Morris, Shirokova \& Tsukanova (2017), exponen que el contexto universitario podría constituirse en una reserva potencial de conocimientos y habilidades, posibilidades de creación de redes, oportunidades para la puesta en práctica de ciertas iniciativas, e incluso, ser un medio para la consecución de capital financiero, aspectos que son determinantes para el éxito empresarial (Guenther \& Wagner, 2008; Robinson \& Sexton, 1994; Shane, 2000; Zhao et al., 2005).

Para Urbano y Guerrero (2013) en este tipo de emprendimiento, los miembros de la organización, haciendo referencia a los estudiantes, deben convertirse en empresarios, interactuando bajo dicho rol con el entorno. Es precisamente por su dinamismo, lo cual les permite estar a la vanguardia, que las universidades ofrecen a los estudiantes acceso a información sobre los últimos desarrollos, permitiéndoles trazar metas con base en ello y, de esta forma, generar una clara visión de cómo llevar a la práctica sus ideas (Hasan, Khan \& Nabi, 2017). En suma, las universidades se constituyen en un espacio propicio para desarrollar habilidades y competencias con relación al espíritu emprendedor, no sólo a través de la construcción de ideas, sino por medio de la intención y posterior materialización de la creación de nuevas empresas.

Para ello, se realizó una revisión de literatura, que según Hart (1998) es una síntesis objetiva y completa, un análisis de la literatura sobre el tema a estudiar. Su objetivo, de acuerdo con Cronin, Ryan \& Coughlan (2008) es actualizar lector al día con la literatura sobre un tema, para así, y constituirse en un pilar para diferentes objetivos, como la oportunidad de futuras investigaciones en el área específica. 
La búsqueda de artículos se centró en la base de datos Web of Science, teniendo en cuenta que es el recurso multidisciplinario más completo y que ofrece una mezcla de revistas especializadas, publicaciones comerciales, revistas desde 1986 hasta la actualidad. Sólo se consideraron artículos que como tema consideraran "University Entrepreneurial" y "Education". Respecto a la demarcación temporal, se consideró como criterio de limitación desde 2003 hasta el 2019, lo anterior sustentado en que el proyecto GUESS con el cual se miden las intenciones empresariales y sus determinantes, incluido el lugar de control y la autoeficacia (Chen, Greene), y Crick 1998; Levenson 1973; Liñán \& Chen 2009), nació en el 2003. Con los criterios de selección anteriormente indicados, se encontrados 18 artículos, los cuales van desde 2014 hasta 2019, Ver ilustración 3. En el año 2017, se observa el mayor número de publicaciones.

En la ilustración 3, se observan las revistas que contienen publicaciones con los criterios mencionados. Como se puede observar en la misma figura, la revista Journal of technology transfer, presenta el mayor número de publicaciones.

Ilustración 3. Publicaciones por año con las palabras "University Entrepreneurial" y "Education", en el tema (Web of Science, 2019).

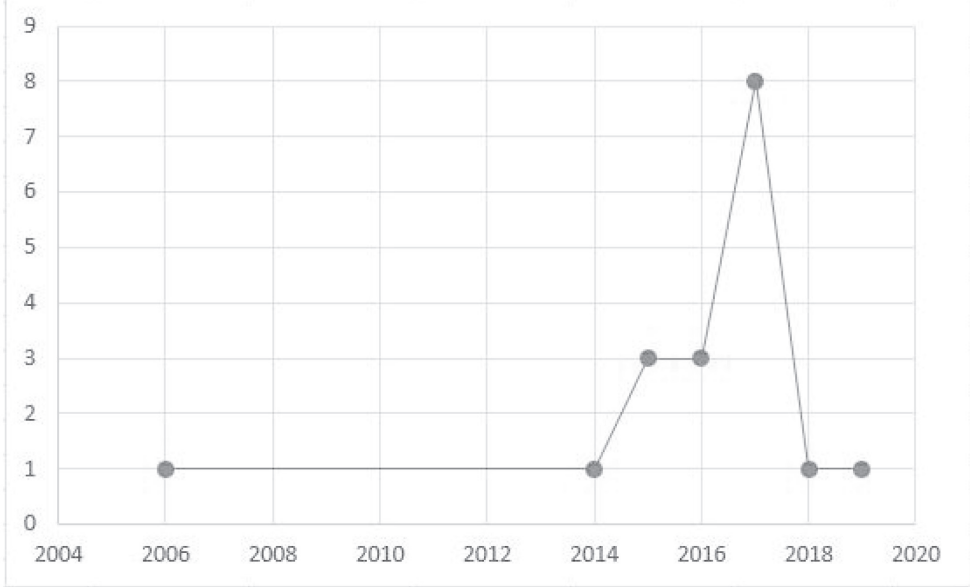

Fuente: Web of Science, 2019 
Tabla 4. Revistas identificadas con la cantidad de artículos publicados, de acuerdo a los criterios de selección escogidos.

\begin{tabular}{ll}
\hline Revista & $\begin{array}{l}\text { Número } \\
\text { de } \\
\text { artículos }\end{array}$ \\
\hline Education and training & 1 \\
Ekonomika regiona-economy of region & 1 \\
Entrepreneurship and regional development & 2 \\
European journal of international management & 2 \\
European management journal & 1 \\
European planning studies & 1 \\
Journal of developmental entrepreneurship & 1 \\
Journal of enterprising communities-people and & \\
places in the global economy & 1 \\
Journal of small business management & 1 \\
Journal of technology transfer & 3 \\
Revista de psicología social & 1 \\
Small business economics & 1 \\
Technological forecasting and social change & 1 \\
Voprosy obrazovaniya-educational studies moscow & 1
\end{tabular}

Fuente: elaboración propia (2019)

En las revistas mencionadas con los criterios presentados, se encontró que no todas pertenecen al Journal Citation Report (JCR), siendo un indicador importante de calidad más conocido y valorado en el campo de investigación.

En la tabla 5. se presenta los resultados obtenidos. Como se observa en la misma, se resalta la revista Journal of Small Business Management, con un Impact Factor de 3.248 y un índice Q igual a $\mathrm{x}$. Cabe anotar que toda la información se sistematizó en una matriz de revisión.

Tabla 5. Revistas identificadas en el recurso JCR

\begin{tabular}{lll}
\hline & Impact & \\
Revista & Factor & Q \\
& 2017 & \\
\hline Education and Training & - & - \\
Ekonomika regiona [Economy of Region & - & - \\
Entrepreneurship and Regional Development & 2,791 & 1 \\
European Journal of International Management & 0.672 & 4 \\
European Management Journal & 2.396 & 2 \\
European Planning Studies & 0.672 & 4 \\
Journal of Developmental Entrepreneurship & - & - \\
Journal of enterprising communities-people and places in & & - \\
the global economy & & - \\
Journal of Small Business Management & 3.248 & 1 \\
Journal of Technology Transfer & 2.931 & 2 \\
Revista de Psicología Social & 0.886 & 4 \\
Small Business Ecnonomics & 2.857 & 1 \\
Technological Forecasting and Social Change & 3.131 & 1 \\
VOPROSY OBRAZOVANIYA- Educational Studies Moscow & - & -
\end{tabular}

Fuente: elaboración propia (2019) 


\section{La búsqueda, según los criterios metodológicos descritos anteriormente se presentan en la tabla 6}

Tabla 6. Criterio de selección de artículos

\begin{tabular}{ll}
\hline Criterio & Descripción \\
& \\
\hline Base de datos & Web of Science \\
Palabras de búsqueda & "University Entrepreneurial" y “Education" \\
Tipo de documentos & Artículos principales \\
Área de búsqueda & Tema \\
Años & $2003-2019$ \\
Criterio & Descripción
\end{tabular}

Fuente: elaboración propia (2019)

Los resultados, a partir de la revisión de artículos basados en los criterios anteriormente mencionados, evidencian un total de 18 unidades muestrales, las cuales se relacionan en la tabla 7 , desde donde fue posible identificar 4 principales ejes temáticos en torno al emprendimiento universitario: los factores ambientales, la intención de creación de empresa, el contexto y la universidad.

Tabla 7. Artículos.

\begin{tabular}{|c|c|}
\hline Artículos & Autores \\
\hline $\begin{array}{l}\text { Entrepreneurial activity and regional competitiveness: evidence } \\
\text { from European entrepreneurial universities }\end{array}$ & $\begin{array}{l}\text { Guerrero, Maribel; Urbano, } \\
\text { David; Fayolle, Alain }\end{array}$ \\
\hline Exploring the intention-behavior link in student entrepreneurship: & Shirokova, Galina; Osiyevskyy, \\
\hline Moderating effects of individual and environmental characteristics & Oleksiy; Bogatyreva, Karina \\
\hline $\begin{array}{l}\text { Managing academic innovation in Taiwan: Towards a } \\
\text { 'scientific-economic' framework }\end{array}$ & $\begin{array}{l}\text { Chang, YC; Chen, MH; Hua, MS; } \\
\text { Yang, PY }\end{array}$ \\
\hline Opportunities to Improve Entrepreneurship Education: & Lima, Edmilson; Lopes, Rose M.; \\
\hline Contributions Considering Brazilian Challenges & Nassif, Vania; da Silva, Dirceu \\
\hline $\begin{array}{l}\text { What makes student entrepreneurs? On the relevance (and } \\
\text { irrelevance) of the university and the regional context for student } \\
\text { start-ups }\end{array}$ & $\begin{array}{l}\text { Bergmann, Heiko; Hundt, } \\
\text { Christian; Sternberg, Rolf }\end{array}$ \\
\hline $\begin{array}{l}\text { The university is the classroom: teaching and learning technology } \\
\text { commercialization at a technological university }\end{array}$ & Levie, Jonathan \\
\hline $\begin{array}{l}\text { The formation of opportunity beliefs among university } \\
\text { entrepreneurs: an empirical study of research- and non- } \\
\text { research-driven venture ideas }\end{array}$ & Heiko Bergmann \\
\hline $\begin{array}{l}\text { Student entrepreneurship and the university ecosystem: a } \\
\text { multi-country empirical exploration }\end{array}$ & $\begin{array}{l}\text { Michael H. Morris; Galina } \\
\text { Shirokova } \\
\text { Tatyana Tsukanova; } \\
\text { Francisco J. García-Rodríguez; }\end{array}$ \\
\hline
\end{tabular}


Entrepreneurial process in peripheral regions: the role of motivation and culture

Entrepreneurial Education at University Level and Entrepreneurship Development

University Environment and Student Entrepreneurship: The Role of Business Experience and Entrepreneurial Self-Efficacy

Entrepreneurial learning and entrepreneurial intentions: a cross-cultural study of university students

Entrepreneurial capacity of universities and its impact on regional economic growth

Expertise, university infrastructure and approaches to new venture creation: assessing students who start businesses

\section{Entrepreneurial education and learning at universities: exploring} multilevel contingencies

University environment and entrepreneurial intention: the mediating role of the components of the theory of planned behavior

Technology and talent: capturing the role of universities in regional entrepreneurial ecosystems

A start-up generation approach for teaching entrepreneurship: an overview of affective learning results
Esperanza Gil-Soto; Inés

Ruiz-Rosa; Desiderio

Gutiérrez-Taño

Sk. Mahmudul Hasan; Eijaz

Ahmed Khan; Md. Noor Un Nabi

Galina Shirokova; Tatyana

Tsukanova;

Karina Bogatyreva

Tatiana Beliaeva; Anastasia

Laskovaia; Galina Shirokova

Kochetkov, Dmitry Mikhaylovich;

Larionova, Viola Anatolyevna;

Vukovic, Darko Bozha

Shirokova, Galina; Osiyevskyy,

Oleksiy; Morris, Michael H.;

Bogatyreva, Karina

Hahn, Davide; Minola, Tommaso;

Van Gils, Anita; Huybrechts,

Jolien

Laguia González, Ana; Jaén, Inmaculada; Topa, Gabriela; Moriano, Juan

Huang-Saad, Aileen;

Duval-Couetil, Nathalie; Park, Jongho

Loi, Michela; Di Guardo, Maria

Chiara

Fuente: elaboración propia (2019)

\section{El emprendimiento universitario y los factores ambientales}

En el estudio de Guerrero y Urbano (2016), siendo el más relevante de esta revisión en términos de citas, se exploró el impacto del emprendimiento universitario a partir de la influencia de los factores ambientales y desde el aporte que se realiza a la competitividad regional, adoptando la economía institucional y los enfoques de crecimiento endógeno. En lo que respecta a los factores ambientales, citando a North $(1990,2005)$, se hace referencia a los formales e informales que han definido la interacción de la comunidad universitaria con otros agentes, los primeros se refieren a las reglas políticas y económicas, así como a los contratos; mientras que los segundos, a los códigos y normas de conducta, actitudes y valores.

Los autores sostienen que la universidad debe promover una cultura empresarial mediante el empleo de acciones estratégicas que permitan la adaptación a los cambios ambientales, siendo 
imperativa la realización de esfuerzos mediante el fortalecimiento de las actividades propias de su quehacer, como son la enseñanza, investigación e iniciativas empresariales. Al estar el dinámico ambiente universitario particularmente asociado con los factores informales, se evidenció que éstos tienen una mayor influencia en la actividad empresarial universitaria que los factores formales.

\section{El emprendimiento universitario y la intención de creación de empresa}

Uno de los determinantes dentro del proceso de emprendimiento es la formación de intenciones empresariales (Krueger, Reilly \& Carsrud, 2000). Shirokova \& Osiyevskyy (2016) sostienen que hay ciertos factores que refuerzan, y otros que atenúan, dentro de las intenciones de emprendimiento, marcadas por peculiaridades individuales, la puesta en marcha del proyecto empresarial. En el estudio de los mencionados autores se evidenció que el contexto empresarial familiar, la edad, el género masculino y el entorno empresarial universitario son factores que refuerzan la asociación intención-creación; mientras que la aversión a la incertidumbre, sentimiento que se experimenta de manera generalizada en un país, debilita tal relación.

Bergmann (2017) considera tales intenciones en términos de creencias de oportunidades de emprendimiento, las cuales define citando a Grégoire, Shepherd \& Lambert (2010) como la certeza que tiene el emprendedor potencial sobre la viabilidad de crear una empresa que tenga acogida en el mercado. Dentro de estas creencias se destacaron, por un lado, aquellas basadas en el conocimiento formal sobre el emprendimiento y las soportadas en la experiencia profesional, y por otro, las que surgen de un proyecto de investigación y las que no. Los resultados del mencionado estudio de Bergman afirman que los conocimientos adquiridos en el ejercicio profesional son importantes en las creencias de oportunidad sólo para las ideas de negocio impulsadas desde la investigación, donde se experimentan altos grados de 
incertidumbre; por su parte, el conocimiento adquirido en las aulas de clase es fundamental en las creencias de oportunidad que no están impulsadas por la investigación, pues probablemente su idea se dirigirá a mercados ya establecidos.

\section{El emprendimiento universitario y el contexto}

Autores como Bercovitz \& Feldman (2008), Welter (2011), Wennberg et al. (2011) y Johns (2006) afirman que el espíritu emprendedor depende en gran medida del contexto, pues éste proporciona una serie de oportunidades, pero también de limitaciones que modelan el comportamiento organizacional. Para Bergmann, Hundt \& Sternberg (2016) el contexto es importante en el proceso de creación de la empresa, así como en la decisión del tipo de idea que se tiene; en su estudio, estos investigadores afirman que los estudiantes de negocios y economía tienen una alta propensión a participar en actividades de emprendimiento, en comparación con los estudiantes que están inmersos en otros campos. De igual forma, hay ciertos indicios que las ideas de negocio que surgen en regiones en crecimiento económico tienden a prosperar más que en aquellas economías desarrolladas. Respecto de la ubicación geográfica, según Lafuente, Vaillant y Rialp (2007) el emprendimiento en los estudiantes tiene un efecto más fuerte en las regiones no centrales, teniendo en cuenta que allí existe más posibilidad de desarrollar ideas nuevas. Así, se afirma que el contexto regional llega a tener una mayor influencia sobre la creación de empresa que el contexto organizacional.

El contexto cultural, también, juega un papel importante para García, Gil, Ruiz y Gutiérrez (2016), quienes buscaban analizar el proceso de emprendimiento a través dela determinación de posibles especificidades culturales, considerando una visión integrada del papel de la motivación en la intención de creación de empresa. Su iniciativa radicó en que cada región tiene características específicas en términos de su capacidad innovadora, y, por 
consiguiente, el impacto que generarán estas en el crecimiento económico será diverso. Asheim, Moodyson \& Tödtling (2011) hacen una distinción entre regiones metropolitanas, industriales y periféricas, caracterizándose estas últimas por una actividad innovadora de bajo nivel debido a la falta de empresas dinámicas y organizaciones generadoras de conocimiento, y una estructura débil de proveedores y de instituciones educativas. Los resultados indican que la educación empresarial y las políticas para fomentar el espíritu empresarial en las regiones periféricas no deben intentar transformar directamente las actitudes de los individuos hacia el espíritu emprendedor, sino centrarse en mejorar la motivación utilizando estrategias pedagógicas intensivas en creatividad que van más allá de sólo mostrar un contenido informativo.

Considerando también el contexto cultural, Beliaeva, Laskovaia \& Shirokova (2017), exploraron el vínculo entre el aprendizaje empresarial y las intenciones empresariales de los estudiantes, examinando el papel de las características de la cultura nacional en esta relación. Los resultados de su estudio revelan una relación positiva entre el aprendizaje empresarial y las intenciones empresariales de los estudiantes. Sin embargo, se encontró que esta relación estaba moderada por diferentes dimensiones de la cultura nacional, siendo más fuerte en las culturas individualistas y más débil en las sociedades de alta incertidumbre.

En cuanto al contexto tecnológico, estudios como el de Huang-Saad, Duval-Couetil \& Park (2018), Chang \& Bogatyreva (2006) y Levie (2014) encontraron un efecto positivo en la actividad de creación de empresa, así se propende por el establecimiento de ecosistemas que facilitan la puesta en marcha de nuevos negocios a través del fortalecimiento de redes, acceso a nuevas tecnologías y desarrollo de talentos, basados en recursos a los que se tiene acceso desde la comunidad universitaria, enfatizando de esta forma la importancia del rol del contexto en la creación de empresa. 


\section{El emprendimiento universitario y la universidad}

Morris, Shirokova \& Tsukanova (2017) consideran las interacciones de los estudiantes, están divididas en tres áreas generales que se pueden encontrar en el entorno universitario: programación curricular, actividades de apoyo co-curricular y recursos financieros para estudiantes emprendedores. Los resultados de su estudio afirman que las dos primeras áreas están relacionadas positivamente con el espíritu emprendedor; mientras que el apoyo financiero tiene una relación negativa con la creación de empresa visualizada por los estudiantes. Es posible anotar, de esta forma, que los cursos de emprendimiento pueden ayudar en la acumulación de conocimientos importantes para los empresarios nacientes, pero también puede aumentar la capacidad de un estudiante para adquirir recursos.

En este mismo orden de ideas y arrojando resultados similares a los del estudio anteriormente citado, Shirokova, Tsukanova y Bogatyreva (2015) se encargaron de evaluar cómo los diferentes tipos de capital para el emprendimiento proporcionados por las universidades afectan la participación de los estudiantes en el espíritu emprendedor. Su análisis reveló que las iniciativas universitarias para desarrollar el capital humano y social influyeron positivamente en la medida en que los estudiantes se involucraban en el emprendimiento; mientras que el capital financiero provisto por las universidades tuvo efectos negativos. Se encontró también, que la experiencia profesional previa de los estudiantes fue capaz de debilitar la relación entre los tres tipos de recursos proporcionados por la universidad (humano, social y financiero) con el alcance de las actividades emprendedoras de los estudiantes, incluido el efecto negativo del acceso al capital financiero.

En el estudio realizado por Guerrero, Urbano \& Fayolle (2014) sobre la medición de la capacidad empresarial de las universidades y su impacto en el crecimiento económico 
regional, se compararon los diferentes rankings en términos de transferencia de conocimientos, considerando entre otros las citas y publicaciones. En la investigación se evidenció que existe una carencia de rankings que midan la innovación, actividad que finalmente conduce al emprendimiento universitario.

Considerando variables que relacionan el emprendimiento universitario con la universidad como un todo, en el estudio de Hahn, Minola, Van Gils \& Huybrechts (2017) se pretendía medir el grado en el que las diversas iniciativas de educación para el emprendimiento impartidas a los estudiantes, afecta sus resultados de aprendizaje sobre emprendimiento, para ello se consideraron aspectos como la experiencia empresarial del estudiante, la pedagogía de la enseñanza empresarial de las universidades y la difusión de la actividad empresarial. En los resultados se evidenció que el coeficiente de edad es negativo y significativo, apoyando la idea que el efecto en los resultados de aprendizaje empresarial es más fuerte para los estudiantes más jóvenes; el coeficiente de género también es negativo y significativo, lo que sugiere que los estudiantes varones informan mejores resultados de aprendizaje organizacional que las mujeres; la educación es positiva y significativa, lo cual sugiere que los estudiantes en un nivel más alto de educación general han desarrollado más conocimiento empresarial; por último, los estudiantes con experiencia familiar en empresas, están en condiciones de alcanzar niveles más altos de conocimiento empresarial cuando asisten a iniciativas adicionales de educación para el emprendimiento.

\section{Oportunidades de investigación identificadas}

En los artículos de los autores, se identifica que una dirección importante para futuras investigaciones es ir más allá de los mecanismos cognitivos (formación de intenciones y traducirlas en acciones, explicadas por TPB), para incluir los mecanismos afectivos que influyen en las actividades de inicio, Shirokova \& Osiyevskyy (2016), ya que de acuerdo a los autores, 
con esto se podría comprender el papel de las emociones (miedo, amenaza) y las pasiones, además de las intenciones cognitivas y explicar el proceso de emprendimiento.

Debido a que la gran cantidad de empresas incipientes en comparación con los nuevos empresarios podrían iniciarse después de la graduación, según lo documentado por Stebro et al. (2012). El efecto general del contexto organizativo y regional en el espíritu empresarial de los estudiantes, solo podría hacerse visible una vez que las personas se gradúen de la universidad e intenten establecer su negocio, Bergmann, Hundt \& Sternberg (2016)., por lo anterior sería interesante evaluar o ahondar la investigación del emprendimiento en un tiempo posterior pero cercano a la finalización de estudios, esto también basado en que se identifica que el contexto empresarial están relacionados con la administración de micro y pequeñas empresas. Lima, Lopes, Nassif \& da Silva (2015).

Finalmente, se puede concluir que el emprendimiento es una herramienta clave para cualquier sociedad. Todos nos podemos beneficiar de este aprendizaje, es por eso que universidades han puesto en sus currículos, materias relacionadas con esta temática, a fin de incentivar a la comunidad universitaria a crear su propia empresa. Esto no significa que deban ser emprendedores, simplemente, buscan brindar las herramientas para que descubran habilidades escondidas y con ello, sembrar la semilla de la creación y puesta en práctica de nuevas ideas.

Con esta revisión se logra conectar los campos de investigación académica con los ecosistemas regionales para llevar la investigación a la práctica y viceversa. Por tradición las universidades han sido las principales patrocinadoras del desarrollo de habilidades y aportes al pensamiento crítico. Es necesario tener en cuenta que, con la apertura de cualquier tipo de empresa, se está aportando al desarrollo económico de la cada región, mediante esos actores que han cobrado una creciente importancia, como lo son los estudiantes. 
Los estudiantes pueden generar conocimiento empresarial y ser partícipes del aprendizaje en el campo del emprendimiento, a medida que la educación empresarial produce ventajas que contribuyen a la conceptualización de antecedentes, moderadores y resultados del aprendizaje en el contexto de esta educación; también ofrecen un conjunto de implicaciones prácticas para el diseño y evaluación de programas de emprendimiento y vías abiertas para futuras investigaciones sobre la creación de empresa en el contexto académico; razón por la cual, se han venido creando este tipo de programas de emprendimiento universitario.

Una premisa central en la creación de tales programas, es que la acción de emprender puede considerarse un fenómeno aprendido, y los educadores desempeñan un papel central en este proceso (Dickson et al., 2008; Elenurm \& Moisala, 2008). El entorno educativo puede ayudar a los estudiantes a desarrollar su autoeficacia y proporcionarles los conocimientos, habilidades y recursos relacionados adecuados para convertir las ideas en acciones empresariales (Pittaway \& Cope, 2007; Solomon et al., 2002). Loi \& Di Guardo (2015) afirman que los estudiantes que toman cursos de emprendimiento, se consideran más capaces de tomar decisiones que aquellos que no lo hicieron. De esta manera es posible afirmar, que las habilidades adquiridas en las clases de emprendimiento universitario sirven como experiencias y oportunidades que fomentan la creación de empresas. 


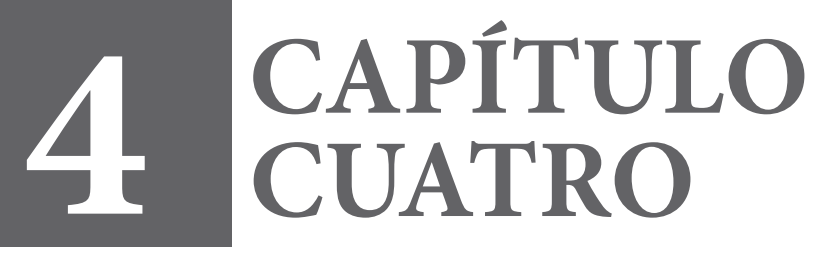




\section{Actores públicos y privados que acompañan el emprendimiento}

\section{La Red Regional de Emprendimiento del Cauca}

Imagen 1. Representantes de entidades de la Red Regional de Emprendimiento del Cauca

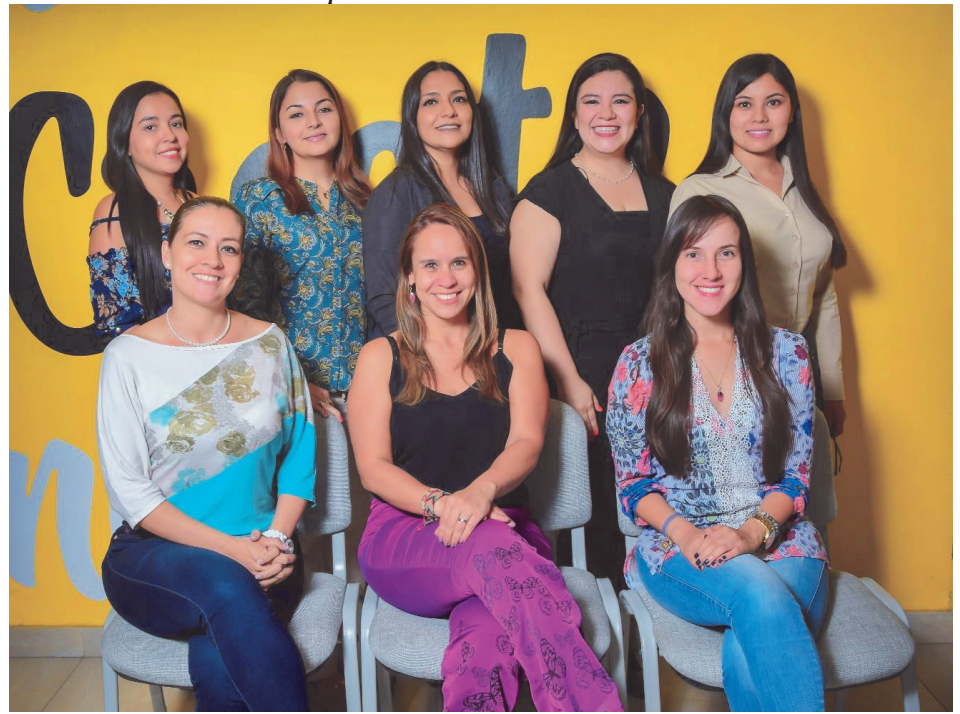

Líderes de emprendimiento de la Red Regional de Emprendimiento del Cauca Fuente: Propia.

La Red Regional de Emprendimiento del Cauca (REE), creada bajo convenio de cooperación en el año 2010, amparada por la Ley 1014 de 2006 y decreto 1192 de 2009 y registrada ante el Ministerio de Comercio, Industria y Turismo, tiene como objetivo:

Promover el desarrollo económico regional, la creación de empresas, el fortalecimiento de la competitividad y productividad, creando políticas, que permitan el fomento a la cultura de emprendimiento en el Cauca; igualmente, establecer políticas y directrices orientadas al fomento de la cultura para el emprendimiento, según las necesidades y los 
planes de desarrollo, bajo la orientación y principios generales de la Red de Emprendimiento Nacional y constituirse como un espacio articulador de organizaciones que apoyan acciones de emprendimientos innovadores y generadores de empleo (Red Regional de Emprendimiento Cauca, 2010).

La secretaría técnica articulada a la Comisión Regional de Competitividad y asumida por la Cámara de Comercio del Cauca, da cuenta de la financiación, organización e instrumentación de la Red.

\section{Institución Educativa Colegio Comercial del Norte}

La Institución Educativa Comercial del Norte ubicada en el Municipio de Popayán, Departamento del Cauca, es un plantel enfocado en el "fortalecimiento de competencias básicas, laborales y ciudadanas, integradas al proyecto de vida que, por su modalidad técnico-comercial, con enfoque empresarial, posibilita el ingreso a la educación superior o su vinculación al sector productivo, en busca del mejoramiento de las condiciones propias y del entorno" (Misión, 2019).

Conscientes que la formación de líderes debe iniciarse desde la niñez, son una apuesta del emprendimiento en su fase de sensibilización y formación, apoyándose del ámbito académico, técnico-comercial y empresarial, para la construcción y desarrollo de la región.

Con 38 años de vigencia, cuenta con cinco sedes, dos de ellas, rurales, ubicadas en el corregimiento la Rejoya y vereda Villa Nueva. De este modo, los estudiantes de $9^{\circ}$ y $10^{\circ}$ grado, desarrollan un trabajo de articulación con el SENA, y en el grado $11^{\circ}$, empiezan su práctica empresarial, logrando otros espacios de aprendizaje en entidades públicas y privadas, entre las que se 
destaca, la Alcaldía Municipal de Popayán, el Centro de Desarrollo Tecnológico Clúster CreaTIC, la empresa Dulce Rinconcito, entre otros.

Estas actividades nacen desde el proyecto educativo institucional, que se ven reflejadas en la malla curricular, con el área empresarial, compuesta por un componente contable, de ética laboral, emprendimiento y práctica empresarial.

Existe entonces, una articulación del emprendimiento académico con los escenarios que se gestan alrededor del emprendimiento en la región. Un ejemplo de ello, es la relación de la institución con el Centro de Desarrollo Tecnológico Clúster CreaTIC y su proyecto Súper Desarrolladores, la Red Regional de Emprendimiento del Cauca, la iniciativa (Mesa) Eureka Colegios, Eureka Profesores y Eureka Estudiantes, proyecto gestado desde la Universidad del Cauca en el que participan más universidades y cerca de 12 colegios (públicos y privados).

Por otra parte, la institución realiza visitas con los estudiantes de grado once a las empresas del norte del Cauca, entre las que se resalta PROPAL, empresa de la Organización Carvajal S.A, Colombina, entre otras, que abren sus puertas para que ellos conozcan el mundo real y que aparte de conocer su departamento, se den cuenta cual es la dinámica empresarial.

También han adelantado ferias institucionales para fortalecer habilidades blandas y competencias específicas en emprendimiento. Andy Rosero Saby, estudiante de la institución indica al respecto que "una de las características que he podido notar, podría ser la coordinación de las áreas que se conforman para la planeación y ejecución de las ferias institucionales. Por ejemplo, existe un área de logística, financiera, cultural etc., que exige un trabajo en equipo. Es decir, de nuestra parte como estudiantes se espera un compromiso en todas las áreas y comités. 
Se requiere poner en práctica lo aprendido en el aula. También, es de resaltar la innovación en proyectos que se presentan en estos espacios que la institución brinda”

Con respecto a EUREKA Colegios, las enseñanzas para la institución, son muy enriquecedoras. Especialmente, resaltan el intercambio de conocimientos para la estructuración de una unidad de negocio o de un plan de negocio. "Los proyectos permiten que cada estudiante, aportemos ideas y entre todos, construyamos un concepto general, que posteriormente, exige ser evaluada, decidir si está bien enfocada, aprender a corregir, y entre todos ayudarnos, cooperar" (Andy Rosero Saby, estudiante de la institución).

Sin embargo, como colegio oficial, los docentes en su mayoría, son licenciados, a diferencia de dos profesionales en áreas empresariales como contabilidad y administración de empresas. En ese sentido, "el mundo empresarial tiene un lenguaje diferente que debe ser abordado desde la práctica". (Guillermo Santacruz, docente de emprendimiento, 2019).

Por consiguiente, se busca desde la idea de negocio, preguntarse por el contexto, y para ello, se abordan las comunas más cercanas adelantando ejercicios de observación. Ello permite evidenciar que las zonas donde se encuentran ubicadas las sedes del colegio, predominan actividades de comercio, en su mayoría en estado de informalidad. En esa búsqueda de necesidades, es cuando se indagan a los estudiantes, preguntando que se podría suplir, qué necesidad evidencian que se podría resolver. Este ejercicio, viene gestándose desde el grado décimo con la asignatura del espíritu empresarial, que posteriormente se materializa, en once con el plan de negocio.

Muchos de los padres de familia, tienen sus pequeños negocios como tiendas, modistería, carpintería, mueblería, servicios generales, entre otros, y lo que tratamos, es que los estudiantes, acompañen el proceso de sus padres. Queremos, 
precisamente que ellos con lo que aprenden en el colegio, ayuden a sus padres de familia a mejorar sus procesos, que tengan mayores posibilidades, y mejoren sus condiciones socioeconómicas. Hay muchas ganas y deseos, tienen sueños como todos los jóvenes y niños, de plasmar esas ideas soñadoras. La institución, sin matar el sueño, van aterrizándolos a procesos. (Guillermo Santacruz, docente de emprendimiento, $2019^{3}$ )

Es así como en la Semana de Emprendimiento y Muestra Cultural Estudiantil, la institución invitó a los padres de familia a dar a conocer sus negocios. Entre ellos, se conocieron emprendimiento del sector de alimentos, Muebles, productos en granito, entre otros. A lo anterior se suma, el interés por promover las industrias culturales. De este modo, se adelantaron presentaciones de música, baile y pintura.

En este esfuerzo de articulación se ha logrado participar en eventos que han sido significativos para los estudiantes. Uno de ellos, gestado por la Fundación Mundo Mujer en el año 2018, permitió la clasificación de emprendimientos de todo el país, recibiendo jóvenes de Cundinamarca, Tolima, Nariño, Valle del Cauca y del Cauca. En esa oportunidad, la institución participó con un grupo de estudiantes de décimo grado, quienes hicieron parte de todo el proceso de emprendimiento, con su idea de negocio denominada Hidrografía, dedicada al diseño

personalizado mediante sumersión del producto. También participaron del programa Ingeniando de la Cámara de Comercio del Cauca.

Otro grupo de estudiantes, de la sede La Paz, diseñaron un video juego para volver más agradable el manual de convivencia del colegio, logrando acceder a un premio por convocatoria de la Alcaldía Municipal de Popayán. "Un video juego para que los

3 Información primaria proveniente de los emprendedores entrevistados. 
niños y los jóvenes les sea más agradable leer o entender el manual de convivencia. Ahora se encuentran recibiendo acompañamiento por parte del Clúster Creatic. A parte de todo lo que están aprendiendo, se espera lograr un video juego con cierta calidad, porque desde el colegio es muy difícil" (Guillermo Santacruz, docente de emprendimiento, 2019).

Sin embargo, la condición de ser estudiantes menores de edad, ha restringido el acceso a fuentes de financiación. Entre la gestión realizada por la institución fue lograr llegar al Fondo Emprender. No fue posible por ser menores de edad. Otras entidades, si le han apostado a esta población como la Cámara de Comercio del Cauca, con una convocatoria a partir de los 17 años en adelante, así como la Alcaldía Municipal de Popayán, con una convocatoria dirigida a colegios desde el Centro de Empleo y Emprendimiento.

Mas allá de los recursos, es la posibilidad de permitirles a los estudiantes enfrentarse y ser capaz de arriesgarse. "Queremos que ellos vean como se debe presentar un proyecto, que oportunidades hay, estamos en la búsqueda de más recursos, de ver otras posibilidades en sectores como las industrias culturales. En este ámbito, trabajamos con madres de familia, experiencia que nos permitió presentar un proyecto para el Ministerio de Cultura relacionado con cocinas tradicionales" (Guillermo Santacruz, docente de emprendimiento, 2019).

Por otra parte, los indicadores permiten lograr una trazabilidad. En ese sentido, se ha analizado los aportes al emprendimiento desde diferentes disciplinas, por ejemplo, desde estadística.

Con los chicos de séptimo empezamos a trabajar la temática de la Economía Naranja. Desde esta asignatura, se adelantan una serie de ejercicios de investigación para que los niños desde ahí empiecen a entender este proceso para prepararlos para 
grados superiores. Cuando ellos investigan, identifican espacios para aplicarlo en las comunas a las que pertenecen las sedes del colegio. Se empieza a seleccionar, por ejemplo, dentro de la economía naranja que tipo de negocio puede haber. (Guillermo Santacruz, docente de emprendimiento, 20194)

Desde el componente ambiental y la asignatura de Química, siempre pensando en una trazabilidad con el emprendimiento, se ha querido lograr un eje articulador. Ese punto de encuentro para el colegio, es la Semana del Emprendimiento. Allí todos los estudiantes se encuentran, trabajan en equipo y ponen en práctica lo aprendido en clase.

Es decir, que la cultura del emprendimiento se va forjando poco a poco. El estudiante Andy Rosero Saby, manifiesta que existe un deseo, un potencial, aun efímero, que en ocasiones se diluye por el simple hecho de rendir en los estudios y alcanzar una nota.

Se ve muchos trabajos informales y negocios independientes, no se ve trabajos en empresas cooperando con otras. La mayoría somos de estrato uno y dos, algunos tres, pero muy pocos. No hay grandes posibilidades de trabajar en organizaciones. Es más común las artes y oficios. Algunos se dedican a estudiar la mueblería, la carpintería, la construcción, tramites y licencias, entre otros. (Estudiante, 20195)

Por consiguiente, entre los aspectos a fortalecer, la institución considera que, desde la institucionalidad gubernamental, se requiere mayor impulso al emprendimiento, incluyendo convocarías exclusivas a colegios orientada a padres de familia y estudiantes.

El sector oficial educativo requiere más recursos dirigidos 
al emprendimiento para fortalecer desde la base. Los niños desde el discurso de sus docentes, empiecen a hablar del emprendimiento, se empieza a sentir curiosidad por una cultura emprendedora.

Los colegios deben enfocarse en la sensibilización hacia la creatividad y la innovación. "En medida que los estudiantes van creciendo y que van subiendo de grado, se va perdiendo la creatividad, entonces les da pena de todo. En cambio, los niños de primaria, se enfrentan al público, manejan bien su discurso, son capaces de parase al frente. Un joven de once no puede hacer lo mismo ya. Es un tema de motivación, y como le apostamos al emprendimiento.

Desde la rectoría expresa que, en las últimas administraciones locales, ha habido una preocupación hacia la actitud emprendedora, que en otros momentos no se había dado. "Se tendría que pensar un poco en el fortalecimiento de las instituciones que de una u otra manera estamos enmarcadas en lo técnico, comercial, industrial, agropecuario, gestión empresarial y en este sentido, por lo menos, por parte de las instituciones, existe el interés. Falta un direccionamiento claro desde los entes, en este caso municipal, que ayuden aterrizar esas iniciativas de las mismas comunidades educativas. Las instituciones gestan más el deseo, el querer, el interés, la mirada desde el contexto, pero se requiere de un acompañamiento sistemático (Rector, Edgar Gregorio Meneses Moncada).

Cámara de Comercio del Cauca

Desde la presidencia ejecutiva liderada por la Economista Ana Fernanda Muñoz Otoya y la Coordinación del área de Desarrollo Empresarial, gestionada por Eliana Marcela Valencia Banguero, se destacan diferentes estrategias en pro de fomentar la cultura del emprendimiento. Entre ellas, el programa Ingenia, como una de las apuestas que ha contribuido al fortalecimiento del emprendimiento en la región. Este servicio de apoyo a la creación 
de empresa y fortalecimiento de las empresas existentes, se realiza de manera práctica a través de capacitaciones, acompañamiento personalizado y comunidades de práctica, que incluye las siguientes etapas (Cámara de Comercio del Cauca) ${ }^{6}$.

Pensar: diseñado para conceptualizar el modelo de negocio, logrando con ello, guiar el emprendedor a que investigue más sobre el sector, entorno en el que desea trabajar. Tendencias: durante esta fase el emprendedor trabaja para obtener su primer modelo de negocio, a través de la herramienta Ingecanvas. Entre los talleres que se desarrollan en esta etapa se encuentra, sensibilización sobre el entorno y modelo de negocio.

Probar: etapa que busca que los emprendedores validen el modelo de negocio con el mercado objetivo, se trabaja con el emprendedor en la forma en la que irá al mercado a aprender más de él. Entre los talleres que se desarrollan en esta etapa, se encuentra validación del modelo de negocio, prototipado, pitch, estructuración financiera.

Empezar: iniciar la operación de la empresa: se busca ayudar al emprendedor en su paso al rol de empresario, intentando que viva las primeras actividades de la operación, ventas y constitución de la empresa.

Crecer: encaminado hacia acelerar el crecimiento de la empresa.

De este modo, la Cámara de Comercio del Cauca ha adelantado concursos de emprendimiento, que buscan fortalecer a los emprendedores de la región en conocimientos y en experimentación, y con ello, otorgarles un incentivo económico en especie, con el fin de apoyarlos en la puesta en marcha de su idea de negocio.

Desde el programa Ingenia, se lanzan dos tipos de 
convocatorias. Una, orientada a emprendedores y otra a microempresarios. Para emprendedores que tienen solamente su idea de negocio, de forma gratuita, se les acompaña y brinda formación mediante talleres y asesorías personalizadas en aspectos que les permita concretar su modelo de negocio. Las temáticas se estructuran según las necesidades, entre ellas, modelo de negocios, validación del modelo de negocio, estructuración financiera, prototipado, manejo contable, formalización, entre otros. De este modo, las asesorías personalizadas, les permite aclarar inquietudes y lograr madurar su proceso de estructuración.

Para los microempresarios, se han realizado otras convocatorias con tarifas subsidiadas por más del 50\%. Estas iniciativas buscan fortalecer a los microempresarios por medio de talleres y asesoría personalizada, ayudándolas a definir su estructura organizacional y mejorar sus procesos internos; mediante la transferencia de conocimientos, metodologías y herramientas prácticas que les permitan proyectar su propio crecimiento.

Algunas de las razones por las cuales se les dificulta su crecimiento, generalmente responde a la falta de organización interna y al comportamiento financiero. Es así como, desde la Cámara de Comercio del Cauca, se identifica esa debilidad y con el asesor, se va acompañando al micro empresario para ir mejorando en el proceso.

De este modo, se viene trabajando para cambiar el imagino del emprendimiento en el departamento del Cauca. Su presidente ejecutiva agrega:

Cuando una persona te sale a montar un negocio, cuando una persona te dice voy a montar una tienda, muchas veces van con la mentalidad de subsistencia, entonces parte del enfoque que hemos querido darle, es que tenemos que acabar con el emprendimiento y con el empresarismo de subsistencia y eso es lo que exactamente busca Ingenia. Lo que busca el proyecto Ingeniando, es enseñarles a estos empresarios a pensar como 
empresarios, y no como ganar el día a día. (Cámara de Comercio del Cauca, 20197).

En ese orden de ideas, se espera que el imaginario hacia la Cámara de Comercio del Cauca en la ciudadanía, vaya más allá de un impuesto. "Es necesario, generar ese crecimiento dentro del mercado, es decir, la masa crítica que son básicamente todos esos emprendedores y empresarios. Al poner en marcha proyectos como Ingenia, lo que se logra, es invertir en el crecimiento de la región. Se le está apostando a que las personas se den cuenta que, si proyecta adecuadamente su negocio, si tiene una buena estructuración, si tiene un buen modelo de negocios, si tiene un buen diseño de toda su estructura de costos, va a generar un crecimiento organizado y formal, va a generar empleo formal, siendo un círculo virtuoso, impactando positivamente en el crecimiento de la economía”.

Por ello, todos los recursos generados desde el registro, son invertidos en estrategias que respaldan y promueven el emprendimiento. Programas como Ingenia, cuenta con una metodología canadiense, que demuestra que se logra estructurar negocios, de los cuales se puede vivir bien, generando empresa y generando crecimiento. Para ello es necesario, que las personas comprendan que lograr la formalidad, implica crecimiento como empresario y crecimiento para la economía.

De esta manera, en términos de resultados, el concurso de emprendimiento ha demostrado que es posible reconocer el esfuerzo a emprendedores. Por ejemplo, el ganador del primer concurso, fue la empresa Biosecol S.AS. (Hoy Bioseguridad de Colombia Company S.AS. - BSC Company), empresa productora de jabón a partir de aceite reutilizado, emprendedor que llegó a la entidad solamente con la idea y hoy cuenta con una empresa que produce y comercializa a diferentes ciudades de Colombia.

7 Información primaria proveniente de los emprendedores entrevistados. 
El concurso le permitió conseguir inversionistas, logrando con ello, una planta de producción en Popayán, Santa Martha y en Cartagena, generando cincuenta empleos, con líneas de producción que responden a las necesidades del mercado desde un enfoque de empresa verde.

Es de resaltar que este modelo Ingenia y el concurso de emprendimiento Ingeniando, fue compartido como caso de éxito entre las Cámaras de Comercio del país, siendo una estrategia que llega a 28 municipios del departamento del Cauca a pesar de ser tan joven. Con ello, se ha reflejado una gran diversidad e innovación de diferentes partes del Cauca, con presencia de municipios como Cajibío con un emprendimiento de huevos orgánicos y de Santander de Quilichao con un emprendimiento a destacar con productos que parecen de cuero, pero son hechos a base de los desechos de las hojas de la piña, proceso con bajo consumo de agua, desde un enfoque ecológico y con una alta proyección de venta en el exterior. "Eso trae como conclusión, que los emprendedores no deben entrar a este tipo de concursos, por el simple hecho de ganar o no ganar. Finalmente, todos ganan. Reciben capacitaciones sin costo, hacen parte de una red de personas dispuestas a impulsar sus ideas y se arriesgan a soñar" (Valencia Banguero, Coordinación del área de Desarrollo Empresarial, Cámara de Comercio del Cauca, 2019).

Otra iniciativa que ha tenido un impacto positivo en los emprendedores, es acercar las experiencias de emprendimientos que se encuentran en su proceso de crecimiento, con el fin que estos, puedan contar sus aprendizajes y con ello, evidenciar que si es posible emprender. Así mismo, estas historias permiten un resultado en doble vía, ya que se empodera quien la cuenta y asesora desde la realidad, y se vuelve posible para aquel que apenas inicia el proceso. De igual forma, se hace este ejercicio, con empresas ya consolidadas en el mercado, quienes contribuyen al ser mentores de los pequeños emprendedores. 
De esta manera, los esfuerzos en emprendimiento requieren ser medidos, y uno de los desafíos que dificulta su desarrollo, es la continuidad de los emprendedores, por su misma naturaleza. Por ejemplo, cuando un emprendedor llega al programa Ingenia, lo puede hacer desde la idea de negocio, hasta en una fase de madurez, por lo cual, desde la Cámara de Comercio del Cauca, se está buscando un punto de equilibrio en el que se pueda demostrar desde indicadores sólidos, cuales han sido los logros, interpretando los esfuerzos y las formas de ejecución desde la variedad del departamento del Cauca.

En estos cinco años del programa Ingenia, nos hemos dado cuenta que el perfil de los emprendedores o de los empresarios es completamente diferente y de alguna manera está asociado al territorio. Eso debe ser tenido en cuenta en el momento de medirse la gestión. Así mismo, la constancia y reconocer los esfuerzos de las entidades para no abandonar a mitad de camino los procesos de formación, es una labor en la que debemos seguir trabajando. Para ello, hemos buscado que el emprendedor comprenda que los servicios de formación son gratuitos, pero si no los culminan, deben pagar. (Cámara de Comercio del Cauca, $\left.2019^{8}\right)$.

Por otra parte, desde la entidad se ha querido trabajar en forjar el esfuerzo de los emprendedores. La gratuidad no es precisamente una herramienta que siempre traiga consigo resultados positivos y por ello, es necesario asignar en algunos casos tarifas muy asequibles y evitar el subsidio del $100 \%$. Sin embargo, ello requiere de formar cultura, y sus efectos se evidencian a mediano y largo plazo.

Actualmente, no existe en el municipio de Popayán un sistema de información conocida por el ecosistema de emprendimiento que permita identificar a las entidades que acompañan el emprendimiento y a su vez, a los emprendedores

8 Información primaria proveniente de los emprendedores entrevistados. 
tanto formales como los que no lo son. De este modo, existen brechas que deben irse cerrando, y la única manera, es trabajar de manera articulada desde la institucionalidad pública y privada, destacando el rol que cada organización tiene para con la región. Sin duda, es necesario mencionar que el sector público se ve afectado por la temporalidad de sus gobernantes, lo que fractura la continuidad de los procesos, y en estos casos, deteriora el camino logrado.

De este modo, el emprendimiento requiere de asociatividad. Una de las apuestas del departamento del Cauca a la que la Cámara de Comercio le ha apostado, es a generar dinámicas de asociatividad, desde la estructuración y puesta en marcha de grupos productores en los que todos terminen ganando. Es necesario pensarse como miembro de asociaciones. Este enfoque también se quiere llevar a la Costa Pacífica.

Estamos identificando la relación de las asociaciones de pescadores de Guapi y determinar el volumen de producción con el fin de adelantar estrategias para acercar al productor con el comprador. Queremos, por ejemplo, que los mejores restaurantes de Bogotá puedan conocer de primera mano los productos de Guapi, que conozcan el producto y con ello, generar el canal de compra inmediato. Eso va de la mano con el suministro de energía y recuperar las camaroneras. Empezar a generar esa dinámica en que todo ese liderazgo tenga un efecto positivo dentro de la economía agrícola del Cauca, es el primer paso para transformarla en agroindustria.

Sin embargo, esa visión de largo aliento debe fomentarse al interior de las organizaciones con los equipos de trabajo. En el Cauca, y específicamente en Popayán, existen organizaciones con alcance departamental, incluso local, que, por aspectos de operatividad, no logran conocer que hacen como un todo al interior de sus empresas. Ello dificulta, ampliar el espectro y pensar en procesos de innovación que generen alto impacto. Al respecto la presidente ejecutiva de la Cámara de Comercio del Cauca, apoyándose del caso particular de su entidad, expresa que es necesario: Abrir espacios para dar lluvia de idea entre 
los colaboradores. Empapar a áreas que hasta un tiempo no conocían de lo que estaba pasando en el sector, entonces por ejemplo tecnología siempre ha estado muy pendiente que el computador funcione, que los reportes salgan, financiera, pendiente que los cheques salgan a tiempo, pero no han tenido tiempo de conocer que hace el otro y, por tanto, cual es la visión global de la organización. En ello, ya hemos avanzado. Lo que sigue, es una escuela de formación de líderes, que involucre no solamente a los directores, sino también a los coordinadores. Los colaboradores deben saber cómo funcionan las áreas de sus demás compañeros y nosotros debemos fomentar el liderazgo colectivo, específicamente el intra emprendimiento, porque hay un gran talento. (Ana Fernanda Muñoz, Presidente Ejecutiva, $\left.2019^{9}\right)$.

Ahora bien, relacionando los aspectos a fortalecer en el entorno, específicamente para los emprendedores, se destaca la parte financiera.

Muchos emprendedores llegan aquí y en la estructura financiera ni siquiera está el sueldo de ellos, entonces están vendiendo productos, pero ni siquiera están ganando. No saben cómo estructurar costos. Nosotros les estamos haciendo ese acompañamiento y nos está yendo muy bien, pero es necesario que otras entidades hagan lo mismo. Es necesario enseñarles, además, como vender su idea. Los emprendedores tienen ideas muy buenas, pero a la hora de venderla no saben cómo hacerlo. (Marcela Valencia Banguero, Coordinación del área de Desarrollo Empresarial, Cámara de Comercio del Cauca, $\left.2019^{10}\right)$.

Se puede asegurar que la cultura del emprendimiento se ha ido fortaleciendo en la ciudad de Popayán. "Aparecieron aspectos interesantes en programas como Ingeniando. Lo que había llegado en los primeros modelos, a lo que está llegando ahora, nos demuestra que el imaginario en Popayán ha ido cambiando. 
Somos principalmente del sector de comercio, donde se compra y se revende, que fue lo primero que llegó cuando iniciamos con esta estrategia. Ahora, son ideas verdaderamente innovadoras. Por ejemplo, una joven transformó las hojas de la piña, en producto deshidratado y genera un producto similar al cuero. Hay entonces, ideas de negocio, diferentes, hay cadena de valor. Eso es esencial en estos procesos.

A eso se refiere la Cámara de Comercio del Cauca, cuando indica la necesidad de salir del concepto del emprendimiento de subsistencia, y trabajar de forma articulada con otras entidades especializadas en aspectos como las TIC. Sin embargo, es necesario seguir promoviendo la importancia que trae consigo la formalidad. Existen procesos de innovación que se están gestando desde estudiantes de colegios que requieren ser escuchadas y apalancadas con recursos mediante convocatorias. Lamentablemente las entidades se encuentran enfocadas a personas mayores de edad, sin embargo, sería interesante considerar un mentor que los acompañe en el proceso y permita asegurar la inversión de los recursos.

\section{Oficina de Gestión de Empleo y Emprendimiento del Municipio de Popayán}

El municipio de Popayán ha venido incorporando en su planeación, el emprendimiento como estrategia hacia la consecución de mayores oportunidades, mejorar la calidad de vida y promover un desarrollo humano integral de los payaneses. Desde el Plan de Desarrollo Municipal de la administración que estaba vigente para la fecha del presente libro "Vive el Cambio" (periodo 2016 a 2019), en su línea estratégica dos: desarrollo económico incluyente y competitivo, se planteó como primera iniciativa de gestión, el programa Empleo, emprendimiento 
e innovación, cuya finalidad buscó "promover condiciones laborales enmarcadas en la política de trabajo decente, que generen un ecosistema de emprendimiento e innovación, que asegure oportunidades de empleo con valor agregado, eficiencia, creatividad y competitividad para todos los ciudadanos con inclusión y accesibilidad” (Plan de desarrollo 2016 - 2019).

El proceso de Gestión de Empleo y Emprendimiento de laSecretariadeDesarrollo AgroambientalydeFomentoEconómico, buscó fortalecer y fomentar la cultura de emprendimiento en el municipio de Popayán, tomando como marco de referencia el Plan de Desarrollo Municipal, y su línea estratégica. Entre los indicadores sobre los que la Alcaldía Municipal direccionó su gestión, se encuentra:

Tabla 8. Indicadores del Plan de Desarrollo Municipal 20162019

\begin{tabular}{|l|l|}
\hline & INDICADORES PLAN DE DESARROLLO 2016 - 2019 ADMINISTRACIÓN "VIVE EL CAMBIO" \\
\hline 1 & 1 política Pública de Emprendimiento en operación \\
\hline 2 & 300 emprendimientos fortalecidos en sus procesos organizativos \\
\hline 3 & 200 emprendimientos que reciben capital semilla \\
\hline 4 & 9 centros Locales de Atención y Vivero Empresarial fortalecidos y operando \\
\hline 5 & 1 ecosistema de emprendimiento fortalecido \\
\hline 6 & $\begin{array}{l}50 \text { instituciones Educativas y de Formación para el trabajo que apropian el programa de pensamiento, emprendimiento } \\
\text { y escuela }\end{array}$ \\
\hline 7 & 4 emprendimientos dinámicos en turismo, cultura, agroindustria, textil y "TIC," creados \\
\hline 8 & 1 Centro Textil fortalecido generando nuevas líneas de negocio \\
\hline 9 & 1 observatorio Regional de Mercado de Trabajo ORMET fortalecido \\
\hline 10 & 1 plan de empleabilidad a padres con niños, niñas y adolescentes trabajadores estructurado \\
\hline 11 & 1 programa de formación para el trabajo de la población en situación de discapacidad promovido \\
\hline 12 & 2 estrategias públicas y privadas que promuevan la empleabilidad de la población joven identificadas \\
\hline 13 & $\begin{array}{l}4 \text { campañas de promoción del teletrabajo realizada en empresas y entidades del sector público enfatizando en grupos de } \\
\text { población } \\
\text { prioritarios }\end{array}$ \\
\hline 14 & 4 campañas para la promoción de la ciencia, tecnología e innovación en las empresas y emprendimientos. \\
\hline 15 & 1 estrategias de Presupuesto participativo implementado \\
\hline
\end{tabular}

Fuente: Elaboración propia a partir de la revisión documental.

Sin embargo, uno de sus actores de interés priorizados, fueron las madres cabeza de familia, especialmente, enfocándose en los procesos organizativos y comerciales a través de estrategias de formación, labor desempeñada en alianza con entidades como el Servicio Nacional de Aprendizaje - SENA, la Universidad del Cauca, Fundación Universitaria de Popayán, Universidad Autónoma, Institución Universitaria Colegio Mayor del Cauca, e instituciones de formación para el trabajo y el Desarrollo 
Humano. Estos procesos formativos fueron realizados en las 9 comunas del municipio de Popayán, a través de los centros locales de atención y vivero empresarial (puntos CLAVE), como parte de la descentralización de los servicios que ofrece el proceso de gestión de empleo y emprendimiento. En articulación con secretarias y dependencias de la administración, también se adelantaron proyectos de formación en emprendimiento que incluyó diferentes tipos de poblaciones, incorporando programas existentes como el de Mujer con equidad, Diversidad Sexual, Jóvenes por el Cambio, Afrodescendientes, Familias en Acción, impactando comunidades afrodescendientes y población víctima del conflicto armado. Durante las vigencias 2016, 2017, 2018 y 2019 la oficina de empleo y emprendimiento del municipio, brindó capacitaciones a 600 emprendimientos principalmente en la elaboración de planes de negocios y estrategias de comercialización, generando espacios para dar a conocer sus productos y otorgando capital semilla a 250 emprendimientos como estrategia de fortalecimiento.

Este proyecto que aporta al indicador dos, de la tabla anteriormente expuesta, buscó fortalecer emprendimientos existentes que requieren comprender el funcionamiento administrativo y comercial de sus unidades de negocio, dirigido principalmente a pequeñas y medianas empresas. Acciones encaminadas hacia la mitigación los índices de desempleo, incentivando la generación de ingresos, a través del autoempleo y la generación de puestos de trabajo adicionales.

Para lograr estos resultados, ha sido necesario determinar un camino a seguir por parte del municipio, que se unifica a través de convocatorias anuales. "Nosotros abrimos convocatorias, ya sean para dar talleres con una duración de 2 a 3 meses. Los emprendedores vienen, toman las capacitaciones y al final se les da un reconocimiento. Como producto se espera el plan de negocios. También brindamos talleres cortos de dos o tres días. Cada año, abrimos una o dos convocatorias para que se presenten y accedan a un recurso económico. Lo anterior, se complementa 
con el programa de Noche de Museos, espacio que se habilita en el centro histórico de Popayán y zonas estratégicas de la ciudad. Se les invita a participar el último viernes de cada mes. También se abren espacios en ferias de otras entidades, para que puedan participar".

En este proceso de acompañamiento, existen diferentes casos exitosos por mencionar. Por ejemplo, uno de ellos, está relacionado con un emprendedor de 21 años dedicado a la producción de calzado, actividad que desempeña por vocación familiar. "Los padres con su empresa familiar habían enseñado a sus hijos el funcionamiento del negocio. Posteriormente, su hijo residente del barrio Lomas de Granada, decidió crear su propia empresa, asistió a todas las capacitaciones que dimos. Después ganó la convocatoria y accedió a ocho millones de pesos (\$8.000.000). Con ello mejoró su maquinaria, insumos y empezó hacer el calzado. Se ha presentado a varias ferias de emprendimiento con su calzado casual deportivo con su propia marca. Como esos, existen diferentes casos como elaboración de pulpas de frutas, entre otros". Es un caso que demuestra que la persistencia y el acceder a este tipo de instituciones, trae resultados positivos.

De igual forma, desde el enfoque de empresarialidad, el municipio también realizó acompañamiento desde el fortalecimiento de empresas constituidas a través de talleres y en alianza con otras entidades que se vienen especializando. Por ejemplo, se adelantó un ejercicio con el Clúster Creatic, dirigido a empresas que requerían conocimientos en TIC, mercadeo, jurídica, entre otras temáticas; además del desarrollo de concursos en alianza con entidades como la Corporación 'Ventures', reconoció los logros a emprendedores.

También participó activamente en las reuniones de la Red Regional de Emprendimiento del Cauca, apoyando la realización de eventos como Cauca Emprende, y el diseño del plan estratégico y de trabajo de la red, permitiendo el fortalecimiento del ecosistema de emprendimiento en el Cauca. 
La asociatividad en el emprendimiento como estrategia de desarrollo, es de gran importancia y ha sido una apuesta del municipio de Popayán. De este modo, mediante convocatorias se han acompañado principalmente en este aspecto a los sectores de turismo, gastronomía, agroindustria, educación, tecnologías de la información y la comunicación. Al respecto, entre experiencias destacadas se encuentran: "Fortalecimiento de la "Corporación Get Up And Go Colombia (๑), organización que promueve el turismo en Popayán, vinculando emprendedores que se han visto afectados por el conflicto armado a través de actividades y proyectos, convirtiendo los antiguos territorios de guerra en destinos culturales y gastronómicos para turistas nacionales y extranjeros (Get Up And Go Colombia) ${ }^{11}$. Entre las actividades que desarrollan, se encuentran los city tour. Su interés, fue crear un café donde pudieran atender a los visitantes en su propio establecimiento comercial. Esta organización se fortaleció desde la parte organizacional y comercial. Se les dio un capital semilla de veinticinco millones. Así mismo, se hizo con la cooperativa red mesa larga, quienes han conservado las recetas y platos tradicionales de la ciudad de Popayán, ofreciendo a turistas y locales la gastronomía típica Payanesa. Por otra parte, se fortaleció la precooperativa café la Rejolla y la Asociación de productores de café y panela de las Mercedes, entre otros emprendimientos asociativos que incluyen fundaciones, asociaciones, cooperativas, ONG y precooperativas. El fortalecimiento se realizó en maquinaria, equipos, tecnología, insumos, solo por mencionar algunos casos. Además, se les brindó un espacio para que los emprendedores pudieran dar a conocer sus productos en las diferentes ferias, muestras empresariales, ruedas de negocio, por ejemplo, en el evento Cauca Emprende, Noche de Museos, que es un evento realizado el último viernes de cada mes durante el cual la ciudadanía puede conocer emprendimientos locales.

Se fortalecieron los sectores en los cuales la ciudad tiene mayor vocación. En el año 2017, en el marco del programa de Ciudades Sostenibles y Competitivas (CSC), programa mediante 
el cual Findeter, junto al Banco Interamericano de Desarrollo BID, impulsan el desarrollo sostenible de las ciudades intermedias del país, desarrollando con cada una de ellas, una visión a largo plazo $^{12}$ (Findeter, 2019), Popayán, accedió al estudio "Popayán, ciudad sostenible y competitiva" que le permitió identificar ciertos sectores con mayor potencial, entre los que se destacaron, el de la informática y comunicaciones, educación, agroindustria, gastronomía, recurso hídrico, entre otros ${ }^{13}$.

Buscando promover y fortalecer la cultura de emprendimiento en 41 instituciones Educativas y de Formación para el trabajo, se diseñó la cartilla aprender a emprender, la cual es una cartilla didáctica elaborada con el objetivo de ser utilizada por docentes y estudiantes de las instituciones educativas como guía para iniciar emprendimientos escolares desarrollando creatividad, confianza y pensamiento positivo.

Es el resultado de la articulación con la academia, no solo con programas de las ciencias contables, económicas y administrativas, sino con programas de salud, como Fisioterapia y enfermería, disciplinas que han aportado a los emprendedores en aspectos como el diseño de esquemas en Seguridad y Salud en el Trabajo, prevención y promoción de la salud. Los jóvenes por su parte, visitan a los emprendedores para conocer en qué condiciones están trabajando, enseñándoles buenas prácticas.

Con respecto a esas necesidades que se han identificado de los emprendimientos y el balance que se ha hecho durante estos años de la administración, se evidenció que la demanda es muy superior a la oferta. En ese sentido, la fuente de financiación de emprendimientos con capital semilla no es suficiente.

Un aspecto de gran valor, es la financiación. Lo que se espera desde el municipio de Popayán, es aportar mediante capital semilla, fortaleciendo a empresas en funcionamiento, que tengan

12 https://www.findeter.gov.co/publicaciones/40037/ciudades_sostenibles_y_competitivas/ 13 https://issuu.com/ciudadesemergentesysostenibles/docs/pub_2016_popayan_col_ces_2018 
validado su producto. Se ha estudiado la posibilidad de articularse con entidades financieras, que, en este caso, estén trabajando para emprendedores.

También es de mencionar el proyecto que se adelanta con el IMPEC, Reclusorio de hombres. Ellos cuentan con unidades productivas que involucran procesos del sector agropecuario, agroindustrial, confecciones, marroquinería y desde el municipio de Popayán, se les ofrece servicios que les permita promocionar a través de piezas publicitarias sus servicios, articulado con medios de comunicación.

Bajo la figura de convenios, se espera diseñar un modelo de financiación mediante una contrapartida, y así brindar una tasa subsidiada para emprendedores, con el fin que ellos puedan beneficiarse. Se espera lograr impactar a unos 250 emprendimientos, para que accedan a tasas muy bajas en comparación con las que se ofrece en el mercado. Sin embargo, es de resaltar que "en estos años de ejecución, hemos fortalecido con capital semilla más de 250 emprendimientos con montos que van desde los 8 millones, 2 millones y en el caso de emprendimientos asociativos, 25 millones para cada emprendimiento, fortaleciendo a 17 de ellos".

\section{Servicio Nacional de Aprendizaje Sena}

Desde el SBDC Centro de Desarrollo Empresarial del SENA, Martha Lucia Vivas Pérez - Líder de la Red SBDC Regional Cauca, y Catherine Lozada - Profesional de apoyo en emprendimiento, manifiestan que su operatividad se enmarca en la Ley de Emprendimiento, y la oferta de servicios tiene como objetivo, orientar y acompañar al emprendedor en toda la ruta, desde la ideación hasta el fortalecimiento empresarial. 
Como Servicio Nacional de Aprendizaje, ofrecen formación gratuita a muchos caucanos que se benefician con programas técnicos, tecnológicos y complementarios, enfocados en el desarrollo económico, tecnológico y social del departamento, en los que se promueve el emprendimiento, y próximamente esta competencia se impartirá en todas las titulaciones.

Dentro de las formaciones complementarias, y como primer pilar de la cadena de valor, se cuenta con el programa Sena Emprende Rural, un mecanismo de fomento para la generación de ingresos en la zona rural.

La cadena de valor de los SBDC, incluye formación para el emprendimiento, asesoría para la modelación, formulación de un plan de empresa, la constitución formal y legal de la empresa, el acompañamiento en la puesta en marcha de las mismas y su fortalecimiento. Bajo este modelo en el 2017 el SENA lanzó la Red SBDC.

La oferta de servicios incluye cuatro componentes, fomento a la cultura emprendedora, la cual llevan a cabo a través de charlas y entrenamientos; la asesoría para la creación de empresas por otras fuentes de financiación, es decir, si el emprendedor tiene algún recurso propio, quiere acceder a un crédito bancario, postularse a alguna convocatoria con otra entidad, entre otras, los SENA-SBDC les brindan acompañamiento para la formulación de un plan de negocio y así poder elegir la mejor opción para ello. También, el SENA ofrece su programa insignia denominado Fondo Emprender, catalogado como el capital semilla más grande que tiene Colombia, por lo tanto, es el de mayor interés para los emprendedores y cuenta con un gran reconocimiento a nivel nacional; y finalmente el servicio para el fortalecimiento empresarial, el cual consiste en un diagnóstico, la construcción de un plan de acción con objetivos estratégicos, cumplibles en un corto o mediano plazo. 
Todo esto se logra con un equipo de trabajo que permite gestar las dinámicas de apoyo a los emprendedores regionales. El SENA-SBDC cuenta con Gestores junior, senior y líderes de centro, quienes, de acuerdo a la trayectoria recorrida en emprendimiento, brindan asesoría a los clientes nivel I -emprendedores, y nivel 2 y 3- empresas, segmentados así de acuerdo a la etapa del emprendimiento.

Ante esto, y considerando la dinámica del departamento, Martha Vivas comenta que ha sido un reto gestionar dinámicas para los clientes nivel tres denominadas gacelas, empresas de rápido crecimiento y alto potencial.

Así, y contando con un equipo interdisciplinario, el talento humano del SENA propende por hacer un acompañamiento en la estructura del modelo de negocio a todos los sectores económicos donde se presente alguna idea empresarial. De este modo, se busca fomentar la cultura de emprendimiento en el Cauca, la región, y el país.

Gracias a nuestras formaciones SENA Emprende Rural y su presencia en los 42 municipios del departamento, se han gestado diferentes ideas de negocio materializadas en los sectores agrícola, pecuarios, artesanales, gastronómicos, de turismo, entre otros. También apoyamos las iniciativas de aprendices Sena, estudiantes universitarios y profesionales.

Por citar un ejemplo de éxito, el SENA-SBDC Cauca apoyó la implementación de Miski, una empresa beneficiaria del Fondo Emprender, la cual también ganó una de las versiones del concurso Ingeniando de la Cámara de Comercio del Cauca, y participó en una de las interacciones de Apps.Co; ha tenido diferentes líneas de negocio y ha generado nuevas oportunidades de empleo.

En el marco de los emprendimientos asesorados, son pocos los que han alcanzado la exportación, sin embargo, los proyectos empresariales de esta entidad le apuntan a ello, a fortalecer sus 
procesos de internacionalización y visibilidad de emprendedores regionales ante el mundo.

En el SENA “medimos el éxito del empresario de manera individual; se recalca mucho el hecho que, para ser exitoso, no necesariamente hay una medida estándar que lo califica así. Tratamos de potencializar cada negocio de acuerdo a su carácter y razón comercial, económica y social, además de fortalecer la visión del empresario y apoyar así la industria colombiana" (Martha Lucia Vivas Pérez - Líder de la Red SBDC Regional Cauca).

De esta manera, una de las estrategias para impulsar las medianas y pequeñas empresas son las agendas comerciales y de negociación que organiza el SENA, ya que es a través de ellas donde se fomenta el emprendimiento local, buscando además dar a conocer las potencialidades en cuanto a recursos, productos, creatividad, servicios, entre otras, que puede ofrecer el emprendedor caucano ante el mundo. De este modo, además, se fomenta la asociatividad entre empresarios, dada la necesidad del mercado o la oportunidad de crecimiento que se ve a futuro con dicha asociación para mejorar la calidad de la producción, reducir costos y ofrecer calidad en el producto que se requiera.

Para Martha Vivas el Fondo Emprender ha dado mérito a los pequeños y medianos empresarios del país, y es el servicios más demandado por los caucanos; hacemos semanalmente charlas de fomento a la cultura de emprendimiento donde ofertamos todos los servicios del SBDC, y un gran porcentaje de la población va especialmente para escuchar sobre el programa, ya que el Fondo Emprender es la fuente de capital semilla más grande que tiene Colombia, y bajo el cumplimiento de indicadores contractuales y de gestión se convierte en un rubro condenable. Este proceso incluye cuatro etapas, posterior a la verificación de requisitos, que consisten en evaluar la idea de negocio, entrenamientos para orientar al emprendedor en la modelación de su negocio, pitch y asesoría para la formulación de su plan de negocio. En 
este sentido, el proceso ha brindado la oportunidad de retar a los emprendedores, posibilitar la elección de iniciativas más sólidas y competitivas en el mercado.

Ahora bien, la formación de los profesionales que acompañan a los emprendedores es decisivo para lograr la calidad en el proceso. El SENA cuenta con un plan de desarrollo profesional para todo el equipo de gestores, y con el objeto de fortalecer sus competencias, se realiza un ejercicio articulador con aliados estratégicos.

Hablando como miembro de la Red Regional de Emprendimiento Cauca, Martha Vivas considera que debe haber una ventanilla única de atención para el emprendedor, con el objeto de direccionarlo en la ruta del emprendimiento, encadenado a la especialidad cada entidad y señala que están trabajando en ese proyecto. También resalta que se trabaja en la organización y ejecución anual de Cauca Emprende, el evento regional más grande de emprendimiento que ofrece dos escenarios: el académico y el comercial, convirtiéndose en espacios de formación, actualización y oportunidades de negocio para el crecimiento empresarial.

\section{Centro de Desarrollo Tecnológico Clúster Creatic}

El Centro de Desarrollo Tecnológico Clúster CreaTIC es una organización que promueve y fortalece el ecosistema de emprendimiento de base tecnológica en el departamento del Cauca. La unidad de Creación de Startup y la Unidad de Tecnología e Innovación con todo un equipo de trabajo promueven espacios en un entorno propicio para que las personas emprendan. Su dinámica se caracteriza por estar rodeados de profesionales, emprendedores y empresarios, que, desde conocimientos específicos y aprendizajes adquiridos con práctica, van dando las 
pautas a aquellos que llegan con el firme propósito de crear su empresa. De esta manera, su transitar por el emprendimiento se vuelve más ameno, evita cometer errores que otros ya cometieron, y si va a tener éxito, lo experimentan de manera rápida, ágil y a un muy bajo costo.

El Clúster CreaTIC, incorporó en el lenguaje de los emprendedores payaneses, el concepto de Startup. Lo han apropiado como un grupo de personas, mínimo dos máximos cinco, que tienen conocimientos específicos en disciplinas duras o blandas. "Estas personas se juntan y ofrecen un servicio o crean un producto tecnológico. Al principio, no tienen una metodología y experimentan una gran incertidumbre. Como mentores, brindamos el paso a paso para que lleguen a un puerto seguro y lo hagan rápido y barato" (Juan Carlos Adrada, líder de la unidad de creación de start-up).

Entonces en ese ejercicio, se evidencian necesidades a fortalecer. Una de ellas, es que los emprendimientos carecen de la posibilidad de conformar equipos de trabajo. No solo se ve en emprendimiento, si no a nivel institucional. La dificultad que existe para tener pensamiento asociativo, la tarea de tratar de unirlos o aliarlos con otros emprendedores, es difícil.

Cuando existen iniciativas similares, hay un cierto recelo, que evita la asociatividad y el trabajo en equipo. "Tenemos abundancia de emprendimientos que hacen desarrollo a la medida y cada quien lo hace por su cuenta; si ellos tomaran la decisión de juntarse podrían ofrecer servicios de desarrollo a la media en cualquier parte del mundo, con gran calidad y a precios muy competitivos" (Juan Carlos Adrada, líder de la unidad de creación de startup).

Si bien CreaTIC, está dirigido a emprendimientos de base tecnológica, usualmente asisten personas con ideas de negocios de otros sectores. Su trabajo, es tratar de vincular la tecnología a esas 
iniciativas que ya tienen. Por ejemplo, "si alguien vende zapatos, nosotros tratamos de decirles que puede hacerlo mejor si lo hace a través plataformas E-Commerce, en donde no solo podrá vender los zapatos que él produce, si no que puede vender los zapatos que producen otros zapateros u otras fábricas, convirtiéndose en un intermediario entre la gente que produce y la gente que consume, dedicándose mayoritariamente a la gestión de su plataforma de E-commerce y ganando mejores rendimientos y expandiéndose con mayor rapidez". (Juan Carlos Adrada, líder de la unidad de creación de startup).

Para su funcionamiento, el clúster cuenta de forma directa con dos asesores que guían el emprendimiento en sus primeras etapas, un equipo de diseño conformado por dos diseñadoras, que se aseguran que el emprendimiento tenga una adecuada presentación, incluyendo material gráfico idóneo para validar en el mercado y un equipo de comunicaciones, que apoya a los emprendedores en el manejo de redes sociales y comunicación asertiva.

Este proceso que se ha venido consolidando desde el 2014, logró ser certificado en el año 2016 en normas ISO 9001, que, si bien no garantiza que los emprendedores serán empresarios exitosos, si le asegura dar los pasos correctos para que el emprendimiento de frutos con mayor rapidez.

La participación de redes como la Red Regional de Emprendimiento, así como actividades con instituciones de educación superior, han permitido promover y fomentar las buenas prácticas en emprendimiento.

Ha sido necesario para la gestión de startup, visitar instituciones, contactar docentes que lideran procesos de emprendimiento al interior de sus entidades con el fin de atraerlos y compartir con ellos la metodología y el proceso que no solo se abarca desde la Ruta Recrea, dedicada a la formación en emprendimiento, sino como un ejercicio articulador. 
A CreaTIC no solamente llegan emprendedores con ideas de negocio, también lo hacen empresarios con un portafolio establecido y ventas, además con procesos y procedimientos definidos. En este caso, no se ubican en una etapa inicial, sino en una etapa avanzada, recibiendo beneficios como el programa de aceleración de empresas" CreaTIC Accelerator", que permite identificar de donde provienen la mayor cantidad de ingresos de las empresas, ubicar posibles cuellos de botella y transformarlos para que sean más competitivas. Así mismo, ingresan a programas en alianza con la entidad ProColombia, institución especialista en procesos de internacionalización. También pueden aplicar a proyectos con la unidad PMO, identificar fuentes de financiación, participar de convocatorias y ganarlas, entre otros aspectos.

“Tenemos empresas muy reconocidas en el sector, que ya están explorando el mercado internacional mediante productos y servicios de tecnología y que tienen una gran proyección de crecimiento" (Juan Carlos Adrada, líder de la unidad de creación de startup).

Esto ha sido posible mediante la ejecución del proceso de Creación de Startups, ruta que consta de cuatro pasos claves. El primero denominado, descubrimientos de clientes, les permite a los emprendedores que solamente llegan con una idea, analizar y asegurar que su proyecto tenga cabida en el mercado y para eso hacen una serie de actividades, como Inteligencia competitiva, útil para identificar referentes competitivos que ya estén haciendo lo que el emprendedor apenas está pensando, encontrando así fuentes de aprendizaje e inspiración. Asimismo, generan modelos de negocio, basados en el método Lean Startup y finalmente aprendiendo y usando el marketing digital, ponen a prueba sus ideas de negocio en el mundo real a través de redes sociales. Esta etapa se fortalece con estrategias de sensibilización y cursos/ talleres de tecnología y negocios, orientadas a motivar a los estudiantes especialmente de instituciones a darse la oportunidad de iniciar con una idea de negocio. Para ello, la entidad cuenta con 
un programa denominado RecreaTIC, un espacio que permite de forma muy rápida, orientar talleres y charlas hacia temas relacionados con el emprendimiento.

Después de esos resultados, pasan a una segunda etapa denominada Validación de Clientes en donde inician el desarrollo de productos y servicios tecnológicos, generan un primer prototipo, se hacen pruebas de usuario, es decir se muestra a los clientes ese prototipo con el propósito de recibir retroalimentación y recomendaciones para sofisticarlo y lanzarlo al mercado como un producto terminado.

Con eso se avanza a una tercera etapa, creación de clientes. El producto cuenta ya con unos primeros clientes o con unas primeras ventas y la intención es fortalecer y crecer esas ventas. Puede haber algo de sofisticación de producto si se requiere, pero el enfoque es netamente comercial.

La última etapa, es Company Building, de desarrollo o construcción de la compañía, focalizado hacia un componente más gerencial. Las primeras etapas son de desarrollo de producto, desarrollo de cliente y la última etapa, es estratégica, donde se dota al emprendedor de capacidades o habilidades para la gerencia de su proyecto, enfatizando en procesos y procedimientos, calidad, internacionalización, entre otros. Se espera que en esta etapa el emprendedor tome la decisión si no lo ha hecho, y se formalice. $\mathrm{Si}$ bien es claro que la financiación es indispensable para materializar las ideas de negocio, la entidad no entrega recursos en efectivo a los emprendedores. Lo que hace es otorgar los espacios, profesionales, técnicas, metodologías y herramientas para que se pueda gestar el proceso de emprendimiento.

Cuando necesitan capital semilla, lo que hacemos es vincularlos con nuestra unidad de proyectos PMO que se encarga de vigilar y encontrar convocatorias que puedan beneficiar a los emprendedores, y los que están interesados en descargar el 
recurso, aplican. Nos hemos aliado con el Fondo Emprender del SENA, logrando a la fecha más de diez emprendimientos que han sido beneficiados con el fondo. (Juan Carlos Adrada, líder de la unidad de creación de startup, $2019^{14}$ ).

Es de recordar que el Centro de Desarrollo Tecnológico Clúster Creatic, fue beneficiado por el Sistema General de Regalías SGR con el proyecto denominado "Fortalecimiento de capacidades de empresas de base tecnológica TIC del Cauca para competir en un mercado global", cuyos recursos fueron por diez y seis mil quinientos millones de pesos (\$16.000.000.000). Recursos destinados a la creación de un Clúster en Operación que fomente el emprendimiento de base tecnológica, a la financiación de programas de aceleración ( 5 en total), créditos condonables para estudiar maestrías y doctorados nacionales o internacionales, espacios de trabajo (CO-working), maratones de desarrollo tecnológico, misiones comerciales y toda serie de actividades que fortalezcan la industria TI del Cauca.

En relación a los reconocimientos, el CDT Clúster CreaTIC ha tenido importantes logros, entre ellos se destaca que Colciencias reconoció a CreaTIC como Centro de Desarrollo Tecnológico, es decir, uno de los actores del Sistema Nacional de Ciencia Tecnología e Innovación SNCTeI, desarrollando investigación interdisciplinar e intersectorial para la generación y uso social del conocimiento. Así mismo, El Centro de Desarrollo Tecnológico Clúster CreaTIC es miembro oficial de la red de aceleradoras de la alianza del pacífico AcelerAP, que permite que las empresas de tecnología puedan abrirse mercados en países como Chile, Perú y México. Además, es reconocida por Apps.co como única entidad en el Cauca para desplegar la metodología de emprendimiento denominado "Descubrimiento de negocios digitales" y que en septiembre desplegará la segunda versión justo en las instalaciones de CreaTIC.

14 Información primaria proveniente de los emprendedores entrevistados. 
Producto de ese ejercicio, fue posible lograr el primer grupo de 15 emprendimientos de descubrimientos en negocios digitales, de los cuales tres fueron reconocidos por contar con un buen modelo de negocio y estructuración de producto. A nivel internacional, se proyecta beneficiar emprendedores con posibilidades de ingresar a mercados en Latinoamérica como México, Chile, Perú de una manera más fácil.

Siendo un proyecto de regalías, el principal indicador asociado a la gestión, estaba relacionado con incubar doscientas nuevas iniciativas empresariales, siendo superada la meta, logrando 215, sin embargo, este no es el único. Específicamente, los indicadores de la unidad de Startup son:

Tabla 9. Indicadores emprendimientos incubados y empresas aceleradas 2014-2019

\begin{tabular}{|c|c|c|c|c|c|}
\hline $\mathbf{N}^{\circ}$ & Indicadores & Valores & & & \\
\hline 1 & Emprendimientos incubados & 436 & & & \\
\hline 2 & $\begin{array}{l}\text { Emprendimientos incubados } \\
\text { de base tecnológica }\end{array}$ & 200 & & & \\
\hline 3 & Empresas aceleradas & 50 & & & \\
\hline \multirow{3}{*}{4} & \multirow{3}{*}{ Empresas formalizadas CCC } & \multirow{3}{*}{103} & \multicolumn{3}{|c|}{ Régimen } \\
\hline & & & Común & Simplificado & Especial \\
\hline & & & 56 & 44 & 3 \\
\hline 5 & $\begin{array}{l}\text { Registros C.C.C Durante el } \\
\text { proceso Startup }\end{array}$ & 56 & & & \\
\hline
\end{tabular}

Fuente: Centro de Desarrollo Tecnológico Clúster CreaTIC

Los resultados alcanzados son insumos para adelantar producción científica que es publicada en revistas indexadas y que permiten visibilizar los esfuerzos, además de generar y transferir nuevo conocimiento.

En ese sentido, se considera que la cultura del emprendimiento se ha ido fortaleciendo. En años anteriores, la entidad comenta que eran muy pocos los que llegaban a contar 
sus ideas, además porque eran muy débiles en comunicaciones. A la fecha, las entidades y la ciudadanía, los reconoce, y llegan a diario nuevas personas a iniciar el proceso. "Llegan nuevos emprendedores a contarnos sus sueños, porque eso es lo que hacemos, escuchar los sueños de la gente y nuestra intención, es ayudar a aterrizarlos y a que los ejerzan. Entonces ha servido todo el trabajo que hemos hecho en espacios como Recrea, Startup Creatic, las charlas que vamos a dar en las universidades, los profesores que nos visitan, las publicaciones que hacemos en redes sociales, coadyuvamos a que cada vez más gente que esté con la intención de emprender y emprenda y lo haga apoyándose de la tecnología" (Juan Carlos Adrada, líder de la unidad de creación de startup).

Debe seguirse fortaleciendo la cultura de emprendimiento, mediante eventos de región. Entre ellos, se menciona algunas iniciativas como el Emprendetón o Cauca Emprende, que se hace a finales del año. Este tipo de eventos deben fortalecerse con fondos de inversión.

Los chicos llegan con muy buenas iniciativas, son súper pilos, llegan a tener clientes, sin embargo, necesitan fuentes de financiación. Popayán es una ciudad que tiene dinero, por eso tiene todos los bancos, pero no se ha creado una cultura fuerte de inversión. Si la gente que tiene los recursos, supiera que hay unas muy buenas iniciativas tecnológicas, unos muy buenos proyectos, seguro que invertirían. Para ello, hay que sensibilizarlos, hay que mostrarles cómo invertir, hay que mostrarles programas para inversores como Shark Tank (tanque de tiburones) cómo funciona, qué métricas pedir para que ellos se animen a invertir en estos chicos que son súper pilos. (Juan Carlos Adrada, líder de la unidad de creación de startup, $2019^{15}$ ).

15 Información primaria proveniente de los emprendedores entrevistados. 


\section{Fundación Universitaria de Popayán}

La Fundación Universitaria de Popayán, después de 35 años, ha logrado ser la institución de Educación Superior privada más grande de la región, conformada por más de 7.000 estudiantes de programas profesionales universitarios y tecnológicos, certificada bajo la norma ISO 9001:2015, que contribuye a la formación integral para el desarrollo sostenible de la Región y del País. Es una entidad comprometida con la identificación y solución de problemas regionales que a la fecha brinda los siguientes programas desde sus siete facultades:

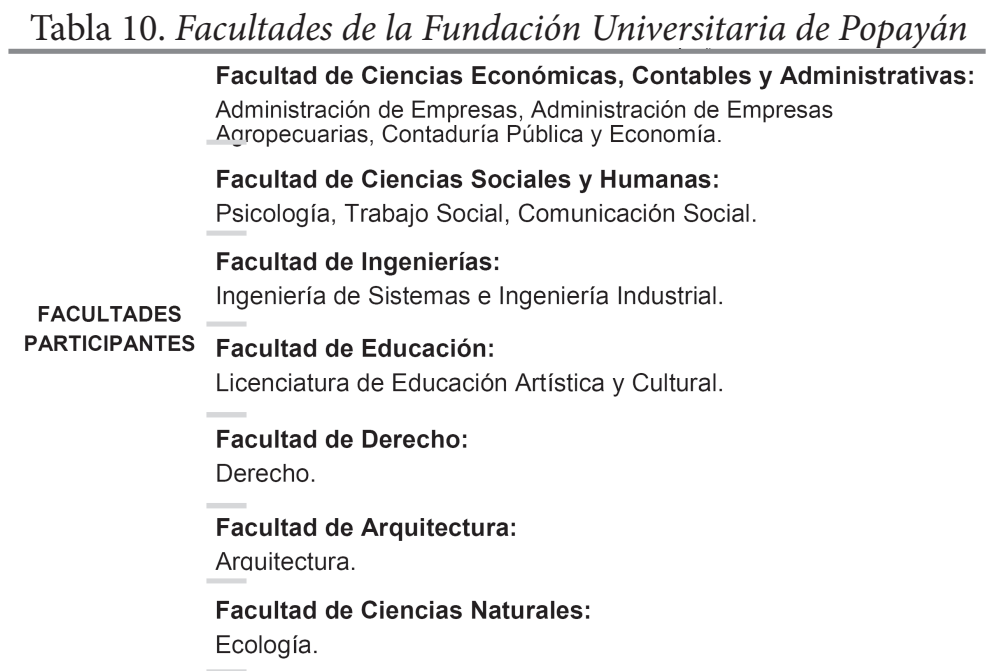

Fuente: Elaboración propia

En el año 2019, propuso a la Red Regional de Emprendimiento, adelantar un ejercicio de reconocimiento de las buenas prácticas de emprendimiento, desde los aprendizajes adquiridos por las entidades que lo acompañan, como desde las experiencias alcanzadas por emprendedores de la ciudad. Este ejercicio, avalado por las entidades que hacen parte de la Red, también fue realizado al interior de la institución, identificando los imaginarios de los docentes que estuvieron al frente del proceso. 
Es entonces como la construcción colectiva desde los programas académicos alrededor de esta iniciativa, evidencia la diversidad de pensamientos de la institución, entre otros aspectos, por el número de disciplinas que confluyen en ella.

El emprendimiento entonces se concibe desde varias ópticas según los campos disciplinares que convergen en la institución. Por parte de las ciencias económicas, contables y administrativas, se enfoca como la actitud para desarrollar proyectos que, desde un plano netamente económico, genere riqueza y satisfacción a necesidades específicas. Sin embargo, el aporte desde las ciencias sociales, lo visualiza como la capacidad transformadora del ser humano, que se refleja en la creación de productos de valor (en el ámbito económico), o en la solución a problemáticas del entorno (en los ámbitos social y ambiental). Como resultado, se logra la creación de valor que beneficia a la empresa, la economía y a la sociedad. De igual forma, es percibido como el inicio de una idea, procesos y acciones por parte de una persona o grupo, para generar ingresos, sostenibilidad y desarrollo a nivel social y empresarial.

Es la transformación del mundo a través de la transformación social, generando resolución de problemas en las relaciones humanas, su fortalecimiento e incremento del bienestar de las personas. Se interpreta el emprendimiento, como la capacidad de una persona para generar nuevas ideas y acciones, lo que las lleva a tomar la iniciativa de hacer parte de cambios sociales.

En un sentido más amplio, el emprendimiento es la forma de perseguir sueños, asumiendo riesgos y esfuerzos. Para ello, se requiere de habilidades y competencias necesarias para la vida profesional, con una visión clara de cómo hacer empresa desde su formación académica. Se infiere entonces que existe la necesidad de formar a los estudiantes en competencias emprendedoras desde semestres iniciales para que logren en su vida universitaria o al finalizar, crear empresa. 
Por ello, el emprendimiento son las acciones encaminadas hacia el desarrollo creativo del individuo para su realización personal. Es decir, el emprendimiento no solo se proyecta como una herramienta de generación de riqueza, sino que es un estado, donde se alcanzan competencias emprendedoras para la vida. Las personas que son emprendedoras, surgen en cualquier ámbito y si así lo deciden, generan empleo, o lideran procesos al interior de las organizaciones. El camino que decidan emprender los convierte por mérito propio, en un modelo a seguir.

El emprendimiento es importante para la institución, porque es generador de nuevas oportunidades para la creación de bienes y servicios, que impulsa el tejido empresarial, fortalece la economía local y genera empleo. Fortalecer a la región, a través de la producción de bienes y servicios, genera riqueza, satisface necesidades individuales y colectivas.

En este sentido, define el camino para que las personas no solo crean en sus sueños, sino que evalúan las posibilidades de implementar acciones que los lleven a cumplirlos. Contribuye en la formación personal de los individuos, convirtiéndose en una forma de vida que busca soluciones disruptivas a problemáticas determinadas.

Estimula la capacidad transformadora del ser humano, promueve la creatividad y la innovación. De hecho, llegar a una cultura de emprendimiento se ha convertido en uno de sus principales retos, pues se conoce la importancia que esta tiene en los índices de empleo del país y en la transformación social del territorio, además de su incidencia en la formación integral del ser humano. El emprendimiento apertura la posibilidad de tener economías dinámicas en las sociedades, $y$, por ende, condiciones de vida y estados de bienestar social. El emprendimiento posibilita orientar procesos comunitarios dirigiéndose a comunidades y organizaciones en la gestión de proyectos sociales a través del emprendimiento. 
Ofrece alternativas de empleo a los egresados, genera soluciones a las problemáticas de la región, del país y del mundo, además permite crecer económicamente y ser independientes.

El anterior escenario, pone de manifiesto la riqueza que aportan los diferentes campos disciplinares para la gestión del emprendimiento. Su articulación con los docentes que adelantan otras funciones propias del programa y que contribuyen a esta labor y el número de horas de dedicación según su tamaño, es un ejercicio que las instituciones adelantan y que aún se debe materializar a mediano y largo plazo.

De igual forma, identificar conductas emprendedoras e ideas de negocio desde semestres tempranos, así como, desde el segmento de egresados, con el fin de adelantar estrategias de sensibilización y socialización, como encuentros con las diferentes mesas de trabajo para la formulación de proyectos sociales, estudios de convocatorias para proyectos, monitoreo de resultados de investigación en emprendimiento, gestión de convenios con entidades públicas y privadas, recursos logísticos, informando y motivando a los estudiantes de forma articulada, es un aspecto a trabajar.

Existe entonces, la necesidad de revisar en las instituciones de educación superior, como diseñar una estructura unificada en red que atienda al proceso de emprendimiento coherente con la naturaleza de cada una, que propenda por dinamizar el diseño de estrategias, ejecución y acompañamiento del emprendimiento al interior de cada institución.

De igual forma, desde los lineamientos institucionales, promover la articulación con las demás funciones misionales (proyección social e investigación), encausándolos para que sus aportes también sevean reflejados en el campo del emprendimiento. Una alternativa de fortalecimiento financiero es el capital semilla, que se suma a otras modalidades que el emprendedor 
puede consultar como capital de riesgo, préstamos, financiación e inversionistas, donde se contribuye financieramente a los emprendimientos que se gesten desde la academia. Esta es una modalidad que podría ser evaluada y reglamentada mediante un fondo de fomento al emprendimiento de impacto institucional y operado a través de convocatorias internas de emprendimiento. Los beneficios son importantes en la medida que los estudiantes se motivan a presentar sus proyectos de emprendimiento e iniciar con un recurso económico desde la institución.

De igual forma, la gestión de ruedas de negocio de impacto regional y nacional, facilita que la comunidad universitaria interactúe con otros sectores interesados en invertir, además de ser un escenario de entrenamiento y validación.

Ahora bien, con respecto a la etapa de creación de empresa, es decir, el conocimiento de la iniciación de operaciones de los emprendimientos, su estado, maduración en el tiempo, requiere de una estrategia para lograr un mayor seguimiento y monitoreo de los mismos, así como una mayor conciencia en la trazabilidad documental. Lo anterior, traería grandes beneficios, entre ellos, un inventario del capital empresarial gestado desde la academia, y a su vez, un instrumento de retroalimentación para atemperar los planes de estudio y sus micro currículos a las necesidades del entorno.

En este sentido y frente al alcance de la ruta y la forma en la que sería conveniente proyectar el emprendimiento institucional, los docentes manifestaron que debería estar encaminado a la creación de cultura emprendedora con enfoque social y ambiental, esto, en concordancia con la realidad del departamento y los planes de gobierno. Manifestaron también que debería planearse, crearse y ponerse en marcha, programas asociados a las asignaturas, con enfoque en proyectos, que permita a los estudiantes hacer práctico su aprendizaje. 
Por otra parte, con respecto a las propuestas de módulos para la ruta, los docentes propusieron los siguientes módulos: Talleres de habilidades blandas que permita al emprendedor conocer sus pasiones e identificar lo que lo mueve. Legislación Comunicativa: no solo plasmar la normatividad si no ponerla al servicio de las personas. Introducción al emprendimiento. Responsabilidad social. Concientización socioambiental. Relación, sujeto y el entorno. Empoderamiento y apropiación comunitaria. Equilibrio y transformación de situaciones. Territorio, ruralidad y urbanidad. Habilidades de comunicación. Escritura. Contabilidad y finanzas. TIC. Modelo de negocios. Fuentes de financiación. Formulación y evaluación de proyectos. Empresarismo. Creatividad e Innovación. Prototipado. Marketing y ventas. Clientes. Ética y valores. Administración. Formalización. Investigación. Liderazgo. Validación.

Con estas propuestas, se logra identificar el interés por el emprendimiento en la FUP, al querer contribuir en el fortalecimiento de un ecosistema de emprendimiento local y regional. El enfoque de los docentes plantea apostarle a una creación de cultura emprendedora alrededor de los proyectos sociales y ambientales, más allá de la misma creación de empresa. Se sugiere crear una ruta que contenga los módulos básicos para la creación de un startup como son Modelo de Negocio, Inteligencia competitiva y vigilancia tecnológica, Prototipado, Marketing digital y validación, Contabilidad y finanzas. A esta podría sumarse algunas relacionadas con introducción al emprendimiento y habilidades blandas, creatividad e innovación y formulación de proyectos. De igual forma, se podría considerar módulos adicionales tipo "énfasis" dependiendo del programa, es decir, módulos con temáticas específicas como territorio, ruralidad y urbanidad, Proyectos sociales y Proyectos ambientales. Lo anterior, para el caso de la Fundación Universitaria de Popayán que podría ser el caso de más instituciones. 
Para ello, es necesario abordar estrategias como talleres, seminarios y formación en las generalidades del emprendimiento, liderazgo, comunicación, innovación, creatividad, focalización de ideas de negocio, ética profesional, puesta a prueba en el mercado con talleres de prototipado, modelos de negocio, administración, finanzas para emprendedores, proyectos, planeación prospectiva, marketing, normatividad, planes de negocio, formalización, responsabilidad social, conocimiento y gestión para la financiación externa.

Por otra parte, entre los desafíos que existe para el municipio de Popayán y la región, se encuentra la necesidad de generar espacios de retroalimentación y articulación, donde los pequeños emprendimientos puedan ampliar y perfeccionar su capacidad instalada para responder a mercados más exigentes. Se han adelantado algunas apuestas desde la Fundación Universitaria de Popayán, como la participación de redes como la Red Regional de Emprendimiento del Cauca, colectivos como la Fundación Innovamundo que hace parte de Empresas Junior, iniciativa que se abordará posteriormente en el documento, y la Red LEAC, a través de la cual, se adelantan intervenciones sociales conjuntas que posibilita crear e identificar emprendimientos.

Además, proyectos que estimulan la asociatividad entre programas con el entorno. Entre ellos, el proyecto del programa de Administración de Empresas denominado "diagnostico productivo y de comercialización. Proyecto participativo con las organizaciones sociales la hacienda el Chayani en el municipio de Cajibio - Cauca”.

Desde la Facultad de Ciencias Sociales y Humanas con el proyecto de investigación en articulación con el programa de Ingeniería de Sistemas y la comunidad Nasa Kite Kiwe, además del proyecto de Lotería Didáctica y el Software de Lengua Nasa del programa de Comunicación Social. 
Desde la Facultad de Educación, en el desarrollo de convenios con la unidad de emprendimiento del municipio de Popayán y el proyecto de investigación realizado en conjunto con el programa de Administración de Empresas Agropecuarias con la comunidad de Silvia, proyecto financiado por Innovación Cauca, entre otros.

La investigación como pilar misional, genera capacidades para la identificación de necesidades del entorno, promoviendo la innovación y la creatividad.

Sibien sevisualiza desdelas opciones degrado, la modalidad de proyectos de emprendimiento, se evidencia oportunidades de fortalecimiento en este aspecto especialmente en la labor de orientación de los mismos por los docentes, logrando encausar los proyectos a fines de mayor impacto.

Es importante resaltar que desde los semilleros de investigación se promueve el emprendimiento como una línea de investigación, sin embargo, en términos de productos, todavía está en su etapa inicial.

De este modo, sería una gran oportunidad, acompañar los ejercicios que se vienen gestando desde algunos programas académicos en temáticas como economía naranja, gestión social, emprendimiento de base tecnológica, innovación de productos, con el fin de articularlos a resultados de emprendimiento institucional, aspecto que aplica a las demás IES.

Ahora bien, si se toma como referencia el emprendimiento como investigación, se puede decir que todavía se encuentra en desarrollo en el entorno académico colombiano. Como evidencia, en el país se cuenta con la existencia de grupos de investigación enfocados al emprendimiento, el emprendedor y la creación de empresas. Interés que se debe principalmente a las universidades 
que abordan componentes como la creación de empresas, el emprendimiento, la innovación, la gestión organizacional y en algunos casos, la pedagogía o formación de emprendedores ${ }^{16}$ (Francisco Javier Matiz B*, 2009).

Se concibe la cultura del emprendimiento como el desarrollo de una visión global y de un liderazgo equilibrado de la gestión del riesgo, cuyo resultado es la creación de valor que beneficia a los potenciales emprendedores y que a su vez les permite desarrollar una manera de pensar y actuar, orientada hacia la creación de riqueza, a través del aprovechamiento de oportunidades. Es entonces, la actitud necesaria para establecer y ejecutar proyectos que generen desarrollo en la región, que posibiliten cambios y adaptaciones a ellos, son las creencias, hábitos, costumbres, y normas que comparten los individuos dentro del sistema organizacional.

Concibiendo la cultura del emprendimiento como un proceso que requiere reflexión permanente y que sus resultados son producto de una cultura institucional, se consideran algunas acciones desde la Facultad de Ciencias Económicas, Contables y Administrativas, en el marco de objetivos y estrategias claramente delimitadas, las siguientes: visitas académicas a grandes empresas eventos que promocionen a los egresados emprendedores, ferias o muestras empresariales y de proyectos, capacitaciones con invitados especiales, fortalecimiento de las opciones de grado, salidas técnicas, acompañamiento de iniciativas en emprendimientos, ferias empresariales, seminarios, conferencias, fortalecimiento de la proyección social como espacio articulador. Con respecto a la cultura del emprendimiento, para el equipo de docentes a cargo del emprendimiento, se concibe como la manera de pensar y actuar orientada hacia el desarrollo humano sostenible, considerando que existe al interior de los programas,

\footnotetext{
16 Investigación en emprendimiento, un reto para la construcción de conocimiento. Tomado de: file://C:/Users/USER/Downloads/480-Texto\%20del\%20 art\%C3\%ADculo-1907-1-10-20130803.pdf
} 
una cultura hacia el emprendimiento, que se promueve desde el desarrollo personal y gestión administrativa en la identificación de oportunidades de desarrollo (Financiación, apoyo logístico, generación de conocimiento) para los estudiantes y sus emprendimientos.

De igual manera, la cultura del emprendimiento la relacionan con el conjunto de valores, creencias, ideologías, hábitos, costumbres y normas, que comparte un grupo de personas hacia el emprendimiento, que surgen en la interacción social, generando patrones de comportamiento colectivos y estableciendo identidad entre sus miembros. Esta cultura para el emprendimiento puede lograrse con acciones basadas en la formación de competencias blandas y técnicas dentro del sistema educativo y su articulación con las necesidades más sentidas de la sociedad.

En este sentido, la cultura del emprendimiento se relaciona con organizar y gestionar las formas de vida de las comunidades y los sujetos para superar retos y problemáticas a través de una actitud innovadora, creativa y productiva.

Como estrategias adelantadas para lograr una cultura emprendedora, se incluye la orientación a los estudiantes a generar ideas, crear y aprovechar el capital intelectual para aportar a las comunidades y su entorno social, además de procesos de formación que fomenten el desarrollo de actitudes y aptitudes, además de, asignaturas específicas como la de Emprendimiento.

De este modo, la cultura del emprendimiento es una manera de pensar y actuar, que se orienta hacia la creación de un proyecto de vida, a través del aprovechamiento de oportunidades, del desarrollo de una visión global y de un liderazgo equilibrado, de la gestión de un riesgo calculado, cuyo resultado es la creación de valor que beneficia a los emprendedores, la empresa, la economía y la sociedad. En ese sentido, es lo que permite a una sociedad progresar económicamente y en otros aspectos, pues le que lleva 
a sus individuos a intentar nuevos retos y proyectos. Se centra en estrategias y actividades para fomentar, fortalecer y ejecutar ideas creativas e innovadoras con el fin de desarrollar proyectos que consoliden el emprendimiento.

Es permear a los estudiantes acerca de la creación de ideas, incentivar la creatividad, logrando que se viva un ambiente de investigación y generación de ideas. Para lograrlo, es relevante propiciar espacios para fortalecer procesos académicos enfocados al emprendimiento y comunicación.

La cultura del emprendimiento, se logra desde el desarrollo de competencias básicas, siendo transversales a todos los programas, destacando aquellas cualidades que los egresados desarrollan una vez terminen su plan de estudios basados en aspectos socioculturales, solución de problemas, trabajo en equipo y liderazgo, emprendimiento, comunicación desde la perspectiva del desarrollo sostenible como elemento fundamental de la misión Institucional.

Por tanto, el ecosistema de emprendimiento regional requiere de esfuerzos mancomunados hacia la misma dirección. Algunas acciones propuestas están relacionadas con fortalecer los encuentros de emprendedores a nivel regional con la unión universidad- empresa, laboratorios empresariales en los que exitosos empresarios transfieran su experiencia a los jóvenes emprendedores, concursos de proyectos empresariales, visitas a IES con el fin de brindar apoyo en el emprendimiento institucional, incrementar la difusión de los planes y programas de apoyo al emprendimiento, realizar procesos de articulación con las entidades que acompañan el emprendimiento mediante asesorías y apalancamiento financiero, formación en cultura emprendedora y empresarismo, financiamiento, beneficios tributarios para creación de nuevas empresas, identificación de fuentes de financiación reales para el desarrollo de emprendimiento. 
Desde la cadena de valor del emprendimiento, se requiere la formulación, puesta en marcha y aceleración, denotando la financiación de los emprendimientos. Generar más espacios de formación y desarrollo para los emprendedores (capacitación), además, de la oportunidad de vincularse fácilmente a redes de emprendimiento, así como a escenarios que permitan visibilizar sus iniciativas y establecer posibles alianzas estratégicas.

A su vez, mantener actualizado el pliego de las necesidades más sentidas del departamento a nivel social, lo cual permita a los emprendedores la formulación de proyectos encaminados a subsanar los requerimientos propios del contexto.

Generar mayor articulación a las Redes de emprendimiento del municipio con el sector educativo, logrando se incremente la participación de estudiantes y egresados. Es fundamental, contar con procedimientos claros para los emprendedores frente a rutas de constitución y formalización, así como mayor oportunidad de financiación. Lograr mayor visibilidad de las estrategias desarrolladas por los entes gubernamentales para el fortalecimiento de la cultura del emprendimiento en nuestro contexto. Valorar más los recursos para el sector del arte y cultura, como tangibles para el emprendimiento.

Más elementos de formación y de motivación para que los emprendedores sientan un acompañamiento por parte de las instituciones, además de fortalecer la protección intelectual. Fortalecer la cadena de abastecimiento, principalmente con productos transformados y no con productos básicos de materias primas, desarrollando productos o servicios que impacten positivamente el medio ambiente.

A pesar que la tendencia apunta a la base tecnológica, no se debe olvidar que la transformación y el desarrollo de productos tangibles son emprendimientos que generan un impacto social. Además, se requiere fortalecer infraestructura de la empresa, 
gestión del recurso humano, desarrollo de tecnología, marketing y ventas.

\section{Fundación Innovamundo Empresas Junior}

La Fundación Innovamundo Empresa Junior, es una iniciativa de las instituciones de educación superior de todo el mundo, en la que grupos de estudiantes dan consultoría a diferentes empresas, empleando sus conocimientos en la práctica real. Esta metodología está presente en Canadá, Brasil, Chile, Argentina, en 14 países europeos más y por primera vez en Colombia desde la gestión de la Fundación Universitaria de Popayán.

En este sentido, la Facultad de Ciencias Económicas, Contables y Administrativas, ha adelantado diferentes estrategias para fortalecer su articulación con el entorno y especialmente para contribuir a la cultura del emprendimiento de la región.

De este modo, el docente de la Facultad de Ciencias Económicas, Contables y Administrativas, Contador Público de profesión y magister en gestión y organización de proyectos, Andrés Felipe Aguilar Burbano, vinculado hace cinco años con la Fundación Universitaria de Popayán, interesado en el emprendimiento y en especial, en esta metodología, adopta un proceso investigativo, después de ejercicios previos que traía la institución a través de su cuerpo docente, entre los que cabe resaltar, exploraciones del impacto alcanzado del emprendimiento en Brasil.

En ese sentido, las Empresas Junior, son entidades que, articuladas con las instituciones de educación superior, contribuyen al crecimiento de la región, mediante la prestación de servicios de asesoría y consultorías en diferentes campos del conocimiento. Es así como la FUP formaliza la creación de la Fundación Innovamundo Empresa Junior, ante la Cámara de Comercio del Cauca, siendo su principal actividad económica, el servicio de asesoría y consultoría. 
Para ello, fue vital el conocimiento del contexto regional, además de reconocer las variables de articulación entre la academia y las organizaciones. Es así como desde esta apuesta, la Fundación Universitaria de Popayán pretende contribuir con un modelo de emprendimiento de carácter internacional, cuyo origen se da en Paris, se expande por Europa y América Latina y se consolida en Brasil, demostrando resultados y el alto potencial para la economía y entorno a la vinculación a redes de conocimiento especializado. Se ha venido trabajando en un modelo de emprendimiento, reconociendo con ello, las potencialidades que podría llegar a tener si se desarrolla en la región, adaptándose al contexto y a la realidad del departamento del Cauca. Es así como las universidades se convierten en las matrices que les otorgan a los emprendedores un capital semilla para que inicien su actividad y ellos mismos, se convierten en gestores de su organización, estructurando su proceso operativo, con un portafolio de servicios definido en asesoría y consultoría.

Se pretende entonces una cierta independencia, donde el estudiante se convierta en gestor, desarrollador de su emprendimiento y se motive a trabajar, teniendo como valor agregado, la consolidación en red entre empresas junior a nivel mundial. Así entonces, se van articulando con otras empresas junior de otras universidades y de esa forma, van integrando conocimientos, saberes, especializándose y van teniendo un mayor grado de aplicabilidad en el contexto.

Sin duda, Brasil es un referente importante en educación superior, ubicando a las universidades en los primeros lugares del mundo, condicionando entonces, la calidad de los estudiantes que egresan y que asumen el compromiso de ofrecer esas consultorías. Es así como el resultado de una red de este tipo, genera una apuesta integral desde la academia, así como el interés por apostarle a la cooperación. 
Desde una visión como confederaciones organizadas anualmente, adelantan congresos con capitales y grandes inversores, con empresas como Petrobras, Bradesco, entre otros, que demuestran la presencia de empresas interesados en apalancar estos emprendimientos nacientes.

Este tipo de metodologías tendrían un alto potencial de convertirse en una red global en emprendimiento, logrando una mayor dinámica entre estudiantes de diferentes áreas de conocimiento "por ejemplo, los estudiantes de ingeniería, terminan conectándose con los estudiantes de Administración de Empresas, y los del sector contable y financiero, con los de psicología. Entre los tres, integran un proyecto para ejecutar" (Docente Andrés Felipe Aguilar Burbano, Facultad de Ciencias Económicas, Contables y Administrativas).

Sería entonces importante pensar que este tipo de ejercicios al final contribuyen a futuro, en una cultura del emprendimiento. "Es una cuestión compleja cuando se habla de cultura, eso implicaría reconocer nuestras prácticas, nuestras costumbres, nuestro que hacer, sentir en relación con lo que nos rodea. Creo que nos falta trabajar mucho en eso. Si se quiere ver, desde un enfoque académico, los estudiantes deben empezar a reconocer su contexto inmediato, su municipio, su pueblo, su región" (Docente Andrés Felipe Aguilar Burbano, Facultad de Ciencias Económicas, Contables y Administrativas).

\section{Universidad del Cauca}

La Universidad del Cauca ha realizado diferentes esfuerzos para fortalecer su vínculo con el sector externo. Entre ellos, se encuentra la gestión adelantada desde la División de Innovación, Emprendimiento y Articulación con el Entorno -DAE de la Universidad del Cauca, instancia articulada a la vicerrectoría de investigaciones. 
La DAE actualmente cuenta con un área de transferencia de resultados de investigación, un área de Emprendimiento e Innovación, área de Interacción social y el área de relaciones interinstitucionales. Dentro de las áreas se brindan apoyo de $\mathrm{I}+\mathrm{D}+\mathrm{i}$, gestión del conocimiento, propiedad intelectual, apoyo a emprendimientos institucionales y apoyo a grupos de investigación, facilitando la articulación de la Universidad con el Entorno empresarial y la sociedad en general, contando, además, con el Centro de Apoyo a la Tecnología y la Innovación (CATI). Es desde allí, donde se gestan estrategias encaminadas hacia el fortalecimiento del Ecosistema de Emprendimiento e Innovación de la institución, siendo este, "un ente facilitador dentro de la comunidad universitaria para la generación de soluciones innovadoras y emprendimientos, a través del fomento de espacios de co-creación, cooperación y articulación con el entorno; fundamentado en la sinergia e interdisciplinariedad y búsqueda del fortalecimiento de la región y su transformación socioeconómica a partir del conocimiento como eje diferenciador" (Misión, Ecosistema de Emprendimiento e Innovación, Universidad del Cauca, 2019).

Entre sus objetivos estratégicos, se destaca desarrollar mentalidad y cultura emprendedora e innovadora en la comunidad universitaria, fomentar competencias para el emprendimiento y la innovación, promover en la comunidad universitaria la capacidad creativa e innovadora, asociada a la docencia y la investigación, articular y generar sinergias y escenarios de cooperación entre los actores internos y externos que participan en el ecosistema, establecer condiciones que soporten el desarrollo del emprendimiento y la innovación y promover la conversión del conocimiento en valor agregado para la sociedad a partir de la generación de soluciones, productos y servicios.

Estas apuestas han permitido destinar recursos para fomentar el emprendimiento. Cabe resaltar el acompañamiento y participación de la convocatoria 001-2019 «Apoyo a 
emprendimientos innovadores de Base Tecnológica de la Universidad del Cauca y la Convocatoria 002-2019 «Apoyo a emprendimientos innovadores, culturales y creativos - Cultulab de la Universidad del Cauca». Como resultado del 2019, se logró premiar a 10 equipos de emprendimientos, beneficiándolos con recursos aproximados de $\$ 10.000 .000$ pesos a cada uno reflejados en servicios técnicos, asesorías, capacitaciones y participación en eventos y/o misiones tecnológicas.

\section{Semillero de Emprendimiento e Innovación Start TIC}

Así mismo, al interior de las facultades de la institución se aborda el emprendimiento desde el interés de los estudiantes y docentes. Un caso de éxito, es el semillero de emprendimiento e innovación Start Tic con vigencia de 6 años, acompañado por la docente mentora, Eva Juliana Maya Ortiz, Ingeniera en electrónica y telecomunicaciones, magíster en ingeniería en el área de telemática y especialista en gestión pública.

Las apuestas desde el semillero, le ha permitido reflexionar ala institución y desde un contexto más próximo, a la facultad, sobre que es emprender, como resultado de un ejercicio de exploración del entorno, especialmente de referentes internacionales que están más adelante en estos temas.

De este modo, el semillero visualiza el concepto emprender como la relación que tiene con iniciar y terminar un proyecto, superando los obstáculos que se presentan, identificar problemas, oportunidades y brindar soluciones apropiadas, considerando el contexto. En ese sentido, emprender, está ligado a la innovación. Cuando se parte de un problema y se brinda una solución que genere valor, se genera procesos de innovación.

De igual forma, es válido pensar que no es emprender desde una mirada de investigación formativa. "emprender para nosotros, no es sinónimo de formar empresa ni un emprendimiento, y eso 
se sustenta, en los referentes y en una mirada propia construida en el tiempo. Tampoco somos una idea de emprendimiento, ni una incubadora. Con fomentar mentalidad, cultura y emprendimiento e innovación hemos tenido bastante trabajo durante estos seis años, entonces hasta ahí llegamos" (Eva Juliana Maya Ortiz, mentora Start Tic).

Start Tic, es un grupo estudiantil de diferentes programas académicos, que tiene como objetivo, fomentar mentalidad y cultura de emprendimiento e innovación. Su funcionamiento está propiciado por convocatorias semestrales orientadas a estudiantes. En ese sentido, el interés de los estudiantes de semestres anteriores, va permitiendo continuar con los procesos alcanzados, sin embargo, debido a la dinámica universitaria y al ser este un espacio voluntario, la rotación de los jóvenes es alto.

Para mí ha sido un reto tener chicos que vienen desde hace varios años y tener nuevos chicos. A todos tengo que llegarles con un mensaje agradable, por la misma naturaleza del semillero, diferente e innovador. Nuestras sesiones deben ser diferentes. Trato de involucrar y empoderar a los muchachos, que se sientan en su laboratorio, que puedan experimentar y desarrollar habilidades. Hasta ahora afortunadamente hemos mantenido un grupo sólido que va creciendo. El mismo semillero es un intra emprendimiento al interior de la universidad, porque no existía un grupo similar pensado hacia el emprendimiento e Innovación y cultura emprendedora. (Eva Juliana Maya Ortiz, mentora Start Tic, $2019^{17}$ ).

Por otra parte, desde una agenda semestral, se programan actividades en diferentes temáticas. Algunas de ellas, están orientadas a combatir los mitos que existen alrededor del emprendimiento y la innovación, y en aprender metodologías relacionadas con el alcance del semillero. También en desarrollar, habilidades y actitudes para fomentar mentalidad y cultura de

17 Información primaria proveniente de los emprendedores entrevistados. 
emprendimiento e innovación. Este camino ha generado resultados interesantes que han permitido participar a la institución a través de sus docentes, en convocatorias de Colciencias y convocatorias regionales para semilleros.

Es de recordar que los semilleros de investigación, están asociados a un grupo de investigación, en este caso, al grupo de ingeniería telemática, clasificado como A1 por Colciencias, siendo grupo multidisciplinar, respaldado por el Consejo de Facultad y por la Vicerrectoría de Investigaciones. Desde ese momento, los resultados son documentados en el Sistema de Información llamado SIRI, plataforma que ha permitido ir registrando proyectos asociados con convocatorias, eventos, entre otros. Precisamente como producto investigativo, la docente Eva Juliana Maya Ortiz, adelantó un artículo denominado "Start Tic: una experiencia de aprendizaje e innovación" en el marco del Encuentro Internacional de Educación en Ingeniería ACOFI, realizado en la ciudad de Cartagena en el año 2017, que da cuenta de las estrategias adquiridas desde la sensibilización y formación en emprendimiento.

Desde la experiencia del semillero, se evidencia que, para un estudiante, significa algo extra, un compromiso que va más allá de todas sus actividades académicas. En ese sentido, se intuye que los jóvenes vienen con la semilla, posiblemente por cursos de sus programas académicos, por referentes familiares o referentes más próximos. De igual manera, el voz a voz, posibilita motivar a más personas a que encuentren valor en lo que se hace. "Son los que ayudan a mantener la motivación del grupo. Ellos deben sentir la posibilidad de crear, de proponer, inventar, compartir y exponer. Los chicos del semillero, son jóvenes que les interesa desafiarse, y la academia debe facilitar dichos procesos".

Sin duda, la articulación con el entorno, ha permitido desarrollar eventos que han generado resultados interesantes. Uno de ello, realizado en el año 2017, por el Semillero de 
Emprendimiento StartTic, denominado, ¡Popayán i: inteligente, incluyente e innovadora!, posibilitó dar a conocer una muestra académica de más de ochenta proyectos de asignaturas, semilleros, grupos, trabajos de grado u otros sobre 1 de los 10 retos de ciudad, además de charlas y actividades sobre ciudades inteligentes a cargo del MinTIC y Huawei, un taller sobre Design Thinking y actividades de creatividad de StartTic,, reconocimientos y premios de los patrocinadores del evento.

Ello invita a reflexionar sobre el tiempo que requiere formar en emprendimiento. "el emprendimiento no es algo de un fin de semana, el prendimiento no es de 2 días, el emprendimiento un esfuerzo constante, permanente en donde la resiliencia, la empatía y van a salir, así como habilidades que se deben madurar" (Eva Juliana Maya Ortiz, mentora StartTic).

La financiación del semillero se ha venido realizando desde el interés de los estudiantes y docentes en participar de convocatorias internas y externas a la institución, así como desde la realización de eventos que otorgan otros incentivos que no son necesariamente recursos en efectivo, como el relacionamiento con empresas y directivos en búsqueda de talentos, conocer otros entornos, incluso internacionales, gracias a su persistencia, la conexión con estudiantes de otros programas de otras regiones con proyectos similares, entre otros.

Posteriormente a las convocatorias, en algunos casos es necesario presentar contra partidas y la institución apoya el proceso, pero es indispensable, ganar este tipo de ejercicios.

En ese sentido, desde la experiencia del semillero de Emprendimiento e Innovación Start TIC, se considera relevante ampliar la definición de emprendimiento en el ecosistema de la región. No solamente debería visualizarse como una forma de crear empresa, explorando los alcances que podrían llegar a tener en el entorno, la conexión del emprendimiento con la innovación, 
entendiendo esta como la solución de problemas reales. "Todos hacemos esfuerzos muy importantes de acercarnos a otras instituciones, organizaciones públicas, privadas, y evidencia un gran potencial, pero a veces trabajamos aislados. Entonces lo ideal sería, conformar un verdadero ecosistema como los que actualmente ya funcionan en el país" (Eva Juliana Maya Ortiz, mentora StartTic).

\section{Centro de Estudios y Servicios - CES}

El Centro de Estudios y Servicios - CES -, de la Universidad del Cauca, es una apuesta estratégica que busca promover la interacción entre la Facultad de Ciencias Contables, Económicas y Administrativas, y el medio externo, a través de "la gestión social, emprendedora y socio-académica, de esta manera, complementa la formación de profesionales idóneos y comprometidos con la región" (Universidad del Cauca, 2019).

Una de las líneas que abarca el Centro, es la unidad de emprendimiento e innovación, que a su vez cuenta con tres servicios. El primero, es el centro de información y asesoría, el segundo, consultoría empresarial, donde se aborda el desarrollo y aceleración de empresas, y finalmente, el observatorio.

Si bien, el Centro ofrece servicios a la facultad, su alcance es institucional, dirigido a toda la comunidad universitaria. Para su operación, se encarga a un profesor del programa de administración de empresas, con el apoyo de uno o dos profesores, y si se requiere de un tema específico, se aborda al o los docentes que se necesiten.

Así mismo, la participación de los estudiantes es muy importante, tanto para los procesos de aprendizaje como para acompañar a más estudiantes que lo requieran. En este espacio, se adelantan pasantías, prácticas, procesos de investigación, y según las necesidades, se van haciendo requerimientos a la facultad. 
Sin embargo, es importante expresar que la razón de ser del CES, no es promover el emprendimiento, ya que, para eso, se cuenta con la unidad de emprendimiento e innovación.

De este modo los estudiantes y docente coordinador, intervinieron indicando que primero fue necesario explorar si la Universidad quería darle una oportunidad al emprendimiento. "Evidenciábamos que la institución formaba para lograr buenos empleados, pero no buenos emprendedores. Para ello, se requiere formación y sensibilización hacia forjar ese espíritu empresarial, dar un salto al vacío y no ser parte del problema, sino ser parte de la solución. Entonces les preguntamos al estudiante si ellos querían emprender, evidenciando ideas de emprendimiento que no habíamos logrado capturar y que teníamos la responsabilidad de acompañar”. (Coordinador CES, docente Henry Ramírez).

Para ello, en primera medida, es necesario formar. "nosotros les preguntamos a los estudiantes que si querían dinero y ninguno dijo que sí. Pedían les enseñáramos y los acompañáramos, entonces con base en ese resultado, nació la brigada de emprendimiento. Primero para formar, segundo para asesorar, entonces ahí está la unidad de emprendimiento y el programa RIE y el consultorio empresarial que es aceleradora e incubadora". (Coordinador CES, docente Henry Ramírez).

A pesar que la institución ha adelantado iniciativas de emprendimiento, la unidad de emprendimiento es muy joven en su estructura, e incluye la formación, la investigación y la interacción social o proyección social. En el proceso de formación, está el programa RIE, que es la ruta de la innovación y el emprendimiento al emprendedor unicaucano con una mirada del contexto regional. También el consultorio empresarial, que a la vez surge como incubadora y aceleradora, que brinda acompañamiento al emprendedor y la aceleradora, que acompaña al emprendedor hasta que este pueda volar y conseguir proveedores, es decir, impulsarlo para crecer. Sin embargo, no se ha concebido el intra 
emprendimiento. "No lo hemos contemplado, estamos más orientados a formar las líneas empresariales, pero es una buena reflexión que deja este encuentro". (Coordinador CES, docente Henry Ramírez).

Sin embargo, es evidente que el intra emprendimiento se da de forma natural en la institución. "en todos los programas hay egresados que son intraemprendedores, que están aportando a nivel de empresariado nacional e internacional." (Estudiante, CES).

En ese sentido, se requiere identificar qué características alcanzan estos intra emprendedores y como la institución ha sido parte de ese proceso, con el fin de replicarlo en sus procesos de formación.

En este sentido, un estudiante que quiera recibir los servicios de la Unidad de Emprendimiento, puede desde el programa de formación, pasar por la ruta de innovación y del emprendimiento, iniciando con un proceso que le permita madurar la idea de negocio que tenga. Posteriormente, deben evaluar el componente financiero con el fin de determinar la viabilidad del negocio. Después, realizar un prototipado, continuando con el asesoramiento, integramos su negocio a eventos de la facultad, y llegan a Eureka, modelos cambas. Este espacio les permite someterse a un pitch, y los ganadores, son los que acceden a ferias empresariales con un stand.

\section{Eureka-E}

Eureka - E, nació como un proyecto de la Universidad del Cauca para generar puntos de encuentro entre estudiantes de diferentes facultades, con el fin de estimular la generación de ideas basadas en una problemática existente del ámbito regional, logrando, acercar a la institución, a otras organizaciones públicas y privadas del departamento del Cauca. 
Es así como desde la Facultad de Ciencias Contables, Económicas y Administrativas (FCCEA), se da pie para que, a través de docentes y estudiantes, este proyecto genere resultados de alto impacto.

De esta manera, el Profesor Titular, Reinaldo Erazo Rodríguez, contador, magister en Contaduría y Finanzas, con estudios en alta gerencia y mercadeo, y con experiencia en emprendimiento, empezó a explorar lo que, en su momento, se denominada actitud emprendedora frente a la vida.

Su paso por el Grupo de Desarrollo Empresarial en el SENA, que permitía a través de equipo de profesionales, asesorar empresas, especialmente, micro, pequeña y mediana, con una proporción muy pequeña de grandes organizaciones.

Posteriormente, la Universidad ICESI, decide explorar cómo hacer campamentos con niños, hijos de empresarios o hijos de trabajadores, para ampliar el horizonte más allá de considerar el empleo como una única forma de generación de ingresos. Es así como, un grupo de profesores, deciden acercarse a colegios públicos y privados, encontrando que el entorno condiciona de alguna manera, el comportamiento de sus habitantes, es decir, posiblemente, lo que el padre haya logrado o sus más sentidos fracasos, se trasladan a sus hijos, principalmente, para que estos logren vincularse laboralmente.

Después de un amplio recorrido por conocer el contexto, la Universidad del Cauca a través de su cuerpo docente y en compañía de las altas directivas, comprende que, de no crear ambientes para ayudar a emprender, difícilmente sería posible articularse con las necesidades del entorno. Se habla entonces de emprender y no de emprendimiento, a lo cual el docente Reinaldo Erazo Rodríguez, manifiesta que "cuando se toma la palabra desde la etimología, está dividida en dos partes, emprender, que es una actitud frente a la vida, y "miento" de mentir. En ese sentido, se 
asocia con el hecho que los estudiantes, tienen ideas y a veces, son muy salidas de la manga, sin ningún tipo de rigurosidad. Por ello, en el lenguaje académico, preferimos hablar de emprender y no de emprendimiento".

Al tiempo, se decide crear una unidad emprendimiento liderada desde la Facultad de Ciencias Contables, Económicas y Administrativas (FCCEA), que nace desde el interés de los docentes y el aval de la rectoría. En su entonces, el decano asume la responsabilidad frente al fondo emprender. Inicialmente, funcionaba para dar respuesta a necesidades específicas, logrando grandes experiencias especialmente en la presentación de proyectos a convocatorias externas. Posteriormente, por razones institucionales, la unidad de emprendimiento se acaba.

Después de varias exploraciones y de adquirir un camino de experiencias, nace la división de Articulación con el Entorno, adscrita a la vicerrectoría de investigaciones, resurgiendo con ello, el interés de seguir formalizando lo que muchas veces se hace desde la práctica, y es el ejercicio de emprender. Ahí desde un colectivo de docentes interesados, nace el ecosistema de innovación y emprendimiento.

Han sido diferentes los escenarios que ha abordado la Universidad del Cauca, que permiten asegurar que el emprendimiento no es un concepto nuevo y que, de forma casi obligada, es asumida por su comunidad. Fueron entonces diferentes proyectos e iniciativas que se gestaron con el afán e interés por fomentar la cultura del emprendimiento, y es ahí cuando nace de un proyecto de grado, EUREKA.

Eureka es un colectivo "sin ánimo de lucro que busca inculcar e incentivar el espíritu emprendedor, innovador y creativo de la comunidad universitaria, mediante la aplicación de talleres, concursos de ideas, bajo la dirección de personal especializado en materias como desarrollo de negocios, tendencias 
de mercado, metodología startup, entre otros. Se busca que los asistentes logren generar ideas de negocio que se transformen en futuros emprendimientos con alto valor agregado y así impulsar el desarrollo de la región" (Misión, Eureka Universidad del Cauca). "Eureka nos ha enseñado que hay que estar abiertos a las imperfecciones, y es ahí, donde uno se ríe de la vida para bien y para aprender".

Paradójicamente, el evento diseñado solo para estudiantes universitarios, recibió estudiantes de colegios interesados en hacer parte del mismo. El profesor Reinaldo Erazo Rodríguez relata que, en su conversación con uno de los estudiantes, le preguntó “¿niño que es lo que tú quieres? y el niño le dijo, "nosotros queremos emprender, porque en el colegio tenemos ideas, pero nadie nos pone atención. El profesor que nos acompaña es el que más o menos nos orienta, pero en el colegio él tiene que dar sus materias y no tiene tiempo. Nosotros queremos participar y ver metodologías". El profesor le respondió al docente acompañante, algo inquieto por el estudiante, "tranquilo profe, me comprometo a que en tres meses o menos, hacemos una Eureka colegios e hicimos Eureka colegios en el año 2017. Trajimos once colegios cada uno con 10 niños".

Para ello, fue necesario previamente, adelantar una reunión con profesores, encontrando que la mayoría de colegios públicos $\mathrm{y}$ algunos privados, aun no tiene apropiado la importancia de emprender en su cuerpo docente y, por tanto, no logran ser los facilitadores hasta llegar a los estudiantes. Esta fue la razón por la cual, posteriormente, nació Eureka profesores. Un espacio orientado a los educadores de instituciones educativas.

Sin duda, la experiencia de este proyecto, lleva a la facultad de Ciencias Contables, Económicas y Administrativas (FCCEA) a aseverar que se requiere fortalecer en capacidades. El estudiante universitario, el niñoy profesor del colegio, requieren ser motivados a través de convocatorias y espacios. "los emprendimientos no 
son plata, eso se necesita después. Lo que se requiere ahora, es encontrarles las competencias de los estudiantes" (Reinaldo Erazo Rodríguez, 2019).

Para generar capacidades, se requiere la fricción y cuando se habla de fricción, se hace referencia a mezclarse y aprender a compartir con el otro. "Que valore tu idea y que la tuya sume para la mía y la mía sume para la tuya, y si restamos, restamos y a lo mejor nos juntamos y emprendemos" (Reinaldo Erazo Rodríguez, 2019).

\section{El emprendimiento desde las ciencias de la salud en la Universidad del Cauca}

La facultad de Salud de la Universidad del Cauca, desde su programa de fisioterapia ha venido realizando acercamientos al emprendimiento como una oportunidad de hacer apuestas diferentes para generar cambios. El interés, principalmente se debe a docentes motivados por esta disciplina, y particularmente por el entusiasmo de los estudiantes.

Una de las docentes que se ha interesado por el emprendimiento en la facultad, es la docente Paola Vernaza del programa de Fisioterapia de la Universidad del Cauca, vinculada a la institución desde hace veintidós años con la apertura del servicio de fisioterapia en la unidad de salud de la Universidad del Cauca, posteriormente, como docente al departamento de fisioterapia, asumiendo cargos administrativos como jefe del departamento, coordinadora académica, secretaria de la facultad de salud, haciendo parte de todas las reformas curriculares del programa. Entre las características abordadas, se ha considerado el emprendimiento desde que se creó el currículo. Inicialmente, se hablaba de una asignatura que se llamaba administración en salud, en la siguiente reforma se incluyó otra asignatura, denominada formulación y evaluación de proyectos, en la tercera reforma se incluye la asignatura de emprendimiento y una electiva en emprendimiento. 
De alguna forma, se ha querido acercar el programa a las necesidades del contexto, y procurar que los egresados no busquen empleo como primera medida, sino que lo generen. Este ejercicio, ha permitido que los estudiantes se vean motivados a presentarse a convocatorias como las del Fondo Emprender, siendo favorecidos. Muchos de ellos, hoy en día egresados, cuentan con sus negocios, producto de dichas convocatorias.

Como casos de éxito, se podría mencionar a la empresa Fisiopilates, como una de las primeras empresas que fue beneficiada con el Fondo Emprender. Se ha sostenido en el tiempo, gracias a su capacidad de innovación en procesos, enfocándose más en el bienestar corporal. También, existe la empresa denominada Terapéutica, especializándose en la práctica de pilates. Como estos emprendimientos, existen otros que han manifestado, la necesidad de fortalecer el acompañamiento en la interpretación y ejecución de la normatividad en salud.

En este sentido, en la institución se han generado espacios para hablar del emprendimiento. En uno de ellos indica la docente "me invitaron a participar del ecosistema, para conocer algunos aspectos puntuales y ver como se podría traer a la Facultad de Salud. Se vislumbrar en el trabajo que se ha estado adelantando, que la facultad si trabaja en emprendimiento, pero quizás no conoce lo que es el emprendimiento. Para ello, es muy importante los laboratorios especializados con los que se cuentan, entre ellos, el laboratorio de valoración funcional y movimiento del programa de fisioterapia, laboratorio de habla y el centro de escritura del programa de fonoaudiología”.

En este sentido, desde la facultad existen múltiples definiciones o actores que se ven interesados en el emprendimiento. En una aproximación más inmediata, se puede decir que algunos lo perciben como un negocio que genera dinero. Sin embargo, hay otras concepciones que el ecosistema ha puesto sobre la mesa, y es considerarlo como la posibilidad de ayudar a trasformar vidas, a trasformar contextos. 
Existengrandesoportunidadesen esesentidoespecialmente para la facultad. Una de ellas, es el Centro Universitario en Salud Alfonso López, espacio que lleva operando más de 30 años. Lamentablemente, la percepción de sus resultados, arrojan que no precisamente a transformado el contexto de esa comuna, sino que, por el contrario, es una comuna más violenta. "Los que van al Centro se encierran. No salen. No se ha concebido realmente el emprendimiento, como tiene que concebirse, de trasformar vidas, de trasformar a las comunidades. En la medida que empiece a concebirse así, realmente los egresados tendrán una concepción diferente. No solamente decir, voy a montar un negocio para lucrarme, si no que en la medida que va trasformando vidas, su negocio va creciendo, el emprendimiento va creciendo" (docente Paola Vernaza del programa de Fisioterapia de la Universidad del Cauca).

Existe entonces unos aportes que permiten materializar el emprendimiento en el programa. Desde el currículo, se evidencia desde la asignatura de Administración en Salud, donde los estudiantes empiezan a conocer la importancia de emprender. Después, desde la asignatura de formulación y evaluación de proyectos, generan un emprendimiento. En ocasiones, se encuentra articulado a los procesos de investigación, espacio donde surgen ideas de emprendimiento, logrando ser acompañados desde eje denominado, administración y gestión. Es así como, desde investigación, se empieza con la ideación. Primero, desde Administración en Salud, los estudiantes conciben la idea de lo que puede ser un emprendimiento alrededor del sector salud, y en Formulación y Evaluación de proyectos, reciben orientación sobre esa idea que gestaron, para ser desarrollada desde el protocolo de formulación y evaluación de proyectos símil a lo que pide el fondo emprender. Sin embargo, se requiere fortalecer en la continuidad de los docentes, orientando estas temáticas. Debe existir, un hilo conductor entre las asignaturas anteriormente mencionadas, logrando los objetivos que se plantean, considerando, además, que este tema se aborda a partir de octavo semestre. 
Por su parte de la docente expresa "se informan a los estudiantes, que también existen otros semilleros de investigación, en los cuales ellos pueden participar, entre ellos, de emprendimiento. Ha sido difícil la interacción de salud, inclusive del docente con otras facultades. Si hubiese esa interacción con otras facultades, realmente lograríamos muchos resultados. (docente Paola Vernaza del programa de Fisioterapia de la Universidad del Cauca).

La cultura hacia el emprendimiento ha ido cambiando para bien en la institución. La vicerrectoría de investigaciones ha fomentado espacios muy productivos entorno a ello a través de las respectivas instancias. "Estas dinámicas, poco a poco han trascendido a otros espacios como la Facultad de Salud. Por ejemplo, fisioterapia que es más a fin con fonoaudiología, empieza a integrarse con proyectos interesantes. Lo que se espera es que los cuatro programas: medicina, enfermería, fisioterapia y fonoaudiología, den su mirada desde su área, evitando apegos propios de cada disciplina. Ya se empiezan a dar los primeros pasos. Todavía encontramos que estamos haciendo las mismas actividades por la falta de dialogo, de entender que hace cada facultad y como esa facultad le puede servir por ejemplo a salud, para apalancar dichos procesos".

La asociatividad entonces es necesaria y se promueve desde salud laboral. En este campo existe, el programa de entornos laborales, que pone de manifiesto, la importancia de la asociatividad. "Si el paciente presenta una molestia musculoesquelética, y estoy asociada, es posible suplirse. En esta dinámica, la profesora Cristina Restrepo, ha trabajado en lo que ella denomina, Empresas Saludables. Para su funcionamiento, es necesario que los profesionales se asocien, logrando disminuir la carga, y no la productividad".

Por otra parte, se han adelantado alianzas con el programa de Ingeniería Telemática y con Ingeniería Física. Desde salud, 
se hace una valoración específica, y ellos, avanzan en todo el funcionamiento de los equipos y del software. De esta forma, establecer desde su área, algún tipo de prototipo. Por ejemplo, "fisioterapia y fonoaudiología han hecho unos mayores avances con software para valoraciones específicas. Ellos quizás no lo llaman emprendimiento, no tienen claro que es el emprendimiento y que es un desarrollo de base tecnológica, pero si lo están haciendo". (Docente Paola Vernaza del programa de Fisioterapia de la Universidad del Cauca).

Es relevante expresar que el sector de la salud, se siente golpeado por el sistema, y ello ha traído consigo la desmotivación de docentes y estudiantes. En ese sentido, es de vital importancia, desarrollar entrenamiento en el cuerpo docente para que logren trasmitir a sus estudiantes otras formas de transformación del contexto, más allá, de ser empleado de una entidad. De todas formas, existe el interés evidenciado desde los semilleros de investigación. "Algunos estudiantes le están apostando a buscar otras formas de tratamientos, así como de diseño de dibujos para libros con el fin de comprender mejor lo que están estudiando, son estudiantes apasionados".

Existe interés institucional por considerar el emprendimiento como un aspecto relevante para la formación estudiantil. Una de esas apuestas, se evidencia desde la política de investigaciones, la cual deja explicito, actividades de investigación y emprendimiento (Docente Paola Vernaza del programa de Fisioterapia de la Universidad del Cauca, 2019).

Para el fortalecimiento del ecosistema de emprendimiento, se requiere la constancia, además de contar con el reconocido institucional, con el fin de generar alianzas para fortalecer espacios que ya existen, pero se encuentran con todo el potencial por explorar. Uno de ellos, es el Centro en Salud de Alfonso López, donde pueden confluir todos los programas de la universidad, logrando un cambio sustancial en esa comuna y la unidad de salud 
de la Universidad del Cauca, que es régimen especial, permitiendo que todos los programas estén allí, podría ser un referente, con un modelo de atención diferente en salud.

Según el análisis del entorno de la Facultad, entre las necesidades y oportunidades identificas en la región, resalta la educación en la cultura de emprendimiento. Desde salud las potencialidades que se tienen en conocimiento e infraestructura para mejorar y transformar vidas con un enfoque emprendedor, son amplias, sin embargo, poco exploradas. Entre otras cosas, porque los docentes que se involucran en estos procesos de emprendimiento, lo hacen por gusto, y no por una designación académica específica.

Por tanto, la ciudad de Popayán, "debería enfocarse en educar, desde la cultura ciudadana, porque si desde ahí empieza realmente la ciudad seria otra totalmente diferente. Cultura ciudadana tiene que ver desde que usted no va a urgencias, si no tiene una urgencia y esa sería como la trasformación, pero tiene que empezar por la educación". (Docente Paola Vernaza del programa de Fisioterapia de la Universidad del Cauca, 2019).

\section{Corporación Universitaria Autónoma del}

Cauca

Para la Uniautónoma del Cauca el emprendimiento no está enfocado en un ámbito únicamente empresarial: se lo concibe como una forma de pensar y de actuar, una actitud de la vida del ser humano, por tanto, se pretende trabajar el concepto desde un ámbito más abierto, con el ánimo de formar emprendedores sociales, ambientales, jurídicos y culturales.

De esta manera, en la Uniautónoma normalmente se le brinda al emprendedor de tres (3) a cuatro (4) clases de Emprendimiento, con doce (12) cursos de Creatividad, doce 
(12) de Observación Empresarial, quince (15) de Cultura Emprendedora y quince (15) de Creatividad e Innovación. En este esquema, que funciona desde el 2018, se diseñan tanto el micro currículo como el quehacer de los docentes que orientan los cursos, que se hacen trasversales a todas las carreras profesionales ofrecidas en la institución. Desde esta estructura se asignan también presupuestos, formulación de planes de trabajo, clases formales, participación en la Ruta CreaTIC y eventos que se hacen cada año en el marco de temas universitarios locales.

Lo anterior ha llevado a que el emprendedor se inmiscuya también en las dinámicas empresariales de la región: a través de la asignatura Práctica Empresarial y en los semilleros de investigación, desde donde se trabaja con el equipo de Finanzas, con el que se pretende involucrar aspectos relacionados con el sector solidario. Con el esquema se fortalece la dinámica de las clases, que ahora se enfocan en temas como pymes, micro currículos, tesis de grado, ferias empresariales, participación de las redes de emprendimiento y demás eventos que realiza la Uniautónoma tanto en investigación como en emprendimiento.

El proceso de emprendimiento institucional, es uno de los pocos en la región que está agrupado y formalizado. De hecho, externos acuden de forma permanente para diferentes asesorías y acompañamientos, llegando a impactar positivamente sus ideas:

Aún nos falta un esquema deliderazgo, porquelos emprendedores no saben qué hacer con la idea, porque no ven más allá. Es allí dondeestamos intentando brindar el acompañamiento necesario, ya que contamos con un equipo profesional interdisciplinario para asesorar cualquier eventualidad que se presente en la constitución, implementación y ejecución de la idea de negocio. En una segunda fase, la de apoyo, se busca fortalecer y asesorar todo tipo de debilidad que tenga el emprendedor, en temas jurídicos, ambientales, financieros, etc. (Martin Valencia, Líder de Emprendimiento de la institución, $2019^{18}$ ).

18 Información primaria proveniente de los emprendedores entrevistados. 
En este sentido, la institución busca formar profesionales que sean autónomos y emprendedores en todos los escenarios donde se desempeñen, siendo transformadores del entorno y convencidos de que en estos se manifestará el emprendimiento. Es así como desde los mismos cursos de evaluación se concreta la formulación de proyectos, en una secuencia de indicaciones que se le dan al estudiante, con las herramientas necesarias para consolidar su idea emprendedora.

En alguna ocasión vimos una sustentación de un joven proveniente de Tumaco. El papá es pescador artesanal de toda la vida y sus tres hijos -que han procurado apoyar el negocio de su padre- son estudiantes universitarios de la Uniautónoma, en los programas de Contaduría Pública, Ingeniería Ambiental y Finanzas. El joven que sustentaba su proyecto, relacionado con Finanzas, comentaba que en su tierra natal se ve mucha embarcación de Ecuador y Panamá, los cuales hacen el mismo trabajo de su padre, pero de una manera moderna y usando tecnología. Su aspiración, es volver a Tumaco y hacer del negocio algo más rentable, con el ánimo de conservar lo propio y acceder a los recursos colombianos para trabajar por la transformación, el crecimiento y desarrollo de su región. Ése es un emprendedor, ése es un uniautónomo. (Martin Valencia, Líder de Emprendimiento de la institución, 2019 ${ }^{19}$ ).

Es de esta manera que la cultura del emprendimiento se fomenta en la formación de líderes que propenden por generar dinámicas de trabajo de interés a nivel social, económico, político y cultural, con el objetivo de tener una posibilidad de reafirmar las bases del emprendimiento y, en alguna medida, motivar a la observación empresarial para entender la necesidad del mercado como una opción para crear ideas de negocio, pero también en su actitud, basada en cualquier campo del saber. De este modo también se incentiva la creatividad en los profesionales que desean emprender, siendo, además, un "laboratorio de vida" para que haya una constitución de empresa. Desde la institución se

19 Información primaria proveniente de los emprendedores entrevistados. 
acompaña hasta el momento de evidenciar certificado de Cámara y Comercio, el uso de suelos, el estatuto de constitución de la empresa, el diseño que haya por parte del modelo que escogieron, etc., y brindar a partir de ese momento, un acompañamiento en la ejecución de dicha empresa. Son hasta el 2018, 600 proyectos acompañados desde su Unidad de Emprendimiento, entre tesis, pasantías basadas en el estudio de factibilidad, creación, intervención y emprendimientos de diversos Egresados.

Por otro lado, la Autónoma direcciona a los emprendedores a los sistemas de financiación para ejecutar las ideas de emprendimiento. Uno de los proyectos a largo plazo será hacer una red de financiadores: "Cuando uno ha trabajado en proyectos encuentra que a nivel internacional hay mucho organismo en los cuales se puede aplicar para financiar proyectos. Por ejemplo, en el sector de caficultores se tiene lazos fuertes con Canadá, Alemania o Estados Unidos, países que cuentan con entidades, fundaciones o personas con recursos que quieren apoyar ideas de negocios de latinos. Involucrándose en estas plataformas, todos estos proyectos son sometidos a evaluaciones para ser elegidos y posteriormente financiados. Eso es lo que falta en Colombia, una red de cooperantes que la Alcaldía y la Gobernación apoye, donde diferentes entidades y universidades contribuyan. Así también debería haber un esquema de asesoría en la ejecución para orientar de mejor manera al emprendedor". Explica Martin Valencia, Líder de Emprendimiento de la institución.

Uniautónoma mide los resultados de egresados, a los cuales se contactan para determinar la pertinencia de su formación recibida, procurando identificar las necesidades que tiene en su actualización profesional y así, plantear dinámicas desde procesos de Educación Continua y contribuir en su proceso de ejecución de emprendimiento. Entonces el esfuerzo realizado como Institución de Educación Superior se materializa finalmente en una Cultura del Emprendimiento, en la cual se viene trabajando a nivel región, como entidad que busca el desarrollo empresarial del Cauca; desde 
la Uniautónoma se trabaja la actitud de sus estudiantes para que se atrevan a emprender, apostándole a esta opción de desarrollo económico para la ciudad.

De hecho, "los que hemos hecho empresa notamos que la ciudad no está preparada para dar respuesta en cuanto a infraestructura vial, servicios públicos, normatividad, impuestos, carga impositiva, etc. Lograr que un Concejo permita tener una exoneración de algo tan pequeño como la Industria y Comercio por cinco años, mientras la empresa se fortalece, es titánico. Lograr que las entidades públicas tengan programas que vayan más allá de la capacitación también es un tema complicado, porque no es solamente sacar estadísticas para corroborar que se preparó cierta cantidad de personas. Es necesario acompañar al emprendedor, estar con él en toda la ruta y en todo el proceso del cambio de mentalidad, y llegar hasta el punto en que lo sientas listo para continuar de forma independiente. Sin embargo, ellos también encuentran una ciudad atrasada en todo" Explica Martin Valencia, Líder de Emprendimiento de la institución.

Desde la misma conectividad hay un riesgo para el empresario porque no hay autoridad: el cierre tan común de las vías de acceso, que acaba con todo proyecto que implique sacar productos de Popayán, y no tener una vía al mar, ente otras, son barreras institucionales que hacen pensar que el emprendimiento local no vale la pena, y que no permiten pensar en competir en un mercado nacional o global, por eso los emprendedores se van a otras ciudades o incluso fuera del país. De hecho, "tenemos una lista de egresados que trabajan con sus ideas de negocio fuera de la región, porque no han visto las mismas oportunidades de crecimiento acá. Y por eso también encontramos siempre los proyectos de subsistencia; de ahí no se salen porque las limitantes siguen siendo muchas" Explica Martin Valencia, Líder de Emprendimiento de la institución. 
De esta manera, fomentar la cultura del emprendimiento en la región debe ir de la mano de políticas de Gobierno que apoyen el impulso de ideas de negocio, fomenten el empresarismo y contribuyan a facilitar el camino del emprendedor, en cuanto a impuestos, facilidad de comercialización, competencia en el mercado, oportunidades de mejora en la implementación de sus proyectos, etc.

Precisamente, desde la Uniautónoma del Cauca se debe hacer una integración de las entidades que fomentan el emprendimiento a nivel regional, con el ánimo de no competir por saber cuál es la que más proyectos finiquita sino para apoyar al emprendedor en su camino, y lograr una cohesión con el desarrollo de la región. De este modo se permitirá también generar nuevas dinámicas industriales que potencien el desarrollo social y económico, y permitan ser competentes en los mercados mundiales.

\section{Institución Universitaria Colegio Mayor del Cauca}

Durante los casi 52 años de existencia, la Institución Universitaria Colegio Mayor del Cauca ha dado muestra de tenacidad y resistencia a las vicisitudes generadas por los hilos de la historia. Un 13 de noviembre de 1967 bajo el amparo de la Ley 48 de 1945 nació en una casona de tres salones en el centro histórico de la ciudad de Popayán en donde hoy se conoce como la Casa de la Cultura en un ambiente familiar y con 60 personas, el para entonces llamado Colegio Mayor de Cultura Popular del Cauca, caracterizado no solo por ser uno de los más jóvenes de los Colegios Mayores de formación femenina en Colombia, sino curiosamente porque dicha apertura se dio también como el primer Colegio Mayor en Colombia en recibir población estudiantil masculina. 
De la mano de una de sus fundadoras y a su vez como primera rectora Ruth Cepeda Vargas, se trazó el camino del crecimiento de la Institución reflejado por la falta de cupos. Esto derivó en la búsqueda de una sede no solo más amplia sino propia: El Claustro de la Encarnación. Siendo un referente histórico, arquitectónico y un lugar de educación, se entregó de manera definitiva y por directriz de la entonces gobernadora del Cauca, Amalia Grueso en 1983 en la coyuntura del terremoto de Popayán.

El emprendimiento en la Institución Universitaria Colegio Mayor del Cauca denota y se refleja en si misma desde su quehacer y crecimiento histórico en búsqueda de la excelencia como centro de educación, pasando no solo con su progreso en infraestructura al manejo de tres sedes más: Casa Obando, Edificio Bicentenario y Sede Norte Bethlemitas, sino por su dimensionamiento desde la naturaleza jurídica y reglamentación en la educación superior, esta última consagrada tan solo en la Ley 115 de febrero 8 de 1994, conocida como la Ley General de Educación.

Desde ahí se identificó a los Colegios Mayores en Colombia como instituciones de carácter tecnológico. Dicha evolución con el transcurrir del tiempo, estructurada en oferta académica y un portafolio de servicios más acorde a la región, permitió que, en el 2008, el Colegio Mayor del Cauca pasara de ser una Institución tecnológica a una Institución Universitaria, es decir lo que es hoy en día, la Institución Universitaria Colegio Mayor del Cauca.

Dado lo anterior, la connotación del emprendimiento para el Colegio Mayor del Cauca acorde a su evolución, lo traslada y lo concibe en su Proyecto Educativo Institucional al estructurarlo para "contribuir al cumplimiento de políticas públicas a nivel nacional, departamental y regional en aspectos importantes como: emprendimiento, desarrollo social, el desarrollo de la ciencia, la tecnología y la innovación, como aspectos fundamentales en el crecimiento y el desarrollo económico de la región y el país. Aportando a este desarrollo desde las áreas de Ciencias Sociales, 
ingeniería y artes." (Proyecto Educativo Institucional PEI - Por una pedagogía activa y diferenciada - Colegio Mayor del Cauca 2019).

A su vez, el PEI también define en su política de Proyección con responsabilidad social una línea de acción específica de emprendimiento, donde el fomento y apoyo a proyectos productivos para el desarrollo de las ideas empresariales e iniciativas de la comunidad estudiantil o del sector productivo, deberán realizarse por medio de alianzas interinstitucionales.

Dicho aporte desde el PEI está concebido en principio para el Colegio Mayor del Cauca, en espacios determinados en el currículo de los diferentes programas ofertados, donde se permite desarrollar unidades de competencias acordes a la filosofía del emprendimiento de la Institución. Por mencionar algunos ejemplos; el programa de Diseño Visual en sus componentes de módulo: Gestión para la empresa, Calidad, Gestión para el diseño, consigna en su área de gestión y como unidad de competencia: "Ser capaz de orientar, articular, integrar y promover la disciplina en el contexto productivo empresarial e institucional, así como la capacidad para gerenciar y hacer eficaz su actividad profesional". (Currículo Programa Diseño Visual - Colegio Mayor del Cauca).

El programa de Administración de empresas desde su concepción propedéutica con las Tecnología en Gestión Comercial y de Mercados y la Tecnología Gestión Empresarial, en sus componentes de módulo contiene Plan de negocios, Investigación y Gestión de empresas dentro del área de formación administración y de las organizaciones y de gerencia de personal, reflejando elementos de emprendimiento.

Para el programa de Ingeniería Informática en su área de administración y como unidad de competencia lo determina como "Ser capaz de coordinar actividades, organizar y manejar recursos, desarrollar proyectos y trabajar en equipo con el fin 
de gestionar de manera eficiente proyectos informáticos" esto a través de su componente de módulo: Administración general.

Cabe resaltar que, en el quehacer de la Institución, los docentes de las diferentes facultades en ejercicios tanto de investigación como trabajo de aula, han generado dinámicas en emprendimiento culminadas en ferias empresariales, ferias tecnológicas, participación de semilleros como ponentes de marco conceptuales o de referencias en la línea del desarrollo empresarial.

De esta manera, cuando se dio inicio al Plan de Desarrollo Institucional 2016 - 2020, "Gestión Transformadora con calidad humana", se concibió la necesidad dentro de su diagnóstico, fortalecer las alianzas institucionales que permitieran la articulación Universidad - Estado - Empresa referenciado seis temas centrales asociados a las condiciones básicas de calidad de instituciones y de programas de educación superior: "Las relaciones de las IES con el Estado, la empresa y la sociedad civil y las relaciones entre las instituciones encargadas de la educación deben fortalecerse creando espacios de diálogo y de construcción conjunta." (MEN, 2013).

Dado lo anterior y para operativizar esta necesidad, se creó un centro que dinamiza el fortalecimiento de las relaciones con sector externo denominado Centro de Innovación y Desarrollo Empresarial del Cauca CIDECAUCA adscrito a la facultad de Ciencias Sociales y de la Administración y perteneciente al Grupo de Investigación GIFIN de la misma, que incluyen acciones articuladas con emprendimiento.

Este centro que cuenta por diez años con el Registro de la Marca y Derecho de Propiedad Intelectual otorgada por la Superintendencia de Industria y Comercio de la República de Colombia, mediante Resolución N. ${ }^{\circ}$ 67427; para la Institución Universitaria Colegio Mayor del Cauca, tiene entre sus retos, 
seguir fortaleciendo la cultura del emprendimiento, apropiando conceptos institucionales, independientemente de la naturaleza de cada facultad, encontrando sinergia desde el currículo y las actividades extracurriculares, con el entorno y responder a las necesidades del mercado.

Una de sus líneas de acción, es propiciar espacios para emprendimiento universitario mediante la concepción, desarrollo e implementación de la unidad de emprendiendo llamada "Unimayor Emprende".

De este modo, la institución Universitaria Colegio Mayor del Cauca, concibe el emprendimiento principalmente con fines empresariales, buscando preparar a los estudiantes, para que una vez culminen sus estudios o antes, puedan materializarlo en una idea de negocio, que posiblemente se formalice. Lo anterior, se debe a la gran incidencia que tiene los programas tecnológicos y profesionales de la Institución. Por consiguiente, al hablar de cultura del emprendimiento en la región y concretamente en la ciudad de Popayán, se percibe que existe un gran camino por recorrer.

Son los egresados precisamente de las instituciones que hacen grandes contribuciones al crecimiento de la región. Para el caso del Colegio Mayor del Cauca los mismos caracterizados en estudios internos, evidencian desarrollo de empresas propias, corroborando un resurgir de la necesidad o perspectivas de la no búsqueda de un trabajo para terceros sino un proyecto empresarial individual.

Sin embargo, es necesario seguir trabajando en la formación y ser conscientes de las ventajas, desventajas y riesgos que tiene el mercado, especialmente, enfocándose en la formación financiera. No solo tener una gran idea, sino materializarla en la parte financiera. 


\section{Escuela Superior de Administración Pública - ESAP}

La Escuela Superior de Administración Pública ESAP, como entidad que "fomenta conocimientos, valores y competencias del saber administrativo público, para el desarrollo de la sociedad, el Estado y el fortalecimiento de la capacidad de gestión de las entidades y organizaciones prestadoras de servicio público, en los diferentes niveles de educación superior, educación para el trabajo y el desarrollo humano, la investigación y asistencia técnica en el ámbito territorial, nacional y global" (Misión ESAP, 2019), hace parte de la Red Regional de Emprendimiento.

En ese orden de ideas, el emprendimiento para la ESAP, recibe lineamientos desde el Proyecto Gobernanza para la Paz Estrategia 2019, para el Desarrollo Económico y Productivo, asesoría en proyectos de desarrollo: formulación, gestión y evaluación de proyectos. Por tanto, el administrador público es un profesional dotado de los valores del servicio público inherentes al estado social de derecho, comprometido con la puesta en vigencia de las instituciones democráticas, participativas y poseedor de las aptitudes requeridas para la comprensión, explicación y solución de los problemas administrativos públicos. Específicamente, el administrador público está en condiciones de liderar procesos administrativos tendientes al fortalecimiento de instituciones y organizaciones pertenecientes al ámbito de lo público (Perfil del Administrador Público).

Por ello, se requiere fortalecer las competencias para el hacer, no solo quedarse con el concepto o conocimiento; sino atender esas problemáticas regionales, a partir de laboratorios, practicas, entrenamientos, para crear $\mathrm{y} / \mathrm{o}$ proponer. 
De este modo, existe una práctica que viene de la mano con quienes egresan de administración pública, que es la perspectiva orientada a conseguir empleo en alguna empresa pública, siendo muy escasos los referentes, de creación de empresa. Por tanto, es común encontrar, mayoritariamente profesionales de otras áreas del conocimiento, vinculados con la administración pública, que administradores públicos ejerciendo su rol desde un enfoque de crear empresa para satisfacer, por ejemplo, necesidades del sector gubernamental. Lo anterior trae como resultado, la necesidad de visualizar y materializar a través del plan de estudios, aportes orientados hacia el emprendimiento. Asimismo, a través de las opciones de grado, que, en el caso de la institución, son abordadas desde tres alternativas: Seminario de Profundización, Práctica Profesional y Monografía.

Se observa en el plan curricular, un conjunto de asignaturas que permiten competencias para el emprendimiento, como aquellas que fortalecen el pensamiento estratégico, el desarrollo de las Tecnologías de la Información y Comunicación (TICS), el bilingüismo, la optimización de procesos, la formulación y evaluación de proyectos, la identificación de fallas y alternativas para el cambio en las organizaciones generando nuevos y mejores servicios.

En ese sentido, la mayor aproximación que se realiza a los procesos de sensibilización sobre el emprendimiento se lleva a cabo en los cursos: de Formulación y Evaluación de Proyectos, Planeación del Desarrollo y Gestión del Desarrollo; no obstante, dado su alcance, no es posible lograr la materialización de las iniciativas.

La ESAP, dentro de su función misional, acompaña a las entidades territoriales para procesos, como formulación de políticas públicas, dinámicas que son atendidas por áreas como Alto Gobierno. Desde esa instancia, se acompañan a líderes públicos como alcaldes, diputados, entre otros. A su vez, existe 
la figura de Asesorías, a través de las cuales, los entes territoriales y las empresas del Estado, reciben orientación para su debida gestión. Esos ejercicios de acercamiento, facilitan la identificación de potenciales empresas, que podrían dar respuesta a necesidades del Estado, siendo posible ahí, hablar de emprendimientos.

La ESAP, dentro de su estructura cuenta con La Subdirección de Alto Gobierno - SAG, que es el área de la Escuela Superior de Administración Pública, que ha establecido como objetivo "impartir la inducción y prestar apoyo a la alta gerencia de la Administración Pública en el orden nacional", la cual dentro de sus funciones debe realizar el acompañamiento en los citados aspectos a gobernadores, alcaldes, concejales, diputados y congresistas electos, adicionalmente, considera "actualizar permanentemente los contenidos temáticos y las estrategias de capacitación e inducción teniendo en cuenta los avances en la Administración Pública, la reingeniería del gobierno y la calidad y eficiencia en la gestión pública”, es en este marco es donde se generan capacitaciones dirigidas de manera particular a quienes representan los mencionados cargos públicos, en los aspectos inherentes a la alta gerencia de las entidades del orden municipal, departamental y nacional, en procura de un mejor funcionamiento del Estado.

Dentro de la subdirección de proyección institucional, la entidad cuenta con el Departamento de Asesoría y Consultoría que en el marco de su visión pretende: "contribuir al fortalecimiento de la gestión y la capacidad de las entidades públicas y organizaciones sociales y comunitarias para incrementar la eficiencia del Estado". Adicionalmente, "Generar, innovar y difundir tecnologías y herramientas eficaces para la racionalización de la gestión e inversión de los recursos públicos y la elaboración y concreción de los proyectos necesarios a fin de dar solución a los problemas de la sociedad colombiana, acordes con los cambios originados en la administración del Estado." Es decir, la ESAP genera 
un marco de acompañamiento directo que se enfoca en dos direcciones: alcanzar mayores niveles de eficiencia del Estado y generar soluciones reales a los múltiples problemas que aquejan la sociedad colombiana, mediante prácticas asociadas al buen gobierno, incluso a través del "intercambio y asistencia con organismos nacionales e internacionales que cumplan labores de la misma naturaleza."

En el anterior marco de referencia (Alto Gobierno, Asesoría), se podría considerar la identificación de problemáticas y propuestas de solución, a través de empresas enfocadas a los objetivos y misiones de las citadas áreas, lo cual, posibilita a estudiantes y egresados generar emprendimientos en tal sentido. Por otra parte, desde la formación para el trabajo y el desarrollo humano, se orientan capacitaciones especialmente alrededor de proyectos, dirigidos hacia la inversión pública, que incluyen estudios de factibilidad. Sin embargo, es necesario fortalecer el enfoque orientado a ese tipo de proyectos, puesto que de los mismos pueden surgir, iniciativas orientadas a la creación de empresas, para dar respuesta a necesidades públicas.

El direccionamiento de orden nacional, ha permitido apostarle, a proyectos con financiación proveniente de cooperación internacional. Entre ellos, se resalta la articulación con cooperación holandesa, orientado hacia el fortalecimiento de las capacidades de los diferentes entes territoriales, determinando como generar capacidades instaladas dentro de la institución. Del mismo modo, la participación en procesos de posconflicto para lograr desarrollar condiciones de fortalecimiento con enfoque hacia el emprendimiento. Eso ratifica, el fortalecimiento en redes que tiene la Escuela Superior de Administración Pública, específicamente en su capacidad de articularse con entidades municipales de difícil acceso.

Por tanto, entre los aspectos destacados de la ESAP, es necesario recalcar la capacidad de articularse en red, y la valoración de lo público, pensando con ello, en la importancia de fomentar 
competencias en los estudiantes para que una vez egresen, estén en la capacidad de liderar procesos de la mejor manera posible, en entidades públicas y de crear empresa conociendo las necesidades del Estado para lograr articulación.

Por consiguiente y desde los aportes que le hacen a la ciudad, se considera que, sí se han generado cambios significativos en los últimos años. Es relevante el fortalecimiento de ejercicios de prospectiva, considerando que la planeación se tiene que hacer en diferentes temporalidades y escalas, con el fin de lograr una visión conjunta a través del tiempo, reconociendo la importancia de la relación Universidad, Empresa, Estado y Sociedad (UEES). Otro cambio importante, fue el que sufrió el Sistema General de Regalías (SGR), contribuyendo con recursos importantes de Ciencia, Tecnología e Innovación, lo cual ha aportado a una mejor articulación entre las instituciones presentes en el contexto regional.

Los procesos de formación que se adelantan en la institución, consideran a las comunidades como el foco principal de atención de la administración pública; a su vez, hay una apuesta regional enmarcada en esta alianza (UEES), en la que la institución participa. De esta forma, se deben fomentar diversos espacios tanto académicos como prácticos a diversas escalas (PYME), con diversidad de públicos (diferentes niveles de cualificación), en los cuales se aborde el tema del emprendimiento desde múltiples perspectivas. La población del Cauca en general, tiene una gran aversión al riesgo. En ese sentido, es necesario apropiar metodologías, como herramienta para formular propuestas de valor, puesto que esto posibilitaría el surgimiento de iniciativas de diversa índole para el municipio, departamento y país.

Finalmente, en el departamento existen múltiples oportunidades para los egresados en administración pública, en los siguientes sentidos: En primer lugar, los diferentes municipios del departamento y del país, suelen perder la oportunidad de 
llevar a cabo soluciones para el mejoramiento de la calidad y condiciones de vida de la población, debido a que no hay suficientes capacidades instaladas alrededor de la formulación, evaluación y gestión de proyectos. Es entonces, un espacio interesante para la generación de empresas encargadas de la formulación, así como asesorías en ejecución, evaluación e interventoría de proyectos y demás áreas del ejercicio de la Administración Pública. En segundo lugar, el Estado constantemente lanza convocatorias para presentar licitaciones en diferentes áreas (Salud, educación, infraestructura, etc.), lo cual brinda la oportunidad no sólo de ser contratista, sino de crear empresas dedicadas a atender esta clase de necesidades. En tercer lugar, las tendencias apuntan a la innovación en las entidades públicas, por lo cual, existe un espacio importante, para la gestación de proyectos que apunten a la generación de valor público, aspecto que resalta ampliamente el nuevo Modelo Integrado de Planeación y Gestión (MIPG) de obligatoria aplicación en las entidades públicas del país.

\section{Corporación Universitaria Comfacauca}

La Corporación Universitaria Comfacauca es una entidad privada, sin ánimo de lucro, fundada en abril de 2002 por la Caja de Compensación Familiar del Cauca. Su cambio de carácter, en el año 2008, ratificó el vínculo que venía logrando con la industria y la empresa, apostándole a una cultura de innovación y emprendimiento.

Después de 17 años, Unicomfacauca es reconocida por la calidad de sus procesos, con importantes resultados en docencia, investigación y proyección social. Emprendimiento por su parte, es sin duda, una apuesta articulada a las necesidades de la región. Para Unicomfacauca, el Emprendimiento es entendido como una aptitud y actitud que tienen y aprenden a desarrollar las personas de la comunidad universitaria, que les permite asumir nuevos 
retos y nuevos proyectos. No es solo la creación de empresas, es la capacidad de identificar oportunidades que se encuentren inmersas en las situaciones de la vida cotidiana, que den pie a la creación de soluciones innovadoras que, al llevarlas a cabo, generen valor para quien las crea y para la sociedad.

De esta manera, entre los actores de la comunidad educativa y personas externas, existe un emprendedor, el cual tiene las habilidades para identificar y poner en marcha, un proyecto de impacto económico o social, una oportunidad que aporta a su calidad y proyecto de vida. En este sentido, la coordinadora de emprendimiento, Oriana Robles Muñoz expresa: "creemos en el talento de nuestros emprendedores y fomentamos la autonomía, la interacción interdisciplinaria, la persistencia en el trabajo y la actitud proactiva con el fin de lograr beneficios individuales, organizacionales y sociales".

Por consiguiente, el emprendimiento ha sido concebido por la Corporación Universitaria Comfacauca- Unicomfacauca desde su Proyecto Educativo Institucional, por ello sus directivas han hecho una importante y acertada apuesta en este tema, permitiendo que a la fecha se hayan realizado ferias con excelentes resultados, convocatorias de emprendimiento, investigación y prototipado, al igual que actividades que fomentan la cultura del emprendimiento.

Todas estas acciones, se han venido gestando y ejecutando con el fin de desarrollar especialmente en estudiantes y egresados, nuevas competencias en el manejo de herramientas, que les permitan desempeñarse de manera competente y oportuna ante la realidad del entorno.

Se han incorporado en los planes y programas, importantes cátedras relacionadas con creatividad, ciencia, tecnología, innovación y emprendimiento, generando en quienes las cursan, nuevos puntos de vista y oportunidades. 
Como Institución de Educación Superior, se han explorado casos de éxito de otras Instituciones, tendencias, nuevas metodologías, aciertos, ecosistemas de emprendimiento de otras ciudades y países, con el fin de generar alianzas estratégicas, formar el talento humano, y finalmente tener la posibilidad de adoptar y adaptar las buenas prácticas, realizar algunas apuestas propias y definir la ruta de emprendimiento. La Coordinadora de emprendimiento manifiesta que

La ruta, es como una simbiosis entre el proceso del currículo institucional de todos los programas académicos y los servicios que presta la unidad de emprendimiento. De manera trasversal, todos los estudiantes deben cursarlas. Adicional a esto, la Corporación, cuenta con la unidad de emprendimiento, instancia que brinda asesorías, sensibilización y actividades que promueven la cultura emprendedora. También, es la encargada de hacer seguimiento a emprendedores que visualizan en esta oportunidad, la realización de su proyecto de vida. De hecho, si el emprendedor no ha cursado las asignaturas, puede acercarse a la unidad desde primer semestre, y empezar las actividades de formación en emprendimiento que parten de un proceso de sensibilización e ideación. (Coordinadora de Emprendimiento, $\left.2019^{20}\right)$.

Es así como, por la misma naturaleza de la Corporación, los emprendimientos de base tecnológica tienen grandes oportunidades para desarrollar procesos de transformación en cadenas productivas y procesos ambientales. Se requieren procesos de fortalecimiento al empresarismo, la sostenibilidad y fortalecimiento del ecosistema regional de emprendimiento. En este sentido, la Unidad de Emprendimiento está adscrita a la Dirección de Proyección Social y Cepride de la Corporación, siendo liderada por un docente ocasional de tiempo completo con funciones de Coordinación de Emprendimiento.

20 Información primaria proveniente de los emprendedores entrevistados. 
Es importante mencionar que la Corporación cuenta con dos (2) coordinadores debido a que tiene presencia en otros municipios, uno que opera en Popayán y otro en el norte del Cauca; sin embargo, es la coordinación de Popayán la responsable de liderar la planeación, organización, dirección y control de todas las actividades propuestas en el Plan de Acción Institucional. La coordinación de Popayán cuenta con el apoyo de un docente tiempo completo y el norte del Cauca con docentes de tiempo completo que asumen funciones de emprendimiento adscritos a los diferentes programas, los cuales apoyan a la Unidad de Emprendimiento en el cumplimiento de sus metas.

Han sido varios los lineamientos que se han diseñado para su funcionamiento como la política de Proyección social, que rige al proceso de emprendimiento, el documento de la Ruta de Emprendimiento, el Acuerdo 021 de 2014 del Fondo Interno de Fomento al Emprendimiento F.E.C.U.C., el manual de operaciones de las convocatorias de Emprendimiento y los términos de referencia de las Convocatorias Interna de Emprendimiento y Prototipado.

Como estrategias de sensibilización, se desarrollan constantemente talleres, actividades y dinámicas alrededor de las fases de la ruta de emprendimiento. Sin embargo, para la Corporación, el emprendimiento es parte del plan de formación integral de los estudiantes; es una apuesta institucional; es responsabilidad social y un factor diferenciador frente a las otras IES de la región. Es transversal a todos los programas académicos. Ello permite, promover la pre - incubación mediante planes de negocio, y desde la formación académica, por medio de los servicios de asesoría personalizada y convocatorias de capital semilla.

Recursos que, por la experiencia adquirida, son más necesarios para la construcción de prototipos con potencial de comercialización y en la puesta en marcha de los emprendimientos con un plan de negocio económicamente viable. 
La Corporación hace parte de redes como la red nacional REUNE, la Red regional de Emprendimiento, y la Red Universitaria de Emprendimiento. Estos esfuerzos al final se ven transformados en trabajos colaborativos. Algunos proyectos se han logrado en el marco de InnovAcción Cauca, así como con asociaciones y productores en diversas agro cadenas.

Es así como para crear y posteriormente fortalecer la Cultura de Emprendimiento en Unicomfacauca, se han venido desarrollando una serie de estrategias de sensibilización y motivación al emprendimiento. Eventos, actividades y creación de espacios que posibilitan la participación de la comunidad Unicomfacaucana, como las muestras y ferias de emprendimiento, espacios en claustros, desarrollo de seminarios y talleres de la Ruta de Emprendimiento, entre otros.

Dichas acciones, han permeado poco a poco la cultura hacia el emprendimiento. Han sido los eventos que permiten involucrar a estudiantes, docentes, egresados y personal administrativo de la Corporación, contribuyendo a la formación de personas integras, con visión emprendedora e intraemprendedora, creativa, innovadora, con perspectiva de desarrollo sostenible y con competencias necesarias para hacer frente a algunos desafíos que presenta la región y el país.

Sin duda, es necesario la articulación para fortalecer el ecosistema regional, generación de políticas regionales para el apoyo al emprendimiento. Por ello, los aspectos que requieren fortalecerse en la cadena de valor para brindar una mejor experiencia al emprendedor, están relacionados con la innovación aplicada a todos los componentes de los proyectos empresariales. Y con ello, la generación de políticas regionales para el apoyo al emprendimiento, el fortalecimiento de la Red Regional de Emprendimiento por parte de los actores gubernamentales, que facilite mayor impacto y cobertura. 


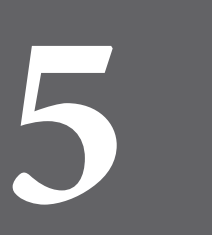

CAPÍTULO CINCO 


\section{El emprendimiento desde historias de vida}

A continuación, se presentan 18 historias de vida contadas por emprendedores que decidieron creer en Popayán. A pesar de no compartir los mismos espacios, e incluso de no conocerse en algunos casos, presentan características y experiencias similares para ser abordadas en pro del fortalecimiento de la cultura emprendedora de ciudad.

De este modo, es un reconocimiento a su esfuerzo, a las ganas de transformar la sociedad de una forma diferente. Se espera, sea un referente cercano para aquellas personas que aún no han tomado la decisión de emprender desde cualquier ámbito de su vida.

\section{El Emprendimiento como apuesta desde la formación básica y media}

\section{Estudiantes del Colegio Comercial del Norte Popayán}

Somos cinco estudiantes del grado once, Kevin Sebastián Dorado, Yonier David Jurado, Luisa Fernanda Martínez, Nicol Ortega y Manuel Herrera del Colegio Comercial del Norte, y queremos contar nuestra experiencia de emprender nuevas ideas. 
Imagen 2. Estudiantes del Colegio Técnico Comercial del Norte y docente de emprendimiento

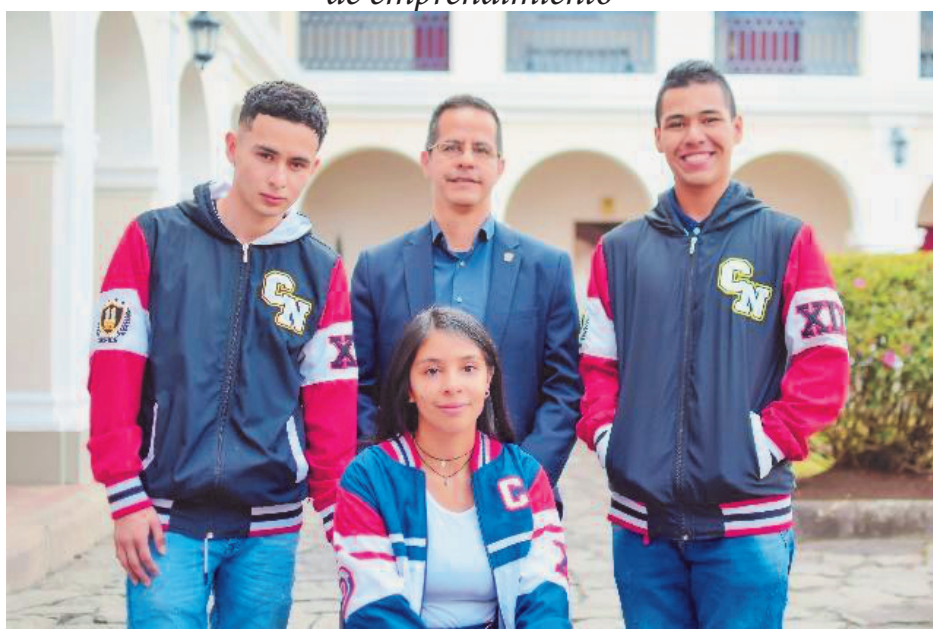

Estudiantes emprendedores Colegio Comercial del Norte Popayán Fuente: Propia

Kevin, Yonier y Luisa Fernanda: iniciando con una idea de emprendimiento desde el aula relacionada con la elaboración de estampados en implementos deportivos, idea que denominamos DIAMANTIC SPORT. Esta iniciativa nació por querer personalizar, llevar un dibujo a la ropa, zapatos, y eso fue lo que conseguimos con el profesor de emprendimiento. Él nos explicó como debíamos de hacer el proceso, nos habló sobre la importancia de identificar necesidades y como poner en marcha un proyecto que a futuro podría convertirse en un emprendimiento. Empezamos con unos guayos a darles color y a diseñar su estampado. Para nosotros, el deporte es muy importante. Con los guayos fuimos materializando las ideas poco a poco, en la medida que íbamos aprendiendo de hidrografía, le íbamos añadiendo la personalización.

La hidrografía, es un proceso mediante el cual, se pone una película hidrográfica en el agua, y se introduce el producto con el fin que quede estampado. Pensamos en Diamantic relacionándolo con diamante, y posteriormente, sport por la actividad deportiva. 
Este ejercicio inicio desde la asignatura de emprendimiento, con el profesor Guillermo Santacruz, quien nos invitó a hacer parte de un proceso, primero teníamos que ser los ganadores del proyecto en el salón, después a nivel institucional, luego en el departamento y finalmente, nos enfrentamos a proyectos nacionales, gestado desde la Fundación Mundo Mujer. Podemos decir que la familia siempre ha estado ahí. Nuestros padres nos apoyaron todo el tiempo.

Nicol Ortega y Manuel Herrera: creamos Hommy, un video juego en proceso, diseñado para que los estudiantes se sientan atraídos, tengan una mejor disciplina y accedan a conocer el manual de convivencia tradicional, siendo este, más didáctico, logrando procesar mejor la información y encontrando respuestas más rápidas a sus dudas relacionadas con el tema.

La idea surgió en el salón, porque el profesor de emprendimiento requería chicos para una convocatoria que iba hacer el Centro de Empleo y Emprendimiento del municipio de Popayán, entonces nosotros decidimos anotarnos, pero teníamos una idea muy diferente. Pensamos en crear un restaurante vegetariano. Después de tener mucha información, decidimos que no era viable, y le apostamos a la tecnología. En ese momento, decimos crear un video juego. Teníamos cursos de programación, entonces eso nos ayudó.

Su nombre se refiere a una manera como se saludan los estadounidenses, especialmente en barrios de estratos bajos. Las pandillas se saludan ¡Hey, Homy!, que significa como, ¡hola compañero!, con ello, tratamos de darle un toque más juvenil.

También nos enfrentamos a dificultades. En nuestro caso, una de las cosas más estresantes, fue la demora que tuvimos al desarrollarlo, sin embargo, hemos pensando en hacerlo realidad. Fuimos a una feria con el profesor de emprendimiento, y mucha gente se interesó en lo que hacíamos, entonces nos orientaron y 
nos indicaron que camino podíamos seguir para conseguirlo. Esta idea la queremos desarrollar a largo plazo como una oportunidad de acercar la educación a los estudiantes, que nuestro video juego se implemente en todas las instituciones de Colombia, y que remplace el manual de convivencia.

Recibir este tipo de asignaturas en el colegio nos amplía la visión. El emprendimiento lo vemos como una gran oportunidad de aprender e ir más allá. Cuando estuvimos en la Feria de Emprendimiento programada por la Fundación Universitaria de Popayán, por ejemplo, fue una gran experiencia para nosotros, porque nos permitió aprender desde la práctica.

Además, hicimos parte de una experiencia muy enriquecedora realizada por la Fundación Mundo Mujer, en la que encontramos proyectos de todo tipo. Como ese espacio, también accedimos al programa EUREKA Colegios, liderado por la Universidad del Cauca.

Para lograr hacer parte de estos escenarios, nuestra familia nos ha acompañado. "Mi mamá y mi papá saben que estamos haciendo este proyecto, ellos nos apoyan mucho. Sin embargo, todos no hemos contado con la misma suerte. En algunos casos, para nuestros compañeros ha sido difícil ingresar y convencer a sus familiares que es importante iniciar con una idea de emprendimiento. Algunos padres dicen que es una pérdida de tiempo. Sin embargo, el emprendimiento desde la formación que hemos recibido, nos ha permitido aprender muchas cosas que nos sirven para emprender, es decir, si queremos iniciar un negocio, ya tenemos unas bases y eso es un aprendizaje para nuestra vida" (estudiante Nicol Ortega).

Algunos estudiantes nos caracterizamos desde pequeños por hacer un cambio en la historia, no solamente quedarnos en la zona de confort. Esta ha sido la oportunidad para interesarte en el emprendimiento. El emprendimiento es innovar, y lo que 
uno busca de la innovación, es sacar un proyecto adelante y que tenga frutos, entonces de esa manera, intentamos innovar con el proyecto para que sea diferente a los demás.

El emprendimiento no solo se basa en encontrar el problema, sino que refleja el esfuerzo de cada persona, y que gracias a ese esfuerzo llegue muy lejos. El emprendimiento, es reconocer ese esfuerzo de las personas que queremos lograr cosas diferentes.

Es reivindicarse, innovar a cada instante para no quedarse atrás. Para ello, es necesario llegar a más emprendedores jóvenes, con estrategias que nos motiven a emprender, a conocer como es el emprendimiento y como se puede construir el futuro, conociendo metodologías y logrando acompañamiento en todo el proceso.

Es necesario decirle al emprendedor, cuáles son los riesgos a los que se enfrenta cuando emprende y como los va a mitigar. Así mismo, revisar el número de trámites y la complejidad de estos. Sin embargo, nuestro mensaje a las personas que quieren emprender, es primero que deben tener una idea bien pensada, acercarse a las entidades y hacer parte de eventos donde puedan aprender, obtener un capital semilla, estructurar muy bien su sueño, como lo va hacer y empezar. Definitivamente, es necesario arriesgarse. Luchar por sus sueños y nunca rendirse, porque los resultados serán solo posibles si deciden actuar.

\section{Soy Autónoma en todos los ámbitos de la vida}

Soy Andrea Tatiana Ordoñez de 23 años, vengo de un pueblo muy bonito que se llama San Pablo Nariño, estudiante del programa de finanzas y negocios internacionales de la Corporación Universidad Autónoma del Cauca, soy deportista y una apasionada de la vida. 
Imagen 3. Estudiante Corporación Universitaria Autónoma del Cauca

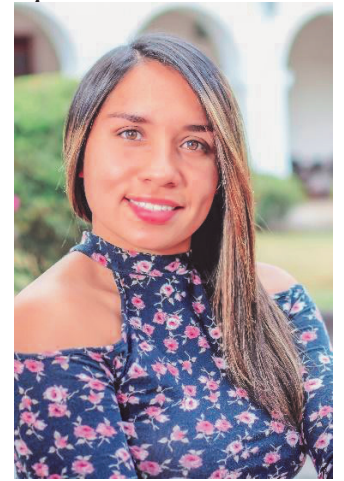

Intra emprendedora Andrea Tatiana Ordoñez Fuente: propia

Inicie con el deporte porque era mi refugio. Mi historia de vida me llevó a buscar alternativas para sobrellevar muchos problemas familiares. Mi papá siempre maltrataba a mi mamá a tal punto que ella llego a quedar en coma dos meses, entonces pasamos por una situación muy difícil, no solamente emocional sino económica. Éramos de muy bajos recursos, y como niña en ese entonces, me sentí muy sola y angustiada.

Es así como inicie con el deporte sin saberlo, era una forma de desahogarme. Mis cuatro hermanos y yo, tuvimos una niñez muy dura, pasamos demasiadas situaciones complicadas y a mis 11 años siendo la segunda ya sentía una cierta responsabilidad de lo que iba a suceder con nuestra vida. Mi mamá tuvo que irse del país para protegerse y es cuando decide viajar a España. Alrededor de todas esas circunstancias, se generan vacíos emocionales que gracias a Dios supe sobrellevar.

Lloraba prácticamente todos los días y todas las noches, estaba muy sola, mi mamá se había ido, así que me independice alos 11 años. Fueron momentos muy difíciles, en los cuales necesitaba un refugio. Cuando me atacaba esa angustia emocional, salía a correr. En ese momento estaba viviendo en Florencia, Cauca y estudiaba en la Institución Educativa Toribio Paz Moncayo. Me 
levantaba a las 5 de la mañana y me iba a correr por las veredas, y así inicie. La gente decía que yo estaba loca, porque en el campo no se veía que las personas hicieran deporte. De todas formas, no me importaba lo que los demás decían, sino más bien me enfocaba en como satisfacer esa necesidad y ese dolor.

Estando en España, mi madre también sufrió mucho al tener sus hijos lejos y en ocasiones nos decía que quería regresar a Colombia, pero esa no era una opción para nosotros que queríamos que ella estuviera bien. Entonces empecé a salir adelante, nadie fue a mi colegio por un boletín porque no contaba con el apoyo de mi papá, mucho menos con el de mi madre, porque no podía, solamente lo hacía enviándonos dinero y llamándonos. Hoy en día soy lo que soy, gracias a ella, soy el resultado de su esfuerzo y su valentía. Ella es una mujer de riesgos y es mi ejemplo.

Mi mamá cuando se fue a España lo hizo solicitando una visa por tres meses y después de ese tiempo estuvo cuatro años escondida de la oficina de Migración, hasta que fue ubicada y a punto de ser deportada. Afortunadamente, por el tiempo que llevaba, le permitieron hacer su proceso de nacionalidad. En esa travesía, empezó a trabajar en la casa de un escritor español, quien escribió la historia de nosotros y sacó un libro llamado "la Noche sin Luces". Él la resguardaba y valoró su trabajo, las ganas de salir adelante. Posteriormente, se radicó en Italia donde hoy en día vive, y se asoció con una amiga también colombiana, de Medellín. Tienen su propio local de pastas. Les ha ido muy bien gracias a Dios, y eso ha sido por su determinación. A veces tienes que sacrificar muchas cosas para obtener algo, eso es lo que uno puede ver en ella. Ese es el ejemplo que tengo, luego de haber pasado toda esa situación del colegio, de la etapa de la adolescencia que son tan difíciles, e iniciar en el deporte.

Estando en Florencia, Cauca, tome en arriendo una habitación, que en esa época costaba entre $\$ 40.000$ y $\$ 50.000$ pesos. Vivía sola, me dedicaba a ir al colegio, gracias a Dios siempre me 
fue muy bien, los profesores eran un apoyo incondicional, ellos eran mi familia, mi segundo hogar, porque todos conocían mi historia. Posteriormente, me di cuenta que en mi pueblito había baloncesto, entonces empecé a jugar baloncesto y así trascurrió el colegio. Realmente pensaba que para mí no estaba hecha la universidad, veía muy lejana esa posibilidad, porque no tenía los recursos económicos en ese momento. Mi mamá a penas se había ido y llegar a un país es muy difícil, arrancar de ceros es complejo, así que mis estudios universitarios no se iban a poder.

No sabía que iba a hacer, hasta que llegué a once y me gradué. Estuve un año cuidando a mis hermanos y de paso pensando que hacer, como lograr entrar a la universidad. En ese momento, escuche de la Autónoma del Cauca. Quería una carrera relacionada con las finanzas, entonces una amiga me hablo que la institución tenía ese programa, Finanzas y Negocios Internacionales. Eso me llamo demasiado la atención, así que fui al programa, revisé el valor de la matrícula, y me decidí.

Con la ayuda de mi mamá, inicié mis estudios universitarios y, además, me enteré que la Autónoma apoyaba a deportistas. Anualmente realiza una carrera de los 5k, entonces me metí a esa competencia y gané el primer lugar. Así, la institución posteriormente me fue becando, y la mitad de mi carrera la pude solventar. La otra mitad ha sido gracias a la ayuda de mi mamá.

Todo para decir que ha sido el reflejo del esfuerzo, del deporte. Poco a poco se van viendo los resultados. Ahora inicie con una idea de emprendimiento con mi novio. Se dio gracias a la universidad, porque la universidad se ha enfocado en el emprendimiento y a despertarnos esa inquietud desde el aula.

Soy sincera, vengo del campo, y uno no oye nada sobre emprendimiento, es decir, en la cabeza no tienes ningún referente al respecto. En la universidad es cuando los profesores empiezan hablar de emprendimiento, de ser una persona autónoma, de 
generar empresa, y eso fue una experiencia muy enriquecedora para mí. Recuerdo que uno de mis profesores siempre decía que las ideas realmente surgen en el momento menos esperado, de lo más loco puede surgir lo más lindo y fue así como empezamos con una idea de negocio.

Como me muevo en el sector deportivo, con mi novio empezamos a fabricar bocadillos, pero no bocadillo de guayaba, sino de fruta. Los deportivas antes de las competencias, durante y después, necesitamos energía. Venden unas gomas energéticas, pero tienen demasiados conservantes, realmente no son muy aptas para la salud. Entonces decidimos hacer lo mismo, pero bocadillos de frutas y hacerlos personalizados, según la fruta que más les guste. La fabricación es 100\% natural con la fibra de la fruta.

Estamos comenzando con esto, y creo que lo más difícil surgió, que es la idea. Tener la idea, la receta, aprender a hacerlos, es una experiencia muy gratificante. $\mathrm{Y}$ todo ha sido gracias a la universidad, porque realmente si yo no hubiera tenido esos conceptos y a los profesores que me motivaron, no habría iniciado.

Ahora bien, en el deporte logre pasar al Desafío de Regiones. Esto ha sido otra historia. En el colegio había participado en los juegos inter colegiados, una vez en atletismo. Había ocupado el segundo puesto y cuando llegue a Popayán, me encuentro a uno de los entrenadores, que incluso trabaja en la institución, el profesor William Gurrute. Un día, me lo encontré en la calle y me dijo que, si seguía haciendo atletismo, que porque no iba a entrenar con él. Pensé en ese momento, que era la oportunidad de volverme a enganchar.

Inicie a entrenar con él nuevamente atletismo, llevaba un año y medio hasta que apareció mi entrenador de triatlón, que es Víctor Catamuscay. No sabía realmente que era el triatlón, pero siempre he sido muy activa, entonces él creyó que tenía potencial. Me invito a realizar triatlón y me explico en qué consistía, que 
era nadar, montar bicicleta y correr. Me invito a una competencia, la realice y quede en primer lugar. Eso a él le llamo mucho la atención, porque no tenía entrenamiento, especialmente en natación. Empecé entonces a entrenar y me encontré que lo más difícil, era la natación, porque no tenía bases y es un deporte que requiere demasiada disciplina y constancia. Si uno quiere mejorar, debe ser constante, sino es muy complicado tomar la técnica. Seguí entrenando y ya no solo participaba en campeonatos departamentales, sino nacionales, iba a copas y me fue muy bien, quedaba de primera y de segunda. Fui a participar a varios lugares como San Andrés, Bucaramanga, Cali y a muchos más, e incluso soy selección Colombia de Triatlón.

Iba ir a un mundial a Pontevedra España, lastimosamente no pude porque se me cruzo con el Desafío. Tenía que tomar una decisión, ir al mundial o ir al Desafío. Opte por ir al Desafío porque era una oportunidad muy bonita de darme a conocer. Como deportista y como persona, se le abren muchas puertas, entonces decidí que esa era la mejor opción.

Una tarde, estaba en la casa haciendo un trabajo de la universidad y sonó el teléfono, contesté y me dijeron que eran del canal Caracol, que estaban buscando deportistas de alto rendimiento del departamento de Nariño, que casualmente él tenía familia en Pasto y le habían dado mis referencias. No sabía de donde habían conseguido mis datos. Entonces me comentó que se trataba de un Reality, y que si estaba interesada. Al principio, se me hacía como extraño, pensaba que eso no era para mí. Sin embargo, acepté, pase los filtros e inicie el proceso.

Tengo que decir que fue una experiencia muy dura, no solamente se necesita tener el estado físico, sino que es necesario tener una preparación mental. La situación era peor de lo que yo me la había imaginado, tuvimos que pasar por unas situaciones extremas en República Dominicana, alejada de la familia y amigos, con unas temperaturas superiores a los 40 grados y estar 
separado de cualquier medio de comunicación. Allá me di cuenta que dependía mucho del teléfono, de elementos de aseo personal, entre otros.

De esa experiencia me quedo el hecho de valorar. Uno cree que valora a su familia, pero realmente no es así. En mi caso, hemos vivido situaciones difíciles, pero jamás hemos llegado a esos extremos por los que tuve que pasar. Allá valoraba hasta lo más mínimo, desde la comida hasta los amigos.

Entonces los intra emprendedores somos personas arriesgadas, claro nos enfrentamos al temor, pero somos capaces de dejarlo a un lado y arriesgarnos. No importa si te estrellas, te levantas nuevamente y vuelves a intentarlo. No es posible quedarse con el miedo, porque las oportunidades están, lo que pasa es que el miedo de no salir de la zona de confort no nos deja surgir. Llegan muchas excusas y no salimos de ahí.

Las oportunidades si están, pero ¿cómo te van a llegar, si tu no las buscas? Es necesario tener un plan, hacerse una autoevaluación y decir, yo soy bueno para esto, guiarse por ese camino y seguir. Decir, yo soy así, y mis características son estas, entonces ¿porque voy a seguir las características de las demás? Enfocarse en uno mismo y así las cosas van surgiendo. $\mathrm{Y}$ en relación con el deporte, tristemente en el departamento y en Colombia como deportista, es muy difícil salir adelante. Para ir a los campeonatos, no hay apoyo en financiación, es algo muy difícil, porque si tú tienes los recursos, muy bien, tú puedes ir a los mundiales que quieras, pero uno ve gente en atletismo, por ejemplo, que tristemente no tienen ni mil pesos. Son muy buenos, tienen todo el potencial, pero no pueden surgir porque no hay recursos económicos.

El problema es que hasta que tu no estés arriba, logrando medallas de oro y obteniendo reconocimiento a nivel nacional, nadie da un peso por ti. Nadie va a decir, usted puede ser buena y vamos a acompañarla a crecer. 
Ahora debo graduarme, finalizar mi carrera. Ya pasé al último semestre de finanzas de negocios internacionales, y estamos evaluando la posibilidad de irme al exterior con mi mamá. Ella está en Italia, y quiere que siga estudiando, seguir emprendiendo, seguir con la idea de los bocadillos.

\section{Emprender desde una mirada de la administración pública y privada}

Imagen 4. Emprendedor del sector público

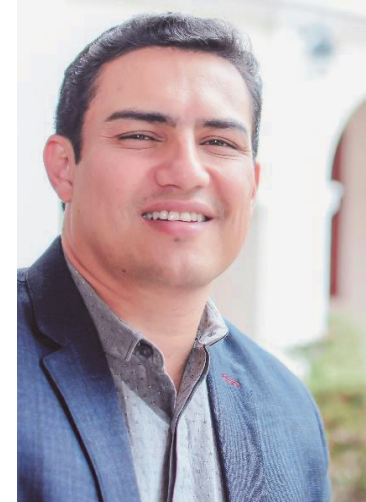

Christian Ortega Gómez - Fundador Concretar Solución Integral S.AS.

Fuente: propia

Soy Christian Ortega Gómez, oriundo del municipio de Morales Cauca, Economista de la Universidad del Cauca, Administrador Público de la Escuela Superior de Administración Pública ESAP, con estudios de especialización en Derecho Tributario de la Pontificia Universidad Javeriana de Cali y maestría en Administración de la Universidad Icesi.

Desde muy joven me radiqué en la ciudad de Popayán para adelantar estudios de básica y media, los cuales terminé posteriormente en el municipio de Morales Cauca. 
Adelanté mis estudios universitarios y una vez egresado, me dediqué a trabajar en planeación pública, específicamente en municipios. En el 2007 me vinculé con una entidad financiera, llegando a ser gerente comercial por 10 años, hice parte de diversas bancas, estructurando y desarrollando negocios financieros. Con los años, adelante estudios de maestría en Administración la Universidad Icesi. Paralelo a esa experiencia, pude cambiar de perspectiva, y decido salir de la zona de confort. Tenía esa tranquilidad que te otorga ser parte de una entidad, estable y con muchos beneficios. Sin embargo, me di cuenta que ya no quería ser empleado.

Esa es una característica del emprendimiento, de salir de las zonas de confort, de mirar un poco más allá y de asumir riesgos. Asumí el riesgo, dejé el cargo que tenía desde hace 10 años y regresé a Popayán.

Lo único que me acompaño durante ese tiempo además de lo laboral, fue mi labor de docente que continué ejerciendo, y que lo hago más por pasión que por cualquier otra cosa. Me encanta, seguramente porque mis padres son docentes. Cuando llegué a Popayán, me empleé como profesor de la Institución Universitaria Colegio Mayor del Cauca, y de la ESAP Cauca.

Después estuve incursionando con unos amigos en diversos proyectos, y es interesante decirlo, porque eran amigos que estaban en igual condición que yo, en el sentido que estaban en una zona de confort, estaban con buenos y estables empleos, con posiciones de direcciones muy interesantes, pero veían que no podían crecer más y tomaron decisiones similares a las mías, de renunciar a lo que tenían y emprender con nuevos procesos.

Efectivamente eso hicimos y estructuramos una firma de consultoría en temas jurídicos y financieros hace ya un poco más de un año y medio. Incursionamos en procesos de proyectos de turismo, asesoría al sector privado y público. 
Entonces fundamos Concretar Solución Integral, una empresa dedicada a la asesoría financiera y jurídica, además de incursionar en obra pública. Sin duda este tipo de ejercicios han sido el resultado de una formación en lo público. En ese sentido, hay que decir que el conocimiento de lo público es complejo y especifico. En temas académicos que he logrado obtener en diversas universidades en las que he estado diferentes a la ESAP, y menos en formación de pregrado, no he visto que se plantee realmente la problemática de entender toda la complejidad del estado, las responsabilidades y demás particularidades de lo público. Eso no te lo enseñan las aulas, si no haces la carrera de administración pública o algún posgrado en temas de administración pública.

El segundo aspecto, está relacionado con redes de conocidos, de amigos que trabajan en lo público. La ESAP es muy buena para el relacionamiento público, entonces tus compañeros de estudio serán futuros alcaldes, diputados, gobernantes y directivos. Eso implica que haces una muy buena red de contactos y ello facilidad la gestión en todos los procesos.

Desde el proceso de consultoría de esta empresa, desde su planeación estratégica, hemos vislumbrado primero, un fortalecimiento y reconocimiento de la empresa que aún sigue siendo pequeña, continuando con la línea de la asesoría jurídica y financiera, siendo este nuestro fuerte. Además, fortalecer el acompañamiento en obra pública, porque nos ha parecido una buena forma de impactar la sociedad, una fuente de negocios y de utilidad.

Sin embargo, emprender ha sido supremamente difícil porque la normatividad a diferencia de otras ciudades, muestra una lectura compleja que no invita a la gestión. En otras ciudades hay más facilidad, existen más recursos de todo tipo, empezando por el recurso humano. Entonces si necesitas conseguir a una persona que sea muy buena en temas por ejemplo de estructuración de manual de funciones para las entidades, es más complejo en Popayán que en otros lugares. 
Se vuelven complejos temas regionales y locales desde la perspectiva de normatividad. No estoy hablando de leyes que expide el Congreso de la República, que también tiene sus complejidades sobre todo en temas tributarios, que les piden a las pequeñas empresas, me refiero a la capacidad de interpretación cuando la normatividad a veces no es clara, cuando tiene esos vacíos que generan complejidades, y que desde la mirada local no se logra agilizar.

Por ejemplo, hay un proyecto turístico muy bonito que tenemos y hemos tenido una gran dificultad porque no hay claridad desde lo local en temas por ejemplo de la estructuración de proyectos inmobiliarios. Los temas del ordenamiento territorial que todavía no está actualizados, entre otras cosas, dificulta salir adelante con estas iniciativas.

Por otra parte, es importante decir que, en este ejercicio de emprender, la familia también es un aspecto a considerar. En mi caso, fue muy difícil irme de Cali. Si bien mi esposa estaba en Popayán y en ella, encontré un gran apoyo, algunos familiares sobre todo mis papás, consideraban que tal vez esa no era una buena decisión. Ellos de una cultura más conservadora y más estática, veían con preocupación que pensara dejar un trabajo estable cuando tenía la responsabilidad de tres hijos. Sin embargo, ese al final se convierte en el motor principal.

El primero, lo tuve muy joven, y hoy en día está estudiando en Popayán Derecho, el segundo estudia en Cali, y mi tercera hija de mi actual matrimonio. Entonces esas responsabilidades implican muchos riesgos, implican que te sientes a veces a evaluar que se viene y como estamos haciéndolo, pero, las presiones que tienes alrededor y desde ese ámbito psicológico, entre otras, te desarrollan capacidades de visualizar cosas que antes no veías. La misma presión implica que uno tenga que movilizarse, que uno tenga que ser creativo, el cerebro se activa, te vuelves más trabajador. 
Hoy en día trabajo mucho más de lo que trabajaba antes, pero estoy feliz con eso y estoy en un proceso de construcción de una mejor persona y una persona más integral de lo que era antes.

El emprendimiento a uno le cambia la vida para bien. Si retrocediera en el tiempo, tomaría nuevamente la decisión. Tenía mucho miedo de dejar de recibir un sueldo fijo, pero realmente si tú eres capaz, si tienes las competencias y eres trabajador, no te tiene que ir mal. Si realmente eres trabajador y tienes algunas herramientas o competencias que te dan la práctica y los estudios, es difícil que no consigas que hacer.

Hay mucho trabajo y muchas cosas por hacer. Popayán tiene ese potencial. Por ejemplo, desde las finanzas evidenciamos grandes oportunidades. Hay empresas que todavía no manejan temas financieros, no tienen un presupuesto, por ejemplo. Yo llegue a empresas que vendían 3 mil millones y no tenían estructurado un presupuesto, y decía como lo hacen. Seguramente contaron con la bondad del mercado y su producto se les vendía sin mucho proceso de planeación, pero los tiempos ya son otros. Hemos estructurado dinámicas muy interesantes con esas empresas, hay varias alternativas para trabajar.

En ese sentido, para mí el emprendimiento es un proceso, por el cual, se toman decisiones referentes a un negocio, se asumen unos riesgos que no están totalmente cubiertos, porque si te pones a valorar todos y cada uno de los riesgos, seguramente tendrás que dar un paso atrás. Lo increíble es que he notado, con gente que le ha ido muy bien y que ha sido conocedora de proyectos muy interesantes, que me decían que si ellos hubiesen tenido el total conocimiento de cómo era el proceso, no lo habían hecho. Tengo una persona muy cercana, una cuñada emprendedora que tiene una empresa en el sector de tránsito y transporte, muy prospera. La complejidad no la conocía, la fue surtiendo en el camino. Donde ella hubiera conocido la complejidad desde el principio y todo lo que requería ese sector tan regulado y los tiempos que se requieren esperar para sacar su proyecto adelante, seguramente 
había desechado la idea. Entonces el emprendimiento es la suma de medir algunos riesgos, y de tomar decisiones arriesgadas, olvidándose que todo lo debe controlar.

De esta forma, las entidades que acompañan el emprendimiento requieren darse a conocer y dar a conocer más lo que hacen. Llamemos a eso, una estrategia de visibilidad. Por ejemplo, somos parte de un proyecto con la Gobernación del Cauca, para la creación de un Centro de Estudios Económicos del Cauca, siendo este un centro especializado en generar conocimiento económico para la toma de decisiones, sumado a ello, aspectos relacionados con política económica. Y dentro de la institucionalidad vi esa articulación tan interesante que hay, por ejemplo, entre gremios privados y públicos, y otra serie de organismos que estructuran estrategias que acompañan a los emprendedores, que no te pueden entregar seguramente un recurso, pero si articulan y generan condiciones.

En mi caso particular, no hice el ejercicio de investigar y acercarme, entonces fue más difícil. En el caso del proyecto de turismo que veníamos adelantando, iniciamos con unas inversiones altas y no sabíamos de todas las opciones que hay en créditos blandos, en estructuración de proyectos y de acompañamiento de esos proyectos por parte de las entidades.

En ese sentido, Colombia debe apostarle no solo a generar emprendimientos, sino que estos sean asertivos y sostenibles. De este modo, a los emprendedores les tengo que decir desde mi experiencia, que, si el emprendimiento es una opción, si es un proyecto de vida, demanda mucho trabajo. Quien quiera emprender y no está dispuesto asumir trabajos en horas de la noche, los domingos, es mejor que no lo haga.

El emprendimiento requiere asumir esos retos, requiere de mucha organización de su tiempo, implica proyectar lo que quiere de su proyecto, para donde va y adelantar un proceso de planeación. 
También estar dispuesto a aceptar fracasos y levantarse. Como emprendedor tuve fracasos que me costaron mucho dinero, y que actualmente todavía los estoy asumiendo. Sin embargo, hay que aprender de esos fracasos, levantarse y ver como se solucionan las cosas.

En todo esto, hay una capacidad de residencia que tienen que tener los emprendedores, pero definitivamente, es un proyecto de vida, es un producto interesante, porque te abre la visión, te genera unas dimensiones que antes no veías, te da libertades para manejar tu tiempo, entre otras cosas. Si vale la pena, pero hay que tener claro el costo de asumir ese tipo de decisiones.

\section{Emprendimiento Tecnológico}

\section{Solmedia Digital}

Imagen 5. Emprendedores digitales

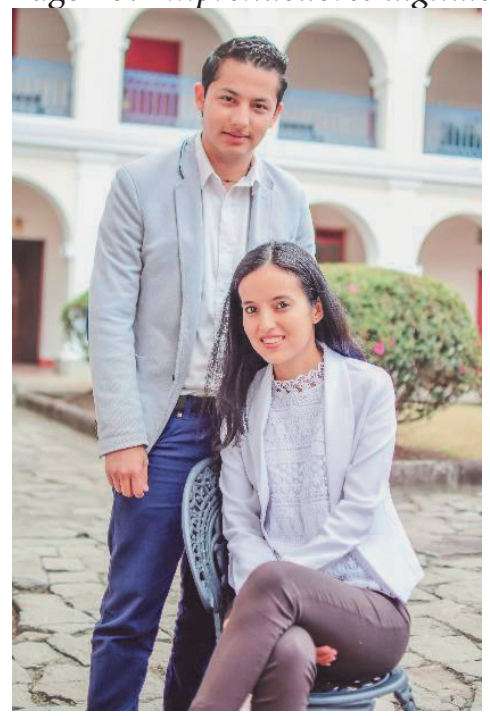

David Sebastián Agredo Navarro - Fundador y CEO de Solmedia Digital Ingrid Araujo - Comunicadora Social y socia de Solmedia Digital Fuente: Propia 
Soy David Sebastián Agredo Navarro de 27 años, del municipio de Timbío, Cauca, de la vereda Las Huacas. Provengo de una familia campesina cafetera, mi padre trabaja en el área de la construcción y mi madre es artesana de la Seda. Para mis papás siempre fue muy importante la educación. Desde muy pequeños a mi hermana y a mí, nos inculcaron la importancia de la educación.

Mis papás con los años, también le apostaron a la formación y mi papá, por ejemplo, se graduó de tecnólogo a los 50 años y mi mamá como artesana de la seda, se capacita continuamente en esos temas.

Hoy en día soy el fundador y CEO de Solmedia Digital, con formación en ingeniería en electrónica y telecomunicaciones de la Universidad del Cauca, con estudios del Servicio Nacional de aprendizaje SENA como desarrollador de software y diseño web.

Desde que tengo memoria, quise tener una empresa de tecnología. Lo mío siempre fueron las computadoras, la tecnología y la informática. Me destaqué en el colegio en eso, graduándome como bachiller a los 16 años. Ingrese a estudiar Ingeniería Electrónica en la Universidad del Cauca. Empecé a ver un vacío en lo que no nos enseñaban sobre cómo hacer empresa, siempre era información para trabajar como empleado.

Entonces me gustaba asistir a seminarios, charlas y conferencias que daban en la universidad y me di cuenta cómo a estudiantes de maestría, por ejemplo, cuando hacían sus proyectos de grado, sí les empezaban a inculcar que crearan empresa. Yo me preguntaba porque no le dicen eso a uno en pregrado. Empecé a ver que la universidad era muy teórica, entonces entre a estudiar al mismo tiempo en el SENA, Análisis y desarrollo de sistemas de información y todo era mucho más práctico, continuando a la par con mis estudios universitarios. Del 2012 al 2014 fueron años complicados en el manejo del tiempo entre ambos estudios, además de trabajar por horas, para contar con recursos para moverme. 
Estando en ese proceso de búsqueda de información sobre crear empresa, empiezo a entender un poco más de emprendimiento, que lo mío era emprender en tecnología, busqué cuál era el camino para emprender; asistí a muchas charlas en la universidad, en el Sena, la Cámara de Comercio del Cauca y otras universidades, también participaba en eventos de ParqueSoft Popayán y hoy en día, Clúster CreaTIC, comprendiendo que lo que yo quería era "Ser un emprendedor". Con todo eso, hice una cantidad de procesos de formación y capacitación, especializándome en desarrollo web.

Posteriormente, encuentro la oportunidad de trabajar con proyectos de desarrollo web y en capacitaciones para la apropiación de TIC en municipios del departamento del Cauca, así mismo iba iniciando algunos proyectos de emprendimiento, que me llevaron a participar en diferentes eventos relacionados con emprendimiento en Popayán y a obtener invitaciones para asistir a actividades similares que me permitieron conocer algunas ciudades del país, enamorándome cada día más, de esa magia que tiene emprender.

Entre trabajar, estudiar en la universidad, proyectos y terminar estudios en el Sena, el tiempo no me alcanzaba y no fue nada fácil, llegó el momento en que tuve que irme a vivir a Popayán, así podía dedicarme más a crear mi empresa.

Todavía no he terminado la carrera, porque ha sido difícil manejar el tiempo. Me ha tocado cada semestre de a poco por así decirlo, pero ya espero terminar pronto, y mis papás también están a la espera que eso suceda. No ha sido fácil para ellos comprender que alguien no decida trabajar para otros sino crear algo propio, pero creo que poco a poco se están dando cuenta de los beneficios de tener empresa propia.

Entre el 2015 y el 2016, se consolida un poco más mi idea de empresa y empiezo a notar que si funciona y que podría tener buenos clientes, luego gané una beca para un diplomado 
en emprendimiento de un programa de Google y Colnodo para fortalecer conocimientos en lo que quería hacer para mi emprendimiento.

Iniciando el 2017 hago una visita a Clúster CreaTIC, quienes apoyan el emprendimiento en el Cauca, les comento a los asesores que ya había estado trabajando un poco en la empresa que en ese entonces se llamaba Social Media Digital Solutions, que es lo que hacemos "Social Media", y les cuento de la idea para ver si funcionaba.

Loqueyo quería, era ayudar a empresasen la transformación digital y que utilizarán medios digitales para obtener clientes y posicionamiento de marca, pero enfocándonos en pequeñas y medianas empresas de ciudades pequeñas, "Marketing digital para MiPymes" era el eslogan en ese entonces.

El apoyo del Centro de desarrollo Tecnológico Clúster CreaTIC fue muchísimo, les pareció muy buena idea, y empezaron a unirse más personas a mi equipo. Llegó Ingrid Araujo una comunicadora social, experta en fotografía y vídeo, a quién debo agradecer mucho ya que fue la primera en creer en mí y en lo que ahora es nuestra empresa; luego se unió al equipo una diseñadora, un administrador de empresas y otro comunicador social, Víctor Stiven Peña, con un super talento quién nos apoya en fotografía, video y animaciones, así poco a poco hemos ido creciendo. Gracias al apoyo de CreaTIC, hemos consolidado este modelo de negocio, producto de las asesorías, de su acompañamiento y de seguir los pasos que su metodología tiene bien definida. Los que nos formamos en el área técnica, ingeniería y desarrollo no tenemos muchos conocimientos en temas gerenciales administrativos contables y gracias a los procesos que se brindan en CreaTIC hemos podido lograr una mayor organización.

Cuando inicié la idea de la empresa el nombre era "Social Media Digital Solutions" era muy largo, y tenía que ser más pegajoso y fácil de recordar, pasando a SM Digital Solutions, 
y después me di cuenta que si lo reducía quedaba Solmedia Digital; era mucho más fácil de recordar. La idea era apoyar a microempresarios para la transformación digital de sus negocios, apoyar en la creación de páginas web y darle importancia al uso de redes sociales para la comunicación y posicionamiento de marca. Antes trabajaba realizando capacitaciones en apropiación de TIC, visitando diferentes municipios del departamento del Cauca y me puede dar cuenta que muchos municipios, con muchos negocios no hacen uso de redes sociales para potenciar sus ventas, como si lo hacen en las ciudades principales. Por eso, empecé con algunos negocios municipios como Timbío y Popayán.

Posteriormente, mi socia, Ingrid Araujo me dijo que el proyecto que estaba iniciando era muy bueno, que debería incluir videos y fotografía para que se complementará y entonces empezó a trabajar conmigo. Luego, ingresó una diseñadora gráfica que aporta lo visual y nos permite ver de forma más agradables lo que hacíamos, después se incorpora, Stiven Peña que fortalece el área de fotografías y videos. Continuamos con marketing digital, con el fin de darle un mayor alcance, necesitándonos formarnos en ese tema, y cuando empezamos a ofrecer planes de servicio que incluían fotografía, videos, páginas web, diseño, gestión de redes sociales y estrategias de marketing digital, ahí fue cuando comprendí que realmente le estábamos apuntando a lo que yo había soñado.

Anteriormente a Solmedia Digital ya había iniciado otro proyecto de ámbito social que ahora quiero formalizarlo como una Fundación. Este proyecto se llama JuvEmTiC "Juventud Emprendimiento y Tecnología del Cauca. Lo que yo quería hacer en ese entonces cerca del año 2012 y 2013 fue una idea que tuve cuando apenas salí del colegio, y consiste en facilitar información a jóvenes qué como yo, son de veredas y zonas rurales, que no tienen muchos conocimientos acerca de la importancia de estudiar y sobre las carreras a elegir. Empecé a brindar unas charlas gratuitas a diferentes colegios en Timbío y en el Tambo, 
Cauca, sobre la importancia de estudiar, sobre emprendimiento, tecnología y las oportunidades de becas de estudios, los contenidos generales de los programas profesionales y con ello, lograr que otros chicos tuvieran oportunidad de estudiar por medio de becas y oportunidades que se pierden por no saberlas aprovechar, e incluso por no conocerlas. Esta actividad la hacía porque me gustaba y aún lo sigo haciendo, pero ya en menor cantidad, por el tiempo, sin embargo, asisto a eventos de emprendimiento donde me invitan en diferentes colegios de Popayán y en municipios del cauca, e incluso he brindado charlas en otras ciudades del país contando mi historia y con ello motivar a que los jóvenes se formen, que emprendan y que conozcan y aprovechen las oportunidades que existen.

Emprender no es fácil. Cuando recibimos el acompañamiento de los asesores de Crea TIC, nos decían, busquen qué tipo de clientes tienen ustedes. Entonces yo sacaba una lista de posibles empresas que fueran clientes nuestros. Te enfrentas a una realidad y es que no conoces a nadie. Es muy difícil tocar puertas, hay un tema de resiliencia y de persistencia. Yo iba a empresas y a instituciones educativas a decir que tenía 23 años, que tenía una empresa, y la gente decía, como puedes hacer eso tú. Intente en muchas ocasiones, casi durante un año entero con una empresa, diciéndole, le ofrecemos esto. Después al mes, lo mismo. Al final de una siete veces de intentarlo, la persona me dijo que sí. Ese fue uno de nuestros primeros clientes.

Recuerdo en el año 2017, gracias a una colaboración del Cauca y Clúster Crea TIC, nos llevaron a participar a una feria en Bogotá. Estaba muy juicioso con mi Stand brindando mis servicios y llegaban muchas personas. Era una feria muy grande. Les contaba sobre mi empresa, y en dos oportunidades, algunas personas, me dijeron, algo como: “y ustedes en Popayán sí han estudiado marketing digital, ¿hay universidades para estudiar allá?" otros me preguntaron: "si uno hace negocios con ustedes 
uno como llega a Popayán, si hay aeropuerto?” Me pareció increíble, que todavía se crean que somos una zona muy alejada sin acceso a tecnología.

Esa experiencia la asocio a lo que quiere hacer mi proyecto social JuvEmTiC, a través del cual, los jóvenes puedan aprovechar oportunidades para estudiar, salir adelante y dar a conocer todas las capacidades que tiene nuestra región.

Hay muchas oportunidades y debemos aprovecharlas. Por ejemplo, ganamos una convocatoria organizada por la embajada de Francia en Colombia. Fuimos los representantes del Departamento del Cauca, en la Apps Hackathon Francia desarrollando un videojuego para el aprendizaje del idioma francés y logramos ganar el premio frente a diferentes equipos del país, el premio fue un viaje a París Francia. Parte de mi equipo, pudimos hacer el viaje y fue una gran experiencia, no solo visitando Francia sino, otros países de Europa. De ese viaje, logramos algo muy bueno, ya que a cada país que visitamos, siempre a la agencia que nos hacía un tour, le daba una tarjeta y le contaba de mi empresa. Soy de Colombia y hacemos esto y aquello. Finalmente, en Atenas, Grecia, entregamos la tarjeta a quién casualmente era director de la empresa del operador turístico y me dijo, yo estoy buscando algo así relacionarlo a lo que hacen ustedes, déjame la tarjeta y después hablamos.

Nosotros llegamos del viaje a Colombia y como a los tres meses, recibimos una llamada y era el señor, diciendo que quería arrancar con nosotros y fue nuestra primera experiencia de exportación de servicios. Imagínate una empresa de Popayán, pequeña vendiendo a Atenas Grecia, entonces eso ha sido un tema que nos ha parecido extremadamente interesante.

Tenemos el objetivo de seguir creciendo y disponer de nuestra empresa para vender productos a mercados internacionales. Tenemos, otro cliente en Chile, a quién estamos 
apoyando. Tenemos la mira en Europa, porque con la visita que hicimos y gracias a gestiones de Crea TIC logramos conocer algunas empresas y algunas entidades, como incubadoras y aceleradoras de emprendimientos.

Nos dimos cuenta, que lo que hacemos nosotros es bien pago y muy necesitado en Europa, por ejemplo, para las industrias creativas, especialmente que se dedican al diseño, fotografía, video. Ahora estamos estudiando idiomas. Con esto quiero decir que veo la empresa en un futuro, como una empresa que se dedique a brindar servicios en el exterior, y que siga apoyando a empresas caucanas.

Otro logro es saber que puedes generar empleo. Cuando uno empieza, no se lo imagina. Uno sabe que en algún punto va a tener que contratar a otras personas, pero no se lo imagina. Hoy contamos con personas que nos ayudan y que les paguemos por lo que pueden hacer con sus conocimientos, aunque no sea mucho, el saber que, gracias a ese esfuerzo previo de sus estudios, uno tiene con qué pagarles algo y que con eso pueden seguir estudiando, y ayudando a sus familias es una gran motivación. Ese tipo de cosas siempre las voy a recordar, ya que espiritualmente se siente muy bien, al generar empleo y ayudar a otros.

Emprender es difícil empezando porque nunca tienes formación desde pequeño en temas de emprendimiento. Cuando sales del colegio, ni se te ocurre que puedes crear una empresa, no se te pasa por la mente. Empezando por ahí, el tema de formación, desde el colegio es muy importante. Decirles a las personas, que hay un camino que es el emprendimiento y es crear empresa. Popayán es una ciudad muy pequeña, no hay muchas empresas grandes a las que puedas brindar servicios y la cultura es de ver todo chiquito, "la ciudad de los itos dice mi papá: más baratico, cuánto vale esito, deme estico". Entonces eso dificulta la venta de los productos o servicios. Yo espero que eso poco a poco vaya cambiando con el apoyo de las entidades que acompañan 
el emprendimiento como la Cámara de Comercio del Cauca, quien organiza programas como Ingenia o Ingeniando, también programas de Universidades, la Alcaldía, la Gobernación del Cauca y Clúster Creatic.

En ese sentido, es necesario seguir generando espacios donde los emprendedores puedan llevar sus ideas y validar si en verdad funcionan, y que eso los lleven a evaluar si deben formalizarse. Hemos visto la diferencia que hay entre la cultura de municipios cercanos, o en otros departamentos, y la propia. La gente está más abierta a los precios, hay gente que ya no te molesta por los precios, eso vale y ya está. Uno se da cuenta que la cultura afecta mucho y afecta al emprendimiento. Las personas crean mucho más, en donde la gente es más unida. En Popayán hay una cultura a veces de la no asociatividad, de querer hacer las cosas solo. Hemos visto que para muchas empresas les es muy difícil aliarse para atender a un cliente grande, es algo que no nos detiene y siempre buscamos alianzas o la forma de trabajar con otras empresas y apoyarnos.

En cuanto a la situación de crecer en emprendimiento hemos tenido la oportunidad de participar en algunas actividades de la Cámara de Comercio del Cauca y otras entidades. Cuando apenas inicias, la formación y capacitación es fundamental, pero luego debes escalar a otras plataformas como Clúster CreaTIC, con procesos más avanzados, donde encuentras recursos económicos que permitan, visitar otras ciudades y hacer actividades para relacionarse con empresarios que pueden ser posibles clientes. Hay un punto en el que hasta ahí llegas, no hay otra entidad en la que uno pueda seguir avanzando un poco más, entonces creo que para procesos iniciales, la formación y capacitación, está muy bien consolidada, pero cuando llegas a un punto en donde ya tienes clientes, ya más o menos sabes por dónde va la cosa, ya está funcionando con un equipo de trabajo, y en ese punto, la capacitación ya no es tan relevante, porque lo que interesa, es expandirte, visitar otros clientes o moverse en otras regiones, 
donde uno pueda ofrecer sus servicios. Siempre hay convocatorias $\mathrm{y}$ actividades en las cuales se queda únicamente en el proceso de formación y capacitación.

A veces no se tienen los recursos como para un viaje hasta Bogotá, por ejemplo, para estar una semana haciendo visitas a clientes, entonces en ese aspecto, creería que hay que hacer algo, con el fin que uno tenga posibilidades para ir a otras regiones y tener espacios donde estar un tiempo, alguien que lo reciba y que le ayude con ciertas actividades que en algunos aspectos lo hace CreaTIC, desde un proceso de aceleración avanzado. Debería haber más entidades que hicieran alianzas entre todos para que eso se logrará.

Otro aspecto indispensable es el apoyo de la familia y los amigos. En mi casa ha sido un poco complejo porque por ejemplo mi familia viene de una cultura muy tradicional, con raíces del campo y son muy pocos los que han logrado estudiar y formarse en una universidad. Ser uno de los pocos que sí entró a la universidad y a una universidad pública, que de un momento a otro les diga a los papás, que se está dedicando a una empresa y que no va a trabajar para otro en una empresa, es extraño. Para mis papás ha sido complejo, porque es lo que han visto en todas las personas, o trabajan o estudian para tener un mejor camino. El paradigma que siempre se tiene, es gradúese rápido y trabajar. Ya poco a poco la situación ha ido cambiando. Se han dado cuenta de los beneficios logrados. Por ejemplo, que haya viajado y que conozca varias ciudades del país por clientes. Empiezan a notar que eso de hacer empresa como que sí funciona, pero al inicio, para familiares y amigos, era lo más extraño que le puede pasar a alguien. Este camino me ha cambiado la vida.

El emprendimiento para mí es ayudar a otras personas con lo que tú haces. 
También es muy necesario visibilizar los casos de éxito y las cosas positivas. En los medios de comunicación, siempre sale lo negativo, y pareciera que lo único que vende es ese mundo negativo, pero también hay un mundo donde la gente quiere salir adelante, quiere esforzarse y quiere trabajar por sacar nuevas cosas. Te das cuenta que hay mucha gente haciendo cosas espectaculares en todos los aspectos, deportivos, artísticos, sociales, y uno se pregunta, esta gente porque no es la que sale en primera plana en los medios. Por ejemplo, en la Gobernación o en la Alcaldía, debería haber una lona gigante, diciendo mira este chico está logrando hacer tal cosa, mira esta chica deportista ha logrado esto, o aquel joven está logrando aquello. Hay que pensar alguna forma que la gente se entere que hay personas que la están rompiendo y que le están apostando, que no es imposible y que hay cosas geniales que se pueden hacer.

A todos los emprendedores que me están leyendo, les quiero decir que lo primero que deben hacer si quieren emprender, es ser conscientes de que emprender tiene sus dificultades y que tienen que prepararse para golpes, a caerse y volverse a levantar y estar dispuestos a afrontar situaciones negativas por montones, pero les aseguro que lo vale. La satisfacción de aprender cada día y de lograr cumplir los sueños propios no tiene comparación, emprender ha sido mi mejor decisión y lo volvería a hacer; si eso es lo que quieres, tienes que arrancar sin miedo, encuentra un problema y brinda una muy buena solución.

Si la decisión es emprender, estar preparados para que la cosa sea difícil, debes insistir, resistir, persistir y nunca desistir. Si lo que uno está ofreciendo realmente es bueno, el camino hay que seguirlo. Y como siempre digo: Recuerden que "Emprender es el camino" 


\section{Inmodigital}

Imagen 6. Emprendedor digital en derecho

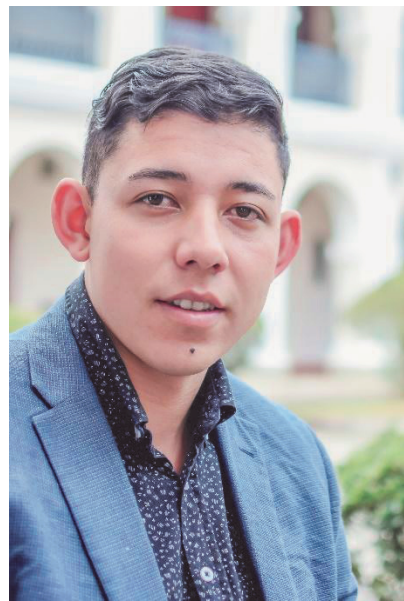

Carlos Raúl Tobar Girón - Fundador Inmodigital Fuente: propia

Soy Carlos Raúl Tobar Girón de 23 años, oriundo de Popayán, Cauca, estudiante de décimo semestre de Derecho de la Corporación Universitaria Autónoma del Cauca. Quiero contarles que mi proceso de emprendimiento se generó a través de un par de situaciones muy lamentables.

Cuando falleció mi madre y siendo el mayor de tres hermanos, me vi obligado a pensar en qué camino tomar, mientras pasaba por el duelo de la perdida, y a la vez, asimilando un diagnóstico médico bastante fuerte para mi (síndrome de gilbert). A pesar de seguir estudiando, no sabía cómo generar un ingreso adicional para ayudar a mi familia, realmente no sabía que iba hacer con mi vida en ese momento.

Por esos días mi abuelo tuvo un inconveniente con un par de inmobiliarias que no satisfacían la necesidad que él requería de vender su predio, siendo una experiencia desgastante y demorada, con muchas dificultades en su tramites internos y una carencia en el acompañamiento y servicio al cliente. 
A partir de ese momento, me propuse a ayudarle a vender su propiedad, investigué sobre el mercado, y al tiempo, me fui interesando en lecturas sobre emprendimiento, innovación, tecnología, marketing digital, entre otros, porque intuía que podrían estar correlacionados hacia la solución de lo que hoy en día viven propietarios e interesados en el mercado de los bienes raíces. De ahí logré una lluvia de ideas y finalmente decidí iniciar emprendiendo un nuevo camino, creando una inmobiliaria dedicada a la prestación de servicios específicos especializada en el acompañamiento de todo el proceso de venta y alquiler de inmuebles para fortalecer las buenas prácticas e innovar en este sector comercial.

En ese momento no contaba con un capital para la infraestructura física que tradicionalmente el sistema nos ha inculcado, sin embargo, encontré otros emprendimientos que han logrado posicionarse en la era digital, siendo un punto de referencia para no limitar mi iniciativa a un punto físico. Es decir, me animo a emprender el camino hacia la digitalización de este nicho de mercado, queriendo además brindar a las personas una asesoría jurídica en tiempo real para comprar y vender inmuebles, generando unas alianzas y convenios con las entidades públicas y privadas en este sector, permitiéndonos a su vez, consolidar un equipo de profesionales idóneos en el campo jurídico de la propiedad raíz y derecho civil, para orientar en los procedimientos legales que se deben hacer antes, durante y después de los servicios prestados por Inmodigital.

Tomando como referencia algunas aplicaciones que cuentan con presencia en otras plataformas digitales, también quería presentar nuestro portafolio de servicios en una página web. En este punto revisando en mis contactos a alguien que pudiera manejar el tema de aplicativos y páginas web, es cuando invito a participar del proyecto a mi actual socio, a Jorge, amigo de la infancia que vive muy cerca de mi casa. Le gustó la idea y decidió acompañarme en este emprendimiento con la firme confianza de sacarlo adelante. 
En este punto me pregunte como podía hacer que mi idea estuviera presente en la era digital, y es ahí cuando conozco por una convocatoria de mi universidad al Clúster Creatic. Expuse la idea y desde ese momento me pusieron a disposición todo un equipo de profesionales, que me asesoraron a través de su metodología y me colaboraron a validar si mi idea era viable o no. Me apoyaron en todo mi proceso desde que apenas tenía una idea, así como en el desarrollo y formalización de la empresa.

Hemos desarrollado estrategias para que nuestro modelo de negocio genere un impacto que permita transformar lo que hoy en día ya existe en el mercado. El recorrido que hemos logrado, ha permitido especializarnos en aspectos concretos y poco a poco e ir creciendo. Jorge, mi socio ha sido crucial en este proceso.

Jorge: Soy Jorge Gutiérrez de 23 años de edad, de Popayán, Cauca. Estudiante de octavo semestre de Ingeniería de Sistemas de la Fundación Universitaria de Popayán - FUP. Soy amigo de Carlos de infancia. Su idea me gusto, intercambiamos algunas ideas, aportándole mis conocimientos en desarrollo de páginas web y aplicativos para teléfonos móviles, y al tiempo que le proponía, me generaba curiosidad en profundizar acerca de estos temas para aportarle a su proceso.

Gracias a los conocimientos adquiridos en un curso tecnológico que tome en el Sena, mis conocimientos de la universidad y el apoyo del Clúster Creatic, ha sido posible continuar con el ejercicio de emprender, especialmente, al profundizar sobre el desarrollo del aplicativo. Manejar una herramienta tecnológica nueva, fue un reto para mí. Nunca lo había trabajado, hay que dedicarle tiempo a estudiar e investigar para poder usarlo.

Carlos: entonces decidimos que todo sería online y lo más pronto posible, desde el ingreso a nuestro portal para la recepción de la documentación hasta el proceso final que concluye con la transacción bancaria. Queremos que los clientes puedan hacer todo desde la comodidad de su casa mediante su computador o a través de su celular con todas las condiciones de seguridad 
informática. Con ello, el cliente no se expone, por ejemplo, a un robo, evita largas filas y desplazamientos a las instalaciones que prestan estos servicios, optimizando recursos, especialmente tiempo. Mediante un grupo de abogados expertos en el tema nos hemos apalancado para generar la confianza en el sector.

Realmente, inicie con una idea muy grande en mi cabeza, pero con mi compañero fui enfocándola hacia nuestras prioridades y en el Clúster Creatic, me ayudaron a identificar las necesidades que actualmente podría satisfacer en el sector de una manera innovadora para este mercado.

Jorge: inicialmente la aplicación funciona ofreciendo apartamentos, casas y lotes para vender, comprar o alquilar. Los clientes ingresaban a la plataforma por la página web o se registraban desde su móvil, seleccionaban el servicio que requerían y nos enviaban la documentación que exigimos de acuerdo a nuestro modelo de negocio. Con este proceso hemos optimizado tiempo, ahorrándonos costos de desplazamientos de ambas partes, y entregamos un acompañamiento adecuado por parte de profesionales en tiempo real.

Carlos: es un reto difícil, el emprendimiento que elegimos. en realidad, el sector inmobiliario no cuenta con investigaciones formales de acceso público, mucho menos de experiencias significativas en el entorno digital. Solo por citar un ejemplo, en Popayán no hay formación certificada en Agente Inmobiliario, y el lugar más cercano es en la ciudad de Cali, y los expertos de este mercado están aliados a grandes consorcios y compañías de Bogotá y Medellín.

Sin embargo, hemos encontrado eco en entidades que acompañan el emprendimiento afortunadamente. Hemos podido acceder a cursos gratuitos digitales, programación de base de datos, videos juegos, además de las asesorías relacionadas con la usabilidad de las aplicaciones. 
Jorge: por otro lado, para mí la familia es muy importante el proceso. Mis padres me dicen que debo enfocarme en lo que me gusta para salir adelante. Me ha tocado dejar algunas cosas de ocio. Ahora invierto mejor mi tiempo en aprender cosas que más adelante seguramente las vamos a necesitar.

Carlos: en cambio en mi caso, fue un poco difícil porque la familia al principio te apoya, pero como vivimos en una sociedad materialista, quieren resultados rápidos, quieren que la idea funcione de un momento para otro. No es fácil. Me crie con mis abuelos, ellos me decían, no mijo usted tiene que irse a estudiar a la universidad y a buscar un empleo, no deje su carrera por esto. Por eso es muy importante la disposición propia, querer materializar aquella idea, hasta que poco a poco se va dando todo.

El apoyo que he tenido hasta ahora es de Jorge, mi compañero de emprendimiento. Me ha ayudado en toda la parte del desarrollo, porque al principio me ayudaban mis amigos, pero luego en el proceso se van, ya no les va gustando o me decían que eso no era tan bueno, que mejor le dedicara más tiempo a mi carrera.

Este no es mi primer emprendimiento, he fracasado en varias ideas anteriormente, pero no me he dejado vencer de los obstáculos. He persistido, me he obligado a salir de mi zona de confort para enfrentar los retos que se me presenta en el camino de la vida. He tenido mucha resiliencia. No me ha dado tanta frustración que me digan que no puedo, es más, me gusta para demostrar lo contrario. Entrar en esta experiencia me ha servido mucho, para volverme una mejor persona, más fuerte y aprender a manejar ese ambiente negativo que a diario nos rodea.

Entonces, esto de emprender se convierte en un reto, nos enseña mucho. En mi caso como estudiante de Derecho, me ha permitido explorar otros campos. No me enseñaron 
administración de empresas, ni cómo manejar un negocio, no tenía conocimientos en esa parte, entonces es un reto para educarse e instruirse.

Jorge: de este ejercicio me queda aprender por uno mismo, no quedarse con lo que le enseña la universidad. La universidad te ofrece las bases, y de ahí en adelante, es cuestión de uno, profundizar en temas y nuevas metodologías para finalmente superarse y sentirse orgulloso en un futuro.

Carlos: entonces el emprendimiento para mí es como protagonizar una idea de negocio, estar en continuo aprendizaje de lo que uno está realizando, superarse, subir un poco la autoestima, y tener la confianza para tomar decisiones con objetividad. En muchos casos, hay que tomar decisiones y aprender a trabajar en equipo.

Para eso, una parte fundamental, es acompañar a los emprendedores a enfocarse, además de fortalecer el campo de la educación financiera, como manejar las finanzas, los procedimientos y ser organizados en el paso a paso. Creo que algunos emprendimientos han fracasado, porque lo toman a la ligera. De pronto logran que el emprendimiento les genere ganancias, pero no reinvierten ese recurso en su negocio. Es importante apoyarse en internet para investigar biografías de personas que hayan tomado el mismo camino, siendo así, un punto de referencia.

Por ello, mi consejo a los emprendedores, es decirles que nunca es tarde ni temprano para iniciar una idea de negocio. $\mathrm{Si}$ uno tiene una idea, lo único que tiene que tener, es confianza y fe en que uno puede lograrlo.

Jorge: así es. Lo que les puedo decir a los emprendedores es que nunca se rindan. Si se sienten solos, si ven que no pueden salir adelante solos a emprender, que busquen a una persona que 
crea en ellos, un familiar, un amigo, una entidad, que les brinde ese apoyo para materializar lo que quieren hacer.

\section{Suricata Teach}

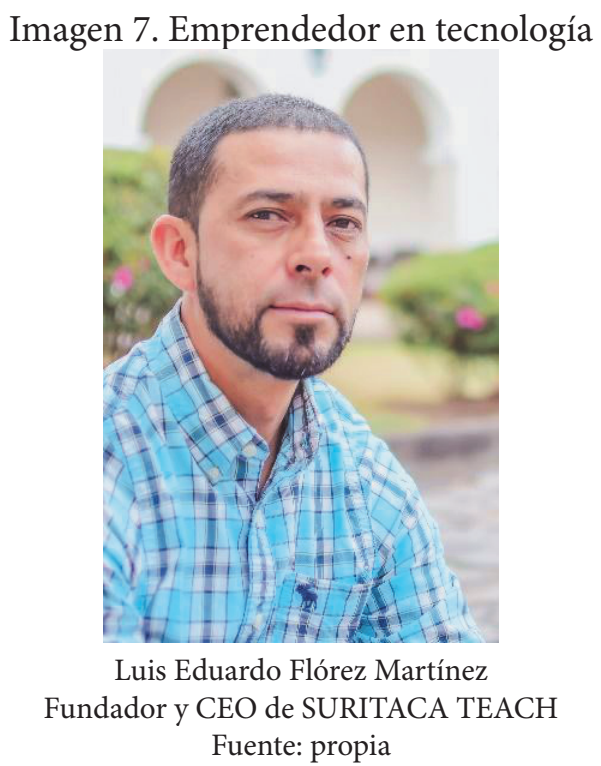

Soy Luis Eduardo Flórez Martínez, payanés y filósofo egresado de la Universidad del Cauca, estudiante del programa Ingeniería Mecatrónica de la Corporación Universitaria Comfacauca Unicomfacauca, con una alta incidencia en la formación industrial que traigo desde el colegio Técnico Industrial y que he ido desarrollando por gusto.

Pareciera que la filosofía y la ingeniería no precisamente se encontraran, sin embargo, es interesante ver cómo me ha dado los elementos para argumentar lo que materializo desde la ingeniería. Por otra parte, el Colegio Técnico Industrial me dio muchas bases desde pequeño, en conocimientos y en interés para haber logrado lo que soy hoy en día. 
Entonces SURITACA TEACH, nace como una idea que se formaliza a finales del año 2010, y que empieza a formarse desde la experiencia que pude recoger al estar vinculado con algunas empresas de seguridad, de tecnologías directamente relacionadas con el entorno de la seguridad, de la electrónica, escenarios que me permitieron adquirir conocimientos y habilidades en software y Hardware, en redes en general.

Sin duda, ha sido una de mis pasiones, la electricidad y la electrónica de la mecánica. Enhorabuena, en el año 2003 entre a trabajar en una empresa que se estaba dando a conocer, y en ese entonces, tenía un perfil muy ligado a la electrónica y electricidad, enfatizando en la seguridad. Al entrar a trabajar con el área de electrónica, tuve la oportunidad de empezar a hacer laboratorios y a experimentar con diferentes tecnologías, a entender lo que hacía, a saber, que era un hardware y un software, integrar esos dos aspectos de manera concreta.

En ese tiempo me desarrolle, y posteriormente, pase a otra empresa que tenía un perfil similar, llegando a ser jefe de monitoreo, luego fui contratista suministrando servicios a entidades nacionales, especialmente en asistencia y soporte técnico en instalaciones de esta índole.

Después de este largo cumulo de anécdotas, vi que tenía potencial cuando me di cuenta que estaba moviendo un porcentaje importante en las diferentes empresas donde había trabajado, y al final, pensé y dije esto que hago para esta empresa lo puedo hacer para mí, y en ese momento tome la decisión.

Inicialmente, para darle nombre a la empresa pensé en mi nombre y la palabra tecnológica entonces nació LEFMAT Tecnológica, que era más o menos el mismo perfil de redes eléctricas, seguridad electrónica, alarmas, cámaras, automatización y redes. Desde ahí se lograron grandes resultados, a las empresas y a los usuarios les gustó nuestra propuesta. Fue una época muy intensa, 
llena de responsabilidades y retos. Sumado a esta dinámica, era estudiante del programa de filosofía en la noche en la universidad, padre de familia y entonces empresario. Fue una etapa muy difícil, pero al final, te habitúas. Así mismo, me di la oportunidad como docente, y finalmente, tenía claro que quería una empresa, porque siempre he sido un soñador en aportarle a la historia.

En el camino, llegó un amigo de España interesado en invertir un capital, con quien hicimos una sociedad, cambiamos la razón social y nos enfocamos en la seguridad electrónica, pasándonos a llamar SURICATA. Con esta marca queríamos proyectar la parte tecnológica en seguridad electrónica. Todos nuestros sistemas están instalados, y se ponen en modo custodia. Cuando hay alguna situación, ellos tienen la posibilidad, gracias a las redes y a las telecomunicaciones, de informar a cualquier persona o a una central de monitoreo o un usuario lo que está sucediendo.

Sin embargo, a pesar de todas estas experiencias, me hacía falta invertir en una ingeniería, y es cuando inicio mis estudios en Unicomfacauca en el programa de Ingeniería Mecatrónica, con una segunda intensión, de proyectar a SURICATA en la academia y más allá de esta, logrando ser parte, por ejemplo, de la feria empresarial que organiza la institución, espacio en el que estuve tres días, logrando un margen genial. Después de eso, tengo que decirlo, he tenido mucha concurrencia de trabajo. He encontrado al interior de Unicomfacauca, unas personas como el profesor Saúl Zarzosa, que reconocen el interés, una intencionalidad, proyección y visión de hacer cosas nuevas, diferentes, por la región, porque estamos haciendo cosas con productos que otros fabrican en otros países, pero nuestra intensión con la ingeniería, es hacer algo nuestro, hacer algo propio.

Sin embargo, en Popayán existen muchos prejuicios desde el punto de vista cultural, incluso político, que no permiten fomentar el espíritu emprendedor, y se fomenta cada vez más el 
espíritu de ser trabajador. La gente quiere salir a hacer cualquier labor, pero no se imagina y no dimensiona, que cualquier labor, puede ser una empresa, incluso puedo tener una empresa que se parezca a otra, pero con grandes aportes de innovación. Este panorama al contrario de los que muchos pueden pensar, se convierte en una gran ventaja para los que si le estamos apostando.

Los emprendedores queremos seguir haciendo, seguir preparándonos entonces en ese sentido, la experiencia ha sido enriquecedora, ahora no ha sido fácil, desde luego, proyectar una idea de negocio sin tener recursos, sin tener ningún elemento, ninguna ayuda, sin tener absolutamente nada, y tener que salir a un mercado donde no te conocen, pero aun así siendo optimista, no es fácil. Entonces el emprendimiento te cambia la vida. Si las personas nos proponemos, podemos hacer lo que nos propongamos. Si somos visionarios, soñadores podemos.

Hay muchas personas que piensan que cuando se habla de emprendimiento, se hace alusión a una gran empresa, con una infraestructura establecida, con sus dependencias, con su personal, con sus productos y servicios, sin embargo, creo que el asunto no es así. El ser emprendedor, implica esa posibilidad que tiene cualquier persona de realizar una actividad con la que pueda resolver necesidades que tienen otros, y al tiempo, de solventar sus necesidades básicas. En ese sentido, el emprendedor es aquella persona que emprende un algo, un quehacer y una labor.

Para ello, las instituciones deben facilitar los protocolos para que la labor no sea más agobiante de lo que ya puede ser para un emprendedor. Debe existir una mayor socialización de las entidades que acompañan el emprendimiento y que estas se encuentren repartidas por fases, por ejemplo, las más fuertes en sensibilización, las que generan procesos de aceleración con capital semilla, entre otros. Por otra parte, en algunas entidades siempre existe una relación muy fuerte con vínculos políticos y de clientelismo que no las deja avanzar, favoreciendo a unos y dejando por fuera a otros. 
Así mismo, debemos considerar el hecho que los estudiantes no vayan a un colegio o a una universidad pensando en estudiar una disciplina para luego vincularse con una entidad como primera opción, sino para que tenga elementos de fondo y exploren la posibilidad de emprender. Si la gente pensara de ese modo, habría más emprendedores y menos trabajadores con cierto sentimiento de frustración.

\section{Popayán puede hacer Industria}

\section{Bioseguridad Colombia Company S.A.S (BSC COMPANY)}

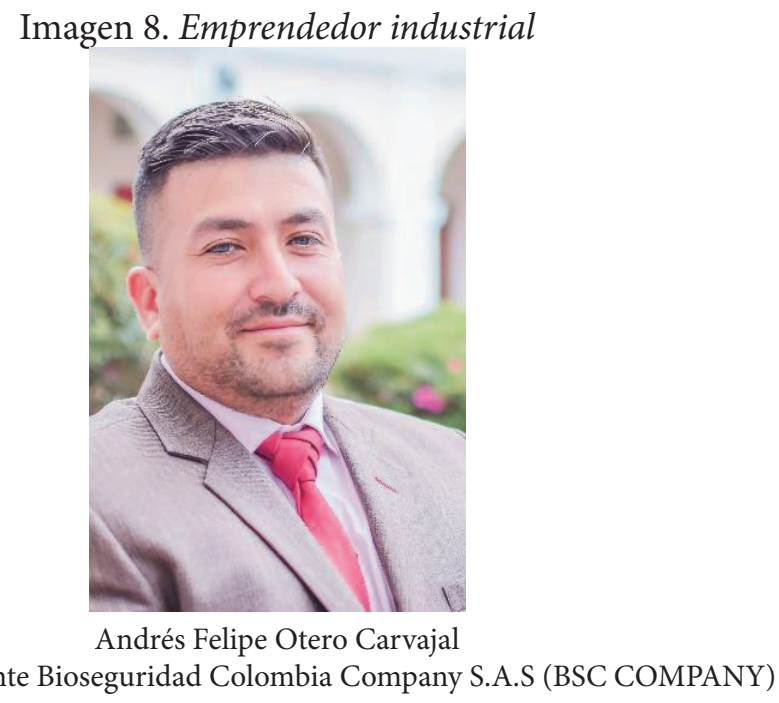

Fundador y Gerente Bioseguridad Colombia Company S.A.S (BSC COMPANY)

Soy Andrés Felipe Otero Carvajal, de 38 años. Nací en el municipio del Tambo, Cauca, y por decisión de mi madre, que era docente, nos trasladamos mis cuatro hermanos mayores y yo, que soy el último de la familia, en búsqueda de un colegio que nos brindara una buena educación.

Soy Ingeniero Ambiental de la Universidad del Cauca. Paralelamente a mi carrera, desarrolle la idea de negocio. 
Inicialmente tuve una experiencia de conocer otras personas y otras partes de Latinoamérica. En ese tiempo, decidí dejar la universidad cuando estaba en tercer semestre. Tomé la decisión de dejarla, porque realmente sentía que era necesario experimentar y crecer en otros ámbitos, entonces afortunadamente conocí unos árabes con los que viajé y tuve la oportunidad de ver realmente que lo que puede generar una economía sólida, es tomar la decisión de emprender. Esa fue mi primera pasión, por qué no te enseñan a emprender en la universidad. El emprendimiento hace parte, más bien de experiencias de vida, desde el hacer y tuve la gran fortuna de hacerlo con árabes, que tienen una gran experticia en el hacer. Aprendí sobre cómo se debe mantener un negocio, conocí otros países como Ecuador, Perú Brasil, Bolivia, Panamá y parte de Centroamérica.

Uno de ellos, era un comerciante interesado en el arte religioso de la ciudad de Popayán. Lo conocí a través de un familiar. Desde ese momento, tuve la posibilidad de trabajar con ellos y aprender algo que para mí fue muy valioso. Para ellos es sumamente importante, el trabajo desde niño. Es una necesidad social. El que no trabaja, no tiene razón de ser. Entendí lo que puede hacer la disciplina en una persona que trabaja dentro de una empresa, que en ese caso el referente era mi madre, y lo que puede hacer alguien que trabaja para sí mismo.

Fue entonces esa la motivación real que me llevó a tomar la decisión de no prepararme y estudiar para ser empleado, sino para generar empresa, para construir y dar empleo. Cuando tú tomas la decisión de hacer empresa, eres consciente que demanda seguramente muchos más sacrificios de forma inicial, más esfuerzo, disciplina, perseverancia y fuerza. Una persona que trabaja por un salario, tiene días de descanso, prestaciones, entre otros. La persona que se dedica a emprender, sus días de trabajo son todos los días, no tiene horarios. 
Entonces regreso en el año 2010 con la mentalidad de aprovechar la universidad y la institucionalidad, como una herramienta para crear la empresa. Es cuando puedo visualizar que el aceite de cocina, era un problema que nadie había resuelto.

A través de la formación académica y de los docentes, me encamino hacia esa idea y logro adelantar un análisis bibliográfico, desde la teoría y un poco desde la práctica, entendiendo que, si era viable, que podría llegar a ser una empresa dedicada a trabajar en un campo que nadie más hacía en ese momento.

El aceite de cocina es un problema ambiental, que lo vez en los hogares. La idea, nació de la observación y esa cualidad nace cuando te vuelves emprendedor. El que emprende, busca solucionar problemas y en un problema ve una oportunidad. Era una realidad en las casas, de hecho, venden unos aparatos para las casas, unos aceiteros como para filtrar de una forma muy física, muy artesanal el aceite. Así nace Biosecol.

Existen unas normas que establecen la diferencia entre residuos ordinarios y especiales o peligrosos y en ambos residuos hay generación de aceite. Entonces Biosecol, no solamente es una fábrica de jabones, sino que es una empresa pensada para la prestación del servicio de aseo y de limpieza de hospitales, de clínicas, de todos los servicios especiales. Para eso se debe partir de la bioseguridad.

Entonces, mi trabajo de grado consistió en hacer un plan de gestión integral de residuos hospitalarios dentro de la Universidad del Cauca para que les dieran la certificación de los laboratorios prestadores y dentro de ese proceso, me di cuenta que se requerían empresas especializadas en ese tema. Se debía salir al mercado y no solamente, resolver el problema del aceite y transformarlo en 55 jabones como lo hacemos ahora, sino en ofrecer todo el servicio del plan de gestión integral a los hospitales, a las clínicas y demás, que necesiten planes ambientales. 
Con esa visión, la empresa cambia de nombre continuando con el concepto de Bioseguridad Colombia y pasa a ser, Compañía de Bioseguridad Colombia S.A.S y sus siglas son BSC Company.

Actualmente, contamos con cuatro líneas y en desarrollo de la quinta. La primera está relacionada con el sector institucional, la segunda con el automotriz, la tercera, la del hogar y la cuarta, de hornos.

Sin embargo, este proyecto tiene un gran horizonte. Queremos hacer presencia en todo Colombia, mediante una matriz de sostenibilidad. Es decir, el aceite de Cali genera el jabón de Cali y genera los servicios prestadores de Cali, y así sucesivamente.

Para lograr que la empresa pudiera desarrollarse desde su producto, me asocié con un químico. Desde mi formación, soy fuerte en el componente ambiental. Necesitaba una persona especializada en química que se dedicara a la fabricación. Entonces le compartí el 50\% de mi empresa.

Es así como la empresa, inicia con una fase educativa de porque las personas no deben botar el aceite, ni venderlo. Posteriormente, se recolecta y se certifican los establecimientos o personas que adelanten el proceso. Entonces, el aceite llega a la planta, se le quitan los ácidos grasos, libres de compuestos cancerígenos, olor, color, sales y todos los productos disueltos. Ese fue nuestro primer proceso de innovación a nivel de ingeniería. Ese producto que resulta, indeseado, se vuelve abono. No hay contaminantes. No tenemos chimenea, tampoco residuos sólidos.

En el proceso, brindamos trabajo a las personas con movilidad reducida. La filosofía y el alma de la empresa, es contribuir a los problemas de la sociedad y transformarlo en algo muy valioso. Esa es nuestra filosofía, ese es nuestro espíritu y es el alma de esta empresa. Demostrar que se puede lograr una gran transformación y puede ser de mucho valor. Es así como de la parte limpia, que viene siendo 95-97\%, se generan 5 líneas. 
De este camino nos fuimos posicionándonos, y ganamos un premio en el evento Cauca Emprende, a su vez hicimos un proceso de prototipado con BTI que es la mejor empresa prototipado colombiana. Entramos a ser parte de las empresas verdes colombianas a través de las CRC. Para fortuna nuestra, en el 2017, el Ministerio de Ambiente nos visita por ocho meses de forma aleatoria, haciendo unas auditorías a la empresa para ver cuál era nuestro proceso. Cuando el Ministerio Ambiente viene y nos evalúa, nos da 99.5 puntos por el proceso social y amigable.

En este momento, lo único que teníamos era mi casa y tenía que compartirla, entonces tuve que desalojarla, quedarnos en una habitación y prestar toda la casa para que funcionará como empresa, pero eso garantizo que cuando el Ministerio Ambiente vino, y evidenció todo el proceso, además que el residuo, genera un abono, entendiera que era una empresa verde. Que es una empresa que no contamina, que no es extractiva.

En el 2018 la Cámara de Comercio del Cauca nos cataloga como empresa innovación Cauca. De ese $100 \%$ que teníamos, dividido en dos partes, logramos hacer que entrara un tercer inversionista y ese inversionista, tuviera una participación del $30 \%$ por el valor que requerimos.

Pasa la voz al Ministerio Ambiente, y el ministerio entiende que hay una forma de solucionar el problema tan agresivo del aceite, porque cada día se contaminan más de 200 millones de litros de agua, y una de las causas, es el aceite de cocina.

Entonces a partir de este proceso, lo que nosotros hacemos, es evitar, por ejemplo, que 77,000 millones de litros de agua no se contaminen cada mes en el Cauca, que es uno de los departamentos que más genera agua. Si evitamos que la fuente no se contamine, aguas abajo se estarán protegiendo. 
Todo lo anterior, para decir que hacer empresa, requiere de un carácter definido y se tiene que separar el corazón de los números. Cuando el Ministerio de Ambiente mediante la matriz que se emplea para evaluación, demostró que éramos una empresa verde, siendo después de 60 ideal, después de 80 necesaria y después de 90 excelente, entonces nos dieron un certificado, como empresa verde, ideal, necesaria y con excelencia en gestión empresarial. Eso fue una gran satisfacción. Estamos en el Cauca por encima de Corposurca, por encima de Empaques del Cauca, por empresas muy grandes que en este momento facturan una gran cantidad de recursos para Colombia. Entonces llegar a ser evaluados con 99.5 puntos, te hace sentir que vas por el camino correcto.

Actualmente, contamos con un terreno donde vamos a construir la planta para el suroccidente colombiano, vamos a recolectar el aceite de Cauca, Valle, Nariño, Putumayo, Huila, Caquetá. Es nuestra forma de demostrarle al mundo, que ser empresa verde es lo más viable desde el punto de vista económico, ambiental y social, desde la generación de empleo, que le apuesta a la sostenibilidad y la sustentabilidad.

Eso me permite decir que emprender en Popayán, es una gran experiencia. Creo que cuando uno logra emprende en Popayán, y se mantiene, puede hacerlo en cualquier parte del país. Popayán es una escuela para formarme como empresario. He visto muchos empresarios que han querido entrar a la ciudad y no lo han podido hacer o lo hacen por un tiempo y se van. La economía de nuestra ciudad es una economía con una dinámica totalmente diferente a la economía del país, desde cómo vendes un producto a alguien y lo fidelizas. Me ha parecido mucho más fácil, vender en el Atlántico a muchos hoteles en Taganga, Santa Marta en Barranquilla que nos compran y son clientes fieles y nos han fortalecidos, que en Popayán. 
Hay que sumarle además el acompañamiento de las entidades. En esta experiencia he sentido un apoyo muy fuerte de la Cámara de Comercio del Cauca, hemos sido gracias a Dios unos afortunados. Siempre hemos tenido de parte de ellos disposición, escucha. A veces el empresario no necesita sólo recursos, porque es la forma en la que te hacen creer que funciona el mundo, que se presenta una idea y vas a encontrar el millón de dólares. Las cosas no funcionan así. A veces los empresarios queremos que nos escuchen, que nos oriente, y ese acompañamiento es más valioso que el dinero. Uno se encuentra con la familia que te dice, consiguiera un trabajo, aproveche la oportunidad del Ministerio Ambiente, lleve la hoja de vida. Es ahí cuando creo que más bien debemos soltar el estrés que tenemos todos y dedicarnos a construir.

Emprender entonces es vivir. A veces se está en el mismo estado, sin crecer y sin poder saber qué tan competitivo eres. El emprendimiento es probar que tan competitivo eres, es vivir en competencia todos los días, entonces para mí el emprendimiento es para competidores y de los mejores. Para ser emprendedor debes ser competitivo.

Hay entonces que fortalecer la educación básica y media. Además de los perfiles profesionales de los programas en las universidades. Por otra parte, pensar en campeonatos locales de emprendimiento, abrir centros culturales, más espacios de encuentro, más espacios comerciales para dar a conocer a los emprendedores. Por qué no van, por ejemplo, donde el señor que vende los mangos, para que desarrolle su producto y pueda competir entre otros y gane el mejor. La idea es que la gente se lo gané, y para eso se necesita incentivos.

A los emprendedores me queda por decirles que primero tienen que evaluar a que están dispuestos. Les digo, si estás dispuesto a trabajar por algo por lo que no te pagarán y serías feliz, hazlo. Si yo estoy dispuesto a luchar por una idea que incluso, si 
no me pagaran la haría, entonces hay que arriesgarse. Si estás buscando ser emprendedor, sólo para ganar dinero, creo que estás equivocado. Hay que evaluar qué tanta pasión tienes, porque para emprender hay que dejarlo todo. Deben ser muy disciplinados, madrugar y acostarse tarde, dormir poco, no hay fiestas, no hay amigos, no hay rumbas, no hay diversión. Muchas veces incluso, hasta el deporte se sacrifica.

INTERA, productos sostenibles en plástico

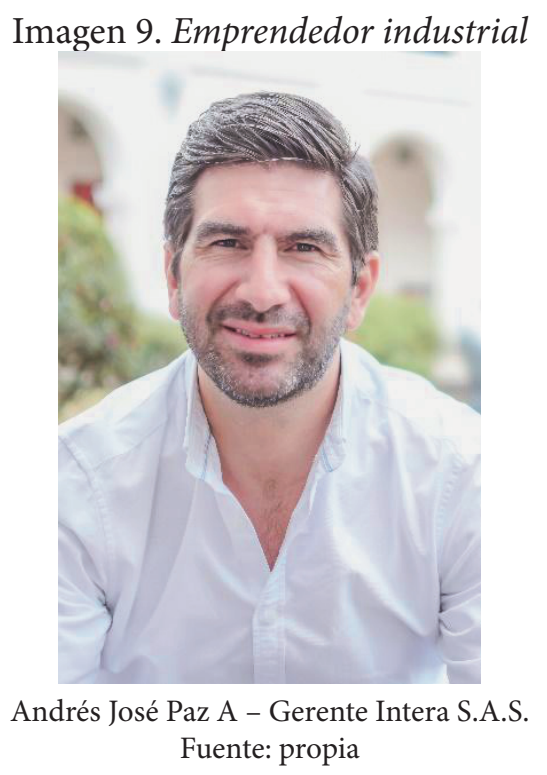

Soy Andrés José Paz A, tengo 37 años y 12 de ellos dedicado a emprender. Esposo y padre de familia de tres hijos. Egresado de Ingeniería Industrial de la Fundación Universitaria de Popayán y especialista en Gerencia de Proyectos de la Universidad del Cauca. Desde mis 16 años empecé a desarrollar proyectos y son varias las experiencias que recuerdo con mucha satisfacción. A los 17 años me fui para Estados unidos y cuando regresé emprendí mi primer proyecto, desafortunadamente las cosas no resultaron como esperaba y perdí, de eso se aprende. Con la Escuela Taller 
adelantamos un ejercicio alrededor del reciclaje de vidrio con una empresa que vendí tiempo después. Siempre ha estado en mí las ganas de intentarlo una y otra vez. Lo que me ha quedado en este camino, es entender, que la condición del empresario, es innovar, crear, poner en marcha nuevas ideas, si funcionan bien, si no, también. Volver a levantarse y seguir intentándolo una y cien veces, esa es la realidad de esto.

Después de graduarme de la especialización, me vinculé con Unicomfacauca como vicerrector administrativo y financiero; había una necesidad desde la Alcaldía Municipal de Popayán de adelantar un estudio por parte de las IES (Instituciones de Educación Superior) para investigar la problemática de las basuras en Popayán, además de analizar el estado de una maquinaria que se encontraba en el basurero de Popayán sin ser usada.

Cuando llegamos al basurero y empezamos a conocer la situación, me encontré personas que trabajaban alrededor del reciclaje y creaban productos artesanales con muy pocas herramientas, pero con absoluta convicción y grandes sueños. $\mathrm{Me}$ pareció atractivo e interesante el tema, pues ya en Colombia se empezaba a hablar del reciclaje.

Entonces inicié un proceso de investigación acerca del reciclaje; ¿cómo se hace en el mundo?, en países desarrollados y como crece el sector año tras año. Tomé el proyecto como reto personal. Gracias a la idea de familiares cercanos estructuré un proyecto para procesar plástico reciclado. Lo más difícil es que no había bases respecto al tema porque la academia no te enseña nada que tenga que ver ni con reciclaje, ni con plásticos.

Hoy por hoy les puedo decir que, si no aprendemos y generamos conciencia desde la formación académica y en cada uno de los hogares, el problema de las basuras va a seguir creciendo día a día. 
En un viaje de trabajo a Bogotá, tuve la oportunidad de presentar el proyecto y después de estar contando el cuento durante dos años, un grupo de inversionistas invirtió en el proyecto. Ahí cambia toda la historia, cambia mi vida, la de mi familia, una proyección diferente, un nuevo estilo de vida.

Cuando iniciamos desarrollamos una fase pre operativa donde compramos y fabricamos la maquinaria, instalamos los equipos, realizamos pruebas y después de muchos inconvenientes, sobre todo sueño atrasado de 6 meses y mucho pero mucho esfuerzo, logramos poner a punto un primer producto para la venta.

Necesitaba saber que pasaba en el medio del reciclaje y de los plásticos, en esa época Popayán no era la plaza para ello, conseguir material reciclado hace 12 o 10 años era muy difícil, en Bogotá ya se tenía un avance, acopios importantes y clasificación de materiales, así entonces, llegamos a entender y a aprender. Desde ese entonces se concibe como Intera, (ingeniería y tecnología del reciclaje), además de la interacción constante para lograr un impacto social, ambiental y económico, siempre pensando en cumplir con objetivos del desarrollo sostenible.

Intera es el resultado del esfuerzo. No podré olvidar que nos demoramos 6 meses en lograr un primer producto para la venta. Fue un proceso largo, tedioso y difícil; iniciar siempre es muy complejo. Aprender la labor desde la operación de una máquina, administrar y direccionar el negocio, desarrollar y salir a vender un producto diferente e innovador, ¡que tarea tan difícil! Lo más importante después de todo, es conocer como la palma de tu mano el proceso y la empresa, sin eso, no hay nada.

Paralelo a nuestra planta de producción, montamos un proceso de reciclaje de plástico en Bogotá, pues si bien podíamos producir, no teníamos el abastecimiento suficiente de materias primas que garantizara los requerimientos y la calidad del producto. 
Formarse en el reciclaje conlleva experiencias de vida muy bonitas y de gran satisfacción, el reciclaje se vive día a día en las calles y se convive muchas veces con las personas más vulnerables de la sociedad. Entenderlos, capacitarlos y motivarlos para realizar una actividad que genere un impacto positivo en sus vidas, es un reto grandísimo.

Como anécdota puedo contar que el primer producto de óptimas condiciones para la venta lo sacamos a las 3 de la mañana; Lloré de la emoción, pues después de 6 meses de trasnochar y pasar muchas noches en vela, me generó una emoción inmensa. El primer producto lo vendí en Bucaramanga, mucho trabajo para lograrlo.

Intera como principio fundamental, debe buscar el cumplimiento de los objetivos del desarrollo sostenible, debe lograr disminuir la tasa de pobreza, mejorar la calidad de vida de quienes hacen parte de esta labor, desde las bases del reciclaje hasta nuestros empleados, pues de una u otra manera los beneficiados somos muchos. Generamos aproximadamente 200 empleos entre directos e indirectos.

Sin duda alguna le estamos apostando al cambio, crear conciencia, mejorar hábitos e impactar positivamente el medio ambiente. No es simplemente salir a vender un producto, son beneficios reales a corto y largo plazo, sobre todo, pensar en un mejor mañana para nuestros hijos y familias.

Adquirido ese aprendizaje, decidimos entonces regresar a Popayán. Tenemos un acopio de materias primas en Bogotá y la producción se realiza en Popayán, esperamos que a futuro se convierta también en la fuente principal de abastecimiento.

Tenemos cuatro líneas de producto. 1. Soluciones de cerramiento, concebida para dar respuesta en zonas urbanas y rurales donde la necesidad de cercar un lote, finca, predio, parcelación, etc., es una prioridad y así lo exige el estado. 
En el campo se sufre mucho por las deficiencias en infraestructura, especialmente con las cercas y otros cerramientos, pues constantemente se reemplaza con la madera talada del mismo predio. Después de algunos años nos enfrentamos a las deficiencias del recurso hídrico. Las malas prácticas destruyen el recurso natural más preciado por el ser humano, "el agua". Esta línea es pensada como el sustituto ideal de la madera en diferentes aplicaciones. Llegamos no solamente al sector agropecuario, sino al sector de infraestructura vial, construcción, entre otros, cualquier persona que tenga la necesidad de hacer cerramientos para delimitar, separar o por seguridad.

2. Contamos con un sistema constructivo basado en un modelo de autogestión. Soluciones para vivienda rural, aulas escolares, albergues temporales, bodegas (e-container) y pisos deck's para exteriores. No requiere de mano de obra calificada, según el área y de acuerdo al instructivo de instalación, cualquier persona puede ensamblar las piezas que conforman una estructura modular tipo lego.

3. Almacenamiento y tratamiento de aguas residuales. Tanques plásticos, canecas de aseo, bebederos y mucho más. Diseñados para una larga vida útil, livianos, higiénicos y muy resistentes.

4. Re-Inventa. Fabricamos y comercializamos perfiles plásticos como materia prima para innumerables desarrollos. Proyectos que transforman nuestros perfiles plásticos en productos innovadores y de alta calidad.

En estos diez años hemos hecho muchas cosas. Intera es una empresa reconocida en el país, hemos trabajado de la mano con empresas como Bavaria, Carvajal empaques, Universidad Externado de Colombia, diferentes fondos de agua, corporaciones autónomas regionales de diferentes departamentos, USAID, fundaciones, cooperativas, iNNpulsa Colombia, la ANDI y 
muchos más. Debemos seguir trabajando arduamente, estamos comprometidos y seguimos avanzando.

Cuando se decide tomar este camino lo más importante es la familia, ese es tu soporte, tu norte, lo que verdaderamente importa y por lo que luchamos día a día. Lo más difícil de emprender es lograr mantener el equilibrio emocional. Salir de tener un empleo, ganar un sueldo seguro y estable, a rebuscar con que mantenerse, diferentes obligaciones cuando no hay con que responder económicamente, es muy duro. El núcleo familiar es indispensable, los amigos se van, cada quien tiene porque responder, se van filtrando, decirlo así puede sonar crudo, pero es la realidad.

Emprender se convierte en un estilo de vida, hay que comprender que es un ejercicio de absoluta convicción, de creer en uno mismo, soñar y mantenerse constante. No se puede ser un emprendedor a medias, esos están destinados a fracasar.

Esta labor requiere de una mirada integral, no solo estructural dentro del modelo de negocio sino un componente psicosocial que apoye y fortalezca al emprendedor. Un ejercicio motivacional, de liderazgo y donde aprender de resiliencia, y paciencia se convierten en una necesidad fundamental.

Los problemas se van a tener que abordar, pero concentrarse en ser diferentes es tal vez uno de los componentes más importantes e indiscutibles de una organización. Vivir sobre un océano rojo no es igual a convivir sobre uno azul. Todos creemos que nuestro emprendimiento es el mejor, pero cuando volteamos a ver, hay 10 iguales, y si vas a ver en el mundo hay 100, entonces, ¿cómo diferenciarse de los demás?

Finalmente diría que se trata de determinación, decisión y absoluta convicción, perder el miedo a fracasar, esa es la diferencia entre el emprendedor y el empresario, perderle el miedo al fracaso. Ese día serás un empresario y tendrás una gran empresa. 
Nube de Tacones, dejando huella desde lo alto

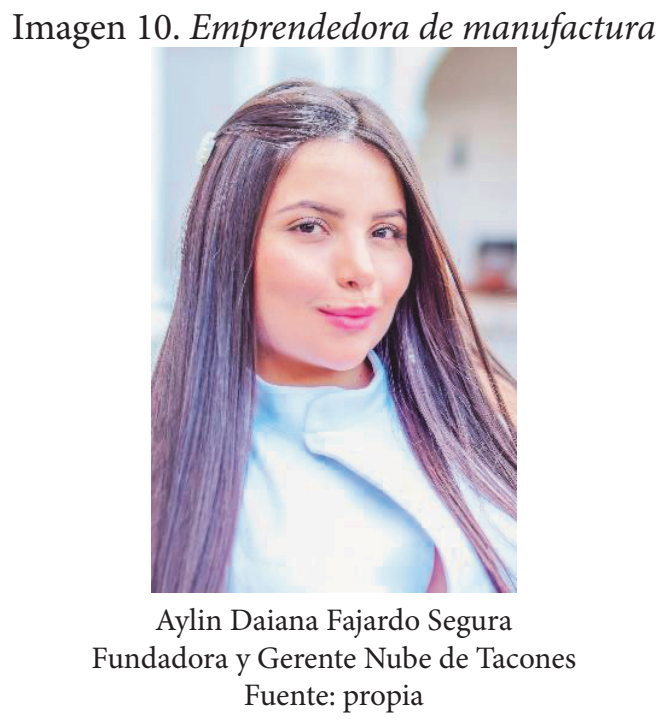

Soy Aylin Dayana Fajardo Segura de 22 años de edad, egresada del programa de Administración de Empresas de la Fundación Universitaria de Popayán. Creadora y gerente de la empresa Nube de Tacones, una empresa que trabaja desde las plataformas virtuales dedicada a la fabricación y comercialización de calzado alto, personalizado, exclusivo, cómodo y de alta calidad. Siempre me he sentido motivada por el emprendimiento desde muy pequeña, desde que estaba en el colegio me he identificado por ser una mujer independiente. Contando con el apoyo de familiares y amigos cercanos, quienes han vivido conmigo todo este proceso.

Nube de Tacones, nace hace 5 años aproximadamente con una plataforma virtual que, en ese tiempo, no era tan llamativa ni tan conocida como Facebook, acompañada mínimamente de Instagram. En ese tiempo, contacté a una persona que era proveedora de calzado alto y su plus era la personalización del mismo, Eso quiere decir que los clientes podían elegir desde el 
inicio las características de fabricación. Con ella, trabajé alrededor de 2 años y medio, después, pasé a tener contacto con las personas que fabricaban directamente el calzado. La empresa comenzó a consolidarse y a vender de forma masiva. Inicialmente nos apoyamos en la plataforma de anteriormente mencionada, que, al tener menos competencia, hacía que las ventas fueran mayores y el producto más llamativo, más en una ciudad como Popayán donde aún es complicado encontrar prendas o accesorios que llamen realmente la atención del público.

Pensé entonces en la fabricación y comercialización de tacones, porque en mis gustos el calzado es de gran importancia. Los zapatos altos te permiten reflejar elegancia, dar una imagen diferente a la común. No es lo mismo ver a una mujer en tenis, que una mujer en tacones, es un producto que genera inmediatamente status. Hay una gran diferencia y lamentablemente, en el calzado las mujeres, nos toca conformarnos con lo que encontramos en el mercado, entonces en la mayoría de tiendas, que tienen una marca establecida, o las boutiques, simplemente se dedican a traer modelos en serie, no está mal, en el comercio todo se vende, sin embargo, para mí la distinción es una regla a seguir y si con mi marca lo puedo expresar.

En el género femenino hoy por hoy aún se limitan las posibilidades de encontrar un producto completo y los pies son una parte del cuerpo difícil de satisfacer, eso qué quiere decir, que hay personas que tienen los pies muy delgados o muy anchos, otras de pie plano o que simplemente necesitan un color específico para un outfit, por ejemplo: un matrimonio, grado, entrevista, celebración específica, entre otros. Entonces nosotros lo que tratamos de fabricar, es un producto que, en su resultado final, sea lo que el cliente realmente desea, a un precio asequible, y que tenga la certeza que la calidad que va a recibir, es por la que está pagando. 
Nace esta idea de negocio, desde mi perfil personal de Facebook. Empecé a ver que en la ciudad de Popayán no había tanta cantidad de tiendas virtuales como lo había visto por ejemplo en ciudades como Bogotá, Cali y Medellín, que son ciudades que ya tenían este tipo de ventas un poco más optimizadas. A pesar que nuestro municipio es visto como pequeño y poco estable a nivel comercial, es inimaginable la acogida que pude tener un buen producto.

Quería que la marca tuviera un diseño que realmente la gente al escucharlo se imaginara inmediatamente de que está hablando, entonces cuando tú te pones zapatos altos, lo que quieres es alcanzar un nivel superior. El logo transmite que quienes busquen tacones puedan plasmar una imagen superior. El cielo para mí, es el límite, sin embargo, cielo de tacones no iba a generar mayor impacto ni recordación por ende tomé las nubes como punto de referencia. Conjugue mi visión personal con lo que estaba ofertando. Entonces, nace Nube de Tacones para personas que buscan trascender y no usar un calzado común. Ello se complementa con el slogan, dejando huella desde lo alto. Eso es lo que quiero, que nuestras clientes cada vez que utilicen el calzado, sientan que están dejando huella en su proceso, ya sea una persona que los use para trabajar, hacer una diligencia, un evento o alguien que simplemente quiera ir a la playa. Se cruzan grandes emociones cuando veo que cientos de mujeres tienen tacones de mi marca luciéndolos con gusto y naturalidad.

Han sido muchas las experiencias para contar desde que decidí emprender. La que más me ha impactado sucedió en el 2019. Nosotros iniciamos contemplando la posibilidad de tener un taller totalmente propio y lo más cerca que tuvimos fue contactar a personas que tuvieran un taller y nos brindaran prioridad para no tener intermediarios. Notamos que hay dificultades en el gremio que se dedica a esta labor. Después de analizarlo muy bien, este año nos enfrentamos al reto de hacer la fabricación directa desde Popayán. Ha sido el paso más grande que he tenido que asumir, 
porque ya no será simplemente dirigirse a la comercialización, marketing y ventas, sino conocer y empezar a vivir una experiencia nueva, ampliar y organizar las áreas de la empresa, enfocándose de lleno a producir y generar mayores empleos, algo que me llena de entusiasmo ya que podré contribuir en que varios seres humanos tengan una mejor calidad de vida.

La parte no tan positiva trasciende en cuanto a que la cultura payanesa, es muy complicada de manejar, no se consiguen fácilmente personas que trabajen en la fabricación de calzado, y quienes lo han hecho, realmente nos han defraudado, entonces estamos adoptando nuevos mecanismos. Hemos tratado de trabajar de forma indirecta con el SENA. Se está dando inicio a la construcción de nuestro propio taller. Con esa decisión, queremos mejorar no sólo los tiempos de entrega, sino la presentación del producto, logrando que sea más llamativo y dedicarnos al diseño de modelos netamente exclusivos.

Cuando hice mi proyecto de grado, idealizaba muy diferente a Nube de Tacones, pero en el 2019, estamos dando un giro demasiado drástico y en este momento vamos a apuntarle a abrir un mercado más amplio en ventas al por mayor, porque actualmente, las ventas por redes sociales, están colapsadas. Hoy todo el mundo puede vender, acceder y la única ventaja que tenemos nosotros en este momento, es la trayectoria en el mercado, el ser pioneros en este tipo de fabricación en Popayán y a nivel nacional gracias a Dios hemos podido mantenernos aun elaborando estos artículos, seguido de la buena imagen que hemos obtenido durante este tiempo. Le vamos a apuntar a un mecanismo organizado de ventas al mayor donde las compradoras, especialmente, mujeres cabezas de familia puedan ingresar a nuestras redes y vender nuestros productos y crecer.

También le vamos a dar prioridad al desarrollo de las redes sociales, con seguidores totalmente orgánicos. Nube de Tacones cuenta en Instagram con 11.100 seguidores esta plataforma, en 
los últimos meses le hemos dado gran importancia ya que está en un punto perfecto para vender y expandirse a nivel local, nacional e internacional. En Facebook contamos con 28.600 y las ventas para esa cantidad, son interesantes, entonces queremos seguir apostándole a eso, y no llenarnos de seguidores que no representan el tráfico que nos interesa. Muchas personas me han dicho, sal de Popayán, crea empresa en otros lados, haz empresa en el Valle, en Antioquia que son regiones que realmente son desarrolladas $\mathrm{y}$ te pueden brindar mayores posibilidades de crecimiento, pero yo creo en Popayán, y veo muchas ventajas como que todavía estamos en un proceso de crecimiento. Creo que quienes se quedan creando empresa, van a tener un gobierno más amplio del sector más adelante, entonces me quedo aquí, el taller se queda aquí y fue una decisión que tomamos este año.

Popayán merece la oportunidad de generar empresas y nosotros lo podemos hacer siempre y cuando se cree una cultura de trabajo en equipo, que es lo que también quiero reforzar. Desde la conformación de la fábrica, vamos a priorizar el clima organizacional, los trabajadores para que todos trabajaremos en equipo, porque sí todos estamos bien, la empresa va a surgir y va a dar buenos resultados. Desde que inicie Nube de Tacones, mi prioridad ha sido el ahorro. El 80\% de lo que he trabajado, lo he ahorrado gracias a Dios. A eso le debo que en este momento estemos construyendo el taller y no hayamos tenido necesidad de acudir a terceros.

Para mí emprender, es literalmente tener un hijo. Es eso que tú creas, eso que idealizas como idea negocio, empiezas a formar, a mezclarla con una cantidad de procesos que, a la vuelta de algunos años, retrocedes y dices: “¡mi hijo ha crecido!”. Generalmente sientes que estás haciendo lo mismo día a día, una serie de esfuerzos consecutivos en vano, pero es falso. Cuando empiezas a tributar, por ejemplo, te das cuenta que sí hay resultados a buen ritmo, si debes pagar impuestos, es porque realmente has evolucionado o cuando mis clientes me escriben o suben sus 
fotos a redes muy contentas con el calzado, son detalles que no tienen valor. No tengo una queja o una anécdota negativa, es real cuando te dicen que debes enfrentarte a demasiados retos como persona y profesional, porque si pasa, suceden situaciones que no son muy alentadoras, te frustran inmensamente, pero todo es para optimizar tu potencial, ese es uno de mis grandes aprendizajes, todo deja una enseñanza que debes comprender, entonces siempre he dicho a los que puedo, emprendan.

Para ello, hay que tener una educación financiera muy establecida. De nada sacas con emprender, si no tienes claro, cuáles son las expectativas alrededor de lo que conlleva este proceso, finalmente, el emprendedor a largo plazo espera tener cierta libertad financiera, eso no se puede negar. Es lo que estoy forjando desde ahora.

Entonces las entidades deben continuar con el apoyo, no solamente a quienes inician, sino quienes se quieren mantener. A los emprendedores para acceder a algún beneficio nos exigen demasiado cuando lo único que queremos es crecer, porque iniciar es fácil, pero mantenerse, es diferente. Sin embargo, creo que es una labor de todos. Por ejemplo, una de las proyecciones que tengo, es reunir un grupo de mínimo 25 personas para que se capaciten en fabricación de calzado en el SENA, y en un año puedan estar elaborando pares, haciendo sus prácticas en Nube de Tacones y los mejores, podrán quedarse trabajando con nosotros.

Comprendo a las personas que quieren iniciar y no se atreven, porque lo más difícil, es tomar la decisión. Siempre te vas a enfrentar a la opinión de la gente, especialmente cuando se cree por cultura que emprender solo es un medio directo para hacer dinero, y no es así. Por otro lado, no lograr lo que uno se propone en los primeros intentos, es difícil. Hay que olvidarse de eso, porque el mejor aliado es la perseverancia y disciplina. Cuando una persona quiere emprender debe darse cuenta que tiene que dejar prácticamente todo, evolucionas o evolucionas. Tú no 
puedes pretender comerte el mundo y al mismo tiempo empezar a emprender, porque no vas a poder, debes tomar el recorrido más largo, de mayor trabajo para obtener mayores beneficios y sentirte realmente satisfecho. Hacerlo es un camino muy lento, tienes que dar pasos muy cortos y de un momento a otro, pasos muy rápidos, tienes que frenar, analizar, volver a empezar, correr y así sucesivamente.

Cada uno sabe las razones internas que lo han llevado a emprender y continuar, en mi caso es esa sed de independencia. En el presente las mujeres podemos valernos por sí mismas, ser auténticas, empoderadas y visionarias, me encantaría representar a este tipo de personas. Cada uno es su mayor motivación, si te caes vuelves y te levantas solito, empiezas de nuevo con un punto a favor, que es la experiencia.

\section{Attis Mascotas}

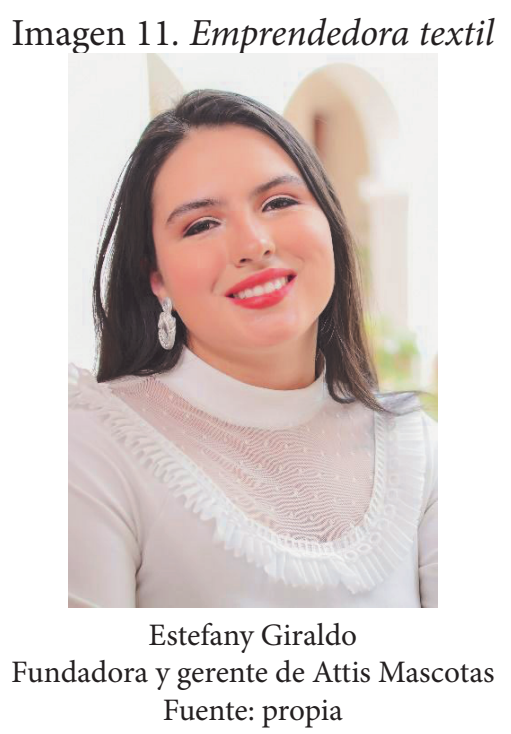

Soy Estefany Giraldo, nací en Urabá, Antioquia. Mis padres emigraron a Popayán cuando era pequeña y por eso realicé todos mis estudios, desde primaria hasta universitaria, aquí. Soy 
patoja de adopción. Actualmente tengo 25 años y tengo una hija de 6. Soy Ingeniera en Automática Industrial, graduada de la Universidad del Cauca y en este momento estoy haciendo una práctica empresarial, trabajando en la hidroeléctrica de Coconuco que se llama EMESA.

Sin embargo, también soy emprendedora. Todo empezó hace cuatro años. Estaba trabajando en los almacenes de Arturo Calle, con un horario rígido de seis horas diarias y a la vez, estudiando. Mis objetivos en aquel entonces eran terminar mi carrera y mantener a mi hija, que tenía solo ocho meses de nacida. Pero llegó un punto en que colapsé. Fue entonces cuando pensé que toda la vida me han gustado las mascotas. Vi la necesidad de emprender para estar más tiempo con mi hija y ser más independiente, además de manejar mi tiempo para estudiar, etc. A eso le sume mi experiencia en telas, colorimetría y muchas más, la tradición sastre de mi familia, ya que por mi mamá aprendí a usar la máquina de coser. Además, a mi mascota le hacía accesorios, corbatines, entre otros, y en aquel entonces una amiga me referenció una página web en Medellín que se dedicaban a vender corbatines para perros, entonces tomé la decisión y luego de año y medio, luego de tener los recursos necesarios, renuncié.

Así nació ATTIS, porque era el nombre de mi mascota, la primera que tuvimos en casa. El nombre proviene del idioma griego y eso nos gustó. De hecho, su muerte fue la motivación para seguir adelante, porque me sentí muy triste cuando sabía que ya no estaría conmigo, pero muchos me dijeron que no, que, al contrario, sería más bonito hacerle un homenaje con mis ganas de salir adelante. Por eso quisimos dejar su legado, porque fue el primero en usar nuestros productos. En ATTIS vendemos diversos tipos de accesorio para mascotas, como collares de todo tipo, incluso algunos hechos con una técnica totalmente artesanal, pañoletas, cascabeles para gatos, también tenemos un producto exclusivo que son juguetes para gatos: unas almohadas pequeñitas 
que tienen rellenos de cascabeles y una hierba exclusiva para ellos, vendemos juguetes y galletas para ese tipo de mascotas que dañan todo lo que les pongan.

Con la empresa siento que he roto esquemas y paradigmas. Empecé cuando tenía 21 años, ya tenía una hija, estudiaba ingeniería y trabajaba. Así demostré que no importa la edad que tengas, realmente se puede. El año pasado también me gané el concurso de emprendimiento Ingeniando de la Cámara de Comercio del Cauca. Esa noche fue increíble. Eran más de cien proyectos que estaban participando y realmente eran muy buenos, hasta llegué a pensar que nunca me ganaría algo así. Pasaron filtros de 50, luego 20, y hasta que llegaron a los ganadores. Cuando nombraron el segundo puesto pensé que no ganaba, y sin ánimo de menospreciar mi idea de negocio, había proyectos innovadores que uno les veía futuro. Fue entonces cuando me nombraron. La sensación de ese momento fue indescriptible. Fue con esto que demostré que sí se puede, que no importa nada de lo que la gente diga, porque me decían que en la ciudad nadie compraba cosas para mascotas, pero no, sólo basta atreverse y demostrar que la gente sí lo compra, sí le gusta el emprendimiento, sí vale la pena. El hecho de tener 21, 22, 23 años no es impedimento, tampoco lo es estudiar una carrera diferente a lo que se hace, y tener una hija mucho menos.

Por eso, sueño con algún día exportar mis productos, llevar la marca a nivel nacional y vender por toda Colombia, además de ser el número uno en el top de este tipo de mercado en Popayán. Ahora estamos pensado en un aplicativo móvil que le permita al cliente aportar también en el diseño, y así articular mi carrera con mi trabajo diario. A la final nuestra carrera como ingenieros mezcla la parte industrial, articula los procesos de mejoramiento de recursos, las líneas de trabajo, etc., y lo que queremos con el aplicativo es automatizar nuestros procesos. También con un ingeniero de la comunidad estamos pensando en la implementación de los GPS, porque Popayán tiene una 
estadística alta de pérdida de mascotas impresionantes y aunque es costoso, el perímetro no es muy amplio y son productos traídos de China, creo que vale la pena.

Emprender en Popayán ahora es más fácil que hace cuatro años. Ahora uno ve emprendimientos que surgen en dos meses y les está yendo bien, les está dando y eso me alegra porque cuando yo empecé era muy difícil, por la mentalidad de las personas, porque Popayán es muy limitada en cuestiones de insumos, lastimosamente casi el $70 \%$ de las cosas que yo compro las tengo que traer de Cali o de Medellín o de otra ciudad porque en Popayán no hay. Uno quisiera que el comercio se quedara aquí, que la rotación de comercio se quedará en Popayán, porque yo como emprendedora estoy creciendo, pero compro mi materia prima en Cali, entonces sigo beneficiando a las empresas de allá. Sin embargo, cada vez ha ido mejorando, y aunque son más costosos los productos acá, cada vez uno encuentra más insumos y es importante no tener que desplazarse hasta allá. Además, siempre he contado con la Cámara de Comercio del Cauca, mis aliados estratégicos, quienes me han apoyado con capacitaciones y programas que me benefician. Las personas ven la CCC como una entidad que solo cobra impuestos, y no es así. La cuota anual que doy como empresaria me beneficia para muchas cosas, pero soy yo la que tiene que gestionar, nadie debe hacerlo por mí. He intentado también vincularme con otras entidades como CreaTIC.

Por otra parte, mi familia siempre ha estado ahí. Afortunadamente en ellos he encontrado apoyo tanto laboral como moral, porque me han dado el ánimo necesario, han entendido la importancia de emprender, saben que debemos conservar el negocio, por eso me han colaborado en la toma de decisiones, en las malas rachas, y también en la forma de crecer. Conozco muchos emprendimientos que realmente no tienen un apoyo familiar y uno ve que es un emprendimiento que por más que se esfuerce es muy poco lo que avanza. 
Por eso siento que he crecido bastante. Emprender te da mucho criterio y te hace madurar, te hace tener otro punto de vista al conocer tanta gente con la cual debes rodearte, porque una de las ventajas más grandes es que creces en un círculo social de manera impresionante y tratas con personas de admirar, que tienen un corazón muy bonito y que te dan muy buenos consejos. Además, creas buenas amistades, entonces cuando uno se rodea de personas tan positivas y motivadas, creces a la par de tu empresa. Así es como uno descubre su potencial, porque por otro lado uno casi no cree en sí mismo. Las demás personas si lo ven, porque creen que es increíble todo lo que haces, por ejemplo, mi hija. Al principio la mantenía alejada de todo esto porque me daba pesar tenerla tantas horas conmigo en ferias o eventos, yendo de aquí para allá vendiendo los productos, contactando clientes, haciendo redes, y así. Llegó un día que ella misma me dijo que no le importaba, ahora se sienta conmigo y hace cositas pequeñas y habla que "las va a vender". Estoy formando una futura emprendedora, una futura empresaria, y eso me hace sentir bien, muy bien.

A aquellos que quieran emprender, que lo hagan. Que, si tiene miedo a perder la supuesta estabilidad económica que le da una empresa, y al miedo de pensar que no les va a ir bien, que debe trabajar más, no importa, que lo haga. Hoy en día hay varias entidades que apoyan los emprendimientos, la Alcaldía municipal, el SENA, la Cámara de Comercio, etc., son oportunidades muy buenas, además de trabajar en lo que uno ama y no hacerlo para otro, es muy satisfactorio. Eso sí, las entidades también deberían pensar en ayudar mucho más al emprendedor, por ejemplo, en impuestos, en los trámites para la formalización, en los límites en las convocatorias, etc. Son asuntos que hay que repensarlos, ya que los emprendedores no les resulta pagar tanto impuesto, hacer tanto papeleo para legalizarse, $\mathrm{o}$, simplemente porque ven limitantes, como la edad. En las convocatorias no se presentan personas con gran potencial. Hay emprendedores de 40 o 50 años que aún pueden salir adelante y si fomentamos eso en el Cauca, nuestro territorio sería otro. Por ejemplo, las universidades. 
Es muy positivo que ahora, desde la formación de pregrado, se fomente el emprendimiento, y casi todas las carreras cuentan con proyectos. Hay que seguir potenciando eso, hacerles más publicidad a las ferias, permitir que personas externas conozcan los emprendimientos, que compren, que generen redes. Sería bueno que las electivas contengan más temas de emprendimiento, para que uno que va estudiando su carrera, también poco a poco vaya implementando su idea de negocio. Así también se podría generar empleos, más contactos, y uno como emprendedor también se podría sentir más apoyado, que al final, es lo que se necesita.

\section{Servicios transformadores}

\section{Fundación Red Emprendedoras Popayán}

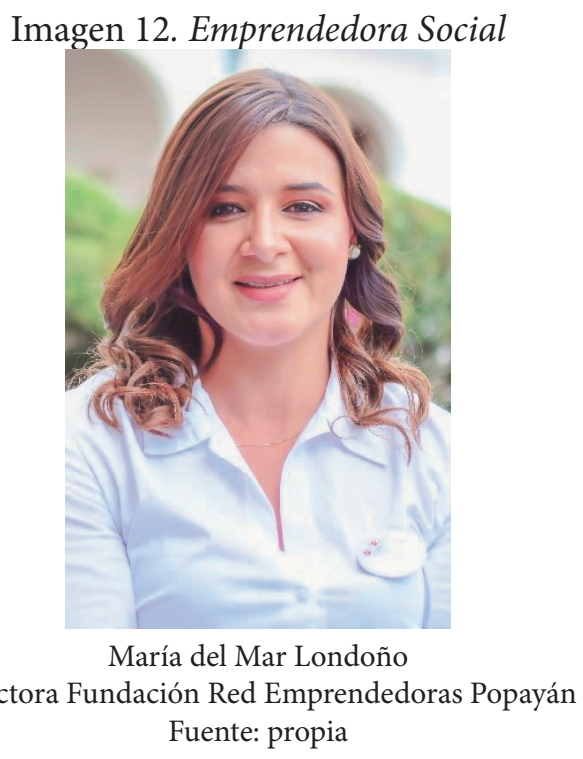

Soy María del Mar Londoño de 35 años de edad, Ingeniera de Sistemas de la Fundación Universitaria de Popayán, Especialista en Gestión de Pymes de la Universidad EAFIT, directora de la Fundación Red Emprendedoras Popayán, constituida desde el 2017, pero con actividades desde el 2016. 
La idea surgió cuando inicié con la búsqueda de proveedores locales de artículos para mi bebe. Como mamá empecé a necesitar productos para el hogar alrededor de nuestro hijo y pensé que lo ideal sería adquirirlos en la ciudad.

En ese momento, inicié con un grupo en Facebook que para ese entonces se denominada, Red de Apoyo a Ventas y Servicios de Mujeres en Popayán, y al transcurrir un año y medio, ya estaba conformado por 90 empresarias y 7.000 miembros que hacían parte del grupo, entre diferentes roles como compradoras, vendedoras y consejeras, incluso, no solo de Popayán, sino de diferentes ciudades del país.

Esta fue una gran iniciativa que nos enseñó a trabajar en red. Cada vez son más las mujeres que encuentran en este espacio, no solo una herramienta para dar a conocer sus productos y servicios, sino para intercambiar ideas, sentirse acompañadas, empoderarse y creer en sí mismas. Adelantamos encuentros, capacitaciones para crecimiento empresarial y personal a través de diferentes estrategias como coaching, asistencia a ferias, asesorías, promoción de productos, y espacios para las talleristas REP, que son mujeres expertas que orientan talleres a las demás, entre otros.

Sin dimensionarlo de esa manera, poco a poco nos hemos dado cuenta de la importancia que ha conllevado para nuestras mujeres la Red. Muchas de ellas, como cabeza de hogar, encuentran en la Red, una forma de potencializar sus talentos y generar ingresos adicionales para sus familias.

Las 90 mujeres integrantes de la Red, ofrecen diferentes productos y servicios, como manualidades en madera, decoración, ropa para niños y grandes, artículos de cuero, transformación del cartón, bisutería, joyería, gastronomía en una amplia variedad, desde snacks, comida para eventos hasta panadería, centros de belleza, tecnología y consultoría en tecnologías y productividad, entremuchosotros. Sin embargo, también ha sido posibleintegrarse 
con entidades y redes nacionales e internacionales que evidencian en este colectivo, una experiencia real de asociatividad. Entre ellas, se encuentra el Centro de Empleo y Emprendimiento, organismo de la Alcaldía Municipal de Popayán, la Fundación Universitaria de Popayán, la Fundación Mujeres TIC, la Gobernación del Cauca, la Cámara de Comercio del Cauca, Unicomfacauca, el Clúster Creatic, entre otras entidades públicas y privadas.

Es por esto qué, desde la Red, el emprendimiento es visto como la capacidad de tener una iniciativa, una idea y buscar hacerla realidad, llevándolo a otro nivel donde desarrollamos planes y ejecutamos procesos que nos generen un ingreso. Para ello, es necesario ser emprendedor, concibiéndolo como una persona con aptitudes y actitudes, capaz de hacer realidad sus sueños.

Entonces el emprendimiento es importante, porque nos permite salir de un estado de confort, nos llena de energía, buscando más allá de lo que tenemos a nuestro alcance, lo que implica capacitarnos, crecer profesional y personalmente. Cuando esto sucede, nuestro entorno cambia de manera positiva y fortalecemos la economía. Sin duda, son diferentes las necesidades y oportunidades que debemos entrar a resolver si le queremos apostar al emprendimiento.

Necesitamos trabajar para lograr mayor apoyo y acompañamiento de los emprendedores desde un inicio de manera integral, con más fuentes de financiación, logrando un trabajo colaborativo real entre entidades públicas y privadas que apoyan el emprendedor. Por consiguiente, más allá que el gobierno y las instituciones capaciten en temas técnicos, deberían motivar a los que deciden emprender, por ejemplo, considerar aspectos como el empoderamiento de mujeres y hombres en temas económicos, resolución de conflictos, trabajo en equipo e incentivar el liderazgo. Desde el emprendimiento, debemos apostarle a seguir creando y consolidando empresas en todos los 
sectores, potenciando la tecnología actual, que facilita la venta desde un móvil o computador, sin necesidad de tener costos fijos de arrendamientos, pago de nómina, etc.

Es una realidad que los emprendimientos mueven actualmente nuestra economía y ayudan a disminuir la tasa de desempleo, son un apoyo a madres cabeza de hogar, madres que desean generar ingresos sin descuidar su hogar. También, existe la oportunidad de incorporar a los adultos mayores en temas de emprendimiento que les generan ingresos y además ocupar su espacio de tiempo en diversas actividades.

Para su debido funcionamiento, la red cuenta con una junta directiva conformada por cinco miembros, así: Presidente/ Directora, Vicepresidente, Secretaria, Tesorera y Vocal. Adicionalmente, con una junta de apoyo que nos colaboran con temas logísticos, reemplazo y representación en reuniones, ejecución y planeación de ideas para el equipo de emprendedoras. Además de estatutos y reglamento interno, dos programas de asesorías: una de emprendimiento y otra de innovación, cronograma de capacitaciones y eventos comerciales para todo el año.

Ello ha permitido promover una cultura del emprendimiento. "Es hablar un mismo idioma, el idioma de convertir los problemas en oportunidades, retos por cumplir, en incentivar el cambio y la búsqueda de nuevas oportunidades, a trabajo en equipo, ser positivo y propositivo. Entender que el fracaso es un paso para el éxito" (María del Mar Londoño, Directora).

Sin embargo, es una labor que se debe fomentar. En el área directiva, por ejemplo, gestionamos espacios de comercialización de productos y servicios, así como, el intercambio de experiencias entre emprendedores y actores clave del ecosistema empresarial. 
Direccionamos y planeamos el programa de capacitaciones REP anual para el fortalecimiento empresarial y propendemos por el buen uso de los recursos de la Fundación.

La emprendedora del mes, es una mención que se le da a la emprendedora que luego de pasar por el proceso de asesorías en emprendimiento y presentar el pitch de su empresa, es elegida ante jurados. Posteriormente, se beneficia con publicidad exclusiva en redes y medio de comunicación local.

Así mismo, el grupo en Facebook con más de 7.000 miembros, permite la comercialización y promoción de emprendedoras de Popayán y otras ciudades. Promovemos a través de nuestras redes sociales los procesos de emprendimiento de la Fundación, así como de los logros de las asociadas. A través del grupo de WhatsApp de asociadas, impulsamos la comercialización de productos entre emprendedoras y compartimos temas de interés sobre emprendimiento.

Pese a ello, se requiere mayor sinergia entre entidades públicas y privadas que apoyan emprendedores, mejorar las fuentes de financiación y el capital semilla, desde la academia, fortalecer el tema del emprendimiento tanto en capacidades técnicas como en habilidades blandas, disminuir los trámites legales para la constitución de empresas, desarrollar programas de apoyo y fortalecimiento a emprendedores en edad adulta y jóvenes.

Luego de dos años en el proceso dentro de la Fundación, las emprendedoras necesitan un acompañamiento para el mantenimiento de sus empresas. Sería más fácil, si contáramos con un programa gubernamental aliado que las apoyara y fortaleciera en la siguiente etapa. Ya no todas están para formarse como si estuvieran en su fase cero. 
Es así como la red se ha convertido en un encuentro genuino de mujeres motivadas por salir adelante, que su principal característica es el carisma, la confianza en sí mismas, en su trabajo, y en el futuro.

\section{Colectivo Happy}

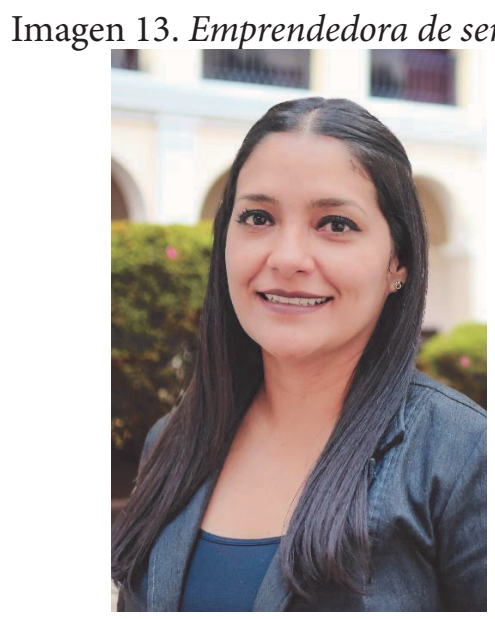

Yesika Paola Torregrosa Gerente Colectivo Happy Fuente: propia

Soy Yesika Paola Torregrosa de 39 años de edad, nacida en Sincelejo, Sucre, egresada de la tecnología en Gestión Empresarial y el programa profesional de Administradora de Empresas de la Institución Universitaria Colegio Mayor del Cauca. En este momento soy la gerente de la empresa Colectivo Happy. Los últimos 32 años de mi vida los he vivido en Popayán, sintiéndome hija adoptiva de esta ciudad que adoro.

Quiero empezar diciendo que mi principal propósito con cada cosa que hago es que todo siempre este mejor (con las personas, en las empresas, en la sociedad, en mí y en los míos), que todo crezca, que todo mejore y por supuesto, dejar mi marca personal en lo que hago. 
He sido emprendedora desde los 19 años y creo que desde mucho antes, pero con un establecimiento formalmente constituido ante la Cámara de Comercio del Cauca, desde esa edad. Mi primer emprendimiento fue "Centro Galería" un restaurante y café bar.

Me parece importante contarles que desde muy pequeña empecé en el colegio vendiendo calcomanías, jabones que alguien fabricaba y yo comercializaba, dulces, bombones y esas cosas que son muy típicas a esa edad. Años después, monte mi primer negocio formal porque veía que los negocios de comida eran muy buenos. Era un negocio interesante y rentable. Inicié con 15 clientes y llegué a tener alrededor de 120. Este negocio estuvo funcionando por aproximadamente 8 años.

Empecé estudiando psicología, pero quedé en embarazo y debido a esa decisión, me vi en la obligación de cambiar mis prioridades, así que me puse a trabajar asumiendo así mi rol de madre soltera $100 \%$. Mi hijo Mateo fue mi aliciente, mi motor y mi compañía en todo este proceso. A partir de esta circunstancia me volví más fuerte, más curiosa y más emprendedora. Empecé a ver los negocios como una opción de sostenibilidad porque la empleabilidad en la ciudad de Popayán, es muy difícil, por los pocos negocios, empresas e industrias y más aún sin un título universitario.

Como lo mencioné anteriormente inicié estudiando Psicología, pero terminé siento Administradora de Empresas y todo esto gracias a Cristina Urrutia, una persona maravillosa que almorzaba en mi restaurante todos los días y trabajaba en el Colegio Mayor del Cauca. Un día me dijo: "yo creo que tú tienes como muy buena actitud para el tema empresarial, ¿no te gustaría estudiar gestión empresarial?" y al otro día me llevó a regalar el formulario de inscripción. 
De alguna manera yo había perdido la esperanza de volver a estudiar Psicología porque cuando quise volver, más o menos cuando mi hijo cumplió cuatro años, fui a retomar y me comentaron que se habían hecho varios cambios de pensum que me devolvían a segundo semestre.

Cuando inicié en el Colegio Mayor la Tecnología en Gestión Empresarial tuve la fortuna de encontrar unos profesores increíbles, que más que docentes, siempre fueron mentores, influenciadores positivos y muchos de ellos, amigos. Me acuerdo mucho de Aída Lucía Toro, por ejemplo, una excelente maestra, María Eugenia Saldarriaga, quien me enseñó a amar el emprendimiento, Néstor Reyes, Rafael Bermúdez, Ricardo Riomalo, y otra cantidad de personas, que me motivaron, incluso el mismo rector actual, que fue mi director de trabajo de grado, Héctor Sánchez Collazos. Con semejante cantidad de maestros maravillosos, empecé a tomarle mucho amor a esa carrera y cuando pude acceder al ciclo profesional, ni pensarlo dos veces, lo hice y con muy buenas bases, creo que aprendí a ser una muy buena gestora empresarial y una muy buena administradora de empresas.

Con esto y con esas herramientas, por supuesto empecé a hacer mis primeros "pininos" de emprendimientos mejor estructurados, mejor consolidados, participe en casi todas las ferias de emprendimiento que organizaba María Eugenia Saldarriaga en el Colegio Mayor, ocupando muy buenos puestos entre las mejores ideas empresariales. Después del emprendimiento de Centro Galería, tuve otro que se llamaba la Bocaditos, luego tuve otro que se llamó Vitruvio y todos en la línea de alimentos. También tenía emprendimientos ocasionales o estacionarios relacionados con consultorías, empecé a especializarme en el componente empresarial, después me dediqué a comercializar ropa, joyas y cualquier cantidad de cosas. Me volví experta en vender.

La vida por supuesto me empezó a cambiar y ya con mis certificaciones universitarias, tuve mejores oportunidades, iniciando en la docencia. Luego, gracias al mismo ambiente 
académico aprendí y me metí en el emprendimiento, es decir el emprendimiento se me volvió una forma de vivir y de hecho estuve vinculada a la Corporación Universitaria ComfacaucaUnicomfacauca casi 5 años en docencia y al frente de la coordinación de la unidad de emprendimiento, eso también empezó a acercarme a otros ecosistemas y a otras organizaciones, generando cierta experticia de cómo crear esos procesos y cómo ayudar a las personas que lograran crear empresa, volviéndome una buena intraemprendedora.

Estando en ese proceso empecé nuevamente a pensar en un emprendimiento propio e inicié con un proyecto denominado "INHERENTE", pensado en consultorías, asesorías y formación alrededor del emprendimiento, la empresarialidad, la educación y la felicidad.

Pasó muy poco tiempo y por esas "causalidades de la vida", me encontré con grandes personas, como Juan Gabriel Bastidas y Vicente Bastidas, y me dicen: "estamos dándole vida a un emprendimiento que nos gusta muchísimo y creemos que tú puedes hacer parte de ese proyecto", entonces me senté con ellos y empezamos a botar corriente. Empezaron a contarme las primeras validaciones que habían hecho al respecto, empezamos a generar varias ideas alrededor y me di cuenta que era bastante afín a lo que me estaba dedicando, así que cuando me dijeron que si quería hacer parte de este proyecto, yo les manifesté que me encantaba y que de una! Así que empezamos a invertirle tiempo y dinero y a darle fuerza, a posicionar la marca y empezamos con pie derecho "Colectivo Happy".

Pasaron algunos meses y mis socios tomaron la decisión de dedicarse a otros proyectos, me vendieron el proyecto y asumí el rol de gerente, con lo cual empecé a darle un rumbo diferente, sin perder la esencia, convirtiendo Colectivo Happy en una empresa que oferta productos y servicios en alianza con los mejores profesionales y empresas de la región. Una empresa 
que está comprometida con el mejoramiento personal, social, ambiental y empresarial de los individuos y de las organizaciones a partir del desarrollo personal, la innovación, la felicidad y el emprendimiento. Trabajando fuertemente en tres líneas de trabajo: Talleres y Cursos, Club de lectura para niños y adultos y Tienda Happy. Nos enfocamos en la felicidad y en el bienestar de las personas.

Nos proyectamos con un gran colectivo de personas y empresas felices, una gran comunidad en pro del mejoramiento personal, social, ambiental y profesional, conscientes de la necesidad de apostarle a mejorar sus condiciones, y con ello, aportarle a la ciudad, al departamento y al país.

Creo que nadie puede dar de lo que no tiene y creo que eso ha sido claro para todos nosotros a lo largo del tiempo. Consideramos efectivamente que, si una persona está bien, por supuesto puede crear, puede generar riqueza, puede propiciar un excelente clima laboral y por qué no, generar bienestar en otras personas, entonces, Colectivo Happy trabaja alrededor de la felicidad, porque en ultimas una persona feliz es capaz de hacer cualquier cosa buena, innovadora y útil, es capaz de crear.

En la creación y consolidación de este nuevo proyecto llamado Colectivo Happy ha habido varios momentos significativos, pero sin duda uno de los más significativos fue alguna vez que nos reunimos con los socios y concluimos que lo más complejo de un proyecto así, es que nos exige mejorar en todos los aspectos de nuestra vida para entregar más de nosotros a otros y mostrarles así que sí se puede ser feliz y estar bien.

Emprender en Popayán es una labor retadora. No es difícil, es retador porque hay todo por hacer. Considero que en el Cauca hay mucho talento y entre todos podemos hacer crecer esta ciudad y este departamento. Por ejemplo, hace un tiempo, cuando recién empecé, no había entidades que acompañaran el 
emprendimiento, era muy difícil tener un apoyo, una asesoría, y lo mejor que podía pasar era tener la posibilidad de acceder a una feria empresarial, una muestra empresarial o la clase de emprendimiento o de creatividad dentro del aula, pero ahora se le ha dado relevancia desde las instituciones de educación superior y demás organizaciones, tanto en el ámbito académico, como en el práctico. Las personas empezaron a entender que definitivamente el emprendimiento es una muy buena opción, de hecho, una opción complementaria o alterna a ser empleado.

Para mí, el emprendimiento es la forma de crear a partir de algún conocimiento, de alguna habilidad o talento y permite generar riqueza. Existen muchas cosas alrededor del emprendimiento: la amistad, la comunicación, el propósito, la proactividad, el crecimiento, el desarrollo, la creatividad y la innovación.

Creo que nos falta tomarnos un poco más en serio el tema del emprendimiento, pero creo que vamos por buen camino, ya son varias las Instituciones y entidades que han consolidado sus programas de formación en emprendimiento, rutas y otros similares para enseñar a estudiantes, egresados de las instituciones y ciudadanía en general, cómo crear sus empresas como el Sena, la Cámara de Comercio del Cauca, CreaTIC y algunas Instituciones de Educación Superior de la región.

Sin duda, para lograrlo, es necesario fortalecer habilidades blandas, para que las personas asuman que el emprendimiento es una oportunidad, para identificar fortalezas, habilidades y conocimientos. Se debe trabajar en la creatividad e Innovación, a partir de cursos y/o talleres. Lo más importante del ejercicio, es que, si una persona tiene la idea de emprender, debe hacerlo, pero apoyada de gente que sabe y está a su alrededor.

En este momento, contamos con varios actores que están dispuestos a facilitar el proceso, de forma responsable para dar 
unas pautas y un acompañamiento que les permita arrancar y fortalecerse. Las herramientas, están en las entidades, simplemente hay que acercarse a ellas y creer que sí se puede.

\section{Kinés}

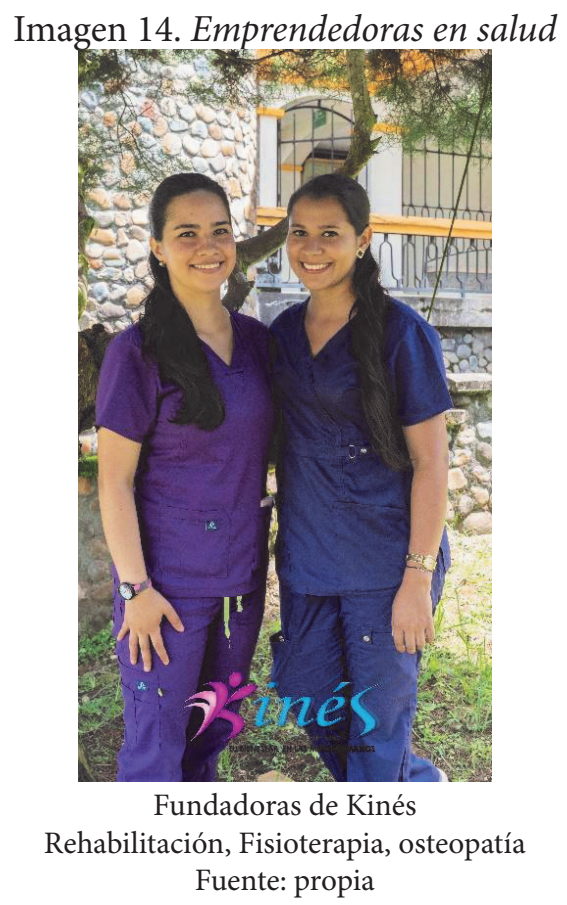

Somos Daniela Fabara de 24 años de Popayán y Danila Sternling de 25 años del municipio de Silvia Cauca, profesionales en Fisioterapia, egresadas de la Fundación Universitaria María Cano.

Daniela Fabara: nuestra historia como emprendedoras inicia desde la universidad, cuando interesadas por conocer más acerca del tema, nos acercarnos a gente emprendedora y empezamos un proceso de formación desde la misma institución, con el firme propósito de aprender sobre aspectos administrativos 
y resolver algunas inquietudes sobre la creación de una empresa, la planeación estratégica. Entonces cuando se da el momento del grado, salimos y nos enfrentamos con que, en la parte de fisioterapia, el sistema de salud, está saturado. Primero, el trabajo no está muchas veces bajo las mejores condiciones y segundo, no es posible ser un buen profesional cuando no existe calidad.

Es ahí cuando uno se pregunta, ¿Qué calidad se le puede prestar a un paciente, cuando tiene que atender en promedio entre 7 y 8 en una hora?, entonces eso no permite una rehabilitación integral.

Aun así, existen algunos paradigmas relacionados con trabajar como empleado, adquirir experiencia y luego crear empresa. Desde ese enfoque, empiezo a trabajar en una institución, a la par con mi compañera Daniela Sterling, quien también lo hace en otra entidad. La situación se empieza a volver aburridora y el sistema cada vez nos fue agotando más. Esta experiencia nos duró aproximadamente entre 2 y 3 meses, y de ahí, conocimos a unos amigos emprendedores, mayores que nosotros y son ellos quienes nos motivan a crear empresa, nos ofrecen su ayuda, que sumado a la de la familia, dio inicio a la idea de Kinés.

Daniela Sterling: la carrera que hicimos juntas con mi compañera Daniela, nos permitió conocernos y saber que podríamos emprender juntas. En mi caso creo que ese interés por el emprendimiento, viene desde mucho tiempo atrás, porque desde pequeña, he sido emprendedora, vendía dulces y un poco de todo. En la universidad, por ejemplo, creamos una tienda y vendíamos productos que yo traía de Silvia que no había en Popayán, y las revendíamos. En ese proceso, conocimos a personas emprendedoras que dijeron, bueno ellas de pronto tienen como otra intención, más allá de salir y buscar trabajo. A mitad de carrera, empezamos un proceso de formación por fuera de la universidad, realmente porque la universidad educa unas inteligencias que no 
son suficientes. Cuando tú sales de la institución, probablemente no es todo lo que necesitas para adquirir ese bagaje y asumir estos retos.

Empezamos con las lecturas de inteligencia emocional, inteligencia financiera, comercial, social y eso en mi caso, fue lo que me hizo perder un poco el miedo a decir, bueno sí yo salgo, de pronto ya tengo una noción de lo que me voy a encontrar, de cómo está hoy en día el empleo, y no me va a dar tan duro arriesgarme, porque finalmente no tengo nada que perder. En este momento, no tengo hijos y estoy joven, entonces de alguna manera proyectamos lo que queríamos. Lo que, si no nos imaginamos, era que iba a ser tan pronto.

Porque, aun así, yo decía, por ejemplo, voy a salir, voy a ganar experiencia y todas esas cosas que se requieren en este campo de la salud, porque la responsabilidad es muy grande. Sin embargo, el inconformismo aceleró la decisión, y la necesidad de ser un instrumento de bienestar ayudó a cristalizarla. En ese momento, sentimos la necesidad de hacer algo diferente.

Entonces se crea Kinés, con la participación no solo de las dos, sino de todo un equipo que apoya a la empresa en aspectos de índole organizacional. La palabra Kinés, es de origen griego que proviene de la palabra kinesiología, que significa movimiento. En ese sentido, Kinés es movimiento, entonces, la fisioterapia es el enfoque en el estudio del movimiento corporal humano.

En este sentido, fue necesario conocer que estaba pasando en el mercado, y encontramos, que el estrés, era uno de los causantes de muchas enfermedades, y ese fue el enfoque que nos permitió dar inicia a nuestra empresa.

Iniciamos con algo muy pequeño ubicado en el barrio Bolívar, en un espacio donde solo cabía una camilla. Sin embargo, como la terapia que nosotros hacemos, no es una terapia tradicional, sino una con muchas técnicas novedosas en la parte 
de fisioterapia, nos dio la oportunidad de crecer rápidamente, y las personas nos referenciaban en su círculo más cercano, entonces llegan más y más pacientes. Entre ellos, un paciente de 24 años de edad que sufre un accidente cerebral, que lo deja con la mitad de su cuerpo paralizado y con una afectación de habla de por vida, además de una parte de retraso cognitivo por causa del estrés. Esta persona, no dormía, tenía largas jornadas laborales y poco a poco logró una recuperación importante. Mi compañera, por ejemplo, en sus espacios de práctica universitario, recibió a una niña de 14 años que le dio lo mismo a causa del estrés, así como otros casos por parálisis facial, tiroiditis por estrés, y todo ello, nos demostró que no existían profesionales en la ciudad que realmente atacaran el estrés desde la parte profesional. Es ahí cuando empezamos terapia física, que es lo normal en la fisioterapia, abrimos otra línea relacionada con experiencias anti estrés, llegando a trabajadores, turistas, personas mayores, entre otros.

Contamos con la satisfacción que muchos nos abrieron la puerta y aún están interesados, Hace pocos meses, diseñamos talleres grupales en el ámbito ocupacional, pero haciéndolo innovador. Incluyen técnicas de respiración, de gimnasio en tu empresa, creando así, las experiencias ocupacionales. Todo esto para decirte, que empezamos a quedarnos cortos con el espacio. Es ahí cuando nos cambiamos de instalaciones, pasándonos para el barrio modelo de la ciudad de Popayán, y posteriormente, al consultorio actual, en el barrio Santa Clara.

En ese proceso de cambios de lugar, pudimos evidenciar que emprender en salud es muy complejo, y se debe a la cantidad de requisitos que hay que cumplir para abrir un establecimiento de este tipo.

Todo empezó siendo muy genuino, muy desde lo que nosotros queríamos brindar a cada persona, y desde el contacto que no queremos perder con el paciente, porque es muy diferente cuando tú estás una hora con un paciente, escuchando sus 
historias y que, a través de ellas, puedes conectarte con ese dolor, que cuando son 5 pacientes en una hora, y a duras penas, sabes cómo se llama. De todas estas reflexiones, es cuando nacen las tres líneas de Kinés: terapia física personalizada, experiencia anti estrés y experiencias ocupacionales.

Pese a todo, como recién graduado, creo que los jóvenes salimos muy ingenuos de la universidad, creyendo que todo el mundo es bueno, que todos te quieren ayudar, y realmente tuvimos experiencias difíciles con personas que aparentaban ser muy buenas, pero que con el tiempo nos íbamos dando cuenta, que tenían sus propios intereses. Adicionalmente, situaciones que no se está preparado para enfrentar. Una de ellas, es el hurto a los establecimientos.

Sin embargo, queremos generar un impacto desde nuestra profesión, generando cambios para transformar esa realidad que nos ha tocado a todos los fisioterapeutas, apoyándose del continuo aprendizaje para brindar un servicio integral. Queremos dejar una huella y no ver en el usuario, una posibilidad de generar dinero, sino la posibilidad de brindar bienestar.

Esta labor no ha sido fácil, especialmente porque el emprendimiento en Popayán, tiene una característica común de las ciudades pequeñas y es la incidencia de la política. Para nosotros es claro que, en la vida, hay leyes y principios que no se pueden desconocer. Por otra parte, los requerimientos son muy extenuantes, más aún si de salud se trata. A lo anterior, se suma, que, como gremio, nos hace falta ser más unidos.

También existen aspectos positivos, entre ellos, que cada vez son más las entidades que acompañan a los emprendedores, especialmente con el SENA con quien hicimos un proceso muy importante para lograr materializar nuestra empresa, definir las líneas, los costos, y en 6 meses logramos mucho. Para todo este proceso el círculo más próximo es fundamental. 
Daniela Sterling: En mi caso ha sido muy satisfactorio, porque vengo de familia emprendedora, ellos son comerciantes, trabajan con ganado, con fresa, tienen sus fincas, y yo crecí viendo a mi abuelo que inicialmente fue empleado y luego, emprendedor. Lo que logró como emprendedor, nunca lo habría hecho como empleado.

Daniela Fabara: Cuando me gradué realmente yo iba a entrar a trabajar en un cargo, en la parte hospitalaria, y en esa época, toda mi familia, insistía que era la mejor opción para mi futuro profesional. Me tocó hacer un curso que era un requisito para trabajar en un hospital, sin embargo, yo no me veía en un hospital y menos con bebés, pues el trabajo era con neonatos. Mi papá que es pensionado y mis hermanas vinculadas a empresas con una trayectoria relativamente estable, solo veían ese futuro para mí. Cualquier otra posibilidad que se alejara de esa alternativa, era susceptible al fracaso.

Entonces me fui encontrando con grandes personas que fueron pacientes y emprendedores, que me decían lo contrario. Que emprender era la solución. Es así como un día, le dije a mi mamá que no iba a aceptar el trabajo. Llamé y les agradecí. Después de un tiempo, mis papás ya lo han aceptado porque han visto resultados, y hoy en día se sienten orgullosos que yo cuente con un consultorio.

Entonces esta experiencia ha sido un cambio del cielo a la tierra, porque en el emprendimiento, eres tú contra ti mismo. Si yo quiero hago y si no quiero no hago, entonces es una formación desde el auto control y de disciplina. El emprendimiento es un vehículo para alcanzar muchas cosas, no sólo materiales, sino también personales. Es decir, permite desarrollar capacidades. Se requiere que las entidades orienten más sobre bancos de proyectos, convocatorias y en general, de ángeles inversionistas, que ayuden a fortalecer el emprendimiento, por ejemplo, una guía donde aparezcan todas las entidades. 
A los emprendedores o los que quieren serlo, les decimos que lean mucho, porque cuando tú lees, tienes bases para decir, necesito esto y esto para emprender o bueno necesito educarme y ahora si salgo a enfrentarme a un mercado, pero el problema cuando tú no lees, cuando tú no te preocupas por formar una disciplina, cuando no te preocupas por asociarse con gente que puede sentirse interesado por tu negocio, no te vas a sentir seguro. Cuando uno no tiene información, nunca va a estar seguro. Además, hay que buscar cuál es el sueño que tienen dentro, porque si uno no tiene algo que lo movilice y que lo lleve a arriesgarse, podrán leerse 500,000 mil biografías y lo que sea, pero si no tiene claro lo que quiere, lo que sueña y lo que anhela, va a ser muy complicado armar un norte.

\section{Tandem}

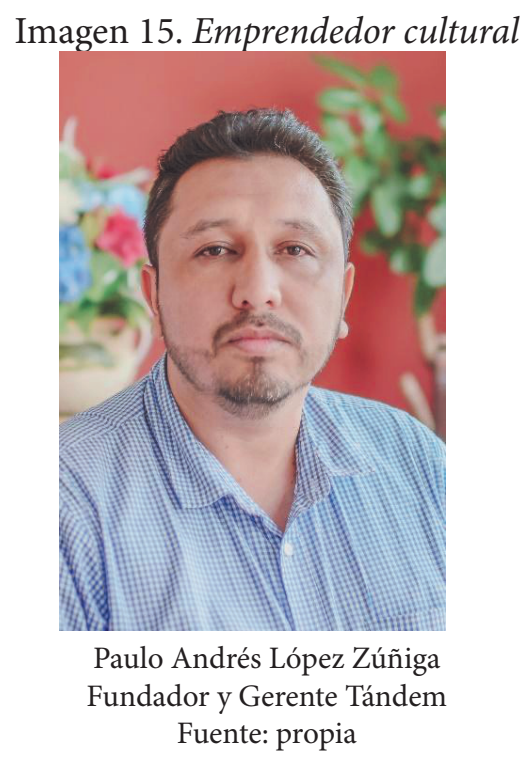

Soy Paulo Andrés López Zúñiga payanés, de formación administrador, especialista en finanzas, con estudios interculturales y culturales, representante legal de Tándem constituida desde el 
2015, una firma dedicada a la consultoría de emprendimientos, entidades o asociaciones interesadas en apostarle a la cultura y a proyectos con alto impacto social.

Es necesario contextualizar, nosotros nos dedicamos a apoyar los procesos de desarrollo cultural y social, ese es el énfasis de lo que hacemos, pero no es una respuesta al emprendimiento, sino una respuesta a la vocación de vida, porque de una u otra forma, lo que lo une desde la cultura, lo que se concibe a partir de la cultura, es la vocación por lo que se hace, entonces en esa medida, siempre he estado del lado de la cultura.

Es una visión muy social, trabajamos desde la formación, desde el emprender y desde el hacer. Entonces llegamos a hablar de la cultura, primero porque la cultura está presente en todo, es decir, es un hecho social, todos los hechos de la vida cotidiana son hechos culturales, de esa manera nos relacionamos, nos entendemos, hablamos, nos comunicamos, escribimos, emprendemos, y finalmente, todo, son hechos culturales.

Mi vocación por la cultura llega a partir de la lectura. Es el primer encuentro particular que tengo. Es una historia que narro de vez en cuando, pero en mi infancia, yo decía que el televisor entraba y salía con frecuencia, mi papá era un personaje muy regular en los negocios y entonces siempre se quebraba y el televisor, era lo primero que se desaparecía de la casa. Mi hermana que es un poco mayor, siempre tenía algunos libros, ella estaba en la universidad cuando yo estaba en la escuela. Entonces, tenía los libros de series, de la universidad, y yo aprendí a los seis años a leer novelas, no pase por la televisión, sino por la literatura. A los seis, siete años ya había leído clásicos, entonces mi encuentro con la idea social y cultural, es a partir de la literatura. No pase por los cuentos infantiles por así decirlo, esta relación siempre la tuve cuando termine mi formación de bachillerato. La pregunta era si seguía en las áreas sociales o empresariales, y me decidí por la empresarial, por una realidad que luego reconozco y es la necesidad 
de cambiar la sociedad a partir de lo que haces, porque desde lo social, se pueden crear discursos, se puede crear conciencia, un pensamiento crítico, pero muchas veces, aborda la realidad, que pocas veces es abordada más allá de la literatura o escritura, es difícil. Mientras que las áreas empresariales, te ayudan a pensar por lo menos en proyectos y apuestas que cambien la sociedad. Es una reflexión personal.

Tándem es prácticamente eso, metodologías para el desarrollo social y cultural, eso es Tándem. Su razón de ser, es plantearse nuevas apuestas para el desarrollo, es decir, desde una formación específica en teorías de desarrollo apostadas hacia la competitividad, pero reflexionando sobre los impactos en las regiones. Sucede que aún se están despreciando los activos culturales, naturales y materiales.

Tenemos una misión, desde la educación, pero con una mirada externa, considerando que allá está el desarrollo, allá están las oportunidades, de hecho, todos crecimos con viajar a Europa o con buscar un trabajo en el exterior etc., pero difícilmente, planteamos desde lo local. Esa es la primera enseñanza desde Tándem. Es decir, ese planteamiento, nos une, reconoce por supuesto lo que está sucediendo afuera, pero plantea dinámicas locales, valorando los activos culturales y naturales que tiene el territorio, y nos encontramos con una serie de apuestas gigantes que muchas veces son apuesta que han sido despreciadas por los mismos locales, no en todo el sentido de la palabra, pero ha sucedido.

La cultura ha vivido sobre todo a partir de la gestión, porque lamentablemente los ingresos no llegan del todo a partir de productos culturales, es decir el instructor finalmente termina siendo un docente de un colegio o termina siendo periodista de algún diario para tratar de sobrevivir. García Márquez era periodista, hasta que se ganó un Nobel y se dedica a vivir de la literatura, pero en sí, era un periodista. Entonces tiene una 
profesión práctica, que indudablemente le da la posibilidad de surgir. Se esperaría que más artistas puedan vivir con sus apuestas culturales, en ese sentido, empezamos a decir, bueno hay unas dinámicas que requieren de nuevas metodologías y nuevos planteamientos.

Muchas veces hay falencias, entre ellas, las cadenas productivas, hay falencias en las metodologías de educación, hay falencias en la concepción del ciudadano sobre conceptos culturales. Ahí viene la pregunta de cómo empezamos a plantearnos unas metodologías de trabajo, y es ahí cuando le apostamos a tratar de destrabar esos espacios vacíos que hay en las metodologías de desarrollo y en las necesidades sociales y culturales en los territorios.

Tándem busca encontrar todo aquello que es cooperativo, usual en todo lo que se hace más de uno, pero es armónico. Hay bicicletas tipo Tándem, de dos puestos en adelante, y además es sin fin, porque Tándem significa eso, sin fin.

Tándem, primero es una metodología de carácter colaborativo y segundo, trabaja sobre objetivos específicos. Es lo correcto. Desde la cultura se pueden pensar en 40 cosas, pero cuales en sentido concreto se logran, cuáles se quieren liderar, entonces se requiere una misión específica sobre esas apuestas.

Son varias las anécdotas en este ejercicio, específicamente a nivel regional, abrir puertas, que la gente entienda que, en esos espacios, no se entra directamente por la innovación del producto o por la innovación funcional, el ahorro en costos y servicios, sino que va más allá, que se trabaja por el impacto social y cultural. Es una discusión bien difícil de dar desde lo regional y las instituciones no tiene formación ni personal que tenga este tipo de perspectiva, esa es la primera complejidad. Se requiere tener un discurso alrededor del entorno de un proyecto y un portafolio de servicios, creíble y vendible para quien tienen formación comercial. 
Por ejemplo, con la Cámara de Comercio del Cauca hemos trabajado la región del pacifico, llegando a Guapi con ellos, luego a través de la Gobernación del Cauca, fuimos a Timbiquí. La región pacífica tiende a ser más fuerte y densa desde lo cultural y con mayores limitaciones, también te permite referenciar las grandes diferencias entre esos lugares donde el patrimonio cultural es más fuerte y aquellas otras que no, entonces hay una distancia cultural gigante entre el pacífico y el resto del interior, además de unas enseñanzas tremendamente grandes.

Desde el pacífico, primero hay que reconocer que los emprendimientos de la cultura, desde lo social, tienen lógica de territorio, es decir no son un estándar que va a servir para todo el país, ni a nivel internacional, sino que tienen una discusión territorial local y esa es una de las grandes diferencias. El pacífico, tiene esa lógica de territorio. La primera, relacionada con la actividad vial. Entonces cuando uno llega desde la lógica del interior, dice, bueno reunámonos, porque es ahí al frente, claro lo que no nos preguntamos, es que aquí está el rio y entonces para eso necesitas conseguir una lancha o un potrillo y que además eso implica combustible, entonces la reunión que querías hacer en una hora más tarde que es al frente pasa por $\$ 200.000$ o $\$ 300.000$ de traslado. El asunto no era tan sencillo o cuando uno dice bueno y por qué no tienen una hora fija para salir o para partir de un sitio a otro con las lanchas, y resulta que están mediados por la marea y la marea se mueve todos los días, entonces la lógica de cambiar el horario no es por incumplimiento, es porque en realidad el pacífico tiene una diversidad en este caso.

Hay que empezar primero por escuchar de manera diferente, y eso implica, reconocer lo local. Lo segundo, tiene que ver con la sustentabilidad, porque el pacífico es un paraíso realmente, pero es un paraíso inexplorado, es un paraíso desconocido y en el caso del gobierno nacional, también un poco ignorado. Hay muchas potencialidades, la biodiversidad es inmensa, la cantidad de especies que se encuentran en el pacífico y las lógicas de consumo son otras. 
Hay un ejemplo muy particular que me parece que es bien interesante. El Ministerio de Cultura hace varios años promovió los talleres de lutería, que son talleres para fabricantes de instrumentos, inicialmente instrumentos de cuerdas, pero ahora se usa para todo el que construya instrumentos. Recordemos que el pacífico, es totalmente musical, entonces la gente construye, instrumentos de percusión como la marimba, el cununo y otros, que son elaborados con materiales que se encuentran en esa misma biodiversidad. Sencillamente te internas en el bosque, buscas las pieles, las maderas y los juncos con los cuales los construyen.

Cuando el Ministerio de Cultura promovió los talleres de lutería, no reflexionó sobre la sustentabilidad del territorio, entonces dijo, generen mayores ingresos, creo una marca y entrego una maquinaria para hacer más efectiva la labor. Lo que sucede en el territorio, es que la chonta, es una planta tan compleja y tan difícil, porque puede tardar hasta 30 años en crecer y ser fuerte, por lo tanto, el fabricante de instrumentos sabe que puede construir cuatro, o máximo cinco marimbas en el año, y no puede construir más. Lamentablemente, este tipo de prácticas va agotando un recurso que no es renovable a corto plazo. Entonces cuando se llevan estos talleres de lutería, con materiales de procedencia natural, se está promoviendo que se devaste la selva del pacifico y se acaben con las especies, es decir, esa dinámica de sustentabilidad, no está reflexionada desde ese enfoque. Sin embargo, las comunidades son conscientes de ello. Cuando llegas con esa mecánica, los habitantes indican que eso no es lo que necesitan, que esa discusión ya la han tenido. Que quieren especies que persistan.

Existe una clara diferencia entre el Pacífico y el centro del departamento. Principalmente, se debe a que las apuestas del Pacífico, son apuestas ligadas al patrimonio cultural, es decir, corresponde a derechos colectivos de las comunidades y a una herencia cultural de sus abuelos y de sus portadores de tradición, esa es en esencia la gran diferencia del pacifico, con otras zonas. El interior, por el contrario, está más permeado por los medios 
masivos, pertenece a ecosistemas de emprendimiento mucho más complejos y la toma de decisiones es diferente. En ese sentido, el Pacífico cuenta con productos patrimoniales, como la música, la gastronomía, las tradiciones de la partería, de la pesca artesanal y que están mediados por el patrimonio. Mientras que, en el interior, hay productos audiovisuales, productos musicales que responden a otras lógicas de mercados.

En el caso de Popayán como ciudad, nosotros seguimos considerando el desarrollo local pensado desde lo social y cultural. Popayán debería ser la esencia de esa diversidad por qué hay unos matices que hacen que el departamento del Cauca sea muy diferente al resto de los departamentos. No se puede desconocer lo que significa que el $45 \%$ de su población sea étnica y de ese porcentaje, el $25 \%$ corresponda a población afrodescendiente, y en una proporción similar, población indígena, continuando con el hecho que esa diversidad, está en el territorio.

Así mismo, Popayán es el reflejo de la historia colonial con concepto histórico. El turismo, por ejemplo, como industria, se nutre de la diversidad y esa diversidad se tiene que reflejar en los actores, porque si no finalmente es más interesante ir al pacifico que ir a Popayán y creo que en ese sentido, hay una reflexión de cómo lo empezamos a organizar.

Nosotros tenemos un reto, de empezar a construir y reflexionar metodologías específicas para la cultura, es decir normalmente se cree que todo es estándar, que cabe a todos los sectores y no es así. La cultura, tiene lógicas diferentes, el sector audiovisual, por ejemplo, funciona de forma diferente al sector musical, al sector editorial. Cada uno, tiene cadenas productivas complejas, y mediadas de legislación diferentes por los derechos de autor, los registros de marcas y patentes. Es por eso que no se puede estandarizar un modelo general de negocio. En ese sentido, estamos trabajando la idea de desarrollar metodologías específicas para cada uno de los sectores que permitan ayudar a 
encontrar ese desarrollo y a tomar decisiones específicas, además que contribuyan en el diagnóstico de las cadenas productivas para fortalecer desde la educación, desde la inversión social, desde el comercio en áreas específicas donde hay eslabones perdidos en las cadenas productivas de la cultura.

Popayán como emprendimiento tienen dos espacios que a mí parecer, son complejos, es decir, se dice que Popayán se quedó como pueblo, con toma de decisiones muy localistas y eso genera una gran dificultad. La economía en Popayán se mueve principalmente por servicios asociados al comercio y a los servicios institucionales públicos, y la industria no aparece. Entonces en esa medida, las cadenas no están maduras, es decir el empleo sigue siendo mediado por la informalidad y esa es la gran dificultad que tenemos.

En el sector de la cultura, tenemos pocos estudios de grabación, hay pocos managers, no tenemos formaciones específicas para la empresa de la cultura, la gran mayoría de la formación que hace la gente tiene que hacerla por fuera, entonces hay deficiencias que no permiten pasar de un nivel productivo, y los emprendedores tienen que buscar respuestas afuera, los managers normalmente son de otras ciudades o incluso algunos del exterior, las áreas de formación las tienen que tomar en Bogotá principalmente, o buscar algunas formaciones de tipo virtual para suplir estos vacíos, especialmente en temas como marketing digital, no tenemos abogados especialistas en temas de derecho de autor, no tenemos oficinas intermediarias en ese campo, es decir, hay una cantidad de vacíos específicos que hace que la cadena pierda competitividad. Por ello, el artista tiene ingresos tradicionales por la presentación en vivo, pero no por la reproducción de su música en plataformas especializadas. Esas labores son las que dificultan el trabajo, y no permite potenciar a los artistas, escritores y músicos.

Desde ahí se ha hecho un ejercicio a la inversa como Tandem, porque somos una organización emprendedora que hace consultoría y en ese caso nos ha tocado, ir abriendo las puertas 
del emprendimiento cultural, es decir, lo que se ha hecho de emprendimiento en las instituciones y en el sector universitario público y privado, ha estado mediado de alguna forma, por el acompañamiento que nosotros como firma hemos hecho.

En ese sentido, vamos construyendo familia, porque la cultura tiene solidaridades, en esencia, no se podría sobrevivir, sino existiese esa solidaridad. Hay entonces un aprendizaje muy grande desde la cultura comparado con el resto de sectores. Por ejemplo, hay un caso curioso y es que cuando se ha tenido la oportunidad de participar en convocatorias de emprendimiento y se hacen pitch, los emprendedores de la cultura sorprenden. Eso se debe a que un pitch cultural vende, vende posiblemente mucho más que un pitch comercial, porque el discurso es un poco más sensible, entonces hay un aprendizaje de como desde la cultura se puede enseñar a los otros sectores, a vender apuestas desde la escancia. En esa medida, se podría aseverar que un gestor cultural, es un emprendedor siempre, porque siempre este emprendedor e innovador, se está trasformando, desde una mirada cooperativa. Emprender entonces, trasforma.

Llevo más de 10 años como independiente, haciendo asesorías, consultorías, acompañamiento a proyectos $\mathrm{y}$ en ese sentido, te trasforma primero, porque uno depende de su tiempo, de su proactividad, creatividad y de la innovación que le puedes aportar. En segundo lugar, porque requiere unas series de habilidades adicionales. Cuando hemos trabajado con algunos consultores con muy buenas formaciones, pero vende un proyecto contra marea, sensibilizar esa propuesta, dar a conocer los alcances, los logros y demás, eso no es tan fácil.

Por eso, el emprendimiento es una actitud de vida, el emprender esta muy asociado al empresarialismo, lo tratan de asociar mucho a crear una empresa, formalizar, pero nosotros lo vemos desde la actitud de vida, por eso un artista es un emprendedor y puede explicarles mucho a los otros sectores de 
cómo se emprende. Un artista es emprendedor, es innovador y creemos que es más la actitud de vida. Esa es la razón de ser, de cómo afrontas los retos de la sociedad, como además dialogas esos retos y como provees soluciones, porque finalmente lo que se quiere, es impactar a la sociedad con propuestas desde lo cultural, lo social y empresarial. Eso al final, lo traduces a persona natural, sociedad jurídica, gran empresa o multinacional, pero finalmente es la actitud de vida con la que se crea.

Por consiguiente, para fortalecer el emprendimiento en la región, primero es necesario reconocerse como ecosistema. El gran problema del emprendimiento en general del Cauca, es la falta de afirmación, no hay un leguaje institucional, y lo segundo, es que el emprendimiento regional, adolece de herramientas practicas específicas, es decir, falta fortalecer aspectos como capital semilla, metodologías, currículos específicos articulados entre todas las organizaciones. En esa medida, parece más bien una competencia local por lograr un mayor reconocimiento y protagonismo, sobre lo que se hace, pero no sobre el desarrollo de la región. Ese tema de articulación siempre ha sido la gran dificultad de la región. Es necesario saber cómo logramos hablar colectivamente, como le apostamos al desarrollo de la región con al menos una herramienta que este reconocida por todas las entidades, y que no sea una competencia.

En el ámbito específico, hay que reconocer que de la cultura se puede vivir con dignidad, porque ese es el primer estigma, que esto no genera ingresos, y que hay otras carreras que tienen mayor proyección. De la cultura si se puede vivir con dignidad y genera ingresos, es altamente rentable, hay oportunidades, hay campos prácticamente inexplorados, hay muchos eslabones que todavía no existen, hay potencialidades. En segunda medida, es reconocer el impacto de lo que haces, porque finalmente los proyectos culturales y sociales finalmente tienen un impacto increíble en la sociedad. En esa medida, hay que empezar a construir la toma de decisiones de como consumimos. 
Antes innovador era el producto, el empaque o el servicio o el costo, ahora hablar de innovación, es hablar del impacto. Quien está detrás de eso, que vida salvo consumiendo este producto, y hay otras historias que se tienen que contar a partir de eso y quienes lo hacen, los que tienen una apuesta desde lo cultural, de lo social, requieren más emprendedores que empiecen a construir esos dos discursos entorno a los productos de las industrias culturales.

\section{Emprendimiento gastronómico}

Tazón

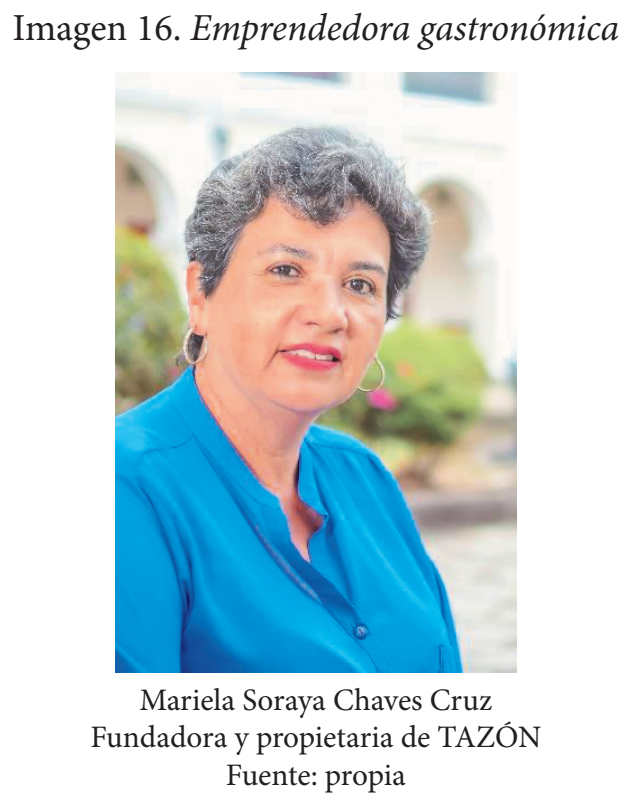

Soy Mariela Soraya Chaves Cruz, nací en Popayán, de profesión secretaria comercial ejecutiva, Técnico en Cocina, estudiante del Técnico en Panificación. Separada y madre de dos hijos. Mi hijo mayor fallecido hace 19 años, y mi hija de 22 años de edad, es estudiante de Administración de empresas en la Universidad del Cauca. 
Mi emprendimiento se llama TAZÓN. Nació como la mayoría de los emprendimientos, por una necesidad. La mía, obtener los recursos necesarios para vivir una vida digna con mi hija. Sin embargo, conseguir trabajo es difícil, más en nuestra ciudad, sumándole que llevaba muchos años sin ejercer mi profesión. Entonces, entre al Sena a hacer el Técnico en Cocina para conocer las técnicas. Me gusta cocinar y según comentarios de amigos y familiares, tengo buena sazón, heredada de mi mamá quien me enseñó a cocinar cuando era niña.

Al terminar el Técnico en Cocina, empecé a trabajar solamente con los utensilios de mi cocina ya que no había dinero suficiente para comprar el menaje propio de esta labor; así inició TAZON, oficialmente el 28 de octubre de 2017 en la casa donde vivimos desde hace dos años en el barrio Palacé. Con la marca de mi emprendimiento me ayudó una sobrina que trabaja en diseño gráfico quien además diseñó el logo, las tarjetas y el pendón.

Para el 2018 me informaron de una convocatoria del Centro de Empleo y Emprendimiento de la Alcaldía de Popayán, que incluía un capital semilla a pequeños negocios. La experiencia inicio para mí con una carrera contra reloj, pues la información de la convocatoria me llegó faltando tres días para que se terminara el plazo de postulación. Afortunadamente alcanzamos a postularnos y fuimos favorecidas con el capital para comprar el montaje necesario para nuestro trabajo, además de formalizarnos ante la Cámara de Comercio del Cauca.

En TAZON elaboramos diferentes productos como pollo relleno, rollos de carne de res, de cerdo, de pollo. También tenemos pasabocas, refrigerios, sin colorantes ni conservantes químicos, tortas y pan elaborados de forma artesanal.

Mi compañera en esta aventura llamada TAZÓN, es mi hija, ella es mi mano derecha. Emprender no es fácil y más en su caso que ha tenido que dividir su tiempo entre la universidad 
y TAZÓN, en ocasiones hemos tenido jornadas duras, especialmente iniciando. Como no había los utensilios adecuados para trabajar, nuestra labor se hacía más dispendiosa y muchas veces trabajamos durante el día y la noche para poder cumplir. Ahora el trabajo se hace más fácil con las herramientas adecuadas. Seguimos innovando, aprendiendo nuevas técnicas que nos permitan mejorar día tras día y con el deseo de hacer de TAZON una empresa que genere empleo.

Con el ánimo de fortalecer nuestro emprendimiento me vinculé a la fundación Red de Emprendedoras de Popayán y a eventos de ciudad como la Noche de Museos.

Emprender para mí ha sido un reto, una forma de demostrarme que puedo salir adelante y que la edad no es un obstáculo. Espero que todo este esfuerzo un día permita que TAZÓN sea reconocido como una marca que ofrece buenos productos. Emprender en Popayán es bastante complicado, hay mucha competencia. La falta de empleo hace que las personas sean cada vez más recursivas y busquen otras alternativas. Es necesario que se abran muchas puertas a los emprendimientos, eventos donde todos podamos participar sin importar color político o religión; que los compradores crean en los productos de los pequeños negocios y paguen de acuerdo a la calidad de los mismos. Si nos apoyamos entre todos haremos de Popayán una ciudad mejor.

Por último, quiero aprovechar estas líneas para agradecer primero a Dios que con Él todo lo puedo, a mi intercesora María Auxiliadora, a mi hija por estar ahí siempre incondicionalmente, a mi familia y a cada uno de esos ángeles terrenales que me han apoyado desde el momento en que me matriculé en el Sena hasta el presente. Bendiciones para todos. Invito a quien tenga una idea de negocio a que se anime y emprenda. Insistir, persistir y nunca desistir. 


\section{Légumier, alimentación consciente}

\section{Imagen 17. Emprendedoras en gastronomía saludable}

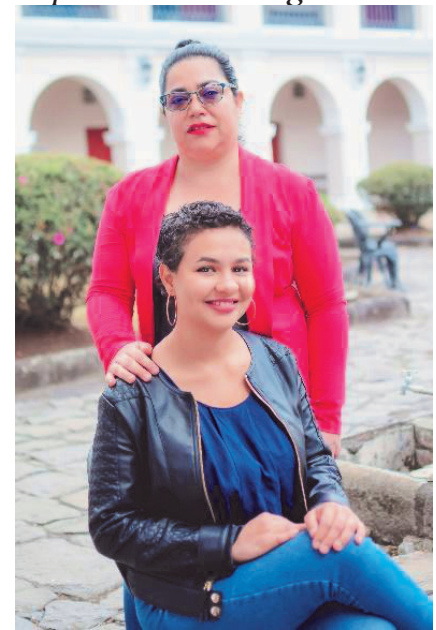

Fundadoras de Légumier

Fuente: propia

Soy Yarleidis Madarriaga Barrios, tengo 25 años, soy del Urabá Antioqueño, vivo en Popayán hace 2 años y tengo estudios en periodismo en la Universidad de Antioquia. Para contarles la historia que me llevó a emprender, debo iniciar diciendo que a los 16 años me fui a vivir a Medellín para iniciar mis estudios universitarios. En el camino descubrí que el periodismo no era lo que me hacía feliz o a lo que quería dedicar mi vida. Poco tiempo después mi esposo tuvo la posibilidad de un nuevo trabajo en Quibdó. Como no estaba trabajando ni estudiando, decidí irme con él. Dos años después nuevamente se presentó la posibilidad de trasladarnos, esta vez a la ciudad de Popayán, donde llegamos cuando mi hijo tenía 3 meses.

Aproximadamente hace un año, comencé, junto con mi socia, a trabajar con Légumier, estructurando la idea. Todo surgió cuando decidí dejar los productos de origen animal. En ese momento, no encontraba opciones de menú variado en los restaurantes de la ciudad. En la universidad también había 
sido vegetariana durante algún tiempo, sin embargo, había más alternativas, de hecho, en la línea de comidas rápidas y de comida gourmet. En cambio, en Popayán, había restaurantes que te brindaban el menú del día y sin muchas opciones de snacks, pasabocas o antojitos veganos.

Entonces dije, ya que no hay nadie quien lo ofrezca, lo voy a ofrecer yo. Lo dije en broma en un picnic con unos amigos y ellos me respondieron que les gustaría la opción de un restaurante vegano, y una amiga que estaba presente en ese momento, hoy en día es mi socia, Carolina Jaramillo.

Iniciamos con una pequeña inversión, más o menos de dos millones de pesos, compramos utensilios, ollas, cucharas, cuchillos y materias primas para preparar los alimentos y almacenarlos adecuadamente. Al poco tiempo hicimos una degustación, presentándole a la gente la propuesta para saber qué esperaban de nuestro negocio y conocer mejor a nuestros potenciales clientes. Confirmamos que el nicho al que le apuntábamos era importante, así que decidimos seguir adelante.

Éramos conscientes de la necesidad de capacitarnos, así que inicié una capacitación con el Centro de Empleo y Emprendimiento de la Alcaldía Municipal de Popayán, y en el proceso nos informaron que se iba a abrir una convocatoria de Capital Semilla. Todo fue a última hora, nos enteramos el martes y la convocatoria se cerraba el viernes, tenía que buscar toda la documentación, registrarme en Cámara de Comercio del Cauca, buscar certificados, redactar los resultados del estudio de mercado ¡Fue una locura! Pero sabíamos que valía la pena. Ese ejercicio lo hicimos sin saber si saldríamos beneficiadas, sin embargo, a los 15 días nos dijeron que ya habían escogido a los ganadores y que estábamos en la lista, ¡Fue una gran noticia! La verdad es que fue de gran ayuda porque habíamos empezado la idea con nuestros ahorros y ya no teníamos cómo seguir, y lo que hacíamos era para cubrir los mismos gastos de producción. Así comenzamos a trabajar y poco a poco nos estamos dando a conocer, ofrecemos 
servicio de almuerzos a domicilio de martes a domingo, luego incluimos en el menú comidas rápidas saludables que le ofrecen a nuestros comensales la posibilidad de darse gusto con un antojo delicioso sin descuidar una alimentación sana, balanceada, rica en fibra, proteínas.

La palabra Légumier es una españolización de la palabra légumière, que en la cocina profesional es el chef encargado de las preparaciones basadas en vegetales.

Légumier quiere brindarle a Popayán una alimentación que los cuida, que los mantiene sanos y les permite estar ahí para sus familias y amigos, una alimentación en armonía con el planeta y con ese amor propio que tanto necesitamos. La alimentación más ecológica y sustentable es la alimentación a base de vegetales, que al contrario de lo que la mayoría de la gente imagina, es deliciosa y variada.

A pesar de todas las experiencias positivas, no ha sido fácil emprender. Una de las experiencias más difíciles ha sido tener que hacer todo, desde cocinar, entregar domicilios, responder solicitudes, hacer publicidad y administrar el negocio. Ha sido un gran reto, ha valido la pena y ha sido muy satisfactorio. Es de verdad algo que nos hace muy felices, algo que hemos construido con nuestras propias manos.

Nuestro sueño más grande hasta el momento es convertir Légumier en una gran franquicia de alimentación saludable y ecológica: Alimentación Consciente. Nos gustaría que fuera la primera franquicia de alimentación a base de plantas del país con gran incidencia en el suroccidente colombiano, una región sumamente rica en producción agrícola con vegetales de todo tipo, sumamente ricos y nutritivos. Nuestro objetivo mayor es generar un gran impacto positivo en la sociedad, y lo vamos a lograr porque nuestros clientes no son solo personas con un estilo de vida basado en el veganismo, sino aquellos que quieran serlo o que simplemente busquen algo delicioso y saludable con qué cuidar su cuerpo y al planeta. 
Es importante decir que Popayán nos ha dado la posibilidad de soñar con esto y ver cómo se está haciendo realidad. Al ser una ciudad pequeña, nos ha facilitado las cosas, hay dos opciones, verlo como una desventaja o como una gran oportunidad. Sin embargo, el hecho que no haya tantas personas como pasa en ciudades como Medellín o Bogotá, nos permite llegarle de forma más efectiva al segmento que queremos. Las personas tienen una buena disposición hacia los emprendedores y poco a poco se va generando ese interés por comprar a marcas y productores locales. La agricultura local además permite experimentar y crear unos productos de alta calidad a muy buenos precios. Eso no pasa en ciudades como Medellín, por ejemplo, donde las opciones vegetarianas y veganas no son tan económicas.

Los emprendimientos se impulsan en momentos en los que hay que tomar decisiones, por ejemplo, cuando mi socia Carolina, se quedó sin trabajo fue cuando realmente vimos la oportunidad de aprovechar el emprendimiento para dar lo mejor de nosotras mismas, y a pesar que por el momento no nos ha hecho ricas, nos ha dado la posibilidad de generar tres empleos y llegar a la mesa de muchos payaneses. Eso demuestra que estamos creciendo.

En este sentido, emprender es arriesgarse, es entender las necesidades que hay en el entorno, aprovecharlas, generar ideas que sean rentables. Para ello se requiere fortalecer capacidades. En Popayán no hay industria, pero se puede crear. Hay gente con ideas de emprendimiento geniales, que todo el tiempo se están moviendo en torno a crear y lo hace a la par de sus actividades laborales como empleados de organizaciones, pero de alguna manera se sienten perdidos a la hora de manejar sus negocios. En ese sentido, es necesario seguir capacitando a la gente en cómo arrancar, que sepan que hay herramientas, convocatorias y personas dispuestas a ayudar, que te impulsan a tomar la decisión. Una de ellas, es la convocatoria de Capital Semilla de entidades como el municipio de Popayán y la Cámara de Comercio del Cauca. 
La gente tiene el paradigma que formalizarse es adquirir una deuda, que solamente asume el pago de impuestos a cambio de nada. Otra gran debilidad es saber administrar bien tu negocio, formular el proyecto, aprender a vender su idea de negocio y administrarlo, son puntos que hay que fortalecer en la ciudad.

El mensaje a los emprendedores es decirles que primero validen su idea, que crean en ella, que den el paso y arranquen, porque si no se empieza con algo pequeño, no se empieza con nada. Hay que dar el salto. Segundo, entender que no va ser fácil, y que el dinero no va a llegar en un mes. Va a ser agotador, exigente, pero vale totalmente la pena. Es satisfactorio saber que todo depende completamente de tu trabajo y que nada sucede si tú mismo no te abres el camino.

\section{Munchys By Manu}

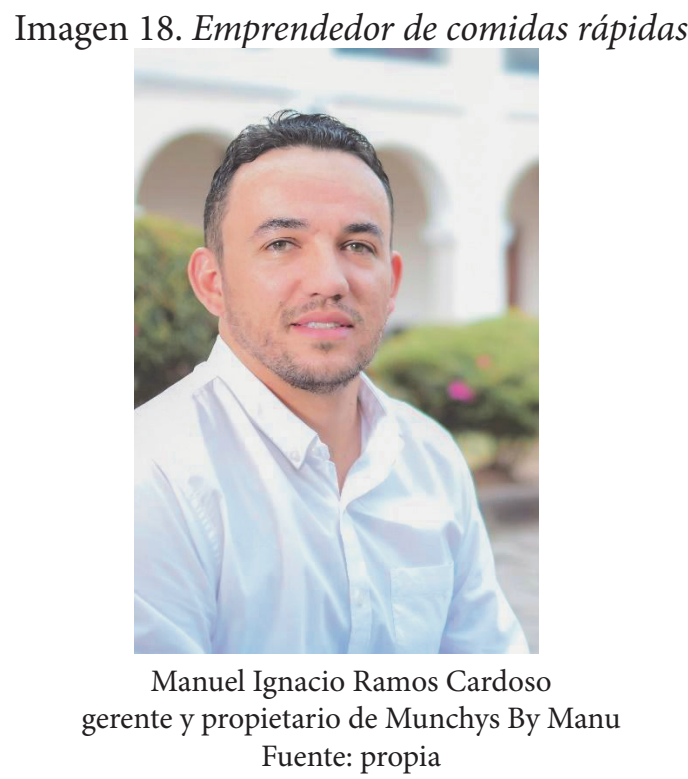

Soy Manuel Ignacio Ramos Cardoso de 35 años de edad, payanés, de Papá patojo y de Mamá costeña, esposo y padre de familia, egresado del Programa tecnológico en Gestión 
Gastronómica de la Corporación Universitaria COMFACAUCA, gerente y propietario de la marca Munchys By Manu.

Mi experiencia como empleado me sirvió mucho para ser emprendedor. Pasé por lo menos por unos 14 empleos diferentes, desde que empecé a trabajar a los 17 años. Trabajé en zonas muy comerciales, en negocios que eran de ventas, de servicio al cliente y me di cuenta que tenía un potencial en eso. Además, me destacaba e iba ascendiendo en los puestos de trabajo. Le sacaba mucho provecho a cada trabajo, aprendía, conocía gente y aprendía de los demás. En el momento en que me quede sin trabajo, me tocó hacer una pausa y pensar que iba hacer. Gracias a Dios siempre conseguía trabajo rápido, sin embargo, en la última oportunidad, pasaron casi seis meses y no sucedía nada.

Tenía una idea algo lejana de querer ser mi propio jefe, tener un negocio. Solo hasta que se me presentó una oportunidad de adelantar un proyecto en sociedad, fue cuando decidí tomarlo, y arranqué. Sin embargo, hubo algunos inconvenientes y no se logró continuar. Después de eso, decidí seguir por el mismo camino. Ya han pasado siete años y aquí vamos, aprendiendo del asunto.

Recuerdo cuando inicie el programa de Ingeniería de Sistemas, que al final de cuentas era más por darle gusto a mis padres. Me retiré a los tres semestres porque me di cuenta que no era lo mío. Entonces decidí emprender con el negocio y dos años después, inicié mis estudios gastronómicos en Unicomfacauca. Me di cuenta de falencias en muchos aspectos que desconocía, por la falta de formación. El negocio había crecido, ya no era la misma producción cuando arranque, y no podía seguir esta vocación de forma empírica desde la cocina. Jamás hice un almuerzo en mi casa, pero las ganas y el amor por salir adelante pueden más que cualquier otra cosa. Lo que realmente me ayudó fue enfocarme y decidirme. La misma necesidad me motivo a estudiar gestión gastronómica, además de otros estudios en el Sena de gestión de mercados. Todo lo aprendido lo iba reflejando en Munchys. 
El nombre de Munchys fue idea de una amiga, y para decir verdad, la primera vez me pareció chistoso. Cuando lo seguía escuchando me pareció un nombre corto que tenía recordación y que tenía buen futuro. Le agregué by Manu (por Manu) porque toda la carta, lo que hemos preparado, lo he hecho yo, que con los estudios que adquirí se ha ido perfeccionando gracias a Dios. Finalmente es una historia de mi vida alrededor de querer crecer y ser el soporte de mi familia.

Este camino no ha sido fácil. Hay unas experiencias que todavía me son difíciles de asimilar. Una de ellas, fue un incendio en el 2014. En esa época llevábamos dos años de operación, y un incendio, no nos dejó abrir en cinco días. Se quemaron varias cosas, entre ellas, materiales, pero lo más importante no se quemó, no se quemaron las ganas de salir adelante, no se perdió nada importante. Las cosas materiales se recuperan gracias a Dios. Tenía un crédito y ese crédito estaba asegurado y me cubrió el incendio. Recibí un subsidio y con ese subsidio, arreglé unas cosas. De ahí me surgió no el ¿porque se había presentado esa situación?, sino ¿para qué?

La formación que nosotros estamos haciendo con mi esposa, que parte hace varios años, nos ha permitido visualizar en Munchys un gran potencial. Para nosotros siete años no es nada, porque hay gente que todavía no nos conoce gracias a Dios y yo digo gracias a Dios porque qué haríamos si ya todos supieran de Munchys, ¿cómo seguiríamos creciendo? Estamos apenas iniciando. Ya contamos con una sede en Villa del Viento, mucho más pequeña y con la que iniciamos en el barrio El Recuerdo en Popayán.

En Popayán las personas tienden a emprender por sí mismas, porque no hay muchas empresas grandes, no hay empleo, y eso obliga a la gente a ver alternativas diferentes. Como te vuelves muy observador, te vas dando cuenta que hay más y más emprendimientos, gente que vende de todo, y hay una cultura 
del rebusque diario, por así decirlo. La gente se las ingenia para salir adelante de alguna forma. Por eso emprender en Popayán ha sido y seguirá siendo tendencia. Viene un auge muy grande relacionado con el no querer trabajar bajo la figura de empleado, especialmente por parte de gente joven que quiere ser su propio jefe.

Esa lectura está siendo coherente con el acompañamiento de las entidades, especialmente en capacitación. En la medida que uno como emprendedor va creciendo, las entidades también se van interesando por seguir fortaleciendo los procesos. Sin embargo, no solamente es suficiente la ayuda de las entidades sino de la familia. Uno comienza con los amigos y con la familia, ellos son los que te dan ese aliciente de saber que si se puede. Porque emprender le cambia la vida a uno. Me ha dejado ver crecer a mis hijos, verlos disfrutar el negocio, y esforzarse porque todo se hace por ellos. El estar con los hijos no lo paga ningún salario.

Entonces para mí, emprender es un estilo de vida que uno decide. Emprender no es para todos, porque no todos toman la decisión de arrancar, de renunciar a un trabajo, de renunciar a un sueldo estable, de renunciar a unas prestaciones y a muchos beneficios económicos. De esta forma, es necesario formar a los emprendedores en conocimientos financieros. Por ejemplo, que exista un manual de emprendimiento donde se encuentren unas pautas claras y que ahí se encuentre de ese desarrollo de la idea, la fase financiera y como arrancar.

Por lo general lo que se tiene es miedo de hacer las cosas, pero uno no se puede dejar ganar por el miedo, porque la única limitante es uno mismo. Uno mismo dice, un amigo puso un negocio de eso y eso no funcionó, una amiga vendía eso y tampoco le funcionó, el tío del amigo de yo no sé quién, tampoco le funcionó. Entonces las barreras las pone uno. La mente es muy poderosa para lo que uno la programe. Lo importante es arrancar y tomar la decisión. Si se tiene miedo, es hacerlo con miedo, pero hacerlo. 


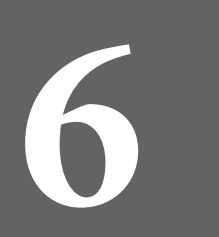

CAPÍTULO SEIS 


\section{Modelo Ecosistema Popayán Emprende ${ }^{21}$}

\section{Concepto de Ecosistema}

Un Ecosistema de Emprendimiento (EE) responde a una agrupación espacial de instituciones que actúan entre sí en pro de la promoción, la asistencia y el desarrollo de proyectos empresariales nuevos o ya existentes (Guerrero \& García, 2013).

\section{¿Quiénes conforman un Ecosistema de Emprendimiento?}

El primer actor de un ecosistema de emprendimiento es el emprendedor. No obstante, esta persona que emprende una acción posee unas características propias y únicas, que lo diferencian de otros actores de una sociedad.

El segundo actor clave de un EE es el gobierno local y nacional, cuyas entidades cubren toda la cadena de emprendimiento desde las etapas de conceptuación y puesta en marcha-con entidades o programas como Apps.co del Ministerio de Tecnologías y Comunicaciones y los Parques tecnológicos del Sena--, pasando por la etapa de crecimiento con programas como el Plan de transformación productiva (PTP) del Ministerio de Comercio Industria y Turismo e iNNpulsa, la agencia de innovación del Gobierno nacional que trabaja con emprendedores y empresarios de toda la cadena de emprendimiento (GEM, 2013).

El tercer actor son las aceleradoras y entidades de asistencia técnica y de consultoría, las cuales también acompañan al emprendedor en gran parte de la cadena de emprendimiento. En las primeras dos etapas --conceptuación y puesta en marcha--, estas entidades prestan servicios de fomento al emprendimiento,

21 Autor: Gabriel De la Torre Solarte. Ingeniero de Minas, Magister en Administración. Docente Investigador PAE-FUP Ex investigador Proyecto InnovAcción Cauca. 
asesoramiento en los planes y modelos de negocio, constitución de la empresa y todo lo relacionado con la operación y el inicio del negocio (Por ejemplo, en Bogotá: Bogotá Emprende, Hubo, Impact HUB Bogotá, Corporación Ventures, ParqueSoft Bogotá, Compartamos con Colombia, Fundación Bavaria, entre otros) (GEM, 2013).

En la etapa de crecimiento apoya la expansión en sus procesos de producción y distribución (Connect Bogotá, Fundación Bolivar-Davivienda) y en la etapa de fortalecimiento su escalabilidad y sostenibilidad con entidades como Endeavor Colombia. Otros actores importantes en el EE son las entidades de financiamiento, las cuales pueden ser públicas o privadas. Al igual que las entidades de asistencia técnica, las entidades de financiamiento acompañan al emprendedor en la mayor parte de su camino empresarial, el cual puede ir desde la primera necesidad de inversión relacionada con los recursos requeridos para el diseño del primer prototipo del producto o servicio, hasta la financiación de estrategias de internacionalización utilizando instrumentos de financiación como deuda pública o salida a bolsa (GEM, 2013).

Los primerosfinanciadores en lacadenadeemprendimiento son los llamados inversionistas informales (amigos, compañeros de oficina, colegas o familiares del emprendedor), los cuales soportan con regularidad a los emprendedores en esa primera etapa.

\section{Emprendedores y emprendimientos}

El "Global Entrepreneurship Monitor" (GEM) clasifica los tipos de emprendimiento según la motivación que el empresario tuvo al momento de tomar la decisión de iniciar un nuevo proyecto empresarial. El GEM hace énfasis en el emprendedor 
como agente de cambio, por lo que realiza su clasificación del tipo de emprendimiento desde el punto de vista de la persona y no del proyecto o empresa que él está creando. En ese sentido clasifica al emprendedor en dos tipos: por oportunidad y necesidad. La tabla 11 muestra estas definiciones.

Tabla 11. Definiciones de emprendedores por oportunidad y necesidad.

\begin{tabular}{|l|l|}
\hline Emprendedor por oportunidad & Emprendedor por necesidad \\
\hline $\begin{array}{l}\text { Aquellas personas que al tomar la decisión de } \\
\text { acometer la actividad emprendedora han analizado }\end{array}$ & $\begin{array}{l}\text { Aquellas personas que, al tomar la decisión de } \\
\text { acometer la actividad emprendedora, no disponían }\end{array}$ \\
en algún grado de detalle las diversas opciones & de otras alternativas de generar ingresos. \\
que poseen, han definido la existencia de una \\
$\begin{array}{l}\text { oportunidad emprendedora y han seleccionado } \\
\text { esa actividad emprendedora frente a otras } \\
\text { alternativas }\end{array}$
\end{tabular}

Fuente: GEM 2013

Relación de la cadena de emprendimiento con el proceso emprendedor, con el tipo de empresa creada y con las diferentes instituciones que conforman un Ecosistema de Emprendimiento El proceso empresarial se relaciona con los diferentes tipos de emprendedor, con el tipo de empresa creada y con las diferentes instituciones que conforman un ecosistema de emprendimiento.

La ilustración 4 muestra la relación entre el proceso emprendedor --según el individuo-- y la cadena de emprendimiento, según la evolución del proyecto empresarial especialmente. En la etapa de conceptuación trabajan los emprendedores potenciales -aquellos que tienen intención de emprender, creen contar con habilidades y capacidades para hacerlo y han visto a su vez buenas oportunidades de negocio en el lugar donde viven-- y los emprendedores nacientes, aquellos que ya realizan distintas actividades para poner en marcha su empresa, pero aún no generan ingresos con sus actividades productivas. (GEM, 2013). 
Ilustración 4. Clasificación del proceso emprendedor según la etapa en la cadena de emprendimiento

\section{Cadena de Emprendimiento}

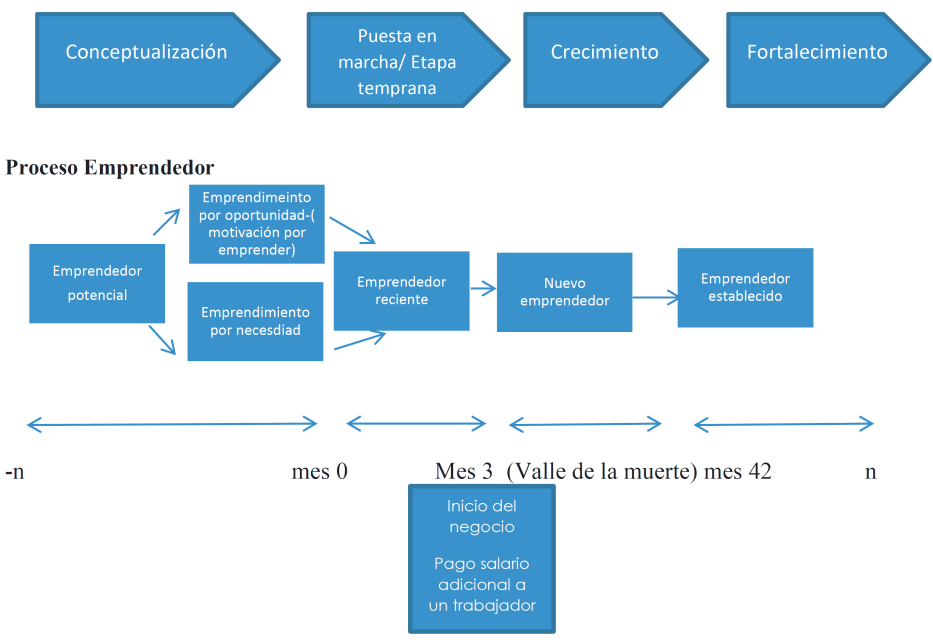

Fuente: Elaboración propia, a partir de información de MinCIT y GEM

Para el MinCIT y el GEM este emprendedor naciente puede estar motivado ya sea por esa oportunidad de negocio que identificó del mercado y desea explotarla, o por una necesidad de generar sus propios ingresos. Independiente de su motivación, se espera que este emprendedor realice sus primeras ventas $\mathrm{u}$ obtenga los primeros ingresos, por ejemplo, vía inversión para desarrollar los prototipos de sus productos y servicios. En este momento, inicia el ciclo de vida de la empresa, cuando esta es capaz de generar los ingresos suficientes para pagar salarios de al menos un empleado en su organización. A este emprendedor se le conoce como nuevo emprendedor, y a la etapa que atraviesa el emprendedor se le denomina etapa temprana o puesta en marcha. (GEM, 2013, Citado por Gabriel De la Torre en el documento de trabajo del proyecto InnovAcción Cauca, 2015)

La ilustración 5, según MinCIT, iNNpulsa y el GEM muestra la relación entre la cadena de emprendimiento y los distintos tipos de emprendimiento por oportunidad existentes. 
Como se visualizó en la ilustración 4, en la etapa de conceptuación el emprendedor motivado por la oportunidad decide emprender, surge de un acto creativo y dinámico. Al momento de crear su empresa, este emprendedor inicia la etapa de puesta en marcha o etapa temprana, en donde él puede ser el propietario de un negocio de emprendimiento tradicional (productos y servicios similares a los ofrecidos en su sector y un modelo de negocios con poca diferenciación) o de una actividad productiva o negocio con alto potencial de crecimiento (sus productos y servicios han cambiado las tendencias de su industria, su modelo de negocio tiene características únicas e innovadoras al tiempo que tiene potencial para escalarse en mercados globales), en este caso el emprendimiento tiene un alto grado de creatividad y de innovación basado en el conocimiento aplicado (GEM, 2013, Citado por Gabriel De la Torre en el documento de trabajo del proyecto InnovAcción Cauca, 2015).

Ilustración 5. Clasificación del tipo de emprendimiento, según la etapa en la cadena de emprendimiento

\section{Puesta en marcha/Cadena de Emprendimiento}

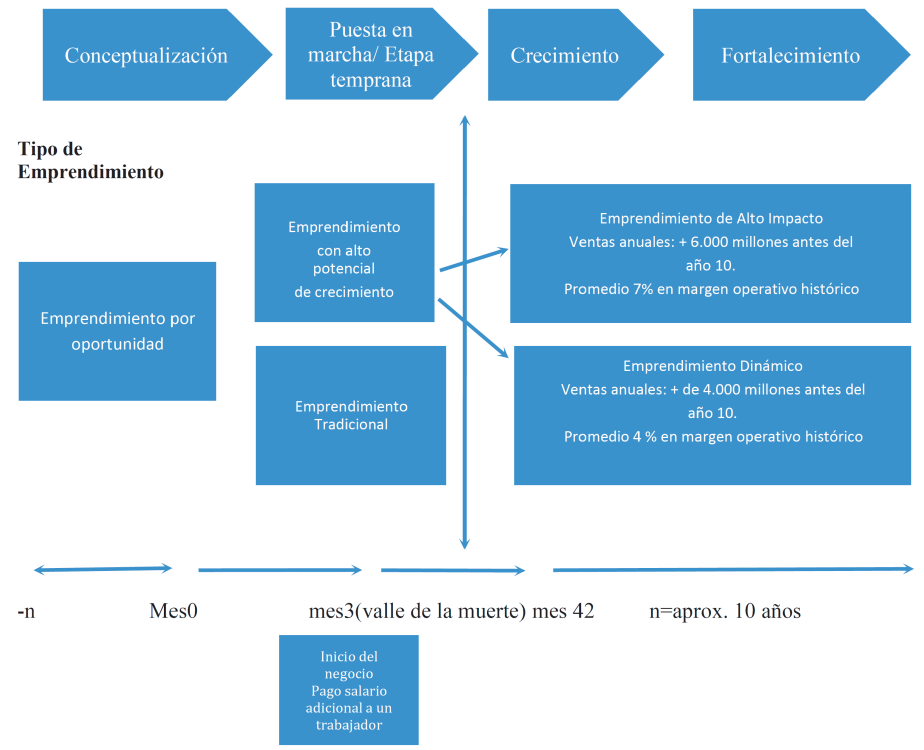

Fuente: Elaboración propia, a partir de información de MinCIT, iNNpulsa y GEM 
En una etapa posterior --crecimiento--, sus ingresos han aumentado significativamente, sus productos y servicios se han posicionado en el mercado convirtiéndola en una empresa líder de su sector, su modelo de negocio ha sido comprobado (el proyecto ha superado el Valle de la muerte), su nivel de ventas y su margen operativo permiten conocer si este emprendimiento se ha convertido en un emprendimiento dinámico e innovador (EDI) o en un emprendimiento de alto impacto (EAI). Los emprendimientos que alcanzan estos estadios, se encuentran en la última etapa de la cadena de emprendimiento, es decir, en la etapa de fortalecimiento, y los emprendedores tienden a reinvertir su experiencia y conocimiento, credibilidad y recursos en la siguiente generación de emprendedores, multiplicando su éxito brindando mentoría e influenciando la dinámica empresarial del país. (GEM, 2013, Citado por Gabriel De la Torre en el documento de trabajo del proyecto InnovAcción Cauca, 2015)

\section{Clasificación de las organizaciones según su rol en el Ecosistema de Emprendimiento.}

Según el estudio del EEB, realizado por la Facultad de Administración de la Universidad de los Andes y la Alcaldía Mayor de Bogotá; las organizaciones de un Ecosistema de Emprendimiento pueden clasificarse según el origen de su concepción en: (1) entidades públicas; (2) entidades privadas; (3) entidades mixtas; y (4) organismos de cooperación internacional. De igual forma, estas entidades pueden prestar servicios a un solo tipo de emprendedor -de oportunidad, por necesidad, de alto impacto- o a un conjunto de emprendedores (Guerrero \& García, 2013).

En cuanto al papel que estas organizaciones desempeñan en un EE, las instituciones pueden dividirse en aquellas que prestan servicios directamente al emprendedor, o aquellas que tienen un papel mixto, es decir, apoyan al emprendedor, pero también dinamizan el diálogo y la interacción entre todos los 
actores del EE. Las primeras, es decir, las que apoyan directamente a los emprendedores se categorizan en: centros de conocimiento e Instituciones de Educación Superior (IES) y centros de desarrollo tecnológico y de innovación; entidades de financiamiento; aceleradoras y entidades de asistencia técnica y asesoríaconsultoría. Las últimas, las dinamizadoras del EE pueden ser: a) entidades del gobierno y b) asociaciones y gremios. (GEM, 2013, Citado por Gabriel De la Torre en el documento de trabajo del proyecto InnovAcción Cauca, 2015)

Un ecosistema de emprendimiento responde a una agrupación espacial de instituciones que actúan entre sí en pro de la promoción, la asistencia y el desarrollo de proyectos empresariales nuevos o ya existentes.

La cadena de emprendimiento. La cadena de emprendimiento incluye todo el ciclo que vive un emprendedor desde el momento en que experimenta el deseo de montar una empresa --ya sea que tenga una idea o no-- hasta el momento en que logra crecer y consolidar su proyecto empresarial. Como en otros conceptos relacionados con el emprendimiento, existen distintas aproximaciones sobre la cadena de emprendimiento. La primera de ellas la aporta el MinCIT, entidad que clasifica esta cadena de emprendimiento según la mirada de las instituciones de apoyo en cinco (5) etapas: sensibilización; identificación; formulación; puesta en marcha; aceleración (Montes, 2008). Ver tabla 15.

Sensibilización. En esta etapa, las instituciones de apoyo y el ecosistema de emprendimiento promueven, a través de distintas actividades, la cultura de la innovación y la mentalidad emprendedora (transformación de paradigmas) (GEM, 2013). En esta fase es importante el papel que cumplen las instituciones de educación superior (IES) y los colegios que incluyen en su pensum cursos de emprendimiento. 
Identificación. En esta, los emprendedores identifican y reconocen las oportunidades, problemas o necesidades del mercado, valiéndose de técnicas de observación, investigación, etnografía, entre otros, con el propósito de diseñar una idea de negocio enfocada a la diferenciación, mediante una propuesta de valor clara y concreta. (GEM, 2013). En esta etapa algunas universidades que cuentan con unidades de emprendimiento aportan elementos importantes, sin embargo, son las incubadoras las llamadas a desarrollar metodologías para identificar ideas de negocios con buen potencial.

Formulación. El emprendedor diseña su modelo de negocios diferenciado, utilizando servicios de prototipo industrial para validar con el mercado su producto y/o servicio. También recibe acompañamiento técnico mediante procesos de mentoría en el diseño de la estrategia y de la visión del negocio a largo plazo, entrenamiento del equipo de trabajo en competencias gerenciales y preparación de los emprendedores para la gestión de recursos de capital semilla (GEM, 2013). A nivel nacional el Fondo Emprender, las Unidades de Emprendimiento de las IES y las incubadoras, como también los programas que desarrollan las Cámaras de Comercio apoyan a los emprendedores a formular los planes de negocio.

Puesta en marcha. Comienza la operación de la empresa y el equipo de trabajo desarrolla procesos de gestión comercial. Es la etapa en la que se valida y se realizan ajustes permanentes para asegurar la innovación en el modelo de negocio, con base en la información que se obtiene en el mercado; se diseñan estrategias y se conforman juntas directivas o consejos asesores; se definen procesos y procedimientos dela empresa; se gestionan proveedores, aliados y asesores especializados en temas gerenciales, financieros, técnicos y comerciales; se busca la generación de un flujo de caja que permita mantener las operaciones de la empresa (GEM, 2013). Para los ecosistemas la puesta en marcha es fundamental y se realizan a partir de instituciones como las Cámara de Comercio, El SENA a través del Fondo Emprender y las Incubadoras regionales. 
Aceleración. En esta etapa, la empresa maximiza su valor agregado a través de la internacionalización y la innovación y orienta sus esfuerzos hacia la consolidación de su crecimiento sostenido, mediante la búsqueda de socios estratégicos y nuevos clientes vía redes de contactos internacionales (diáspora) y atracción de capital. La aceleración de empresas involucra el incremento en la velocidad de ejecución --escalabilidad-- y consecución de resultados de la gestión directiva, comercial, administrativa, financiera, tecnológica y de recursos humanos de una empresa, alineados a una serie de objetivos y estrategias de negocio, en un tiempo determinado (GEM, 2013). Esta etapa quizás es la más débil en los ecosistemas, pero iNNpulsa juega un papel muy importante para potencializar los emprendimientos de alto impacto y algunos programas de Start Up que se desarrollan en ecosistemas potentes de Colombia como el de Ruta N en Medellín, Bogotá Emprende, Cali Emprendedora y Manizales Mas entre otros.

Tabla 12. Distintas clasificaciones de la cadena de emprendimiento

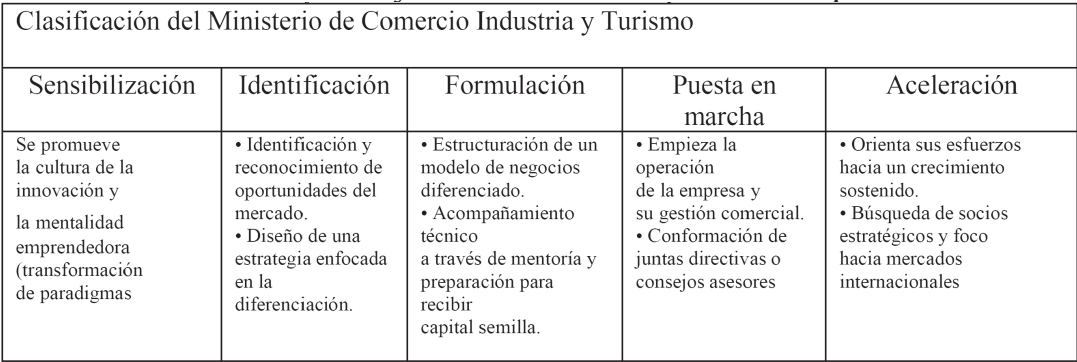

Fuente: Ministerio de Comercio, Industria y Turismo de Colombia, 2013

Para MinCIT, Endeavor y Universidad de los Andes en el estudio denominado GEM Bogotá 2013, plantean quelas siguientes entidades cumplen un papel importante en las dinámicas de los ecosistemas de emprendimiento:

Centros de conocimiento, Instituciones de Educación Superior (IES) y centros de desarrollo tecnológico y de innovación. Desarrollan actividades de generación de 
conocimiento, investigación, capacitación técnica y académica, preparación de proyectos empresariales y empresas, desarrollo del espíritu emprendedor y contactos interinstitucionales. Son organizaciones de conocimiento las universidades, las instituciones técnicas y tecnológicas, los centros de investigación y las unidades de análisis e investigación en organizaciones de los sectores público y privado (GEM, 2013).

Entidades de financiamiento. Proveen recursos financieros a los emprendedores para que desarrollen sus proyectos. Las organizaciones de financiación son los fondos de capital semilla, algunos concursos de planes de negocio, los fondos de capital en etapa temprana, las redes de ángeles inversionistas, las cooperativas, los bancos, las organizaciones de microcrédito, los financiadores multilaterales y los donantes. El objetivo general de estas organizaciones es proveer los recursos financieros, el diseño y la ejecución de instrumentos de financiación y el fomento de la cultura de inversión en emprendimiento (GEM, 2013).

Aceleradoras y entidades de asistencia técnica y asesoríaconsultoría. Desarrollan actividades de asistencia general --talleres de sensibilización o de identificación de oportunidades de negocio-- y/o de actividades específicas de incubación y puesta en marcha --talleres de gestión de marca, asesorías legales, trámite de patentes-- o de aceleración -mentorías estratégicas, funcionales, "networking" y diagnósticos operativos-. Cuanto más específica es la asistencia, menor volumen de emprendedores atiende, puesto que es un enfoque "hecho a la medida". En cuanto a asistencia general, se destacan las siguientes actividades: talleres de identificación de oportunidades, pasos para la formalización, cuentas y estrategias de mercadeo, gestión financiera y de recursos humanos, entre otros. Otras entidades en esta clasificación son aquellas que prestan espacios para la construcción de redes entre emprendedores, consultores y asesores "co-working space"22 (GEM, 2013).

22 Espacios de trabajo colaborativo. 
Entidades del gobierno local, nacional y organismos multilaterales. Sus actividades se basan en el diseño, promoción y ejecución de políticas públicas sobre emprendimiento y fortalecimiento de pequeñas, medianas y grandes empresas. Estas políticas se orientan tanto al apoyo de los procesos de los emprendedores como al aumento del alcance y la eficiencia de las organizaciones que apoyan esos procesos. Algunas de estas entidades proveen financiación a proyectos en etapas tempranas por medio de convocatorias, o incentivos tributarios y fiscales articulados a las políticas públicas que desarrollan (GEM, 2013).

Asociaciones y gremios. Su principal objetivo es la gestión gremial para el fortalecimiento de los sectores productivos que representan ante los diferentes actores del EE y otros involucrados. Sus servicios suelen estar comúnmente asociados con programas que buscan capacitar y fortalecer los modelos de negocio de sus asociados (GEM, 2013).

La ilustración 6 muestra la relación entre los diferentes actores de un EE y las etapas en la cadena de emprendimiento en las que participan. En primer lugar, están las organizaciones y los gremios, los cuales soportan tanto a los nuevos emprendimientos en las etapas de conceptuación y etapa temprana -como el concurso de planes de negocio realizado por la ANDI del futuro--, y a empresas en etapas de crecimiento y fortalecimiento (los gremios sectoriales de la ANDI para apoyar el fortalecimiento de los productos ofrecidos a la industria y Analdex que fomenta la internacionalización de las empresas colombianas) (GEM, 2013). 
Ilustración 6. Clasificación de los distintos papeles de las entidades de un EE, según la etapa en la cadena de emprendimiento.

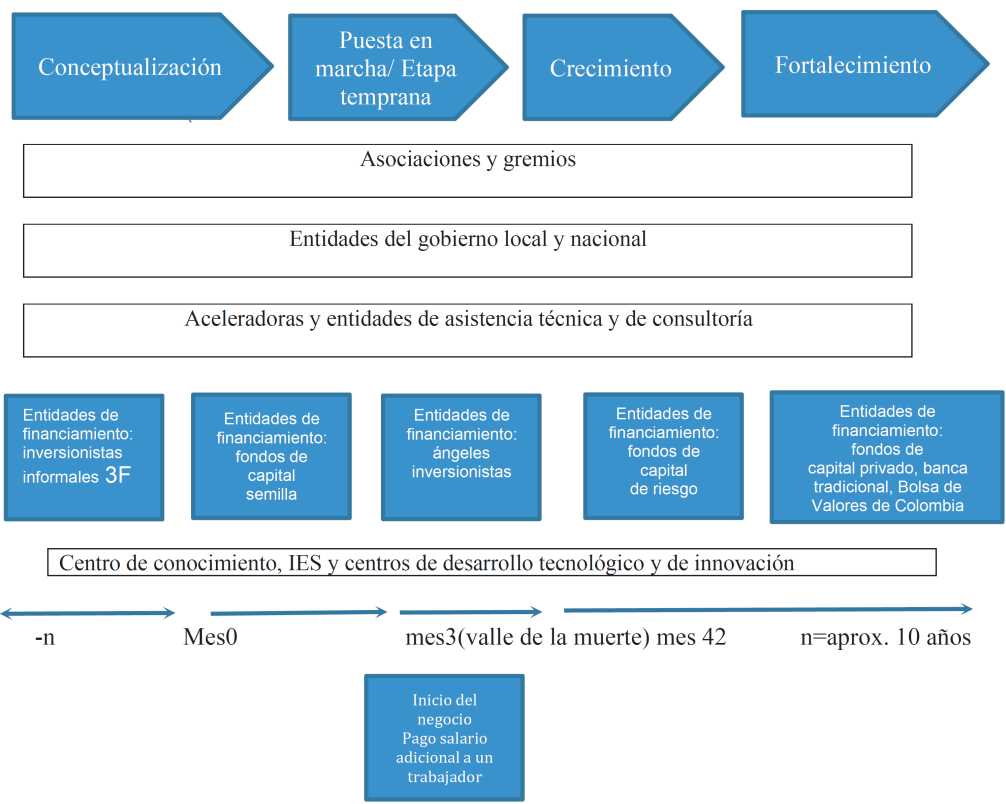

Fuente: elaboración propia, a partir de información de Mincit, Endeavor y Universidad de los Andes

En cuanto a la puesta en marcha aparecen los fondos de capital semilla como el Fondo Emprender, así como recursos puestos por entidades de asistencia técnica como la Fundación Bavaria, con el programa Destapa Futuro, ola Corporación Ventures con el concurso del mismo nombre. También hay asociaciones de ángeles inversionistas, los cuales buscan potenciar el desempeño de las empresas con inversiones temporales a corto o mediano plazo (Red Nacional de Ángeles Inversionistas de Bavaria, Ángeles de los Andes). Para las etapas de crecimiento y fortalecimiento, en las que las empresas buscan crecer sostenidamente, reinventar y escalar su modelo de negocio, la banca tradicional, los fondos de capital de riesgo y los fondos de capital privado son los llamados a financiar esas necesidades empresariales. La banca tradicional ha diseñado distintos modelos de financiación para empresas ya constituidas que facilitan el crecimiento de sus negocios (GEM, 2013). 
Un ejemplo de estos instrumentos planteados en el GEM, es el "factoring", el cual consiste en la cesión de la cartera de cobro a clientes convirtiendo las ventas a corto plazo en ventas al contado, siendo una opción para las Pyme que no pueden soportar una línea de crédito en el corto plazo o buscan solvencia inmediata. Las políticas públicas sobre emprendimiento se orientan tanto al apoyo de los procesos de los emprendedores como al aumento del alcance y la eficiencia de las organizaciones que apoyan esos procesos (GEM, 2013).

Los fondos de capital de riesgo se focalizan en emprendimientos dinámicos e innovadores (EDI) o en emprendimientos de alto impacto (EAI) en sus primeros años de vida, pues realizan inversiones a mediano o largo plazo y buscan mecanismos de salida que les permitan reinvertir en otros proyectos. Algunos fondos de capital de riesgo en el EEB son el Fondo Inversor y el Fondo Progresa Capital (GEM, 2013).

Por su parte, en el informe GEM realizado en el 2013, se plantea que los fondos de capital privado son fondos más robustos, los cuales se caracterizan por invertir en empresas maduras y en procesos de expansión. Las inversiones de estos fondos en las empresas son a largo plazo y comúnmente el nivel de involucramiento en los aspectos claves del negocio es alto. Algunos de los fondos de capital privado del ecosistema son los Fondos Bamboo Finance, Altra Investments, Aureos Capital, entre otros (GEM, 2013).

El último actor de un EE son los centros de conocimiento y las instituciones de educación superior (IES), según MinCIT, iNNpulsa y el GEM estas entidades desempeñan un papel fundamental en la primera etapa de la cadena de emprendimiento, pues se encargan de sensibilizar a los emprendedores potenciales para que inicien de forma definitiva su proceso empresarial. (GEM, 2013). En este sentido las IES tienen el rol de generar cultura emprendedora para fortalecer el ecosistema de emprendimiento regional. 
Según los estudios realizados por MinCIT, iNNpulsa y el GEM Bogotá 2013, los centros de emprendimiento de estas IES son fundamentales para la consolidación de las ideas empresariales por estudiantes y egresados --normalmente su público objetivo--. Estos centros se convierten por lo regular en el primer paso de la cadena de emprendimiento, ya que de allí los emprendedores acuden a otros servicios del ecosistema como los concursos de planes de negocio, los recursos del Fondo Emprender, los servicios de entidades de apoyo local o regional que existen en los ecosistemas de emprendimiento más avanzados de Colombia.

Otras actividades importantes de estas entidades en un EE son el apoyo en el desarrollo de los primeros prototipos de estos proyectos, las redes de contacto disponibles, los diplomados o cursos temáticos para empresarios establecidos y otros más relacionados con el fortalecimiento de las actividades empresariales. Un ejemplo muy importante a nivel nacional es el papel que desarrollan en este sentido las universidades que hacen parte del ecosistema Manizales Más.

Los centros de conocimiento y las instituciones de educación superior (IES) desempeñan un papel fundamental en la primera etapa de la cadena de emprendimiento, pues se encargan de sensibilizar a los emprendedores potenciales para que inicien de forma definitiva su proceso empresarial.

\section{Ecosistema de Emprendimiento en Popayán}

El ecosistema de emprendimiento de Popayán debe ser una suma de actores públicos, privados y académicos que busque impactar el desarrollo económico de la ciudad mediante el fortalecimiento de las condiciones necesarias (ecosistema de emprendimiento) para crear y crecer empresas.

En el proceso se deben articular actores como la alcaldía de Popayán, Creatic, AgroInnova, Universidades, Ministerio TIC, MINCIT y la Red de Emprendimiento, con el propósito 
de fortalecer el ecosistema a través de un número sostenible de empresarios nuevos y acelerados a lo largo del tiempo. En estos momentos ya existen dos centros de apoyo para la tecnología e innovación-CATI, uno perteneciente a la Universidad de Cauca y otro del Clúster Creatic como respuesta a lo planteado en el diagnóstico de la problemática del ecosistema regional.

El fortalecimiento del ecosistema POPAYÁN EMPRENDE tiene como objetivo el desarrollo económico a través de:

- Construcción de capacidad permanente para el crecimiento de las empresas.

- Empoderar a los emprendedores

- Motivarquelosactores delecosistema generen nuevos programas para los emprendedores, a través de la experimentación

- Desarrollar modelos exitosos a seguir y mentores para emprendedores generando un cambio de cultura /mentalidad - Lograr victorias tempranas y resultados medibles de largo plazo, para construir un modelo a seguir.

\section{Propuesta de Modelo de Ecosistema de Emprendimiento Popayán Emprende}

Filosofía del Modelo

Cultura Emprendedora e Innovación. Todo el modelo debe soportarse en la construcción de una cultura emprendedora basada en compartir: Conocimiento; Contactos e ideas. Una cultura que rompa los esquemas mentales arraigados en una mentalidad feudalista y de empleados. (Ver ilustración 7).

En estudio realizado por De la Torre se plantea que: La mentalidad cristiano feudal se mantuvo en las urbes de los dos primeros siglos de la colonia, pero en la última década del siglo XVIII, el impacto del mundo mercantilista tocó a Latinoamérica, trayendo como bandera su mentalidad burguesa, instalada 
en las clases criollas imbuidas con las palabras progreso y libertad comercial. Ante esta revolución ideológica las ciudades respondieron diversificándose según sus posibilidades: la gran mayoría se "aburguesaron", otras combinaron las dos estructuras, y finalmente algunas pocas continuaron siendo hidalgas como le sucedió a Popayán (Urreste, 1999, pág. 58).

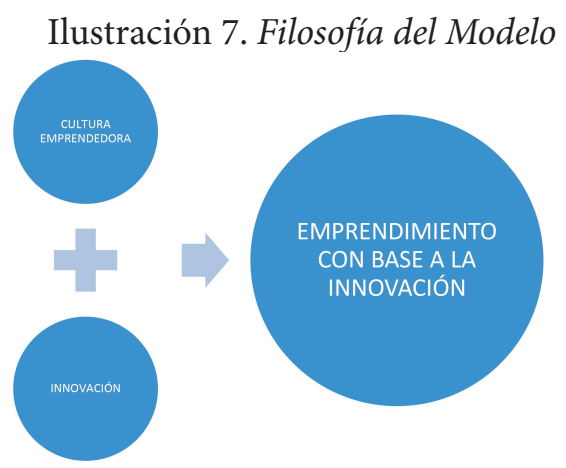

Fuente: Elaboración propia

De la Torre cita a Romero en su análisis de la modernidad para analizar la cultura que más ha influenciado la ciudad: A partir de 1983 después del terremoto la ciudad ha crecido, se han ido los payaneses hidalgos, abandonaron el centro de la ciudad y crearon nuevos barrios, nuevos grupos sociales se integraron a la ciudad provenientes de diferentes regiones del país que no pertenecían a las castas patojas y que por ende no manejaban ni respetaban sus significados. Los habitantes de Popayán aún en 1983 se resistían a desprenderse de su nobleza, representado en su sector histórico. El advenimiento de la ciudad burguesa trajo consigo la necesidad de borrar con el pasado colonial y con ello el antiguo casco urbano de las ciudades de indias fueron demolidos, las antiguas familias hidalgas llamadas de la plaza ocuparon nuevos lugares de la fisonomía de la ciudad: "las nuevas burguesías se avergonzaban de la humildad del aire colonial que conservaba el centro de la ciudad y, donde pudieron, trataron de transformarlo, sin vacilar, en algunos casos, en demoler, algunos sectores cargados de tradición. La demolición de lo viejo para dar 
paso a un nuevo trazado urbano y a una nueva arquitectura fue un extremo al que no se acudió si no en unas pocas ciudades; pero se trasformó en una inspiración que parecía resumir el supremo triunfo del progreso" (Romero, 1976, p. 275).

La mentalidad cristiano feudal comenzó a ser remplazada por la mentalidad burguesa en la Jerusalén de América solo recientemente, ya que en la primera se vivía dentro de una comunidad y para ella, por lo cual podía trabajarse en una obra cualquiera por decenios y aun siglos; en tanto en la segunda se edifica rápidamente, porque ahora el que construye lo hace para su propio beneficio. Este sentido de comunidad se está desvaneciendo en la ciudad y diariamente nos encontramos ante el asombro de los payaneses al presenciar el cambio acelerado dentro del caso urbano local. Una nueva ciudad empieza a dar sus primeros pasos, una ciudad de industrias y semáforos, liderada por la mentalidad burguesa. Pareciera que las entrañas de Popayán han estado aliadas a la naturaleza para despojarla de su mentalidad feudal y premoderna. Dos acontecimientos de carácter catastrófico, uno el terremoto de 1983 y el otro la tragedia del río Páez, ambos hechos trágicos destrozaron las murallas mentales construidas para evadir la modernidad, y le abrieron las puertas a un incipiente progreso que quizás sea la semilla de una era empresarial para la generación que actualmente se está educando bajo nuevos paradigmas.

A pesar del largo trayecto recorrido en la historia no muchas cosas han cambiado dentro del imaginario colectivo, que les han impedido a los actuales habitantes de la ciudad de Popayán despojarse de esa mentalidad premoderna, que los afectó emocionalmente y les impidió por sí solos tomar las riendas de su propio destino. Sólo acontecimientos migratorios ocurridos por fenómenos naturales como el terremoto de 1983 y la avalancha del Rio Páez, permeabilizaron su anquilosada postura ante los vientos de la modernidad que soplaban desde hace tiempo en el mundo y en Colombia. ${ }^{23}$

23 De la Torre, Gabriel. Análisis sobre la mentalidad de los micro, pequeños y medianos empresarios de la ciudad de Popayán. Universidad del Valle, 2012.p. 23. 
Por lo tanto, para fortalecer el ecosistema se debe trabajar colaborativamente entre la Universidad, el Estado y la Empresa para construir una nueva cultura, una cultura emprendedora.

Según el manual de Oslo, las teorías de innovación constituyen la base de un importante número de temas relacionados con la política y la medición de la innovación, tales como por qué innovan las empresas, qué fuerzas fomentan la innovación y qué factores la dificultan. También están relacionadas con el funcionamiento interno de las empresas y con qué tipo de prácticas de negocio se siguen para promover la innovación. Es, asimismo, importante tener en cuenta la naturaleza del conocimiento, cómo se acumula y cómo fluye entre actores y, finalmente, cómo los procesos de innovación se expanden a través de sectores, regiones y países.

El manual de Oslo plantea que el trabajo de Joseph Schumpeter ha influido sobremanera en las teorías de la innovación. Schumpeter defendió que la innovación fomenta el desarrollo económico a través de un proceso dinámico, definido como "destrucción creadora", en el cual las nuevas tecnologías reemplazan a las antiguas. Según Schumpeter, las innovaciones "radicales" dan lugar a cambios bruscos e importantes, mientras que las innovaciones "incrementales" alimentan continuamente el proceso de cambio. Schumpeter (1934) propuso una lista de cinco tipos de innovaciones:

- Introducción de nuevos productos.

- Introducción de nuevos métodos de producción.

- Apertura de nuevos mercados.

- Desarrollo de nuevas fuentes de abastecimiento de materias primas u otros recursos.

- Creación de nuevas estructuras de mercado en un sector. ${ }^{24}$

24 MANUAL DE OSLO. Directrices para la obtención y análisis de la información e innovación. Disponible en: www.madridmasd.org. 2014. 
Según lo anterior el modelo de ecosistema emprendedor para Popayán se sustenta en dos conceptos fundamentales la cultura emprendedora y la innovación, como ejes fundamentales para la construcción colectiva de un escenario que fundamente a Popayán como una ciudad emprendedora e innovadora.

\section{Estructura del Modelo de Emprendimiento}

La estructura del modelo se plantea a partir del ejercicio realizado desde la participación en el diplomado de mentoring para emprendedores ejecutado por el Clúster Creatic como investigador en el proyecto InnovAcción Cauca, y basado en el modelo de emprendimiento del Universidad Javeriana de Cali. En este modelo interactúan de forma holística y sistémica los siguientes actores: Entidades de Acompañamiento, Institutos de Investigación, Fuentes de Financiación; Sistema regulatorio como primer eje de influencia para crear y fortalecer el Emprendedor como actor principal por su talento en este modelo y en una segunda zona de influencia las Empresas y los Mentores. (Ver ilustración 8).

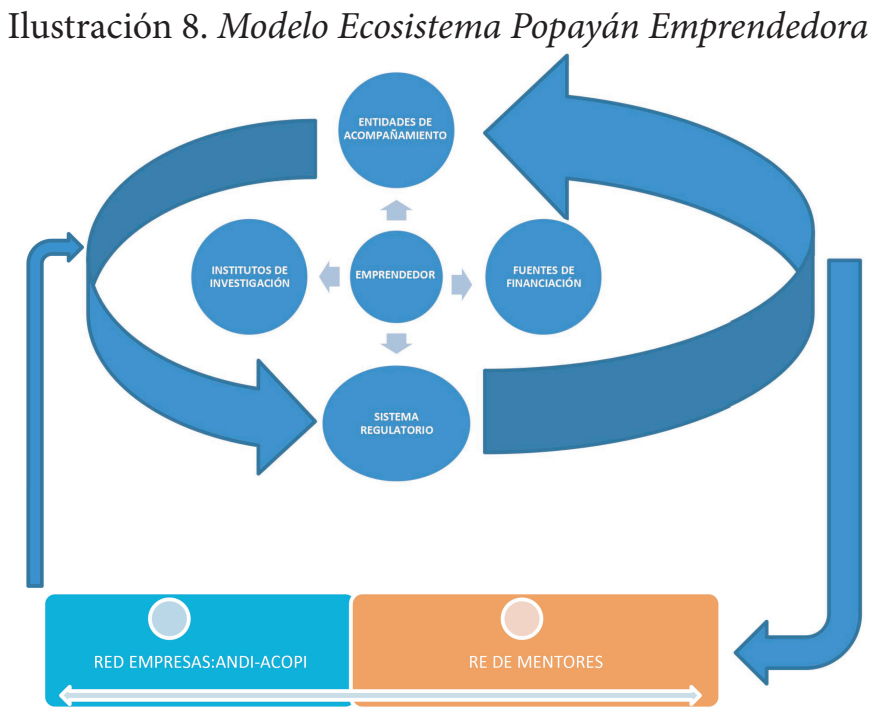

Fuente: Elaboración propia 
Tabla 13. Actores del ecosistema:

\begin{tabular}{|c|c|c|c|}
\hline ENTIDADES DE ACOMPAÑAMIENTO & $\begin{array}{ll}\text { INSTITUTOS } & \text { DE } \\
\text { INVESTIGACIÓN } & \end{array}$ & $\begin{array}{ll}\text { FUENTES } & \text { DE } \\
\text { FINANCIACIÓN } & \end{array}$ & $\begin{array}{l}\text { SISTEMA } \\
\text { REGULATORIO }\end{array}$ \\
\hline Red ASIES Cauca-SENA & CREPIC & Fondo Emprender & Ley de emprendimiento \\
\hline $\begin{array}{c}\text { Unidades de emprendimiento de la red } \\
\text { Asies Cauca: FUP; Uniautónoma; } \\
\text { Unicomfacauca; Unicauca, ESAP, UCC, } \\
\text { UNICAUCA }\end{array}$ & $\begin{array}{c}\text { Grupos de Investigación } \\
\text { de las IES }\end{array}$ & iNNpulsa & $\begin{array}{c}\text { Políticas } \\
\text { gubernamentales: } \\
\text { nacionales, } \\
\text { departamentales y } \\
\text { municipales }\end{array}$ \\
\hline INCUBADORAS:Creatic ;Agroinnova & $\begin{array}{l}\text { Centro de desarrollo } \\
\text { tecnológico de CREATIC }\end{array}$ & Bancos & \\
\hline Cámara de Comercio del Cauca & & MINTIC; MINCIT & \\
\hline & & Colciencias & \\
\hline EMPRESARIOS & \multicolumn{3}{|c|}{ RED DE MENTORES; RED DE EMPRENDIMEINTO REGIONAL } \\
\hline ANDI & \multicolumn{3}{|c|}{ Empresarios } \\
\hline ACOPI & \multicolumn{3}{|c|}{ Emprendedores exitosos } \\
\hline FENALCO & \multicolumn{3}{|c|}{ Mentores instituciones de acompañamiento } \\
\hline
\end{tabular}

Fuente: Elaboración propia

Entidades del Ecosistema Popayán Emprende según su Rol.

En la actualidad en el Ecosistema Popayán Emprende se destacan los siguientes actores públicos y privados que acompañan el emprendimiento, las cuales hacen parte de este estudio:

Centros de conocimiento, Instituciones de Educación Superior (IES) y centros de desarrollo tecnológico y de innovación: Servicio Nacional de Aprendizaje Sena, Centro de Desarrollo Tecnológico Clúster Creatic, Fundación Universitaria de Popayán, Universidad del Cauca y su CATI, Corporación Autónoma del Cauca, Institución Universitaria Colegio Mayor del Cauca, Escuela Superior de Administración Pública - ESAP y la Corporación Universitaria Comfacauca.

Entidades de financiamiento: El SENA a través del Fondo Emprender y otras instituciones que, aunque no fueron objeto de estudio de este proyecto, se destacan: Fundación Mundo Mujer, COOMEVA, Banco W, Bancamía y los demás bancos que tienen algunas líneas de crédito

Aceleradoras y entidades de asistencia técnica y asesoría-consultoría: Clúster Creatic, Cámara de Comercio del Cauca, CATI-Creatic, CATI Unicauca 
Entidades del gobierno local, nacional y organismos multilaterales: SENA, Cámara de Comercio del Cauca, Oficina de Gestión de Empleo y Emprendimiento del Municipio de Popayán, La Red Regional de Emprendimiento del Cauca, Pro-Colombia.

Asociaciones y gremios: En el ecosistema de emprendimiento de Popayán los gremios que se destacan son: ANDI, ACOPI y FENALCO.

Clasificación de las entidades según su papel en la cadena de emprendimiento

Identificación: En esta etapa se identifican las IES como: Fundación Universitaria de Popayán, Universidad del Cauca, Corporación Autónoma del Cauca, Institución Universitaria Colegio Mayor del Cauca y la Corporación Universitaria Comfacauca.

Formulación: En el Ecosistema de Popayán se destacan en esta etapa: Cámara de Comercio del Cauca, Servicio Nacional de Aprendizaje Sena, Centro de Desarrollo Tecnológico Clúster Creatic, Fundación Universitaria de Popayán, Universidad del Cauca, Corporación Autónoma del Cauca, Institución Universitaria Colegio Mayor del Cauca y la Corporación Universitaria Comfacauca.

Puesta en Marcha: En el ecosistema de Popayán las instituciones identificadas que se encargan de esta etapa son: Cámara de Comercio del Cauca, Oficina de Gestión de Empleo y Emprendimiento del Municipio de Popayán, Servicio Nacional de Aprendizaje Sena, Centro de Desarrollo Tecnológico Clúster Creatic, Agroinnova, Fundación Mundo Mujer, Universidad del Cauca y Corporación Universitaria Comfacauca.

Aceleración: En esta etapa solo una institución ha realizado procesos de aceleración y es el Clúster Creatic 


\section{Estrategias para el fortalecimiento del modelo:}

Construir colectivamente una cultura emprendedora que comparta:

- Conocimiento

- Contactos

- Ideas

Construcción de conceptos compartidos:

- Definición de emprendimiento

- Tipos de emprendimiento

- Definición de emprendedor

Fortalecimiento de la densidad de emprendedores:

- Aumentar la masa crítica de emprendedores

- Aprovechar el talento joven y el de los expertos

Encadenamiento del apoyo:

Evitar el protagonismo y los egos institucionales

Cada actor se debe enfocar en su aporte al proceso emprendedor, definiendo el rol de cada uno de los actores regionales del ecosistema

\section{Estrategias para fortalecer el Ecosistema:}

Se debe desarrollar una metodología y trabajo en pro del emprendimiento, para lo cual se deben realizar convenios a través de la gestión de la red de Formación INNOVACCIÖN con universidades como la universidad de HALMSTAD y a través de la ANDI con las universidades de Estados Unidos como Babson College y el MIT, aprovechando la experiencia adquirida por la Fundación Luker en el ecosistema de Manizales. Igualmente, con el apoyo de ParqueSoft y las universidades de la región socias de Innovación, generar convenios con la Universidad javeriana, el ICESI y la EAFIT muy avanzadas en su modelo de emprendimiento: 
Por ejemplo, Babson College de USA, es la Universidad número uno en el tema de Emprendimiento, en su programa global, desarrolla la capacidad de emprendimiento de las localidades adecuando las políticas, estructuras, programas y clima para fomentar el emprendimiento de alto impacto usando la educación de emprendimiento pensamiento y acción.

El Instituto Técnico de Massachusetts -MIT, es una institución educativa de clase mundial dedicada a la enseñanza y la investigación, con énfasis en la práctica. Con una amplia y reconocida trayectoria en la creación de empresas a partir de resultados de investigación. La misión del MIT es el conocimiento avanzado y la educación de los estudiantes en ciencia, tecnología, y otras áreas que contribuyan al servicio del mundo en el Siglo 21.

Estas universidades apoyan proceso de formación e innovación curricular para construir procesos de emprendimiento en las universidades y proceso de planeación estratégica y prospectiva para fortalecer los emprendimientos innovadores.

Creatic hace unos años suscribió un convenio con la Universidad Javeriana y creó el programa del diplomado mentoring para emprendedores que fue cursado por personas de las diferentes instituciones que hacen parte de la red de emprendimiento. En Manizales con el apoyo del Babson College se han revisado y transformado 12 currículos universitarios y se han vinculado 3 docentes en el programa global de esta universidad en emprendimiento.

Se debe buscar el apoyo de entidades financieras como Davivienda, Bancoomeva, grupo Aval, Fundación Mundo Mujer y Bancolombia para compartir experiencias de emprendimiento con empresarios del mundo.

Se debe desarrollar el programa Adventure con el apoyo de Manizales Mas en el que se implementan estrategias como el 
bootcamp, creación de star-up con equipos de emprendedores con 6 semanas de entrenamiento intensivo en el que se mezcla: Mentoría, Formación, Asesoría, Networking y Negocios Reales.

Para fortalecer el ecosistema según las lecciones aprendidas en el curso de mentoring impartido por la $U$ javeriana y organizado por el Clúster Creatic, se presentan las siguientes estrategias:

- Establecer el proceso emprendedor y los actores Fortalecer las Unidades de emprendimiento de las IES e instituciones de acompañamiento.

- Crear y fortalecer las aceleradoras en el ecosistema.

- Crear una estrategia de financiación clara para emprendimiento.

- Crear un sistema de comunicación del ecosistema, como un portal de servicios

- Diseñar un sistema de trazabilidad de emprendedores

- Registro de grupos de investigación + desarrollo y un estudio de inteligencia de oportunidades.

- Registro de retos y necesidades de la región.

- Consolidar un plan de acción del ecosistema

- Realizar misiones a otros ecosistemas del mundo.

\section{Estrategias para fortalecer la relación del ecosistema con el entorno.}

- Generar vivencias de ciudad: coworking spaces, cafés emprendedores, eventos net working, micro eventos, etc.

- Crear club de mentores, equipos de asesores y orientadores, constituidos por empresarios expertos, emprendedores exitosos y expertos en el tema de emprendimiento.

- Establecer relaciones internacionales.

- Educar empresarios para convertirse en inversionistas.

- Educar las empresas para invertir en emprendimientos corporativos. 


\section{Conclusiones y recomendaciones}

- Adelantar este tipo de investigaciones relacionadas con la interacción de personas motivadas con la generación de cambios de los sectores económicos de la ciudad, contribuyen al empoderamiento de las mismas y son un punto de partida para fortalecer el ecosistema de emprendimiento local y regional.

- Para el desarrollo del proyecto, se presentaron algunas limitantes como la disponibilidad de la población abordada, especialmente por parte de los directivos y líderes de las entidades que acompañan el emprendimiento, debido a la coyuntura del paro indígenas efectuado desde el mes de marzo de 2019, paralizando el debido funcionamiento de la ciudad por 25 días y afectando diferentes sectores económicos, además de la planeación de la Semana Santa, uno de los eventos más representativos de la capital caucana.

- Existe un interés institucional por fortalecer el ecosistema del emprendimiento principalmente en el contexto local de la ciudad de Popayán y con ello, la asignación de recursos ha crecido progresivamente. Esto es percibido no solo entre entidades sino por parte de los emprendedores, quienes comparten que se ha ido avanzando en este aspecto.

- Algunos factores externos, como los índices de desempleo y la necesidad del mejoramiento de la calidad de vida, han promovido la creación de nuevos emprendimientos, especialmente con una mayor participación de la población joven.

- Las entidades del ecosistema de emprendimiento han evidenciado la necesidad de promover los emprendimientos asociativos, con el fin de lograr trabajos colaborativos con altos índices de cooperación traducidos con un mayor impacto. Sin embargo, argumentan que existe una gran resistencia por parte de algunos emprendedores en este aspecto, así como en la comprensión de la tecnología como una herramienta para cualquier tipo de emprendimiento, situación que se ha ido mitigando con esfuerzos liderados por entidades expertas en este campo.

- Existe un amplio portafolio de formación en emprendimiento, promovido por las entidades, incluso con subsidios hasta 
del $100 \%$, así como la ejecución de estrategias a través de convocatorias de financiación de ideas y modelos de negocio. Sin embargo, se evidencian oportunidades de ampliar las líneas de formación a sectores potenciales que aún no se han desarrollado en la ciudad apoyándose de estudios de factibilidad ya realizados, además de aspectos transversales como la innovación y la creatividad aplicadas al emprendimiento para desarrollar factores diferenciadores, tanto en el sector privado como público. Por otra parte, incrementar el número y alcance de las convocatorias de financiación, incluyendo públicos especiales como instituciones de educación básica y media, y personas adultas, sin condicionar los requisitos a un límite de edad.

- Se requiere conocer y documentar las características sociodemográficas de los emprendedores y su contexto más inmediato (familia y amigos), estudiando que incidencia podría tener la atención psicosocial, con los resultados en emprendimiento.

-Existen similitudes en el comportamiento de los emprendedores, relacionado con la forma como asumen el riesgo, su resiliencia, perseverancia, iniciativa y motivación.

- En la práctica no se evidenciaron metodologías específicas enfocadas a tipos de emprendimiento, así como un trabajo que asocie el emprendimiento a los campos disciplinares abordados desde la academia, suponiendo que cada uno requiere de un trabajo particular, hipótesis que sería objeto de investigación. (ejemplo: salud + emprendimiento, derecho + emprendimiento). - Tampoco se evidenció la implementación de metodologías de acompañamiento a emprendimiento con fines de exportación.

- Existe un reducido equipo de talento humano en las entidades que acompañan el emprendimiento, además de la necesidad de fortalecer su formación específica en competencias y experticia en emprendimiento. Este panorama puede estar relacionado con la gestión en emprendimiento realizada por las instituciones, incluyendo indicadores de seguimiento y publicación de resultados a través de informes de gestión.

- En algunos casos se evidenció ausencia en la estandarización de procesos y procedimientos relacionados con el emprendimiento, situación que se vuelve compleja para aquellas organizaciones 
con un número importante de colaboradores. Esta problemática podría contribuir a que las organizaciones no prioricen y se especialicen en algunas fases del emprendimiento, haciendo las mismas acciones que sus pares.

- Se percibe una desarticulación del sector público con el privado en espacios de construcción del emprendimiento. Sin embargo, algunos eventos de emprendimiento como Cauca Emprende, demuestran una intencionalidad de cohesión institucional que busca optimizar recursos y lograr un mayor impacto.

- Existe un desconocimiento de las fuentes de financiación asociadas al emprendimiento que evidencia una distancia entre las entidades financieras, la universidad, la empresa y el estado, que plantea como hipótesis sujeta a una futura investigación, que no exista visión de inversión en emprendimientos locales como potencial de negocio.

- Poca visibilidad de información consolidada tanto de las entidades que acompañan el emprendimiento como emprendedores acompañados. No existe un banco de proyectos con estudios de prefactibilidad que permita ganar tiempo a los emprendedores, encontrar información fácil y sin costo.

- Las entidades reconocen que existe un gran número de emprendimientos de subsistencia, siendo esta una modalidad muy empleada en la ciudad de Popayán. Entre sus características, mencionan la necesidad de incrementar los niveles de innovación y valor agregado para evitar la saturación de la oferta.

- Las dinámicas que con el liderazgo del Centro de 'Desarrollo Tecnológico Clúster CreaTlC, se están haciendo con el clúster TIC, es un ejemplo que, si se puede hacer este tipo de apuestas de región, que vinculan incubadoras, emprendimientos de base tecnológica, grupos de investigación, unidades de emprendimiento de las universidades y el gobierno, con la participación del Ministerio de las TIC y la Gobernación del Cauca. Esta dinámica acompañada por emprendedores jóvenes con una visión arriesgada y ambiciosa, ha generado alianzas estratégicas con empresas de talla mundial como Microsoft. Entonces, existe el reto de construir un parque tecnológico y la creación de empresas de base tecnológica (EBT), además de la apuesta de una empresa de talla mundial.

- El ecosistema Popayán Emprende puede articularse con el 
Parque tecnológico del café ubicado en la venta de Cajibío para dinamizar emprendimientos basados en la innovación.

- Es importante que las IES continúen trabajando en la financiación del proceso de emprendimiento de sus instituciones, con el fin de reforzar el apoyo que les dan a sus emprendedores, mediante capital semilla (propia o articulada a fuentes externas), estandarización de procesos, seguimiento de casos exitosos y deficientes para su fortalecimiento, medición de la gestión. Son muchas las acciones que se adelantan, pero poco se documentan.

- El desarrollo de clúster ha sido una estrategia de competitividad que algunas regiones en el mundo han sabido desarrollar a partir de la dinámica de la Universidad - Empresa - Estado. El reto para Popayán es identificar por ejemplo en la cadena productiva del café, la posibilidad de desarrollar un clúster, con la participación del Parque Tecnológico del Café, y empresas líderes en este renglón de la economía, además de construir alianzas con las universidades y gremios como la ANDI para el impulso de centros empresariales que sirvan de incubadoras de emprendimientos de alto impacto, que sean proveedores de esta industria a partir de los retos y problemas identificados, con presencia del gobierno a través de políticas que incentiven la inversión y generen un clima de negocio ágil y seguro.

- Existen pocas estrategias orientadas hacia aceleración de empresas diferentes a formación, especialmente, aquellas que requieren relacionamiento con mercados externos.

- Poca difusión de los casos de éxito en emprendimiento desde diferentes medios de comunicación de la ciudad, sumado a la necesidad de seguir difundiendo los beneficios de los programas que acompañan el emprendimiento.

- Ausencia de lineamientos en emprendimiento para instituciones educativas de educación básica y media con convocatorias dirigidas a esta población objetivo.

- Se percibe por los emprendedores que no son suficientes los resultados ni apuestas colectivas relacionadas con el medio ambiente, las industrias culturales, el sector industrial en Popayán, la tramitología de formalización, estrategias de distribución para un mayor acceso a materias primas con fines de transformación y recursos para el fortalecimiento de redes de 
emprendimiento autónomas (colectivos que se reúnen dadas las necesidades de empoderamiento social).

- Se percibe por los emprendedores que el diseño de los perfiles profesionales de los programas académicos de las instituciones de educación superior debería resaltar la actividad emprendedora como una ocupación tan importante como la vinculación laboral a organizaciones.

- Es necesario continuar promoviendo en los emprendedores, el uso de técnicas de observación como herramienta de investigación para hacer lecturas del contexto y con ello, identificar problemáticas que permitan tener un mayor conocimiento de los requerimientos del entorno.

- El intercambio de experiencias a través de la participación en viajes de negocio, a otros países, misiones empresariales, misiones tecnológicas, las alianzas con universidades avanzadas en emprendimiento a nivel mundial, la conexión con redes de emprendimiento nacionales e internacionales, la participación de empresarios en las dinámicas de formación de formadores, tomarse un café alrededor del tema de emprendimiento, la construcción de historias de vida de emprendedores locales, darán el impulso para construir colectivamente un ecosistema de emprendimiento de talla mundial a partir de la pasión por emprender.

- Aunque la Red Regional de Emprendimiento del Cauca, está en su proceso de fortalecimiento, presenta dificultades en el relacionamiento con las instituciones públicas de gobierno que por razones políticas o de poder impiden que se desarrolle con mayor agilidad y de fona estratégica.

- Es importante que esta nueva dinámica de la Red Regional de Emprendimiento del Cauca esté enfocada en la construcción de una política pública para fortalecer el ecosistema de emprendimiento basado en la innovación.

- Es necesario que el trabajo de la Red Regional se articule con una Red de Emprendimiento Universitaria local, y ambas se encuentren atemperadas con la Red Nacional de Emprendimiento (REUNE)

- Para el fortalecimiento del ecosistema Popayán Emprende, sería conveniente continuar la búsqueda de referentes nacionales, con experiencias exitosas como el proceso que se lleva a cabo en la 
ciudad de Manizales en la construcción y fortalecimiento de su ecosistema de emprendimiento. Este ha logrado cohesionar los esfuerzos e identificar los roles de los actores. Es de resaltar que el relacionamiento Universidad Empresa Estado, permitió posicionar la marca región de Manizales como ciudad emprendedora. En Popayán ya se está evidenciando un esfuerzo, sin embargo, requiere de mayor difusión.

- Por ejemplo, ha sido muy importante para el ecosistema de Manizales la alianza estratégica de las universidades con la fundación Luker para lograr la vinculación de las universidades de Babson College y el MIT, para adelantar procesos de movilidad, intercambio de experiencias y asesoría en la innovación curricular de programas académicos y emprendimientos innovadores de la región. Por lo tanto, sería pertinente incluir en la dinámica de emprendimiento desde el escenario de la Red Regional de Emprendimiento. fundaciones como Mundo Mujer, Fundación Corona a través de la dirección seccional de la ANDI, entre otros.

- Es muy importante continuar con el compromiso de rectores de las universidades para crear o fortalecer las unidades de emprendimiento y visibilizar el emprendimiento en los planes estratégicos de sus instituciones, además de apoyar la creación de una Red de Emprendimiento Universitario que permita jalonar procesos de cambio, así como la interacción con universidades como la MIT y la Basson College para dar apertura a procesos de innovación curricular, así como en los procesos de incubación de nuevos emprendimientos con base a la innovación, como en su momento lo hizo el ecosistema Manizales Más.

- La estrategia de crear un parque tecnológico sería apropiada para Popayán, identificando los núcleos de innovación que tengan una dinámica importante como el sector de las TIC, con el liderazgo de Creatic, el núcleo de biopolímeros que jalona la cadena productiva de la yuca, soportando grupos de investigación y la posibilidad real de construir a partir de la universidad, spin off de alto impacto. Esto permitirá cohesionar y generar sinergia entre la Universidad con sus grupos de investigación, emprendimientos con base en innovación y empresas anclas del sector gubernamental y financiero. 


\section{Bibliografía}

Ajzen, I. (1991). The theory of planned behavior. Organizational Behavior \& Human Decision Processes, 50(2), 179-211.

Amorós, J. E. (2012). El proyecto global Entrepreneurship Monitor (GEM) Una aproximación desde el contexto latinoamericano. Academia, Revista Latinoamericana de Administración, 15.

Arias, M., \& Pérez, R. (2014). Emprendimiento: Como Comenzar una Empresa con Éxito. Face, 182.

Asheim, B., Moodyson, J., \& Tödtling, F. (2011). Constructing regional advantage: Towards state- of-the-art regional innovation system policies in Europe? European Planning Studies, 19 (pág. 7), 1133-1139. doi:10.1080/09654313.2011.573127

Athayde, R. (2012). The impact of enterprise education on attitudes to enterprise in young people: An evaluation study. Education + Training, 54, 709-726.

Audretsch, D. B. (2014). From the Entrepreneurial University to the University for the Entrepreneurial Society. The Journal of Technology Transfer, 39 (3), 313-321.

Beliaeva, T., Laskovaia, A., \& Shirokova, G. (2017). Entrepreneurial learning and entrepreneurial intentions: a cross-cultural study of university students. European Journal of International Management, 11(5), 606-632. 10.1504/EJIM.2017.10007649.

Bercovitz, J., \& Feldman, M. (2008). Academic entrepreneurs: Organizational change at the individual level. Organization Science, 19(1), 69-89. doi:10.1287/orsc.1070.0295. 
Bergmann, H. (2017). The formation of opportunity beliefs among university entrepreneurs: an empirical study of researchand non-research-driven venture ideas. The Journal of Technology Transfer, 42(1), 116-140. 10.1007/s10961-015-9458-Z

Bergmann, H., Hundt, C. \& Sternberg, R. (2016). What makes student entrepreneurs? On the relevance (and irrelevance) of the university and the regional context for student start-ups. Small Business Ecnonomics, 47, 53-76.doi:10.1007/s11187-016-9700-6

Bernal, C. A. (2013). Proceso Administrativo para las Organizaciones del Siglo XXI. Bogotá: PEARSON.

Bozhikina, I., Macke, J., \& da Costa, L. F. (2019). The role of government and key non-state actors in social entrepreneurship: A systematic literature review. Journal of Cleaner Production Volume 226, pages 730-747.

Buitrago, J. A. (2014). Emprendimiento en Colombia. Administración \& Desarrollo, 9.

Cantillon, R. (1755). Essai sur la nature du commerce en general. Londres: Macmillan.

Cardona, M., Vera, L. D., \& Tabares, J. (2008). Las dimensiones del emprendimiento empresarial: la experiencia de los programas cultura e y fondo emprender en Medellín. Cuadernos de Investigación, pág. 10.

Caro González, F. J., \& Otros. (2016). Impacto de la formación en emprendimiento en estudiantes sin formación empresarial. VII Jornada de Innovación e Investigación, 20-34.

CCB. (12 de marzo de 2019). Cámara de Comercio de Bogotá. Obtenido de https://www.ccb.org.co/Sala-de-prensa/Noticias$\mathrm{CCB} / 2018 /$ Septiembre/Realice-la-ruta-del-emprendimiento-enla-Camara-de-Comercio-de-Bogota 
CCC. (12 de marzo de 2019). Cámara de Comercio del Cauca. Obtenido de: https://www.cccauca.org.co/soy-emprendedor/ programa-ingenia

CCC. (2012). El emprendimiento Innovador, herramienta para la prosperidad democrática. Obtenido de: https://www.ccc.org.co/ file/2011/10/PresentacinEmprendimientoMC.pdf.

Chamorro, E., Osorio, H., \& Botero, J. J. (2013). Política de Emprendimiento en Colombia 2002-2010. EG - Estudios Gerenciales Journal of Managment and Economist for Iberoamérica, 33.

Chang, Y. \& Bogatyreva, K. (2006). Managing academic innovation in Taiwan: Towards a 'scientific-economic' framework. Technological Forecasting and Social Change, 73, 199-213. doi:10.1016/j.techfore.2004.10.004

Chen, C., P. G. Greene, and A. Crick (1998). "Does Entrepreneurial Self-Efficacy Distin- guish Entrepreneurs from Managers?” Journal of Business Venturing, 13, 295-316.

Congreso de la República de Colombia. (2006). Ley 1014. Colombia.

Constitución Política de Colombia. (1991). Constitución Política de Colombia. Bogotá.

Cronin, P., Ryan, F. \& Coughlan, M. (2008). Undertaking a literature review: a step-by-step approach. British Journal of Nursing, 17(1), 38-43.

De La Torre, G. (2011). Análisis sobre la mentalidad de los micro, pequeños y medianos empresarios de la ciudad de Popayán. Universidad del Valle, p.23. 
Dickson, P. H., Solomon, G. T. \& Weaver, K. M. (2008). Entrepreneurial selection and success: does education matter? Journal of Small Business and Enterprise Development, 15(2), 239258.

Dinero.com. (18 de agosto de 2016). Revista Dinero. Obtenido de https://www.dinero.com/edicion-impresa/caratula/articulo/ crisis-economicas-en-colombia-de-los-ultimos-anos/228934

Duarte, T., \& Ruiz, M. (2009). Emprendimiento, una opción para el desarrollo. Scientia et Technica. Año XV, No 43, 326-331.

Dudin, M. N. (2019). Environmental entrepreneurship: characteristics of organization and development. Entrepreneurship and Sustainability Issues 6(4), 1861-1871.

El Espectador. (17 de septiembre de 2008). Colombia y crisis financiera internacional. Obtenido de: https://www.elespectador. com/opinion/editorial/articulo-colombia-y-crisis-financierainternacional

El Tiempo. (2017). Emprendimiento en Colombia, la nueva fuerza de sostenibilidad. Obtenido de: https://www.eltiempo. com/colombia/emprendimiento-en-colombia-la-nueva-fuerzade-sostenibilidad-150144

El Tiempo. (21 de agosto de 2015). Colombia, un país emprendedor. Obtenido de: https://www.eltiempo.com/archivo/documento/ CMS-16266245

Elenurm, T. \& Moisala, A. (2008). Human resources for entrepreneurship: comparing orientations of Estonian and Finnish business students. European Journal of International Management, 2(4), 454-470. Obtenido de: https://www.inderscience.com/info/ inarticle.php?artid=21248 
European Management Journal, 34, 386-399.doi: 10.1016/j. emj.2015.12.007

Formichella, M. M. (2004). El concepto de emprendimiento y su relación con la educación, el empleo y el desarrollo local. Rivadavia 1439.

Formichella, M. M. (2004). El concepto de emprendimiento y su relación con la educación, empleo y el desarrollo local. En M. M. Formichella, Chacra Experimental Integrada Barrow. Tres arroyos. Pág. 10.

García-Rodríguez, F.J., Gil-Soto E., Ruiz-Rosa, I. \& GutiérrezTaño, D. (2016).

Entrepreneurial process in peripheral regions: the role of motivation and culture. European Planning Studies, 25(11), 20372056. 10.1080/09654313.2016.1262827

Gartner, W. (1989). "Who is an entrepreneur?" is the wrong question. En: W. Gartner, Entrepreneurship, Theory and Practice (págs. 47-68). Summer.

GEM. (2017). Global Entrepreneurship Monitor. México: Babson. Global Entrepreneurship Monitor AGER. (2016). New York.

Global entrepreneurship monitor. (2012). Informe gem, Colombia.

Global entrepreneurship monitor. (2013). Informe gem, España.

Gómez, H. J., \& Mitchell, D. (2014). Innovación y emprendimiento en Colombia: balance, perspectivas y recomendaciones de política, 2014-2018. Bogotá: Cuadernos de Fedesarrollo.

González, J. J. (2010). Caracterización emprendedora de los empresarios en los Valles de Tundama y Sugamuxi. Boyacá (Colombia). Pensamiento \& Gestión, 167. 
González, M., Valantine, I., \& Crespo, J. (2014). La investigación sobre emprendimiento en el ámbito deportivo. Revisión de los documentos publicados en la WOS. Journal of Sports Economics \& Management, págs. 55-66.

González, V. (2017). Juventud y emprendimiento en tecnología. Revista de estudios de juventud, 129-143.

Grégoire, D. A., Shepherd, D. A., \& Lambert, L. S. (2010). Measuring opportunity-recognition beliefs: Illustrating and validating an experimental approach. Organizational Research Methods, 13(1), 114-145. doi:10.1177/1094428109334369.

Guenther, J. \& Wagner, K. (2008). Getting out of the ivory tower - new perspectives on the entrepreneurial university. European Journal of International Management, 2(4), 400-417.

Guerrero, M. \& Urbano, D. (2016). Entrepreneurial activity and regional competitiveness: evidence from European entrepreneurial universities. Journal of

Technology Transfer, 41, 105-131.doi:10.1007/s10961-014-9377-4

Guerrero, M., Urbano, D., \& Fayolle, A. (2014). Entrepreneurial activity and regional competitiveness: evidence from European entrepreneurial universities. Journal of Technology Transfer, 41, 105-131. Retrieved from: http://doi. org/10.1007/

Guía 39 La cultura del Emprendimiento en los establecimientos educativos. (2010). Guía 39 La cultura del Emprendimiento en los establecimientos educativos. Bogotá, Cundinamarca, Colombia.

Guil Marchante, C., \& Montoya Sánchez, M. d. (2015). El emprendimiento social y el empleo de calidad. Revista de relaciones laborales, 180-206. 
Guzmán, A., \& Trujillo, M. A. (2008). Emprendimiento socialRevisión de literatura. Revista Estudios Gerenciales, 105-125.

Hahn, D., Minola, T., Van Gils, A., \& Huybrechts, J. (2017). Entrepreneurial education and learning at universities: exploring multilevel contingencies. Entrepreneurship \& Regional Development, 29(9-10), 945-974.

Hart, C. (1998). Doing a Literature Review. Sage Publications, London.

Hasan, Sk. M., Khan, E. A., \& Nabi, MD. N. (2017). Entrepreneurial Education at University Level and Entrepreneurship Development. Education and Training, 59 (7-8), 888-906. 10.1108/ET-01-20160020 .

Hebert \& Link. (1982). The entrepreneur mainstream views and radical critiques. New York: Praeger Publishers.

Hernández Acosta, J. (2013). La educación empresarial para el emprendedor cultural. Revista Forum Empresarial, 73-97.

Herrera Echeverri, H. (15 de marzo de 2019). Scielo, Revista Científica. Obtenido de http://www.scielo.org.co/scielo. php?script=sci_arttext\&pid=S0121-50512009000100003\&lng=en \&nrm=iso\&tlng=es

Hisrich, D. R., Peters, P. M., \& Dean, S. A. (2005). Entrepreneurship = Emprendedores. Madrid: Mac Graw Hil/Interamericana de España. s.a.u.

Huang-Saad, A., Duval-Couetil, N., \& Park, J. (2018). Technology and talent: capturing the role of universities in regional entrepreneurial ecosystems. Journal of Enterprising Communities: People and Places in the Global Economy, 12(2), 92-116. 
iNNpulsa Colombia. (abril de 12 de 2019). iNNpulsa Colombia. Obtenido de: https://iNNpulsacolombia.com/es/nuestraorganizacion

Isa \& Juanmi. (12 de marzo de 2019). Más y Mejor. Obtenido de https://masymejor.com/fases-de-crecimiento-de-un-negocio/

Johns, G. (2006). The essential impact of context on organizational behavior. Academy of Management Review, 31(2), 386-408. doi:10.5465/AMR.2006.20208687.

Katz, J. A. (2003). The chronology and intellectual trajectory of American entrepreneurship education: 1876-1999. Journal of Business Venturing, 18(2), 283-300.

Kochetkov, D. M., Larionova, V. A., \& Vukovic, D. B. (2017). Entrepreneurial capacity of universities and its impact on regional economic growth. Economy of Region/Ekonomika Regiona, 13(2), 477-488. doi: 10.17059/2017-2-13

Kourilsky, M. L., and W. B. Walstad (1998). Entrepreneurship and Female Youth: Knowledge, Attitudes, Gender Differences and Educational Practices. Journal of Business Venturing, 13(1), 7788.

Krueger, N. F., Reilly, M. D., \& Carsrud, A. L. (2000). Competing models of entrepreneurial intentions. Journal of Business Venturing, 15(5-6), 411-432.

Lafuente, E., Vaillant, Y., \& Rialp, J. (2007). Regional differences in the influence of role models: Comparing the entrepreneurial process of rural Catalonia. Regional Studies, 41(6), 779-796. doi:10.1080/00343400601120247.

Laguía González, A., Jaén, I., Topa, G., \& Moriano, J. (2019). University environment and entrepreneurial intention: the mediating role of the components of the theory of planned 
behaviour/El entorno universitario y la intención emprendedora: el papel mediador de los componentes de la teoría de la acción planificada. Revista de Psicología Social, 34(1), 137-167.

Latin Business Chronicle. (2013). https://latintrade. $\mathrm{com} /$ ? $\mathrm{v}=42983 \mathrm{~b} 05 \mathrm{e} 2 \mathrm{f} 2$. Lima.

Laukkanen, M. (2000). Exploring Alternative Approaches in Highlevel Entrepreneurship Education: Creating Micromechanisms for Endogenous Regional Growth. Entrepreneurship and Regional Development, 12 (1), 25-47.

Levenson, H. (1973). Multidimensional Locus of Control in Psychiatric Patients. Journal of Consulting and Clinical Psychology, 41(3), 397-404.

Levie, J. (2014). The university is the classroom: teaching and learning technology commercialization at a technological university. Journal of Technology Transfer, 39, 793-808.doi:10.1007/ s10961-014-9342-2

Lima, E., Lopes, R., Nassif, V., \& da Silva, D. (2015). Opportunities to Improve

Entrepreneurship Education: Contributions Considering Brazilian Challenges. Journal of Small Business Management, 53, 1033-1051.doi:10.1111/jsbm.12110

Liñán, F., and Y. W. Chen (2009). Development and Cross-Cultural Application of a Specific Instrument to Measure Entrepreneurial Intentions. Entrepreneurship: Theory and Practice, 33(3), $593-$ 617.

Loi, M., \& Di Guardo, M. C. (2015). A Start-Up Generation Approach For Teaching Entrepreneurship: An Overview Of Affective Learning Results. Journal of Developmental Entrepreneurship, 20 (4), 15-27. 
Manual de Oslo. Directrices para la obtención y análisis de la información e innovación. Disponible en: www.madridmasd. org.2014.

Martin, B.C., McNally, J.J. and Kay, M.J. (2013). Examining the formation of human capital in entrepreneurship: a meta-analysis of entrepreneurship education outcomes, Journal of Business Venturing, 28 (2), 211-224.

Martínez, L. F. (2018). Política pública de Emprendimiento en Colombia 2006-2016. Un análisis cognitivo desde los instrumentos de planificación. Universidad Externado de Colombia, 5.

Marvez, G. (2011). Emprendimiento. Revista Cuadernos Unimetanos 26, 1-5.

Mayorga, D. (12 de febrero de 2012). El Espectador. Obtenido de elespectador.com: https:/www.elespectador.com/noticias/ economia/interbolsa-historia-de-un-desplome-articulo-385920

Mihai Nacu, C., \& Avasilcăi, S. (2014). Environmental factors influencing technological entrepreneurship: research framework and results. Procedia - Social and Behavioral Sciences 109, 1309 1315.

Ministerio de Cultura. (2010). Manual de emprendimiento cultural. Bogotá: Ministerio de Cultura.

Molina, G. (12 de marzo de 2019). Gestionar Fácil. Obtenido de https:/www.gestionar-facil.com/etapas-de-un-emprendimiento/

Momete, D. C. (2016). Promoting Technological Entrepreneurship through Sustainable Engineering Education. Journal Procedia Technology 22, 1129 - 1134 .

Moncayo, R. (2009). Profesor de los programas de Emprendimiento del MBA del IDE Business School. Quito. 
Morales Gualdrón, S. T. (2008). El emprendimiento académico y la decisión de crear spin-off: Un análisis del caso español. Valencia: Universidad de Valencia. Facultad de Economía.

Morales Gualdrón, Silvia Teresa. El Emprendedor Académico y La Decisión De Crear Spin-Off: Un Análisis Del Caso Español, presentada por: Tesis Doctoral dirigida por: Dr. D.

Moreira, P., \& Urriolagoitia, L. (2011). Emprendimiento Social. Revista española del tercer sector, 17-40.

Moreno, H. M., \& Olmos, R. (2010). Análisis de las características del emprendimiento y liderazgo en los países de Asia y Latinoamérica. Portes, Revista mexicana de estudios sobre la Cuenca del Pacífico, 201-211.

Morris, H. M., Shirokova, G. \& Tsukanova, T. (2017). Student entrepreneurship and the university ecosystem: A multicountry empirical exploration. European Journal of International Management, 11(1), 65-85. 10.1504/EJIM.2017.081251.

Mwasalwiba, E. S. (2010). Entrepreneurship education: A review of its objectives, teaching methods, and impact indicators. Education and Training, 52(1), 20-47.

Nacu, C. M., \& Avasilcă, S. (2013). Technological ecopreneurship: conceptual approaches. Procedia - Social and Behavioral Sciences, $229-235$.

North, D. C. (1990). Institutions, institutional change and economic performance. Cambridge, UK: Uni- versity Press.

North, D. C. (2005). Understanding the process of economic change. Princeton, NJ: Princeton University Press.

Oliva Abarca, J. E. (2017). Factores, condiciones y contexto del emprendimiento cultural. Revista de investigación de la Universidad de la Salle Bajío, 442 - 464. 
Orrego, C. (2008). La dimensión humana del emprendimiento. Revista Ciencias Estratégicas, 1-12.

Perdomo Charry, G. (2010). Empresarialidad y empresa: una aproximación desde la escuela austriaca. Investigación doctorado en administración, EAFIT- HEC, Colombia - Canadá. Publicado en la Revista Estudios Gerenciales. Vol. 26 No. 115, 161-178.

Peterman, N. E.\& J. Kennedy (2003). Enterprise Education: Influencing Students: Perceptions of Entrepreneurship. Entrepreneurship: Theory and Practice, 28(2), 129-144.

Pickle, H. B., \& Abrahamson, R. (1990). Small business management. New York: John Wiley \& Sons.

Pinzon, F. F. (12 de marzo de 2019). Grandes Pymes. Obtenido de: https://www.grandespymes.com.ar/2017/01/08/cuales-son-lasetapas-de-un-emprendimiento/

Pittaway, L., \& Cope, J. (2007). Entrepreneurship education: A systematic review of the evidence. International Small Business Journal, 25(5), 479-510.

Porfirio, J. A., Carrilho, T., \& Mónico, L. (2016). Entrepreneurship in different contexts in cultural and creative industries. Journal of Business Research.

Portafolio. (11 de abril de 2017). Emprendimientos Colombianos, los terceros más emprendedores a nivel mundial. Obtenido de :https:/www.portafolio.co/negocios/emprendimiento/ colombianos-los-terceros-mas-emprendedores-a-nivelmundial-504919

Portafolio. (2013). Colombia Líder en Emprendimiento. Obtenido de https:/www.portafolio.co/negocios/empresas/colombia-lideremprendimiento-79086 
Portafolio. (7 de diciembre de 2017). Colombia líder de emprendimiento en la Obtenido de https://www.portafolio.co/ negocios/emprendimiento/colombia-lider-de-emprendimientoen-la-region-512352

RAE. (10 de marzo de 2019). Diccionario de la Real Academia de la Lengua Española. Definición de Emprender. Obtenido de https://dle.rae.es/?id=Esip2Nv

Red Colombiana de Universidades en Gestión Cultural. (febrero de 2012). Caracterización de la formación en emprendimiento cultural en Colombia. Obtenido de: http://culturayeconomia.org/ wp-content/uploads/3.-IF-ROSARIO1.pdf

Red de Emprendimiento. (2011). Diagnóstico ecosistema de emprendimiento del Cauca. Popayán.

Revista Dinero. (26 de septiembre de 2011). Por qué Colombia no avanza en emprendimiento. Obtenido de https://www. dinero.com/negocios/articulo/por-que-colombia-no-avanzaemprendimiento/ 136128

Reynolds, P. D. (2005). Understanding business creation: serendipity and scope in two decades of business creation studies. Small Business Economics, 24(4), 359-364.

Ríos Cortés, B. P. (2015). Más allá del formato. Una mediateca virtual como propuesta de emprendimiento cultural para creadores emergentes. Revista Anagramas, 81-94.

Robinson, P.B. \& Sexton, E.A. (1994). The effect of education and experience on self- employment success. Journal of Business Venturing, 9 (2), 141-156.

Rodríguez Moreno, D. C. (2016). Emprendimiento sostenible, significado y dimensiones. Revista Katharsis, 419-448. 
Rodríguez Ramírez, A. (2009). Nuevas perspectivas para entender el emprendimiento empresarial. Pensamiento \& Gestión.

Salvador Roig Dobón Departamento de Dirección de empresas y el Dr. D. Antonio Gutiérrez Gracia del Instituto de Gestión de la Innovación y del Conocimiento (CSIC-UPV). Valencia España, 2008.

Sanabria Navarro, J. R., \& Otros. (2019). Emprendimientos deportivos: Caso Subregión Sabana, Departamento de Sucre, Colombia. Retos, número 35, 140-146.

Sanabria, S. E., \& Hurtado, E. (2013). Emprendimiento verde en Colombia: El caso del mecanismo de desarrollo limpio (MDL). Revista Entramado. Vol. 9 No. 1, 38.65.

Sanabria, S., \& Hurtado, E. (2016). Emprendimiento verde en torno a la conservación y recuperación del agua y sus espacios en Bogotá y Medellín (Colombia). Revista de la Facultad de Ciencias Económicas: Investigación y reflexión, 419-448.

Schumpeter, J. (1950). Capitalism, Socialism and democracy. New York: Harper y Brothers.

Semana. (2009). Revista Semana. Obtenido de: https:// www.semana.com/enfoque/articulo/cronologia-principalesacontecimientos-del-2008/98671-3

Shah, S. K., \& Pahnke, E.C. (2014). Parting the Ivory Curtain: Understanding How Universities Support a Diverse Set of Startups. The Journal of Technology Transfer, 39 (5), 780-792.

Shan, S., \& Otros. (2018). Assessing relationship and contribution of China's technological entrepreneurship to socio-economic development. Technological Forecasting \& Social Change. 
Shane, S. (2000). Prior knowledge and the discovery of entrepreneurial opportunities. Organization Science, 11 (4), 448469.

Sharma, P., \& Crhrisman, J. J. (1999). Toward a Reconciliation of the Definitional Issues in the Field of Corporate Entrepreneurship. Obtenido en: https://www.researchgate. net/publication/242756045_Toward_A_Reconciliation_ of_the_Definitional_Issues_in_the_Field_of_Corporate_ Entrepreneurship

Shirokova, G., Tsukanova, T., \& Bogatyreva, K. (2015). University Environment and Student Entrepreneurship: The Role of Business Experience and Entrepreneurial Self-Efficacy. En: Voprosy Obrazovaniya/ Educational Studies. Moscow, 3, 171-196. 10.17323/1814-9545-2015-3-171-207

Shirokova, G. \& Osiyevskyy, O. (2016). Exploring the intentionbehavior link in student entrepreneurship: Moderating effects of individual and environmental characteristics.

Solomon, G. T. (2007). An examination of entrepreneurship education in the United States. Journal of Small Business and Enterprise Development, 14(2), 168-182.

Solomon, G.T., Duffy, S. \& Tarabishy, A. (2002). The state of entrepreneurship education in the United States: a nationwide survey and analysis. International Journal of Entrepreneurship Education, 1(1),1-22.

Souitaris, V., Zerbinati, S., \& Al-Laham, A. (2007). Do entrepreneurship programmes raise entrepreneurial intention of science and engineering students? The effect of learning, inspiration and resources. Journal of Business Venturing, 22, 566591. 
Staniec, I. (2018). Technological Entrepreneurship: How does Environmental Turbulence Impact upon Collaboration Risk? Journal Sustainability.

Suaréz Galvis, F. (2017). Fomento del emprendimiento a través de actividades académicas e investigativas. Revista de la Facultad de Ciencias Económicas y Administrativas, 183-196.

Telefónica Digital y Universidades de Berkeley y Stanford. El Start-up Ecosystem Report De 2012

Thunen, J.H. (1826). El Estado Aislado en relación con la agricultura y la economía nacional. Hamburgo.

Timmons, J. A. (1998). New Venture Creation. Entrepreneurship for the twenty first century.

Toledano, N. (2012). El fomento de las competencias emprendedoras en las instituciones universitarias. Un estudio de casos en España. Unión Europea Fondo Social Europeo.

Torregroza, Y. (12 de Marzo de 2019). Fases del Emprendimiento. (F. Pasaje, Entrevistador)

Turgot, J. (1766). Reflexiones sobre la formación y distribución de la riqueza. Paris.

Universidad Javeriana. Diplomado Mentoring en Emprendimiento, Parquesoft, Clúster Creatic. Popayán, 2014.

Urbano, D., \& Guerrero, M. (2013). Entrepreneurial universities: Socio-economic impacts of academic entrepreneurship in a European region. Economic Development Quarterly, 27(1), 4156. 
Venkataraman, S. (2004). Regional transformation through technological entrepreneurship. Journal of Business Venturing 19, $153-167$.

Vérin, H. (1982). Entrepreneurs, entreprise, histoire d'une idée. En H. Vérin, Avantpropos (págs. 9-14). Paris: PUF.

Volery, T., Müller, S., Oser, F., Naepflin, C. \& Rey, N. (2013). The impact of entrepreneurship education on human capital at uppersecondary level. Journal of Small Business Management, 51(3), 429-446.

Walter, S. G., Parboteeah, K. P., \& Walter, A. (2013). University departments and self-employment intentions of business students: A cross-level analysis. Entrepreneurship Theory and Practice, 37(2), 175-200.

Welter, F. (2011). Contextualizing entrepreneurship-conceptual challenges and ways forward. Entrepreneurship Theory and Practice, 35(1), 165-184. doi:10.1111/j.1540-6520. 2010.00427.x.

Wennberg, K., Wiklund, J., \& Wright, M. (2011). The effectiveness of university knowledge spillovers: Performance differences between university spinoffs and corporate spinoffs. Research Policy, 40(8), 1128-1143. doi:10.1016/ j.respol.2011.05.014.

Zapata, G. A. (2017). El emprendimiento tecnológico: Análisis de sus determinantes macro-contextuales y micro-individuales. Universidad de Santiago de Compostela. Tesis de doctorado.

Zhang, Y., Duysters, G., \& Cloodt, M. (2014). The role of entrepreneurship education as a predictor of university students' entrepreneurial intention. International Entrepreneurship and Management Journal, 10, 623-641. 
Zhao, H., Seibert, S.E. \& Hills, G.E. (2005). The mediating role of self-efficacy in the development of entrepreneurial intentions. Journal of Applied Psychology, 90 (6), 1265-1272.

Zona Económica. (2010). Zona Económica. Obtenido de: https:// www.zonaeconomica.com/jeisonandres/impacto-crisis-mundialcolombia 
